\title{
METATHESIS OF 1-HEXENE OVER HETEROGENEOUS TUNGSTEN-BASED CATALYSTS
}

\author{
Arisha Prithipal \\ [BSc. (Eng)] \\ In fulfilment of the requirements for the degree of \\ Master of Science in Engineering at the School \\ of Chemical Engineering, University of KwaZulu-Natal
}

March, 2013

Supervisor: Prof. M. Starzak

Co-Supervisor: Dr. D. Lokhat

The financial assistance of the National Research Foundation (NRF) towards this research is hereby acknowledged. Opinions expressed and conclusions arrived at, are those of the author and are not necessarily to be attributed to the NRF. 
As the candidate's Supervisor I agree to the submission of this thesis:

Professor M. Starzak

Dr. D. Lokhat

\section{DECLARATION}

I, Arisha Prithipal declare that

(i) The research reported in this dissertation/thesis, except where otherwise indicated, is my original work.

(ii) This dissertation/thesis has not been submitted for any degree or examination at any other university.

(iii) This dissertation/thesis does not contain other persons' data, pictures, graphs or other information, unless specifically acknowledged as being sourced from other persons.

(iv) This dissertation/thesis does not contain other persons' writing, unless specifically acknowledged as being sourced from other researchers. Where other written sources have been quoted, then:

a) their words have been re-written but the general information attributed to them has been referenced;

b) where their exact words have been used, their writing has been placed inside quotation marks, and referenced.

(v) Where I have reproduced a publication of which I am an author, co-author or editor, I have indicated in detail which part of the publication was actually written by myself alone and have fully referenced such publications.

(vi) This dissertation/thesis does not contain text, graphics or tables copied and pasted from the Internet, unless specifically acknowledged, and the source being detailed in the dissertation/thesis and in the References sections.

Signed:

Date: 


\section{ACKNOWLEDGEMENTS}

I would like to acknowledge the following people whose help and support I appreciate immensely;

Firstly I would like to thank my supervisors, Professor M. Starzak and Dr. D. Lokhat, for all their time, guidance and assistance, for which I am deeply grateful.

I wish to thank my family, my dad, Anil Prithipal, my mum, Lalitha Prithipal, and sister, Rasmika Prithipal, without whom I would not have been able to achieve all that I did. Your love and support are immensely appreciated. I would like to thank Saihesh Sewduth for his help, support and motivation; it is greatly valued. I would also like to thank Kaalin Gopaul for her help, it is much appreciated.

Sincere thanks to Professor Friedrich and Mzamo Shozi from the School of Pure and Applied Chemistry for their advice and assistance in the characterization of the catalysts.

Many thanks to the technical staff, Mrs. Rekha Maharaj, Mr. Sadha Naidoo, Mr. Dudley Naidoo and Thobekile Mofokeng of the Chemical Engineering Department of the University of KwaZulu-Natal for their continued assistance as well as the Pollution Research Group of the University of KwaZulu-Natal for their willingness to assist.

I would like to thank my undergraduate and postgraduate friends whose company was something to look forward to everyday.

Finally, the financial support provided by Sasol through my undergraduate career and the financial support of the National Research Foundation for my postgraduate career is greatly appreciated. 


\section{ABSTRACT}

Olefin (alkene) metathesis can be used for the redistribution of carbon bonds to produce preferred higher range carbon number olefins $\left(\mathrm{C}_{10}-\mathrm{C}_{16}\right)$ from low value medium chain olefins such as 1-hexene. In this study, the performance of various heterogeneous, tungsten based catalysts was investigated for the gas-phase linear cross metathesis of 1-hexene. The tested catalysts included tungsten trioxide on alumina, at various specific loadings, $8 \mathrm{wt} \%$ tungsten trioxide on silica as well as $8 \mathrm{wt} \%$ tungsten trioxide on silica, at various specific loadings of a potassium promoter. An existing lab-scale, fixed bed metathesis reactor system was used to conduct the required experimental work under steady state conditions.

The experimental plan used for conducting the investigation of the alumina-supported catalyst was a combination of the One-Variable-At-a-Time (OVAT) approach as well as the factorial design method. The domain of the range under investigation was $8-20 \%$ for the specific loading of tungsten trioxide, $420-500^{\circ} \mathrm{C}$ for reaction temperature and $30-80 \mathrm{~mol} \%$ for the feed composition of 1-hexene with constant space time. A half factorial experimental design was used for the $\mathrm{WO}_{3} / \mathrm{SiO}_{2}$ and potassium doped $\mathrm{WO}_{3} / \mathrm{SiO}_{2}$ catalysts. The potassium loadings of the $8 \mathrm{wt} \% \mathrm{WO}_{3} / \mathrm{SiO}_{2}$ catalyst were between $0.05-0.5 \mathrm{wt} \%$. Reaction temperatures of between 420 $460^{\circ} \mathrm{C}$ were used together with 1 -hexene feed compositions of between $60-80 \mathrm{~mol} \%$ and space times of 200-400g.min. $\mathrm{mol}^{-1}$.

The $\mathrm{WO}_{3} / \mathrm{Al}_{2} \mathrm{O}_{3}$ catalyst was found to be an inferior catalyst for the metathesis of 1-hexene at all combinations of specific loadings and operating conditions tested. The highest yields obtained for both the detergent range olefins $\left(\mathrm{C}_{10}-\mathrm{C}_{16}\right)$ and primary metathesis product decene $\left(\mathrm{C}_{10}\right)$ were less than $1.5 \%$. Changes made to the calcination temperature, calcination time and $\mathrm{pH}$ of the impregnation solution during the catalyst preparation stages had no significant effect on the yields produced. The $\mathrm{WO}_{3} / \mathrm{Al}_{2} \mathrm{O}_{3}$ catalyst was found to behave more as an isomerization catalyst rather than one for the metathesis reaction.

The optimum reaction conditions determined when investigating the $8 \mathrm{wt} \% \mathrm{WO}_{3} / \mathrm{SiO}_{2}$ catalyst were found to be a reaction temperature of $460^{\circ} \mathrm{C}$, a feed gas composition of $60 \mathrm{~mol} \% 1$-hexene and a space time of $400 \mathrm{~g} \cdot \mathrm{min} \cdot \mathrm{mol}^{-1}$. The conversion of 1-hexene, the yield of the detergent range olefins and the yield of decene at the above mentioned reaction conditions were $82 \%$, $8.30 \%$ and $5.92 \%$ respectively. 
Doping of the $\mathrm{WO}_{3} / \mathrm{SiO}_{2}$ catalyst with potassium was found to be successful in reducing the amount of isomerization and increasing the yields of both the detergent range olefins and decene by approximately $1.5 \%$ and $2 \%$ respectively when doping with 0.1 and $0.5 \mathrm{wt} \%$ potassium. The experimental runs conducted were at the optimum reaction conditions obtained using the $8 \mathrm{wt} \%$ $\mathrm{WO}_{3} / \mathrm{SiO}_{2}$ catalyst. The highest selectivity of the detergent range olefins (24.64\%) and decene $(23.62 \%)$ was obtained when using the $0.5 \mathrm{wt} \% \mathrm{~K}$ doped $\mathrm{WO}_{3} / \mathrm{SiO}_{2}$ catalyst. At the optimised reaction conditions, the $0.5 \mathrm{wt} \%$ potassium loading on $\mathrm{WO}_{3} / \mathrm{SiO}_{2}$ performed the best. 


\section{NOMENCLATURE}

\section{Notation}

\section{Units}

a

Levels of factor A

A

Area of peak

$\mathrm{m}^{2}$

b

Levels of factor B

c

Levels of factor $\mathrm{C}$

d

Levels of factor D

Relative response factor

$f_{\text {critical }}$

Critical f value

F

Molar flow rate

$\mathrm{mol} / \mathrm{s}$

$\mathrm{F}_{0} \quad$ F-ratio

$l_{i} \quad$ Effect of factor i

m Mass

MM

Molar mass

MS

Mean sum of squares

$\mathrm{n}$

Number of replicates

$\mathrm{n}_{\mathrm{C}}$

Number of observations at the centre points

$\mathrm{n}_{\mathrm{F}}$

Number of factorial design points

$\mathrm{n}_{\text {observations }}$

$\mathrm{P}$

Total number of observations/points

$\mathrm{R}$

Pressure

$\mathrm{Pa}$

Gas constant

$\frac{\mathrm{m}^{3} \cdot \mathrm{Pa}}{\mathrm{K} \cdot \mathrm{mol}}$

SS

Sum of squares

$\mathrm{T}$

Temperature

${ }^{\circ} \mathrm{C}$

Volumetric flowrate

$\mathrm{m}^{3} / \mathrm{s}$

Mass fraction

Mole fraction

$\mathrm{X}$

$\mathrm{X}$

Conversion

$\%$

$\overline{\mathrm{y}}_{\mathrm{F}}$

Average of the responses

$\overline{\mathrm{y}}_{\mathrm{C}}$

Average of the $n_{C}$ runs at the centre points

$\mathrm{z}_{\mathrm{j}}$

Standardized normal score 


\section{Subscripts}

A

B

C

D

$\mathrm{AB}$

$\mathrm{AC}$

$\mathrm{BC}$

1

2

3

4

5

6

7

8

ad

cd

ac

abcd

$\mathrm{ab}$

bc

bd

cat

E

i

j

$\mathrm{k}$

\section{Superscripts}

$\mathrm{k}$ with respect to factor $\mathrm{A}$

with respect to factor $B$

with respect to factor $\mathrm{C}$

with respect to factor $\mathrm{D}$

with respect to the interaction between factor $\mathrm{A}$ and $\mathrm{B}$

with respect to the interaction between factor $\mathrm{A}$ and $\mathrm{C}$

with respect to the interaction between factor $\mathrm{B}$ and $\mathrm{C}$

with respect to point 1 on the design cube

with respect to point 2 on the design cube

with respect to point 3 on the design cube

with respect to point 4 on the design cube

with respect to point 5 on the design cube

with respect to point 6 on the design cube

with respect to point 7 on the design cube

with respect to point 8 on the design cube

with respect to point (1) on the design cube

with respect to point ad on the design cube

with respect to point $\mathrm{cd}$ on the design cube

with respect to point ac on the design cube

with respect to point abcd on the design cube

with respect to point ab on the design cube

with respect to point bc on the design cube

with respect to point bd on the design cube

catalyst

with respect to the error

with respect to component $\mathrm{i}$

the count

reference component

number of factors 


\section{Table of Contents}

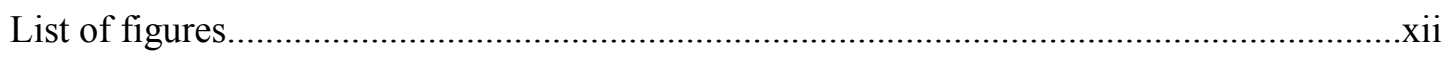

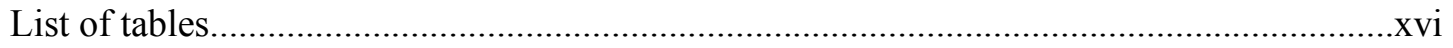

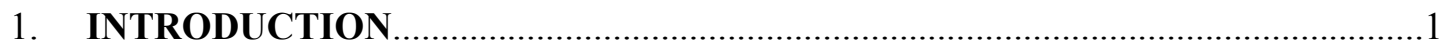

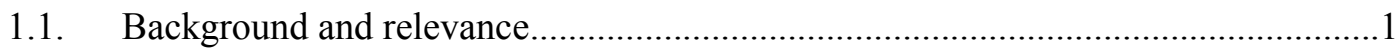

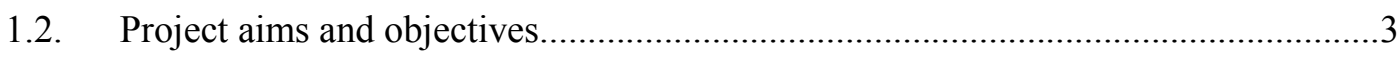

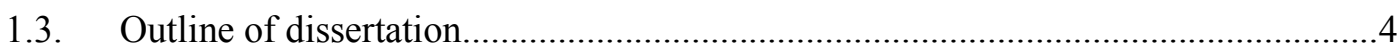

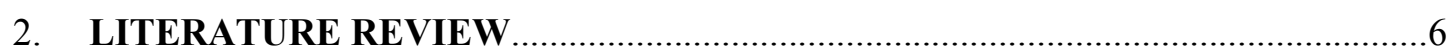

2.1. Early developments of the metathesis reaction.....................................................

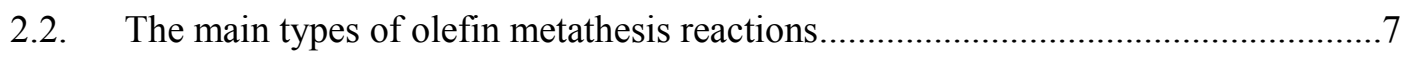

2.3. Industrial applications of metathesis - production of normal olefins.........................8

2.3.1. The Phillips Triolefin Process and Olefin Conversion Technology.....................8

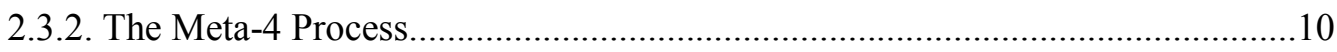

2.3.3. 1- Hexene Production........................................................................................11

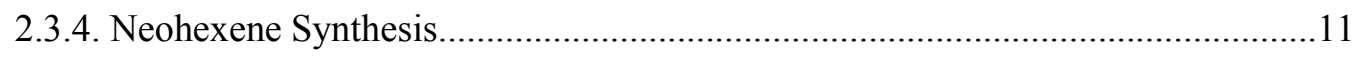

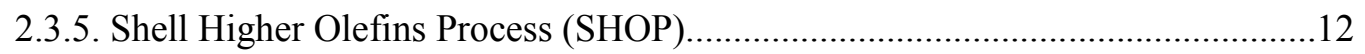

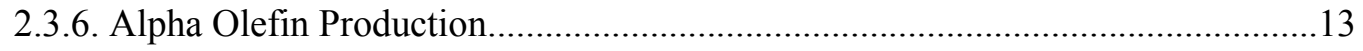

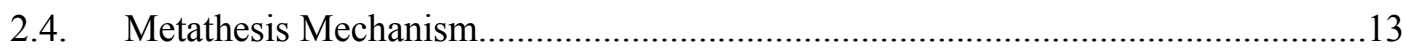

2.5. Common heterogeneous metathesis catalysts........................................................16

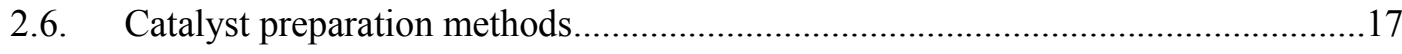

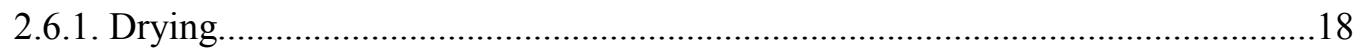

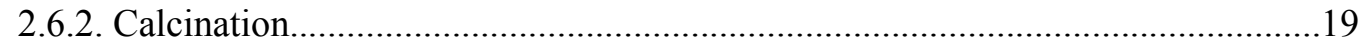

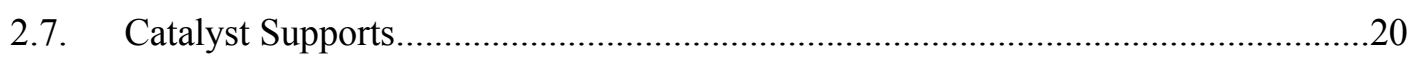




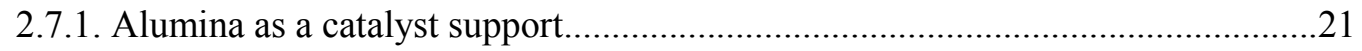

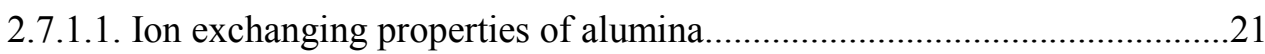

2.7.1.2. Transformation sequence of alumina during calcination..........................23

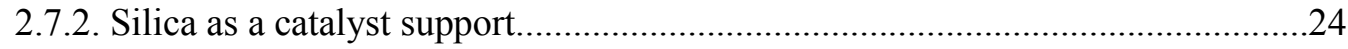

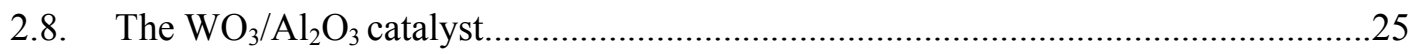

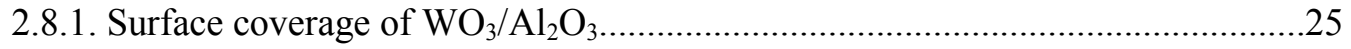

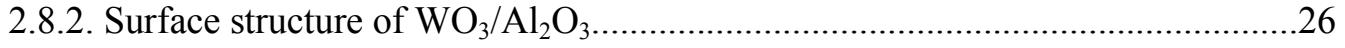

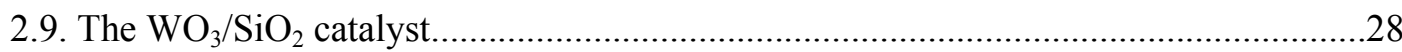

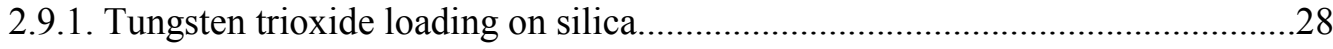

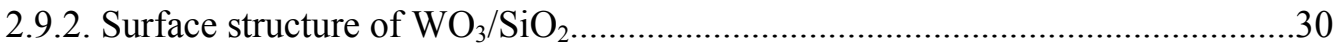

2.10. Isomerization reactions and redction of isomerization activity...............................30

2.11. Coke formation and catalyst deactivation............................................................

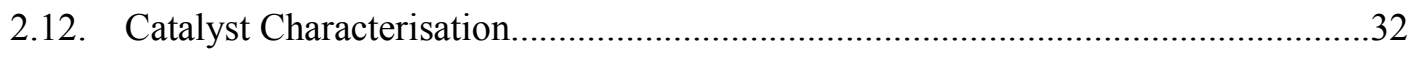

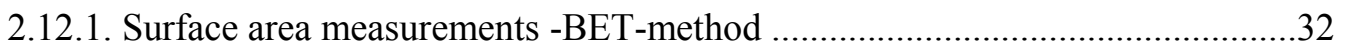

2.12.2. Surface characterisation- Fourier transform infrared spectroscopy (FTIR)......33

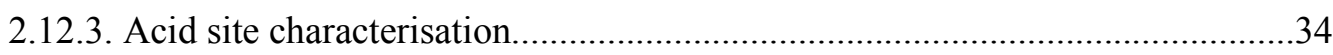

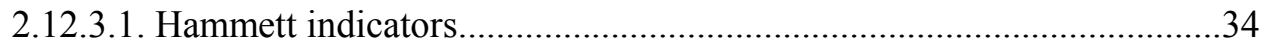

2.12.3.2. $\mathrm{NH}_{3}$ - TPD

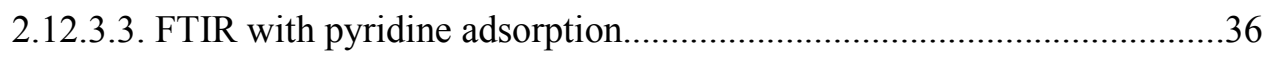

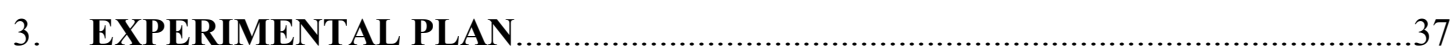

3.1. Experimental plan for the investigation of the $\mathrm{WO}_{3} / \mathrm{Al}_{2} \mathrm{O}_{3}$ catalyst........................37

3.2. Experimental plan for the investigation of the $\mathrm{WO}_{3} / \mathrm{SiO}_{2}$ catalyst and

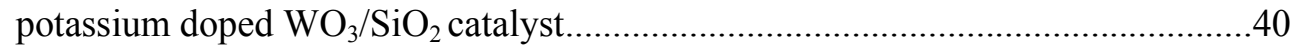

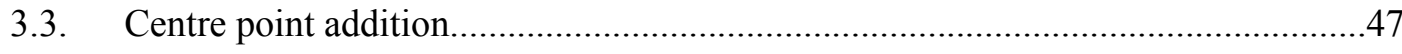

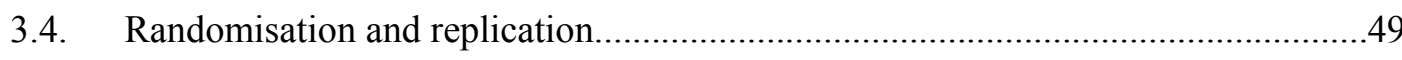




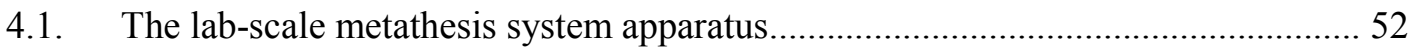

4.1.1. 1-Hexene storage and heating apparatus.......................................................... 52

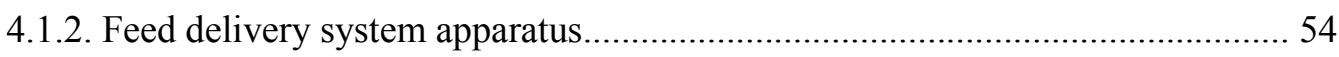

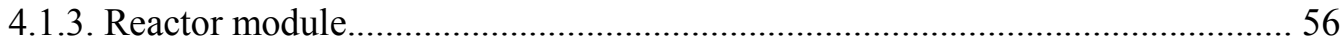

4.1.4. Product collection apparatus............................................................................ 57

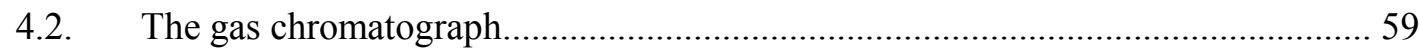

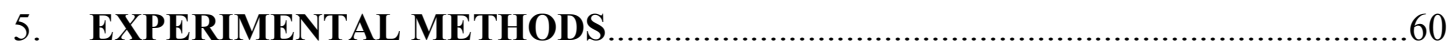

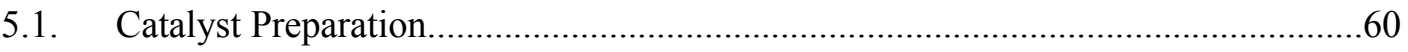

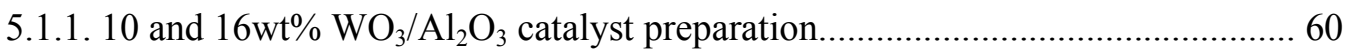

5.1.2. $20 \mathrm{wt} \% \mathrm{WO}_{3} / \mathrm{Al}_{2} \mathrm{O}_{3}$ catalyst preparation......................................................... 61

5.1.3. Potassium doped $\mathrm{WO}_{3} / \mathrm{SiO}_{2}$ catalyst preparation........................................... 61

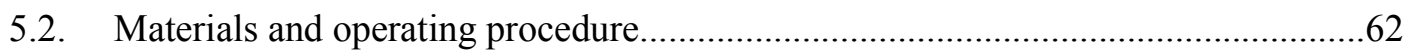

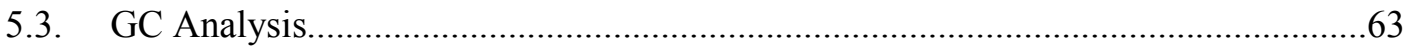

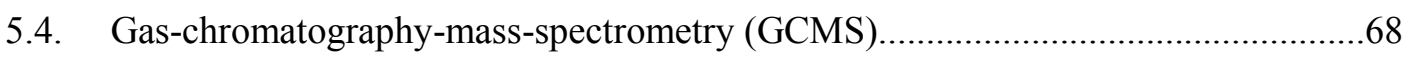

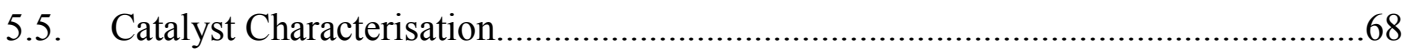

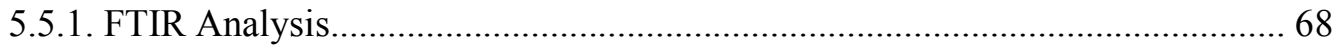

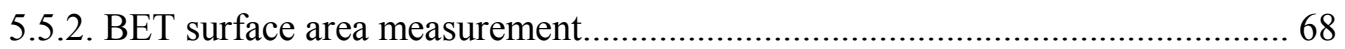

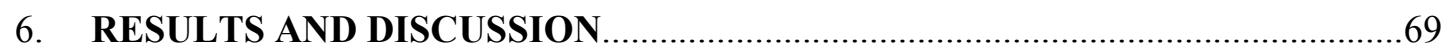

6.1. The $\mathrm{WO}_{3} / \mathrm{Al}_{2} \mathrm{O}_{3}$ catalyst: experimental results and discussion.............................69

6.2. The $\mathrm{WO}_{3} / \mathrm{SiO}_{2}$ catalyst and $\mathrm{K}$ doped $\mathrm{WO}_{3} / \mathrm{SiO}_{2}$ catalyst: experimental results

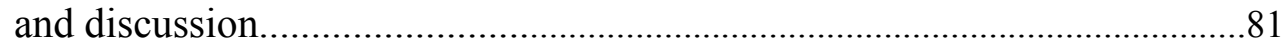

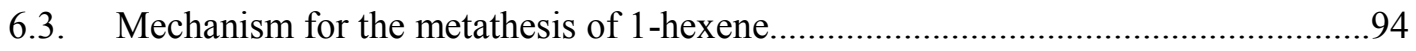




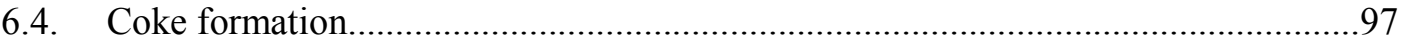

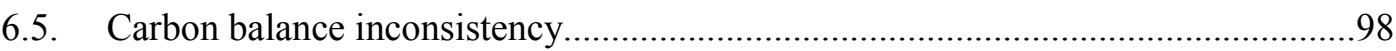

6.6. Statistical analysis of the potassium doped $8 \mathrm{wt} \% \mathrm{WO}_{3} / \mathrm{SiO}_{2}$ catalyst...................100

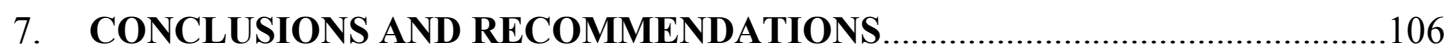

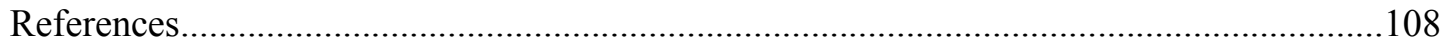

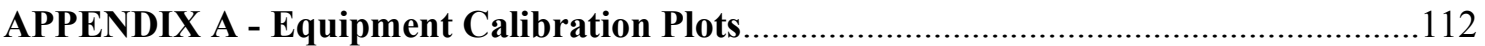

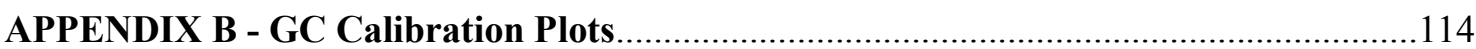

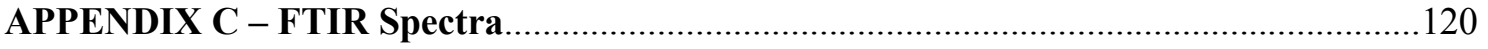

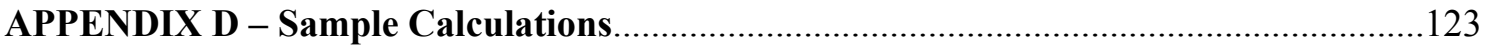

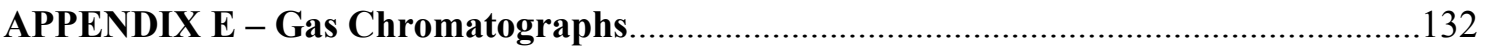

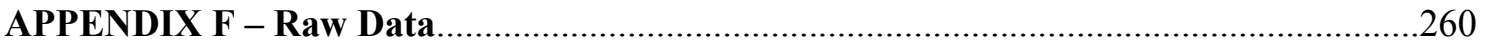

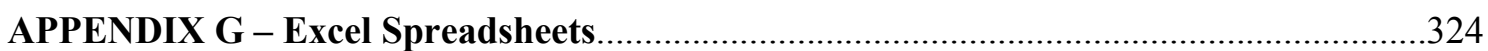




\section{List of figures:}

\section{Chapter 2}

Figure 2.1: The main types of olefin metathesis reactions (Delaude and Noels, 2001) f.............. 7

Figure 2.2: Metathesis of acyclic alkadienes and polyenes (Mol and Leeuwen, 2008) ................ 8

Figure 2.3: The OCT process (reversed Phillips triolefin process) (Mol, 2004).......................... 9

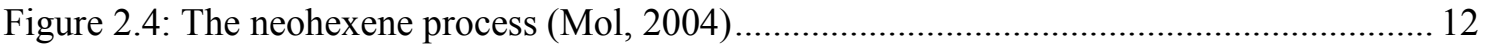

Figure 2.5: Formation of initial metal carbene complex (Mol and Leeuwen, 2008)................. 13

Figure 2.6: Basic mechanism for alkene metathesis (Delaude and Noels, 2001) ....................... 14

Figure 2.7: Dehydrated $\mathrm{WO}_{3} / \mathrm{SiO}_{2}$ complex (a) prepared by impregnation (b) prepared by cogelation (Van Roosmalen and Mol, 1982)

Figure 2.8: The interaction between non-reduced dehydrated $\mathrm{WO}_{3} / \mathrm{SiO}_{2}$ complex and propene (Van Roosmalen and Mol, 1982)

Figure 2.9: Reduction of $\mathrm{WO}_{3} / \mathrm{SiO}_{2}$ catalyst (a) prepared by impregnation (b) prepared by cogelation (Van Roosmalen and Mol, 1982).

Figure 2.10: Initiation mechanism for metathesis (Van Roosmalen and Mol, 1982)

Figure 2.11: Amount of tetrahedral surface tungsten oxide species and metathesis activity as a function of calcination time (Huang et al., 2007)................................................ 20

Figure 2.12 : Schematic representation of hydroxylation of alumina (Stiles, 1987)......

Figure 2.13: Structure of the $\left[\mathrm{H}_{2} \mathrm{~W}_{12} \mathrm{O}_{40}\right]^{6-}$ ion present in ammonium metatungstate (van der Vlies, 2002) 23

Figure 2.14 : Modification sequence of alumina upon calcination (Perego et al., 1997)............ 24

Figure 2.15: Surface coverage as a function of tungsten loading (Llambias et al., 1998) .......... 25

Figure 2.16: Tetrahedral coordination of the tungsten oxide (van der Vlies, 2002) ................. 27

Figure 2.17: Formation of $\mathrm{WO}_{3} / \mathrm{Al}_{2} \mathrm{O}_{3}$ as a (a) Lewis acid site (b) Brønsted acid site (Logie et al., 1999)

Figure 2.18: Conversion and selectivity to linear $\mathrm{C}_{14}$ products as a function of the $\mathrm{WO}_{3}$ loading (Spamer et al., 2003)

Figure 2.19 : Conversion as a function of time on-line for catalyst with varying $\mathrm{WO}_{3}$ loadings (Spamer et al., 2003)

Figure 2.20: Diels-Alder type condensation reactions involving butadiene (Trimm et al., 1982) 


\section{Chapter 3}

Figure 3.1: $\mathrm{A} 2^{3-1}$ fractional factorial design (a) the principal fraction $\mathrm{I}=+\mathrm{ABC}$

(b) the alternate fraction $\mathrm{I}=-\mathrm{ABC}$

Figure 3.2: Depiction of the 23-1 fractional factorial design represented by a cube .................. 43

Figure 3.3: A $2^{4-1}$ fractional factorial design (Montgomery and Runger, 2007) ......................... 43

Figure 3.4: Depiction of experimental design for potassium doping investigation...................... 48

\section{Chapter 4}

Figure 4.1: Piping and instrumentation diagram for metathesis of 1 -hexene...............................51

Figure 4.2: Lab-scale gas-phase fixed bed metathesis reactor system ...................................... 52

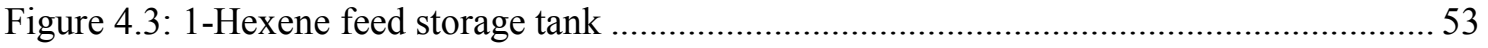

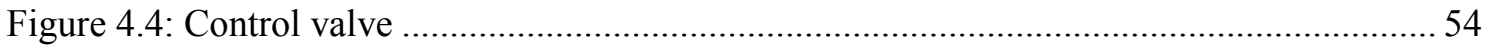

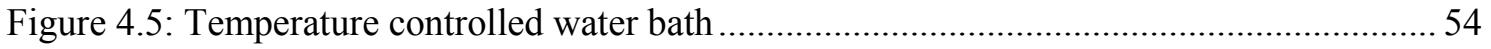

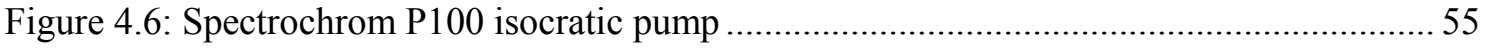

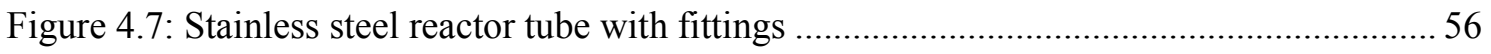

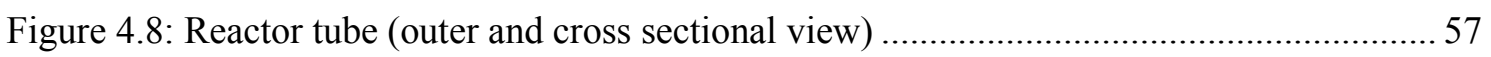

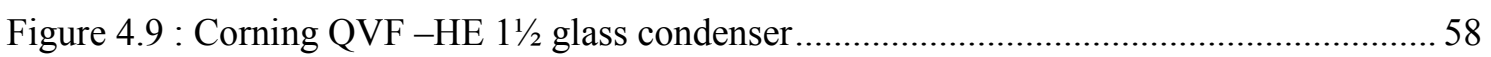

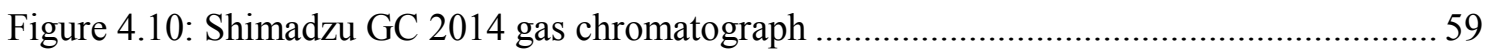

\section{Chapter 6}

Figure 6.1 : Selectivity sequence towards dehydration and dehydrogenation (Tanabe, 1989) ... 69

Figure 6.2: Yield of detergent range olefins vs. reaction temperature at different specific loadings of $\mathrm{WO}_{3}$ and 1-hexene feed compositions $\left(\mathrm{WO}_{3} / \mathrm{Al}_{2} \mathrm{O}_{3}\right.$ catalyst).

Figure 6.3: Yield of decene vs. reaction temperature at different specific loadings of $\mathrm{WO}_{3}$ and 1-hexene feed compositions $\left(\mathrm{WO}_{3} / \mathrm{Al}_{2} \mathrm{O}_{3}\right.$ catalyst) ....................................... 73

Figure 6.4: Universal indicator paper colour change according to $\mathrm{pH}$....................................... 75

Figure 6.5: Conversion of 1-hexene vs. reaction temperature at different specific loadings of $\mathrm{WO}_{3}$ and 1-hexene feed compositions $\left(\mathrm{WO}_{3} / \mathrm{Al}_{2} \mathrm{O}_{3}\right.$ catalyst $)$

Figure 6.6: Yield of isomerized hexene vs. reaction temperature at different loadings and hexene compositions $\left(\mathrm{WO}_{3} / \mathrm{Al}_{2} \mathrm{O}_{3}\right.$ catalyst $)$................................................... 79

Figure 6.7: Conversion of 1-hexene vs. reaction conditions $\left(\mathrm{WO}_{3} / \mathrm{SiO}_{2}\right.$ catalyst)...................... 85

Figure 6.8: Yield of detergent range olefins vs. reaction conditions $\left(\mathrm{WO}_{3} / \mathrm{SiO}_{2}\right.$ catalyst)

Figure 6.9 : Yield of decene vs. reaction conditions $\left(\mathrm{WO}_{3} / \mathrm{SiO}_{2}\right.$ catalyst $)$........ 85 
Figure 6.10: Yield of isomerized hexene vs. reaction conditions $\left(\mathrm{WO}_{3} / \mathrm{SiO}_{2}\right.$ catalyst $)$. 86

Figure 6.11: Conversion of 1-hexene vs. reaction conditions of $\mathrm{K}$ doped $\mathrm{WO}_{3} / \mathrm{SiO}_{2}$ in the optimised $\mathrm{WO}_{3} / \mathrm{SiO}_{2}$ region.

Figure 6.12 : Yield of detergent range olefins vs. reaction conditions of $\mathrm{K}$ doped $\mathrm{WO}_{3} / \mathrm{SiO}_{2}$ in the optimised $\mathrm{WO}_{3} / \mathrm{SiO}_{2}$ region

Figure 6.13: Yield of decene vs. reaction conditions of $\mathrm{K}$ doped $\mathrm{WO}_{3} / \mathrm{SiO}_{2}$ in the optimised $\mathrm{WO}_{3} / \mathrm{SiO}_{2}$ region .

Figure 6.14: Yield of isomerized hexene vs. reaction conditions of $\mathrm{K}$ doped $\mathrm{WO}_{3} / \mathrm{SiO}_{2}$ in the optimised $\mathrm{WO}_{3} / \mathrm{SiO}_{2}$ region 90

Figure 6.15: Conversion of 1-hexene vs. reaction conditions of $\mathrm{K}$ doped $\mathrm{WO}_{3} / \mathrm{SiO}_{2}$ for all reaction conditions

Figure 6.16: Yield of detergent range olefins vs. reaction conditions of $\mathrm{K}$ doped $\mathrm{WO}_{3} / \mathrm{SiO}_{2}$ for all reaction conditions

Figure 6.17: Yield of decene vs. reaction conditions of $\mathrm{K}$ doped $\mathrm{WO}_{3} / \mathrm{SiO}_{2}$ for all reaction conditions

Figure 6.18: Yield of isomerized hexene vs. reaction conditions of $\mathrm{K}$ doped $\mathrm{WO}_{3} / \mathrm{SiO}_{2}$ for all reaction conditions 93

Figure 6.19: Structure of the dehydrated $\mathrm{WO}_{3} / \mathrm{SiO}_{2}$ catalyst (Van Roosmalen and Mol, 1982) 94

Figure 6.20: Structure of the dehydrated $\mathrm{WO}_{3} / \mathrm{Al}_{2} \mathrm{O}_{3}$ catalyst (Logie et al., 1999) .94

Figure 6.21: Formation of the Lewis acid/alkene complex for the metathesis of 1-hexene........ 95

Figure 6.22: Reduction of the $\mathrm{WO}_{3} / \mathrm{SiO}_{2}$ catalyst 95

Figure 6.23 : Colour change of the $\mathrm{WO}_{3} / \mathrm{SiO}_{2}$ catalyst as a result of reduction (a) before reduction (b) after reduction 96

Figure 6.24: Formation of the metal carbene initiator..... .96

Figure 6.25: Original and spent catalysts (a) $\mathrm{WO}_{3} / \mathrm{SiO}_{2}$ catalyst (b) $\mathrm{WO}_{3} / \mathrm{Al}_{2} \mathrm{O}_{3}$ catalyst.......... 97

Figure 6.26: Carbon balance inconsistency for the 10, 16 and $20 \mathrm{wt} \% \mathrm{WO}_{3} / \mathrm{Al}_{2} \mathrm{O}_{3}$ catalysts ..... 99

Figure 6.27: Carbon balance inconsistency for the $\mathrm{WO}_{3} / \mathrm{SiO}_{2}$ and $\mathrm{K}$ doped $\mathrm{WO}_{3} / \mathrm{SiO}_{2}$ catalysts

Figure 6.28: Normal probability plot

Figure 6.29: Depiction of the $2^{4-1}$ fractional factorial design represented by two cubes. 103

\section{Appendix A}

Figure A.1: Spectrochrom P100 isocratic pump calibration for 1-hexene

Figure A.2: Rotameter calibration for the Bailey Porter Fischer 10A6132NB1C precision bore flowrator tube using nitrogen gas 


\section{Appendix B}

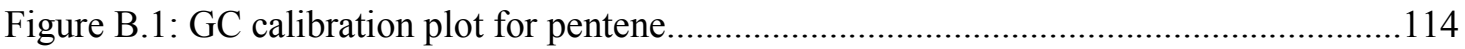

Figure B.2: GC calibration plot for heptene .....................................................................115

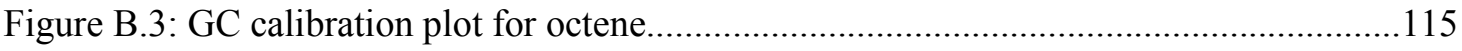

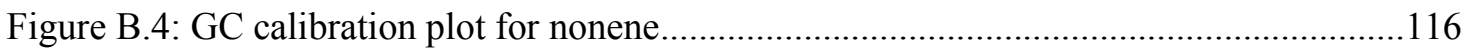

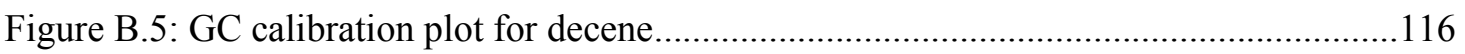

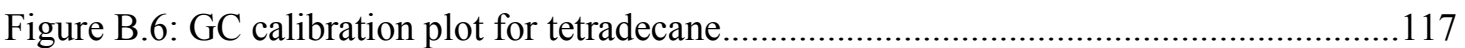

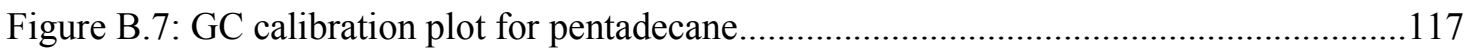

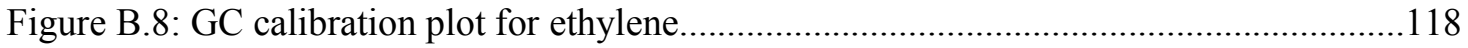

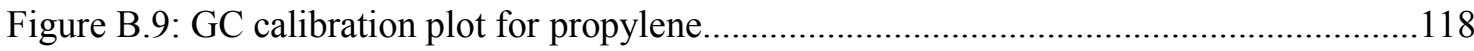

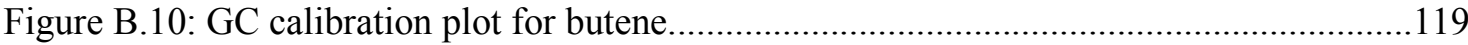

\section{Appendix C}

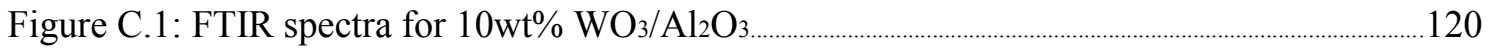

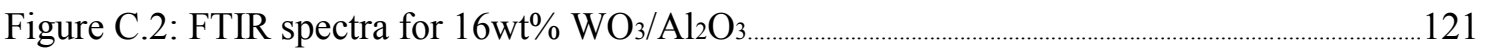

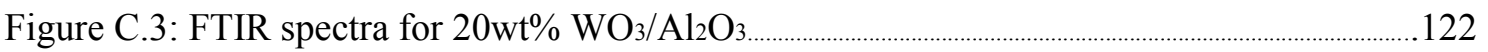




\section{List of tables:}

\section{Chapter 2}

Table 2.1: Comparison of the most common metathesis catalysts

[Adapted from Dwyer (2006)]

Table 2.2: Typical adsorption temperatures for gases used in surface area measurements

(Adapted from Anderson and Pratt, 1985).

Table 2.3: Hammett indicators used for acid strength determination (Yurdakoc et al., 1998) ... 35

\section{Chapter 3}

Table 3.1: Table of experimental points to determine the optimum loading of tungsten trioxide on $\mathrm{WO}_{3} / \mathrm{Al}_{2} \mathrm{O}_{3}$ (for a fixed reactor space time)

Table 3.2: A $2^{3-1}$ design table representing the principal fraction

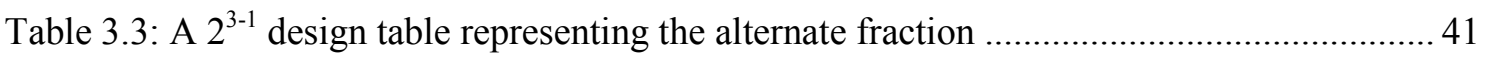

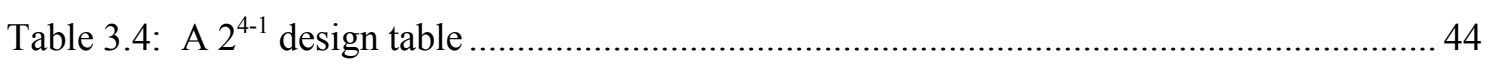

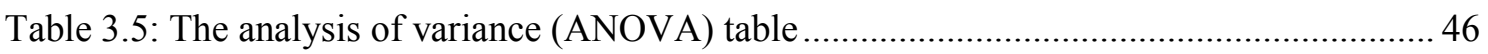

\section{Chapter 5}

Table 5.1: GC operating conditions and temperature program used for analysis of gas phase metathesis products

Table 5.2: GC operating conditions and temperature program for analysis of liquid phase metathesis products

Table 5.3: List of relative response factor $\left(f_{i, k}\right)$ values for each component (reference component :1-hexene)

\section{Chapter 6}

Table 6.1: Table of experimental runs conducted and results for $\mathrm{WO}_{3} / \mathrm{Al}_{2} \mathrm{O}_{3}$ catalyst .76

Table 6.2: List of components present in a liquid sample identified by the GCMS $\left(\mathrm{WO}_{3} / \mathrm{Al}_{2} \mathrm{O}_{3}\right.$ catalyst) .78

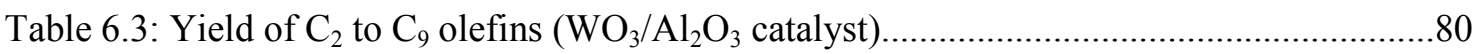

Table 6.4: BET surface area results for $\mathrm{WO}_{3} / \mathrm{Al}_{2} \mathrm{O}_{3}$ at varying specific loadings of $\mathrm{WO}_{3} \ldots \ldots . . . .81$

Table 6.5 : Table of experimental runs and results for the $\mathrm{WO}_{3} / \mathrm{SiO}_{2}$ catalyst .......................... 83

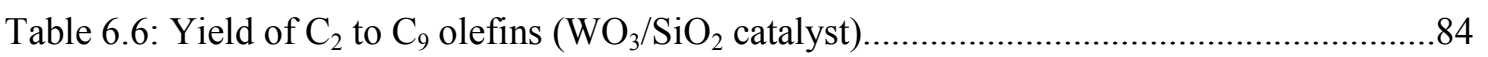


Table 6.7: Table of experimental runs and results for the $\mathrm{K}$ doped $\mathrm{WO}_{3} / \mathrm{SiO}_{2}$ catalyst in the

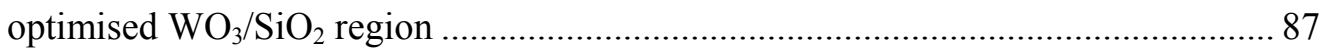

Table 6.8: Yield of $\mathrm{C}_{2}$ to $\mathrm{C}_{9}$ olefins in the optimised $\mathrm{WO}_{3} / \mathrm{SiO}_{2}$ region...................................87

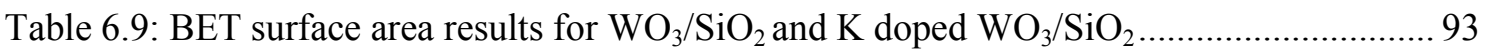

Table 6.10: Design table for the potassium doped $\mathrm{WO}_{3} / \mathrm{SiO}_{2}$ catalyst $\left(2^{4-1}\right.$ fractional factorial

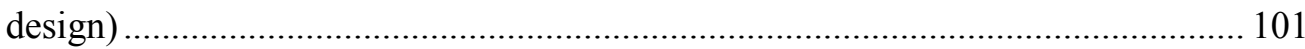

Table 6.11: Calculated values of the effects and sum of squares of the factors and their combinations [ A (temperature), B (feed gas composition), C (space time)] .......... 102

Table 6.12: ANOVA table for the potassium doped $\mathrm{WO}_{3} / \mathrm{SiO}_{2}$ catalyst.................................. 104 


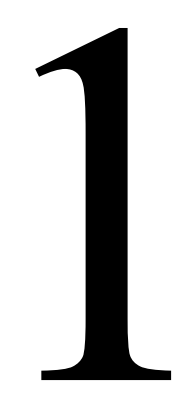

\section{CHAPTER ONE}

\section{INTRODUCTION}

\subsection{Background and relevance}

Metathesis is defined as a reaction where parts of each of two reactant molecules are exchanged to form two new products as shown below (Equation 1.1).

$$
\mathrm{AB}+\mathrm{CD} \leftrightarrow \mathrm{AC}+\mathrm{BD}
$$

Olefin (alkene) metathesis is a reversible, organic reaction also known as transalkylidenation. The proposed project involves the metathesis of 1-hexene and is categorized under olefin metathesis as a linear alkene cross metathesis reaction. The cross metathesis reaction involves the cleaving of the alkene double bonds of the reactant molecules and redistribution or exchange of the fragments to form product molecules, consisting of parts of each of the reactant molecules as illustrated in Equation 1.2.
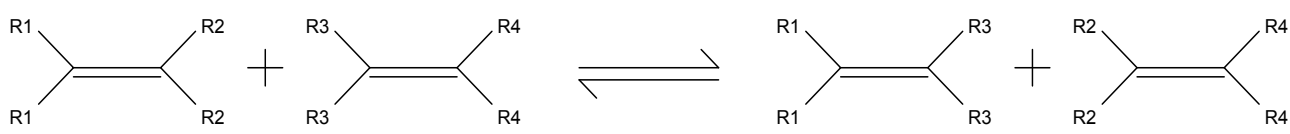
The significance of alkene metathesis is that it allows for the conversion of available alkenes into desired alkenes which may be more useful than the starting alkenes or which may be required to produce a particular product. Thus alkene metathesis is used to synthesize speciality alkenes that are important raw materials in polymers, plastics, perfumes, medicines, surfactants, detergents and agrochemical products and that serve as starting materials for other organic molecules.

Equation 1.3 depicts the formation of the primary metathesis products produced from the metathesis of 1-hexene:

$$
\begin{array}{ll}
2 \mathrm{H}_{2} \mathrm{C}=\mathrm{C}_{5} \mathrm{H}_{10} \longrightarrow \\
\text { 1-hexene } & \mathrm{H}_{10} \mathrm{C}_{5}=\mathrm{C}_{5} \mathrm{H}_{10}+\mathrm{H}_{2} \mathrm{C}=\mathrm{CH}_{2} \\
\text { 5-decene } \quad \text { ethylene }
\end{array}
$$

If one of the product molecules can be removed, the reaction will be driven to the right as desired, limiting the undesirable effect of the reaction reversibility. This is the case in the selfmetathesis of 1-hexene where 5-decene and ethylene are the major metathesis products. Ethylene, being volatile, can easily be removed.

Metathesis allows for the redistribution of the carbon bonds to produce preferred higher range carbon number olefins $\left(\mathrm{C}_{10}-\mathrm{C}_{16}\right)$. Olefins in the $\mathrm{C}_{10}-\mathrm{C}_{16}$ range are preferred since they can be used in the production of detergent alcohols or detergent alkylates when reacted with benzene to form linear alkylbenzene ( $\mathrm{LAB})$. $\mathrm{LAB}$ is an intermediate used in the production of linear alkylbenzene sulfonate (LAS) which is a biodegradable surfactant for use in detergents. There exist many other routes to produce the olefins used in the production of LAB, however these routes mainly consist of the conversion of alkanes to alkenes by dehydrogenation of alkanes, chlorination of alkanes, wax cracking or oligomerization of ethylene. The Shell Higher Olefin Process (SHOP) is an example of a process in which ethylene is oligomerized. A mixture of olefins ranging from $\mathrm{C}_{4}-\mathrm{C}_{40}$ is produced and further steps of isomerization, metathesis and distillation are required to produce the olefins in the desired $\mathrm{C}_{10}-\mathrm{C}_{16}$ range. Thus, there is a growing interest in the direct conversion of low value medium-chain alpha alkenes to internal higher alkenes. A key role for this is seen in the Sasol Fischer-Tropsch process which produces fuel from syngas derived from natural gas or coal (Mol, 2004). Low value linear alpha olefins $\left(\mathrm{C}_{4}-\mathrm{C}_{7}\right)$ are also present in the fuel stream in large quantities and are recovered by distillation. 
Metathesis would allow for the conversion of the low value linear alpha olefins into more valuable higher range carbon number olefins $\left(\mathrm{C}_{10}-\mathrm{C}_{16}\right)$.

One of the limitations of the metathesis reaction however, is the selectivity achievable of the desired product. The reactant and product alkenes formed are free to react with each other or with other alkenes in the system to form new alkenes as well undergo isomerization reactions resulting in a mixture of product. An example of this is depicted in Equations 1.4 and 1.5 which show the formation of secondary metathesis products:

$$
\begin{array}{cccc} 
& \mathrm{H}_{2} \mathrm{C}=\mathrm{C}_{5} \mathrm{H}_{10} \stackrel{\text { isomerization }}{\text { 1-hexene }} & \\
& \mathrm{H}_{4} \mathrm{C}_{2}=\mathrm{C}_{4} \mathrm{H}_{8} & \\
\text { 2-hexene } & \\
\mathrm{H}_{2} \mathrm{C}=\mathrm{C}_{5} \mathrm{H}_{10}+\mathrm{H}_{4} \mathrm{C}_{2}=\mathrm{C}_{4} \mathrm{H}_{8} \longrightarrow & \mathrm{H}_{8} \mathrm{C}_{4}=\mathrm{C}_{5} \mathrm{H}_{10}+\mathrm{H}_{2} \mathrm{C}=\mathrm{C}_{2} \mathrm{H}_{4} \\
\text { 1-hexene } & \text { 2-hexene } & \text { 4-nonene propylene }
\end{array}
$$

The metathesis reactions can be accelerated by the presence of various homogeneous and heterogeneous catalysts. Common heterogeneous catalysts for this reaction are transition metal oxides such as molybdenum, tungsten and rhenium on a high surface area support such as silica or alumina. The catalysts being investigated in this project included tungsten trioxide supported on alumina, at various specific loadings, $8 \mathrm{wt} \%$ tungsten trioxide on silica, as well as $8 \mathrm{wt} \%$ tungsten trioxide on silica, at various specific loadings of a potassium promoter. The optimum loading and optimum operating conditions were determined by analysis of the catalyst performance. Performance was assessed in terms of 1-hexene conversion, selectivity and yield of the primary metathesis product 5-decene, selectivity and yield of the detergent range olefins $\left(\mathrm{C}_{10}-\mathrm{C}_{16}\right)$ as well as amount of isomerization.

\subsection{Project aims and objectives}

This study involves the investigation of the gas phase linear cross metathesis of 1 -hexene, over various tungsten based catalysts, with the intention of optimising the yield and selectivity of the primary metathesis product, decene and the detergent range olefins. The successful preparation of the catalysts was essential in producing the correct surface structure required for the 
metathesis reactions. The catalysts prepared included alumina supported tungsten trioxide, at various specific loadings, $8 \mathrm{wt} \%$ tungsten trioxide on silica, as well as $8 \mathrm{wt} \%$ tungsten trioxide on silica, at various specific loadings of a potassium promoter. The appropriateness of alumina as a catalyst support for the metathesis reaction was to be investigated. The optimum loading of tungsten trioxide on alumina, at various combinations of reaction temperatures and feed gas compositions of 1-hexene, was to be determined while maintaining the same residence time. The performance of alumina for use as a catalyst support for the metathesis reaction was also to be assessed. Silica is another commonly used support for metathesis catalysts. The performance of the $8 \mathrm{wt} \% \mathrm{WO}_{3} / \mathrm{SiO}_{2}$ catalyst was investigated and the optimum reaction conditions determined in terms of the highest selectivity and yields produced. At these optimised reaction conditions, the effect of doping on the catalyst was to be established.

\subsection{Outline of dissertation}

The dissertation is broken down into seven chapters. An outline of the content that can be expected in each chapter is provided below.

Chapter 2 is a general review of literature about the metathesis reaction and its industrial uses and moves on to compare the various catalysts that can be used for the reaction. A review of the literature describing the chosen catalyst and supports follows, including the chosen preparation method, structure of the catalysts and chemical characterisation.

Chapter 3 describes the specific experimental designs used for each part of the research project. This includes the OVAT and factorial methods used for the alumina based catalyst and the half factorial design for the silica based catalyst and the potassium doped silica based catalyst. A description of the statistical analysis procedure was also discussed.

Chapter 4 discusses the experimental equipment and describes the various pieces of equipment used to conduct the required experimental runs. A piping and instrumentation diagram (P\&ID) is also included.

Chapter 5 deals with the experimental methods used as well as the operating procedure that was followed to undertake each experimental run. The method of determining the relative response 
factor for the $\mathrm{GC}$ analysis and the methods used for the preparation of the catalysts are discussed.

The results obtained from the experimental runs as well as the analysis of these results are presented and discussed in Chapter 6.

The final conclusions and recommendations that can be made about the investigation are provided in Chapter 7. 


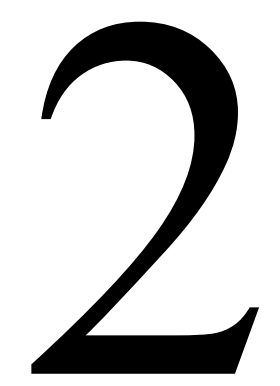

\section{CHAPTER TWO}

\section{LITERATURE REVIEW}

\subsection{Early developments of the metathesis reaction}

The catalysed metathesis reaction was discovered during the late 1950's by chemists at the Phillips Petroleum Company when attempting to find an alternative to the HF acid catalyst which was used for olefin-isoparaffin alkylation (Mol, 2004; Wagner, 1992). The alternative used was a heterogeneous catalyst of molybdenum-on-alumina. However, the reaction observed was not the conversion of olefins into high-octane gasoline as desired but instead the splitting of the propene olefin into ethene and 2-butene i.e. the discovery that the metathesis reaction occurs in the presence of transition metal catalysts (Mol, 2004). Many hypotheses were brought forward about the mechanism for the metathesis reaction; the most widely accepted one being by Yves Chauvin in 1971. He suggested that metathesis was initiated by a metal carbene as discussed in Section 2.4.

Research into the development of the early metal-carbene catalysts were conducted by many chemists, among them being Robert H. Grubbs and Richard R. Schrock who were responsible for breakthroughs in the development of the metal-carbene catalysts (Rouhi, 2002). 


\subsection{The main types of olefin metathesis reactions}

The different types of metathesis reactions that are possible include cross metathesis $(\mathrm{CM})$, ring opening metathesis (ROM), ring opening metathesis polymerization (ROMP), ring closing metathesis (RCM) and acyclic diene metathesis (ADMET) polymerisation (Error! Reference ource not found.).

$\mathrm{n}$

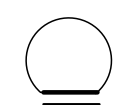

Ring-Closing Metathesis (RCM) -n $\mathrm{H}_{2} \mathrm{C}=\mathrm{CH}_{2}$

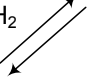

Ring-Opening Metathesis Polymerization (ROMP)<smiles>C=CCCC=C</smiles>
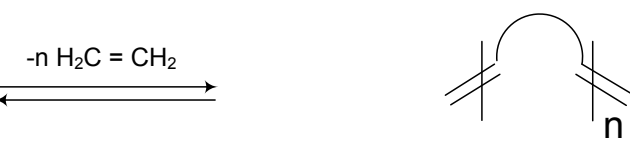

Acyclic Diene Metathesis Polymerization (ADMET)<smiles>[R]C=C</smiles><smiles>C1=CCCCC1</smiles><smiles></smiles><smiles>[R]C=CCCC=C</smiles>

Ring-Openeing Metathesis (ROM)<smiles>[R]C=C[SH2+]</smiles><smiles>[C]=C</smiles><smiles>[R]C=C[R]</smiles>

Cross-Metathesis (CM)

Figure 2.1: The main types of olefin metathesis reactions (Delaude and Noels, 2001)

The type of reaction which is of interest for the study of the metathesis of 1-hexene is linear alkene cross metathesis. The cross metathesis reaction involves the cleaving of the alkene double bonds of the reactant molecules and redistribution or exchange of the fragments to form product molecules, consisting of parts of each of the reactant molecules. When the reactant molecules are of the same olefin it is called self metathesis as is the case in the metathesis of 1hexene. The applications of cross metathesis are found in the manufacture of bulk chemicals, the conversion of oleochemicals into valuable products as well as in the conversion of less desirable lower range olefins into high value olefins that are more useful. The latter describes 
the purpose of the project in which lower range carbon olefins $\left(\mathrm{C}_{4}-\mathrm{C}_{7}\right)$ are converted to the preferred higher range olefins $\left(\mathrm{C}_{10}-\mathrm{C}_{16}\right)$ since these are used in the production of detergent alcohols and detergent alkylates. ROM involves the cross metathesis of a cyclic and acyclic olefin to produce polyunsaturated products or dienes (Mol and Leeuwen, 2008). ROMP is used in the production of unsaturated polymers in the manufacture of speciality plastics from cyclic alkenes by metathesis of these alkenes into a growing polymer chain. Either RCM or ADMET polymerisation takes places for the metathesis of acyclic alkadienes and polyenes depending on whether an intramolecular or intermolecular path (Figure 2.2) is followed (Mol and Leeuwen, 2008). The path chosen depends on the product stability. If the intramolecular path is followed, RCM takes place. If the intermolecular path is followed, the triene produced further reacts to form unsaturated polymers of high molecular weight. This reaction process is known as ADMET polymerisation (Mol and Leeuwen, 2008).

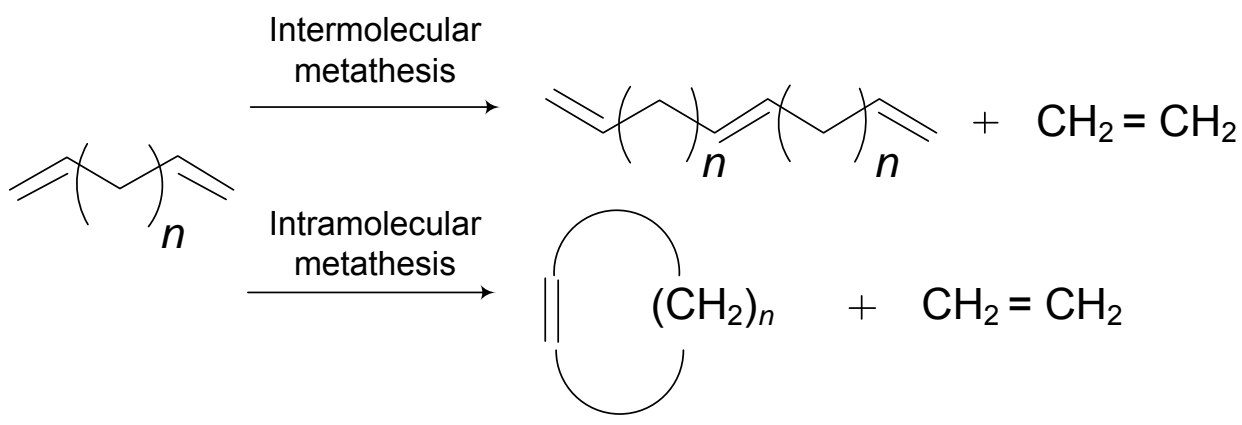

Figure 2.2: Metathesis of acyclic alkadienes and polyenes (Mol and Leeuwen, 2008)

\subsection{Industrial applications of metathesis - production of normal olefins}

The industrial applications of olefin metathesis are discussed extensively by Mol (2004), Dwyer (2006) and Delaude and Noels (2001) and a review of this is provided below.

\subsubsection{The Phillips Triolefin Process and Olefin Conversion Technology}

The first commercial process using olefin metathesis over a heterogeneous catalyst was introduced by the Phillips Petroleum Company as the Phillips triolefin process involving the conversion of propene into ethene and 2-butene. The catalysts used at the time were cobalt 
molybdate supported on alumina as well as tungsten(VI) oxide on silica. The tungsten-silica catalyst required higher temperatures of between $300-375^{\circ} \mathrm{C}$ as compared to the molybdatealumina catalyst $\left(120-210^{\circ} \mathrm{C}\right)$, to achieve $\sim 40 \%$ conversion of propene (Delaude and Noels, 2001). The propene was obtained as a co-product from naphtha steam crackers and from the gasoline manufacturing refineries' fluid catalytic cracking (FCC) units. Other sources of propene include propane dehydrogenation and coal gasification, but these processes produce relatively small quantities.

The olefins conversion technology (OCT) process, which is the reverse reaction of the triolefin process, was commercialised during the 1980's when the demand for propene rose worldwide. In the OCT process, butene (C4) is mixed with ethene and passed through a guard bed as depicted in the process flow diagram of Figure 2.3.

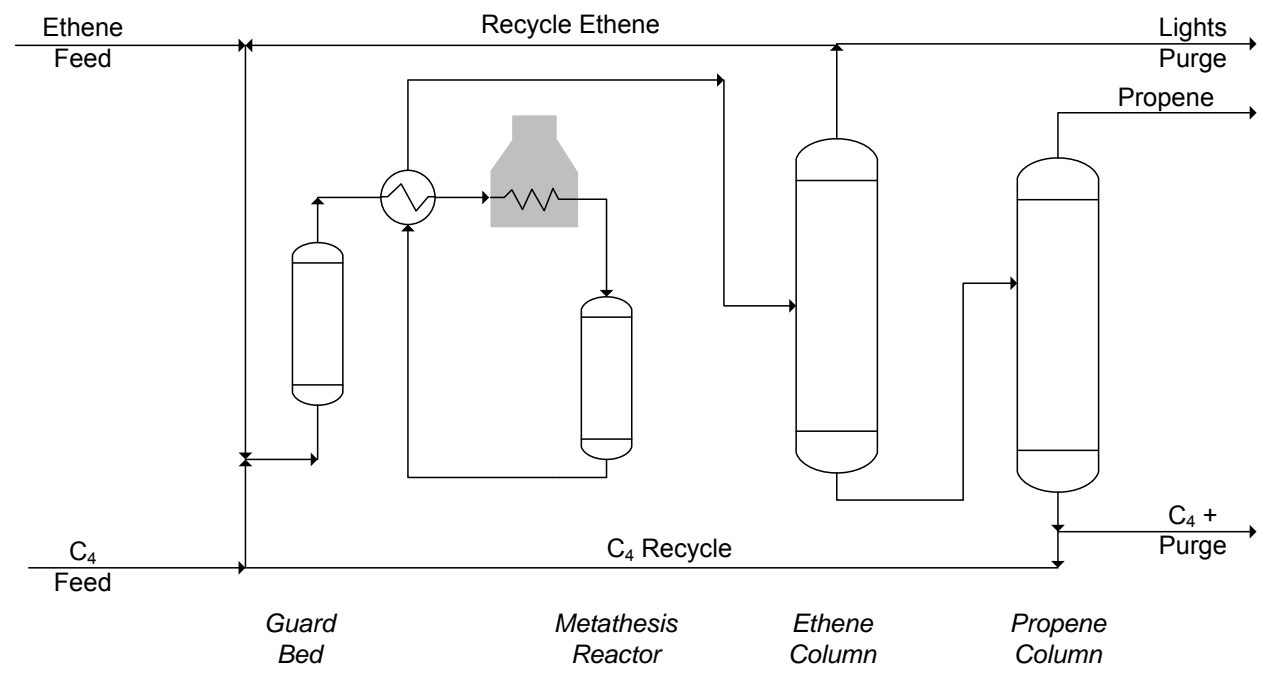

Figure 2.3: The OCT process (reversed Phillips triolefin process) (Mol, 2004)

The purpose of the guard bed is to remove trace impurities before the mixture is heated and sent to the fixed-bed metathesis reactor (Mol, 2004). The heterogeneous metathesis catalyst used is $\mathrm{WO}_{3} / \mathrm{SiO}_{2}$. An isomerization catalyst, $\mathrm{MgO}$, is also used if 1-butene is present in the feedstock as it promotes the isomerization of the 1-butene to 2-butene as required for the reaction (Delaude and Noels, 2001). The reaction conditions for metathesis is a temperature greater than $260^{\circ} \mathrm{C}$ and a pressure between $30-35 \mathrm{bar}$ (Mol, 2004). The high pressure is not a requirement for the reaction but is used because paradoxically it simplifies the operation and allows for a less costly process. Ethene for the process is supplied at elevated pressures and the propene produced downstream is required at elevated pressure. Thus by maintaining a high pressure 
from the start, the need for decompression and later recompression downstream is eliminated (Dwyer, 2006). A conversion of $>60 \%$ butene per pass and a selectivity $>90 \%$ propene is achieved in the OCT process. Catalyst regeneration is required on a regular basis because of the deactivation of the catalyst by coking, due to the high temperature required for the tungsten catalyst (Dwyer, 2006).

Integration of the OCT process into the naphtha steam cracking process was applied to further increase the production of propene from the cracking process by converting some of the ethene produced into propene. This was done at BASF FINA Petrochemicals plant in Texas (USA) in 2001. Initially the plant produced 920000 tonnes per year ethene and 550000 tonnes per year propene. The addition of the metathesis unit in 2004 was expected to increase the production of propene to 860000 tonnes per year, resulting in a decrease in ethene production to 830000 tonnes per year (Mol, 2004).

More recently, the OCT process has found application in plants in Asia since 2004 due to the increase in propene demand. Osaka Works in Japan increased their propene production by 140000 tonnes per year, being the first plant in Japan to use the OCT process. Shanghai Secco Petrochemical in China, which is part of BP Chemical, Sinopec and Shanghai Petrochemical Corporation, has built a naphtha cracker with an integrated metathesis unit thus incorporating the OCT process to increase propene production. PCS in Singapore has also applied the OCT process to increase their propene production by 200000 to 300000 tonnes per year (Mol, 2004).

\subsubsection{The Meta-4 Process}

The Meta-4 process is similar to the OCT process, but a different catalyst is used. The process was developed by the Institut Français du Petrole (IFP) and the Chinese Petroleum Corporation. The catalyst used is rhenium (VII) oxide on alumina as it is more active and operates at much lower temperatures compared to tungsten and molybdenum catalysts $\left(\sim 35^{\circ} \mathrm{C}\right)$. The disadvantages of using this catalyst are that high pressures (60 bar) are required, the catalyst itself is very costly, it undergoes rapid deactivation and it requires a high purity feed stream as any impurities poison the catalyst. For these reasons the process has not yet been commercialized. 


\subsubsection{1-Hexene Production}

1-Hexene is used together with ethylene in the production of polyethylene by copolymerization. The OCT process is used to convert butene into 3-hexene, ethene and propene by metathesis (Mol, 2004). The 3- hexene is then isomerized into 1-hexene as desired using a solid acid catalyst.

\subsubsection{Neohexene Synthesis}

Neohexene (3,3-dimethyl-1-butene) is produced by the cross metathesis of 2,4,4-trimethyl-2pentene and ethene (Equation 2.1 and 2.2). The former is found in di-isobutene together with its other isomers including 2,4,4-trimethyl-1-pentene. A dual catalyst is used to isomerise the isomers with terminal double bonds like 2,4,4-trimethyl-1-pentene into 2,4,4-trimethyl-2pentene which is used in the metathesis reaction. The heterogeneous catalyst mixture (ratio of 1:3) consists of $\mathrm{WO}_{3} / \mathrm{SiO}_{2}$ for the metathesis reaction and $\mathrm{MgO}$ for the isomerization. With this dual catalyst, a conversion of $65-70 \%$ di-isobutene and selectivity of $\sim 85 \%$ neohexene is achieved at reactor conditions of $370^{\circ} \mathrm{C}$ and 30 bar with an ethene to di-isobutene molar ratio of 2.

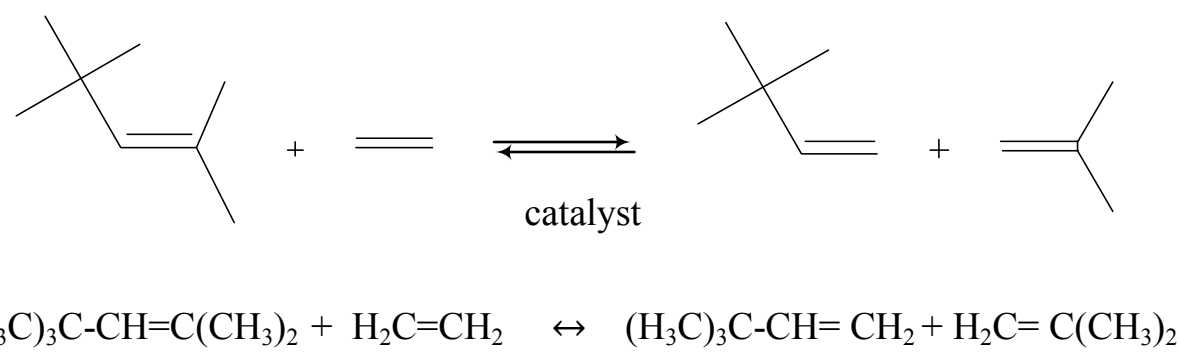

In the industrial neohexene process (Figure 2.4), an oxidation inhibitor has to be removed from the commercial di-isobutene to prevent poisoning the dual catalyst. The di-isobutene is thus fractionated and enters the top of the metathesis reactor together with a compressed ethene stream. The ethene stream is compressed to the required pressure. A stripper and fractionation columns are used to separate the reactants and the products. Reactivation of the catalyst is accomplished by coke combustion using a mixture of air and inert gas. 
A neohexene production unit was built at Chevron Phillips Houston petrochemical complex in 1980. Neohexene is used as an intermediate in the production of synthetic musk perfume and anti-fungal agents (Mol, 2004).

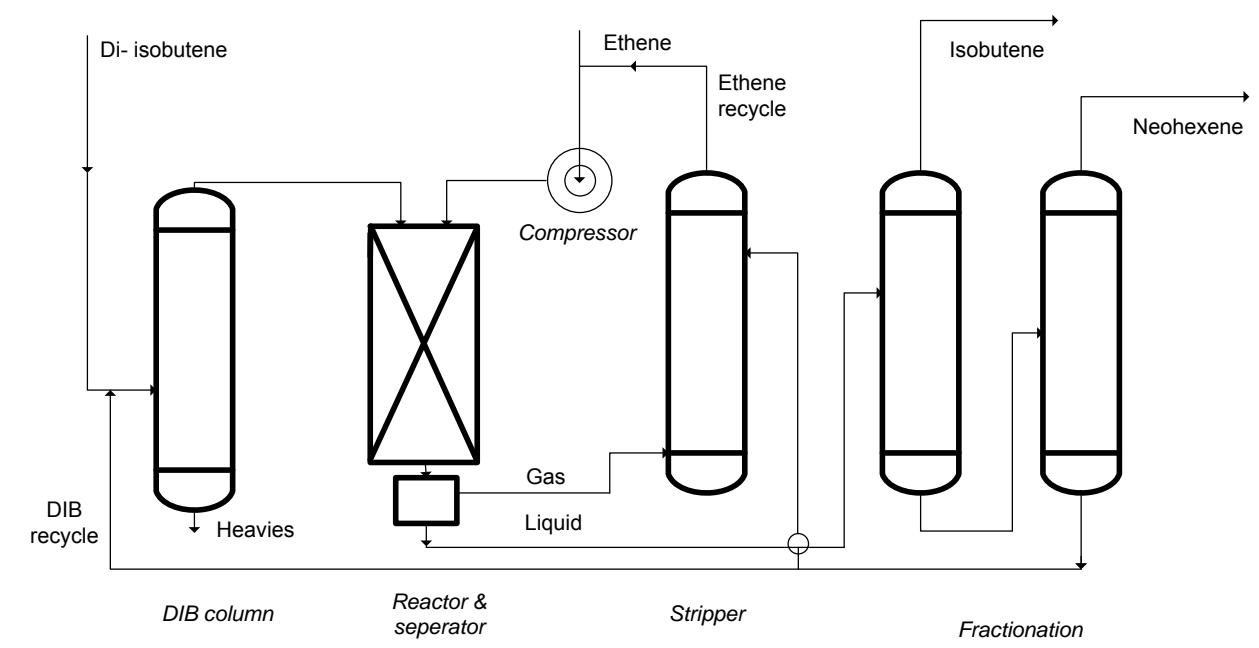

Figure 2.4: The neohexene process (Mol, 2004)

\subsubsection{Shell higher olefins process (SHOP)}

SHOP uses olefin metathesis to produce linear higher olefins from ethene. It consists of a three step process, the first involving the oligomerization of ethylene in the presence of a catalyst and polar solvent. The catalyst used is homogeneous nickel-phosphine and the solvent used is 1,4butanediol (Mol, 2004). The reaction temperature is $90-100^{\circ} \mathrm{C}$ and the reaction pressure is 100 110 bar. The product consists of linear even-numbered $\alpha$-olefins $\left(\mathrm{C}_{4}-\mathrm{C}_{40}\right)$. Distillation of the product mixture results in the separation of the $\mathrm{C}_{6}-\mathrm{C}_{18}$ range of alpha-alkenes from the lighter $(<$ $\left.\mathrm{C}_{6}\right)$ and heavier $\left(>\mathrm{C}_{18}\right)$ alpha alkenes (Mol, 2004). The next step consists of double bond isomerization of the lighter and heavier alpha alkenes over a potassium or magnesium oxide catalyst to give a mixture of internal alkenes (Dwyer, 2006). This mixture of internal alkenes undergoes redistribution by cross metathesis reactions which constitutes the third step. The metathesis catalyst used is molybdate supported on alumina and the yield of desired internal linear $\mathrm{C}_{11}-\mathrm{C}_{14}$ alkenes produced per pass is about $10-15 \mathrm{wt} \%$ (Mol, 2004). The operating conditions for both the isomerization and metathesis catalysts are $100-125^{\circ} \mathrm{C}$ and 10 bar. The desired internal linear $\mathrm{C}_{11}-\mathrm{C}_{14}$ alkenes produced can be converted into detergent alcohols or detergent alkylates. There are currently four SHOP plants in operation worldwide and the total production of linear alpha and internal olefins is approximately greater than $1 \mathrm{Mt}$ per year (Dwyer, 2006). 


\subsubsection{Alpha olefin production}

The Sasol Ltd Fischer-Tropsch process produces fuel from syngas derived from natural gas or coal (Mol, 2004). Low value linear alpha olefins $\left(\mathrm{C}_{4}-\mathrm{C}_{7}\right)$ are also present in the fuel stream in large quantities and are recovered by distillation. The olefin metathesis reaction is under consideration for the conversion of the low value linear alpha olefins into more useful higher range carbon number olefins $\left(\mathrm{C}_{10}-\mathrm{C}_{16}\right)$ to be used in the production of detergent alcohols. The heterogeneous tungsten catalyst and the active ruthenium complex are of interest for the metathesis reaction. The high reaction rates and selectivity of the ruthenium complex makes it an attractive option. An example of a highly active ruthenium complex is the $2^{\text {nd }}$ generation Grubbs-type catalyst (Mol, 2004).

\subsection{Metathesis Mechanism}

The general mechanism for metathesis that is currently accepted, after much research, is the mechanism that was first proposed by Chauvin in 1971. This mechanism describes alkene metathesis as a chain reaction where the formation of the metal-carbene complex constitutes an important step. Various routes for the formation of the initial metal-carbene complex have been postulated since.

Mol and Leeuwen (2008) describe the formation of the initial metal-carbene very simply as the coordination of the reactant alkene to the metal centre (

Figure 2.5). A hydride transfer then occurs followed by the formation of the metallacyclobutane and metal carbene complex (Mol and Leeuwen, 2008).

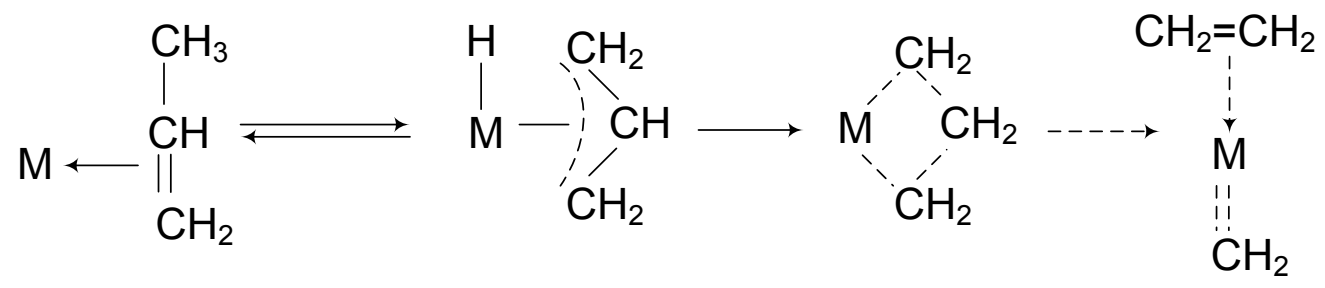

Figure 2.5: Formation of initial metal carbene complex (Mol and Leeuwen, 2008). 
Another reactant alkene then coordinates to the metal carbene complex formed. A shift of the alkene and opening of the double bonds results in the formation of a metallacyclobutane intermediate (Dwyer, 2006). Rearrangement of the metallacyclobutane intermediate produces a new alkene and a new propagating metal carbene complex each formed by the exchange of parts (Figure 2.6). The process is repeated for the new metal carbene and hence a chain reaction results.
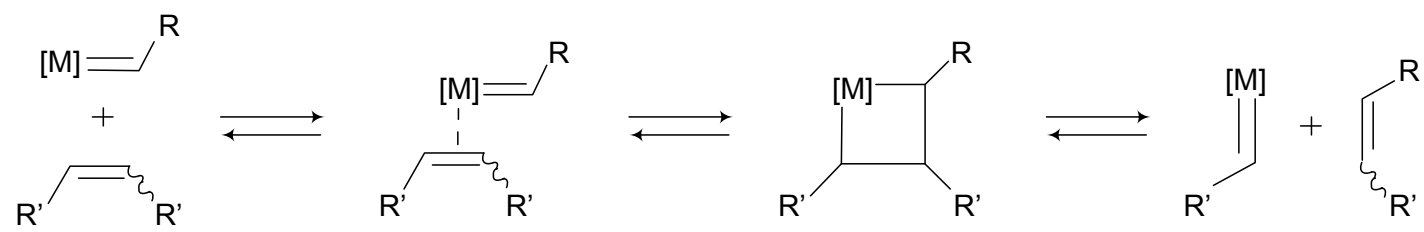

Figure 2.6: Basic mechanism for alkene metathesis (Delaude and Noels, 2001)

Van Roosmalen and Mol (1982) give a more detailed study of the metathesis mechanism and suggest an occurrence of a series of reactions which result in a metal carbene initiator. The system studied was the metathesis of propene over a $\mathrm{WO}_{3} / \mathrm{SiO}_{2}$ catalyst. The mechanism model presented, however, can be used to describe metathesis systems involving other reactants and catalysts in a similar manner (Van Roosmalen and Mol, 1982).

The first of the series of reactions involves the interaction between the non-reduced dehydrated $\mathrm{WO}_{3} / \mathrm{SiO}_{2}$ complex and the reactant alkene. It was established from previous studies by Van Roosmalen and $\mathrm{Mol}$ (1982) that the dehydrated $\mathrm{WO}_{3} / \mathrm{SiO}_{2}$ complex depends on the catalyst preparation method and is of the structure given in Figure 2.7.

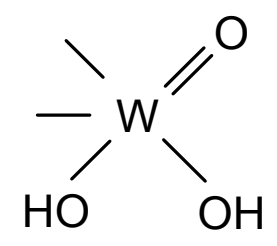

(a)

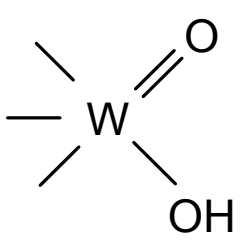

(b)

where $\quad$ represents $\equiv \mathrm{Si}-\mathrm{O}$ bridges to the silica lattice

Figure 2.7: Dehydrated $\mathrm{WO}_{3} / \mathrm{SiO}_{2}$ complex (a) prepared by impregnation (b) prepared by cogelation (Van Roosmalen and Mol, 1982) 
The reaction between the dehydrated $\mathrm{WO}_{3} / \mathrm{SiO}_{2}$ complex (prepared by cogelation) and the reactant alkene is given below with propene as an example (

Figure 2.8).

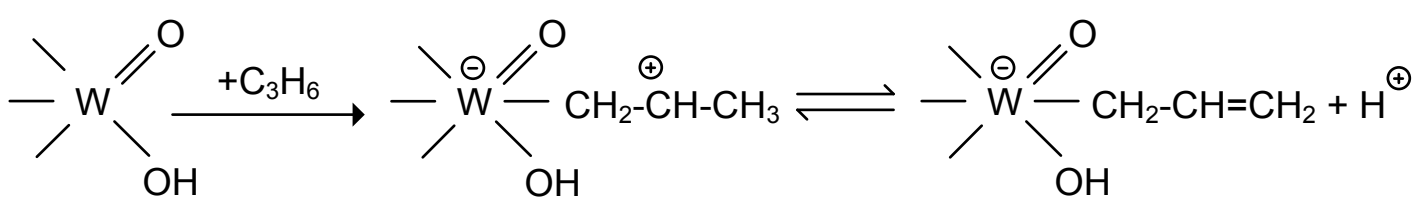

Figure 2.8: The interaction between non-reduced dehydrated $\mathrm{WO}_{3} / \mathrm{SiO}_{2}$ complex and propene (Van Roosmalen and Mol, 1982)

The $\mathrm{WO}_{3} / \mathrm{SiO}_{2}$ complex has silanol groups with Lewis acid sites. The $\equiv \mathrm{Si}-\mathrm{O}$ bridges are electron attracting groups and behave as a Lewis acid. The alkene is chemisorbed onto the $\mathrm{WO}_{3} / \mathrm{SiO}_{2}$ complex, to form a Lewis acid/alkene complex, and due to the Lewis acidity, has a tendency to donate a proton (Van Roosmalen and Mol, 1982).

Activation of the $\mathrm{WO}_{3} / \mathrm{SiO}_{2}$ catalyst, termed 'catalyst break-in' occurs when the catalyst is reduced on contact with pure reactant alkene feed or hydrogen (Figure 2.9).

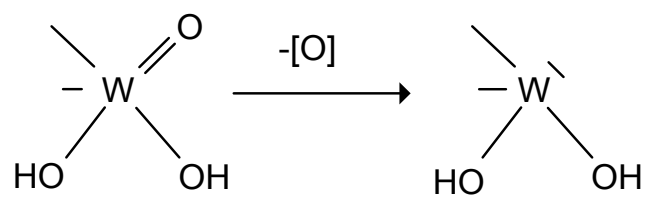

(a)

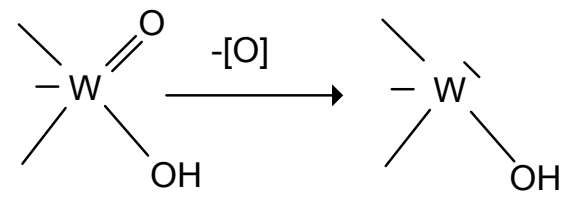

(b)

Figure 2.9: Reduction of $\mathrm{WO}_{3} / \mathrm{SiO}_{2}$ catalyst (a) prepared by impregnation (b) prepared by cogelation (Van Roosmalen and Mol, 1982)

If the pre-treatment of the catalyst involves hydrogen or carbon monoxide, the [O] released reacts to form water or carbon dioxide. If there is no pre-treatment with hydrogen or carbon monoxide and reduction occurs during prolonged contact with the reactant alkene, the [O] 
released reacts with the reactant alkene. An oxidation state of +4 for tungsten is required for optimum catalytic activity (Fierro and Mol, 2006).

The formation of the Lewis acid/alkene complex and subsequent donation of a proton as well as the reduction of the tungsten oxide/silica catalyst both play a role in the formation of the initial metal carbene initiator. The proton donated from the Lewis acid/alkene complex reacts with the reduced tungsten oxide/silica catalyst to form a tungsten hydride as depicted. The alkene is then adsorbed onto the hydride resulting in a $\beta$-hydrogen addition. The final metal carbene initiator is formed by the donation of a proton as shown in Figure 2.10 below.

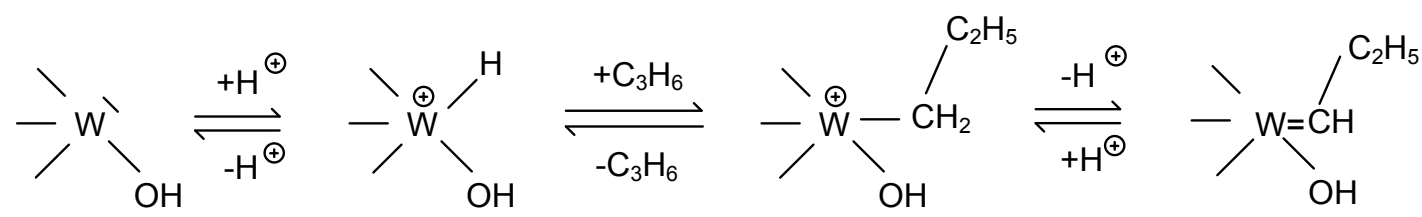

Figure 2.10: Initiation mechanism for metathesis (Van Roosmalen and Mol, 1982)

\subsection{Common heterogeneous metathesis catalysts}

Heterogeneous metathesis catalyst systems are mainly based on the oxides of molybdenum, tungsten and rhenium on a silica or alumina support (Dwyer, 2006).

Rhenium and molybdenum catalyst systems operate at much lower temperatures $\left(-20-100^{\circ} \mathrm{C}\right.$ for rhenium and $50-300^{\circ} \mathrm{C}$ for molybdenum) when compared to tungsten catalyst systems (300$550^{\circ} \mathrm{C}$ ) (Dwyer, 2006). Due to their low operating temperatures, their selectivity is good as they are not prone to negative side-reactions like double bond and skeletal isomerization and cracking (Spamer, 2003). The operating pressures for the rhenium oxide catalyst are higher than the pressures for tungsten and molybdenum to keep the reagents in the liquid phase (Dwyer, 2006). Table 2.1 provides a comparison of the most common metathesis catalysts.

The rate of metathesis is higher when using the molybdenum catalyst compared to a tungsten catalyst even though it is believed that the reaction between the metal carbene and alkene $(C=C)$ is faster for the tungsten complex. This could be because the metallacyclobutane intermediate 
for tungsten is more stable than the molybdenum intermediate resulting in a slower rate (Delaude and Noels, 2001).

The advantages of the tungsten oxide catalyst include its ability to tolerate branched olefins. It also has a longer online lifetime and can be easily regenerated without loss of activity or structure (Schalkwyk et al., 2003). The disadvantages include the lower selectivity achieved due to isomerization and side reactions which occur as a result of the high reaction temperatures and use of an acidic support. Another disadvantage is the formation of coke due to high reaction temperatures (Schalkwyk et al., 2003).

Table 2.1: Comparison of the most common metathesis catalysts [Adapted from Dwyer (2006)]

\begin{tabular}{|l|c|c|c|}
\hline Type & Tungsten Oxide & Molybdenum Oxide & Rhenium Oxide \\
\hline $\begin{array}{l}\text { Operating temperature } \\
\left({ }^{\circ} \mathrm{C}\right)\end{array}$ & $300-500$ & $50-300$ & $-20-100$ \\
\hline Operating pressure (bar) & $1-30$ & $1-30$ & $1-60$ \\
\hline Activity & $\begin{array}{c}\text { Good towards cyclic } \\
\text { and acyclic olefins }\end{array}$ & $\begin{array}{c}\text { Good towards linear } \\
\text { olefins }\end{array}$ & $\begin{array}{c}\text { Good towards } \\
\text { simple olefins }\end{array}$ \\
\hline Selectivity & $\begin{array}{c}\text { Poor: prone to } \\
\text { negative side- } \\
\text { reactions like double } \\
\text { bond and skeletal } \\
\text { isomerization and } \\
\text { cracking }\end{array}$ & Good & Excellent \\
& $\begin{array}{c}\text { Coke formation but } \\
\text { catalyst can be } \\
\text { regenerated } \\
\text { continuously, } \\
\text { tolerates branched } \\
\text { olefins }\end{array}$ & $\begin{array}{c}\text { Deactivates in the } \\
\text { presence of branched } \\
\text { olefins, does not } \\
\text { readily tolerate } \\
\text { functional groups }\end{array}$ & $\begin{array}{c}\text { Deactivates in the } \\
\text { presence of } \\
\text { branched olefins, } \\
\text { more tolerant to } \\
\text { certain }\end{array}$ \\
& $\begin{array}{c}\text { Gas } \\
\text { functional groups }\end{array}$ \\
\hline Reaction phase & $\begin{array}{c}\text { Gas } \\
\text { Gas or Liquid }\end{array}$ \\
\hline
\end{tabular}

\subsection{Catalyst preparation methods}


The main objective when preparing the catalyst is to produce one that has a high activity as well as good selectivity towards the desired metathesis products. The catalyst preparation method and conditions are important factors that need to be accurately determined since the resulting surface structure of the tungsten species is dependent on it.

The two methods that are commonly used in the preparation of catalysts are termed the precipitation method and the impregnation method (Satterfield,1991). Incorporated in both these methods are drying, calcining and reduction of the catalyst. The impregnation method is the most commonly used method in the preparation of supported tungsten catalysts. It is the easier of the two methods and is desirable when using an expensive active component, such as tungsten, since only a small quantity of it is needed to be spread through the support. The precipitation method on the other hand may not make full use of the expensive metal catalyst since 'some of the active ingredient may be enclosed by other material present and thus unavailable for reaction' (Satterfield, 1991).

There are two types of impregnation, the first being 'dry' impregnation and the other being 'wet' impregnation. Wet impregnation is used when there is interaction between the precursor and support and when the specific loading of the precursor is low (Pinna, 1998). It differs from dry impregnation in that an excess amount of solution containing the precursor is used. The catalyst preparation method to be used in this project is the wet impregnation method. In the preparation of the $\mathrm{WO}_{3} / \mathrm{Al}_{2} \mathrm{O}_{3}$ catalyst, the ammonium metatungstate hydrate will be dissolved in excess water to form an aqueous solution which will be used to impregnate the support. This will be followed by ageing of the mixture under stirring, drying and calcination.

\subsubsection{Drying}

Drying of the catalyst is an important step in the wet impregnation method as it eliminates the excess water that was added in the previous preparation step to form the aqueous solution of ammonium metatungstate hydrate. Drying usually occurs at temperatures between $80^{\circ} \mathrm{C}$ and $200^{\circ} \mathrm{C}$. The temperature at which the drying occurs, the length of time the catalyst is left to dry, and the rate of drying, are factors which need to be taken into account since they affect the distribution of the active sites (Pinna, 1998). Complex factors that are difficult to take into account include the rate of nucleation, pore size distribution, degree of liquid saturation and the degree to which liquid paths between pores are connected (Satterfield, 1991). 
The rate of drying affects whether the active sites will concentrate at the catalysts external surface or deep within its pores. If the rate of drying is too fast and the temperature is too high, the solvent (water) will evaporate quickly from the outer surface of the particle. This will result in capillarity forces drawing the solution (water and the metal precursor) from within the pores towards the outer surface of the particle (Satterfield, 1991). Thus the metal precursor will concentrate on the outer surface and will not remain within the pores to form the active site. If the rate of drying is slow, slow evaporation from the outer surface of the particle will cause the metal precursor salt to diffuse into the liquid deep in the pore. When the rate of drying is too slow, the salt penetrates too deep into the pore and will not be accessible as an active site (Pinna, 1998).

\subsubsection{Calcination}

Calcination is a heat treatment process which consists of heating the catalyst under air. The calcination temperature used is an important factor in catalyst preparation. The temperature used is usually around or higher than the catalytic reaction temperature for which the catalyst is being prepared (Perego, 1997). The purpose of calcination is to eliminate the chemically bonded water or atmospheric $\mathrm{CO}_{2}$ and to form the active phase metal oxide by decomposition of the precursor (Pinna, 1998).

Calcination of ammonium metatungstatehydrate results in crystalline $\mathrm{WO}_{3}$ which is inactive in the metathesis reaction (van der Vlies, 2002 and Huang et al., 2007). However, calcination of ammonium metatungstatehydrate on an alumina support results in tetrahedral, octahedral and polytungstate species. Huang et al. (2007) has studied the activity and performance of a $\mathrm{WO}_{3} / \mathrm{Al}_{2} \mathrm{O}_{3} / \mathrm{HY}$ zeolite catalyst while varying the calcination time for the metathesis of ethene and 2-butene. The loading of tungsten used by these authors was $12.6 \mathrm{wt} \%$. X-ray diffraction (XRD), UV-Vis and UV Resonance Raman measurements were used to characterize the coordination state of the surface tungsten oxide species. They found that the activity related surface tungsten oxide species are tetrahedrally coordinated and the amount of tetrahedral surface tungsten oxide species is dependent on the calcination time. They also found that there is an optimum calcination time, beyond which the number of tetrahedral surface tungsten oxide species and thus the metathesis activity decreases (Figure 2.11). 


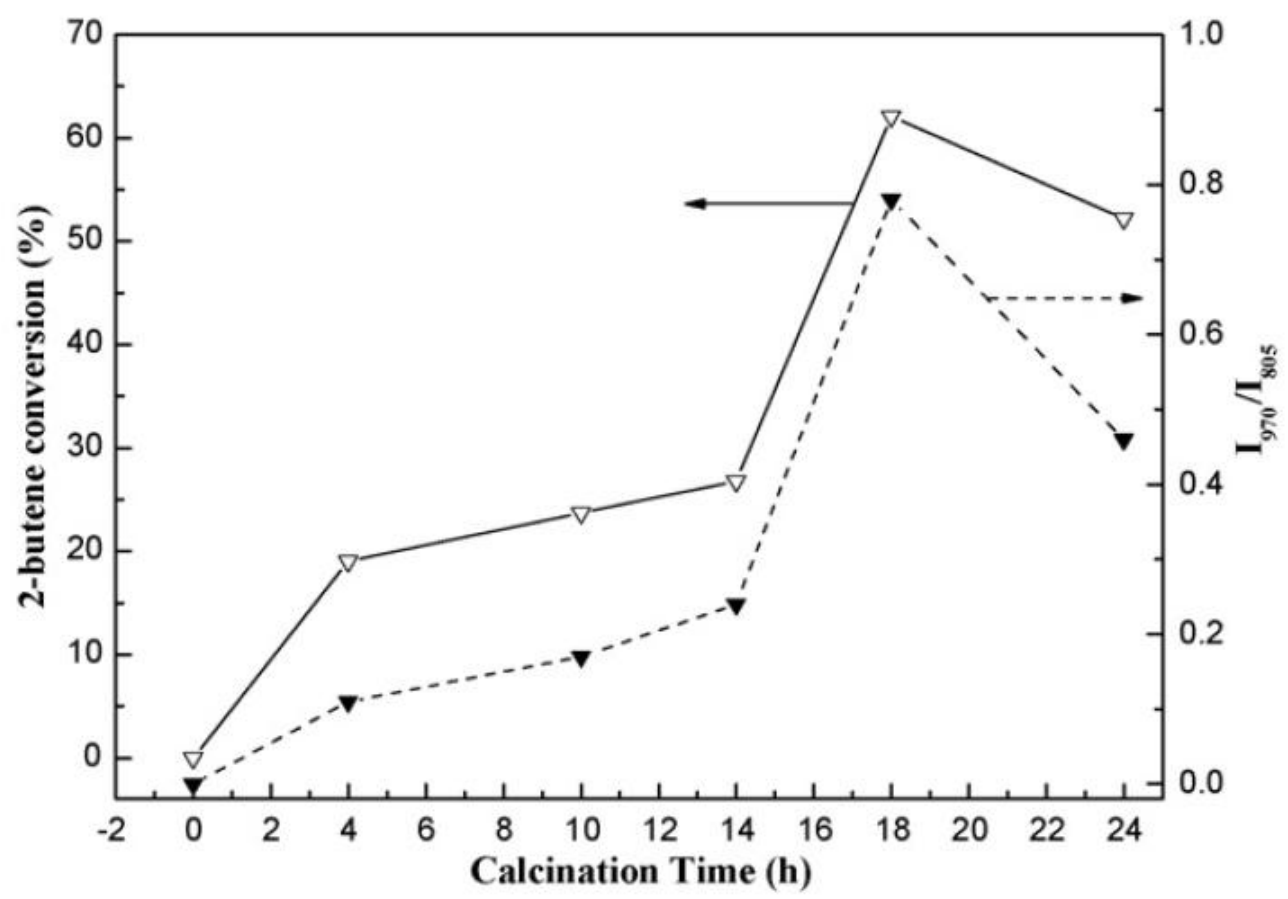

Figure 2.11: Amount of tetrahedral surface tungsten oxide species and metathesis activity as a function of calcination time (Huang et al., 2007)

\subsection{Catalyst supports}

The purpose of a catalyst support or carrier varies depending on the catalyst itself. For the olefin metathesis reactions, the supports commonly used are silica $\left(\mathrm{SiO}_{2}\right)$ and alumina $\left(\mathrm{Al}_{2} \mathrm{O}_{3}\right)$. The support provides a platform for the uniform and broad distribution of the catalyst to achieve a larger surface area. One of the reasons for the support is to prevent coalescing and agglomeration of the lower melting point metal oxide catalyst (Stiles, 1987). Apart from the above reasons for using a support, it was more recently determined that the support contributes catalytic activity for certain reactions (Satterfield, 1991). Therefore the selection of a support for a particular reaction is important and is dependent on both its physical and chemical properties.

Satterfield (1991) lists certain physical properties that a support should have:

1. Inertness to side reactions

2. Stability under reaction conditions 
3. Porosity (pore size $<2 \mathrm{~nm}$ is not desirable as plugging may occur during catalyst preparation)

4. Surface area (usually a high surface area is desirable)

5. Good mechanical properties (hardness, compressive strength)

\subsubsection{Alumina as a catalyst support}

One of the supports to be tested in this study is alumina $\left(\mathrm{Al}_{2} \mathrm{O}_{3}\right)$. Apart from having the physical properties stated above, features of alumina as a support include its amphoteric property, wettability as well as its high melting point. Amphoteric refers to the ability of alumina to function as either an acid in a basic medium or a base in an acidic medium (refer to Section 2.7.1.1). Wettability refers to the capillary forces of alumina which allow for the quick penetration of aqueous solutions into its pores (Stiles, 1987). The high melting point of alumina (greater than $2000^{\circ} \mathrm{C}$ ), indicates that it is a refractory oxide and thus serves as a thermal stabiliser (Stiles, 1987). This means that it possesses properties which allow it to separate the particles of the fine catalyst over the support to prevent agglomeration of the catalyst.

\subsubsection{Ion exchanging properties of alumina}

The adsorption of the tungsten ions onto the alumina support is found to be dependent on the equilibrium $\mathrm{pH}$ of the solution due to the amphoteric property of alumina. Alumina adsorbs water from moist air at ambient temperature and the water dissociates to form $\mathrm{OH}$ groups i.e. hydroxyl groups (Figure 2.12). These $\mathrm{OH}$ groups display amphoteric behaviour.

Thus alumina may function as an acid in a basic medium or as a base in an acidic medium, implying that the $\mathrm{OH}$ group may take on a positive or negative charge depending on whether the aqueous impregnation solution is acidic or basic (Stiles, 1987). In an acidic medium, the hydroxyl group in alumina would become polarized positively allowing for the adsorption of an anion. 


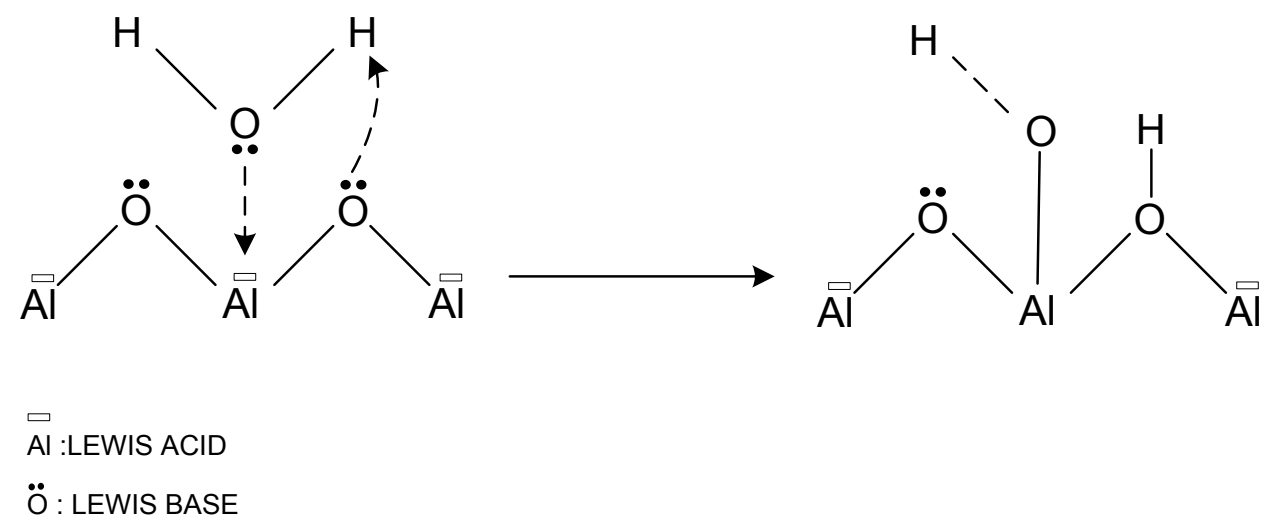

Figure 2.12 : Schematic representation of hydroxylation of alumina (Stiles, 1987)

This is represented by Equation 2.3 where $\mathrm{S}-\mathrm{OH}$ represents the hydroxyl group on the surface of the alumina.

$$
\mathrm{S}-\mathrm{OH}+\mathrm{H}^{+}=\mathrm{S}-\mathrm{OH}_{2}^{+}
$$

The opposite occurs in a basic medium where the hydroxyl group in alumina would become polarized negatively and thus acts as a cation adsorber. This is represented by Equation 2.4 below.

$$
\mathrm{S}-\mathrm{OH}+\mathrm{OH}^{-}=\mathrm{S}_{-} \mathrm{O}^{-}+\mathrm{H}_{2} \mathrm{O}
$$

It is important to take into account the iso-electric point (IEP) of the support as this is the $\mathrm{pH}$ zone that is in balance with the impregnation solution (Stiles, 1987). The iso-electric point is also known as the point of zero charge of alumina and occurs between a pH of 8.5 and 9 (Stiles, 1987). Therefore, as the $\mathrm{pH}$ decreases below 8.5 , increasing adsorption of the anion is favoured and above a $\mathrm{pH}$ of 9 , increasing adsorption of the cation is favoured. This implies that the higher the acidity of the medium (i.e. the lower the $\mathrm{pH}$ of the medium), the higher the adsorption of the tungstate anions.

The tungsten component of the tungsten oxide supported on alumina $\left(\mathrm{WO}_{3} / \mathrm{Al}_{2} \mathrm{O}_{3}\right)$ catalyst is obtained from ammonium metatungstate hydrate $\left(\left(\mathrm{NH}_{4}\right)\left[6 \mathrm{H}_{2} \mathrm{~W}_{12} \mathrm{O}_{40}\right] \cdot \mathrm{xH}_{2} \mathrm{O}\right)$. The structure of 
ammonium metatungstate consists of corner shared $\mathrm{WO}_{6}$ octahedra (Figure 2.13) thus giving it an oxidation state of $6+$ (van der Vlies, 2002).

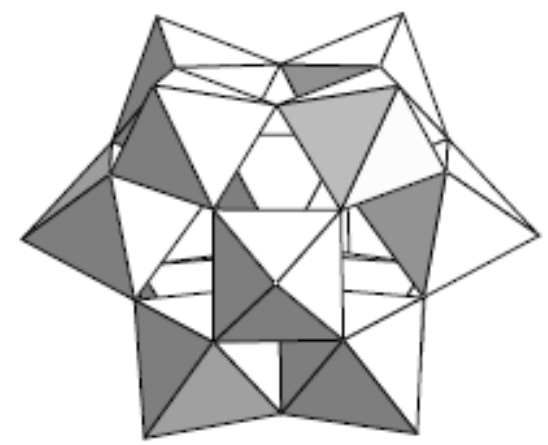

Figure 2.13: Structure of the $\left[\mathrm{H}_{2} \mathrm{~W}_{12} \mathrm{O}_{40}\right]^{6-}$ ion present in ammonium metatungstate (van der Vlies, 2002)

In solution the ammonium metatungstate hydrate dissolves to form $\mathrm{WO}_{4}{ }^{2-}$ anions. Thus it would be required that the alumina acquire a positive charge for the $\mathrm{WO}_{4}{ }^{2-}$ anions to be readily adsorbed. A positive charge is acquired on alumina in an acidic medium as explained above.

\subsubsection{Transformation sequence of alumina during calcination}

Alumina undergoes form transformation as the calcination temperature is increased as depicted in Figure 2.14.

The form of alumina that is of interest for use as a catalyst support and thus desired during catalyst preparation is the high surface area $\gamma$-alumina which is formed above $450^{\circ} \mathrm{C}$ (Perego et al., 1997 and Satterfield, 1991). As can be seen from Figure 2.14, alumina formed at about $300^{\circ} \mathrm{C}$ is not hydrated. At higher temperatures $\left(>300^{\circ} \mathrm{C}\right)$, loss of bonded water occurs when alumina $\mathrm{OH}$ groups are converted to water and evolve upon heating. This exposes the aluminium atoms (Lewis acid sites). 


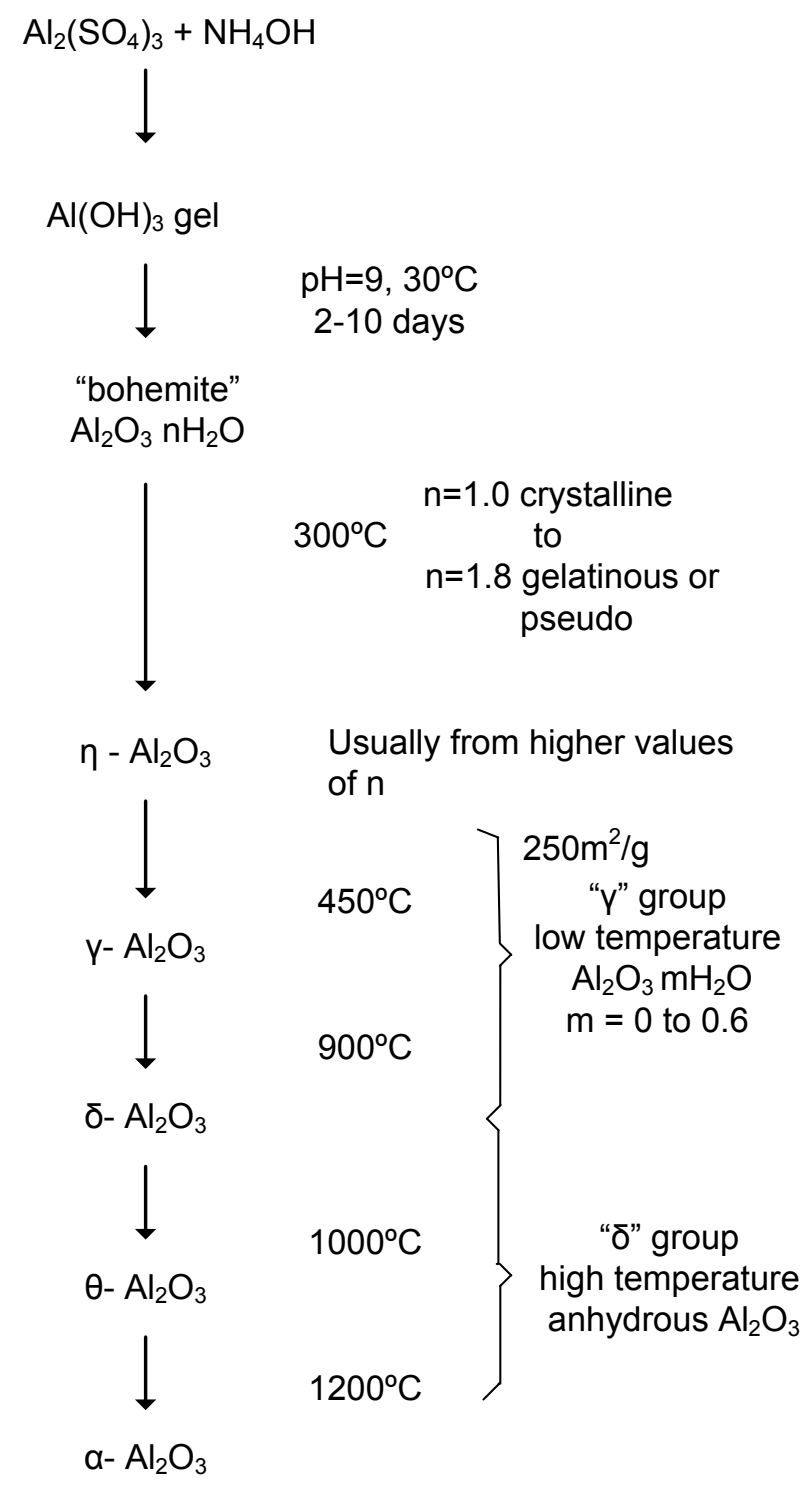

Figure 2.14 : Modification sequence of alumina upon calcination (Perego et al., 1997)

\subsubsection{Silica as a catalyst support}

The main advantage of using silica as a support over alumina is its higher resistance to acid media (Stiles, 1987). According to Harmse et al. (2010), the number of acid sites on the silica support is very low at $0.01 \mathrm{mmol} / \mathrm{g}$ and there is no evidence of Lewis acid sites being present. Therefore there is no 'noticeable evidence' of silica being an acidic support (Harmse et al., 2010). This makes it more desirable as a catalyst support in the metathesis reactions. 


\subsection{The $\mathrm{WO}_{3} / \mathrm{Al}_{2} \mathrm{O}_{3}$ catalyst}

\subsubsection{Surface coverage of $\mathrm{WO}_{3} / \mathrm{Al}_{2} \mathrm{O}_{3}$}

The surface coverage of the supported phase can be determined by various methods including ion scattering spectroscopy (ISS), CO adsorption and the electrophoretic migration method. Knowledge of the surface coverage of the supported phase is important since the surface structure at higher coverage ( $\sim$ monolayer coverage) differs from that at low coverage (Horsley et al., 1987). Llambias et al. (1998) has used the electrophoretic migration method to find the surface coverage values at different loading of tungsten on the alumina support and compare this to values found in previous studies using the ISS and CO adsorption methods. A linear relationship was found between the surface coverage and percent loading of tungsten as shown in Figure 2.15.

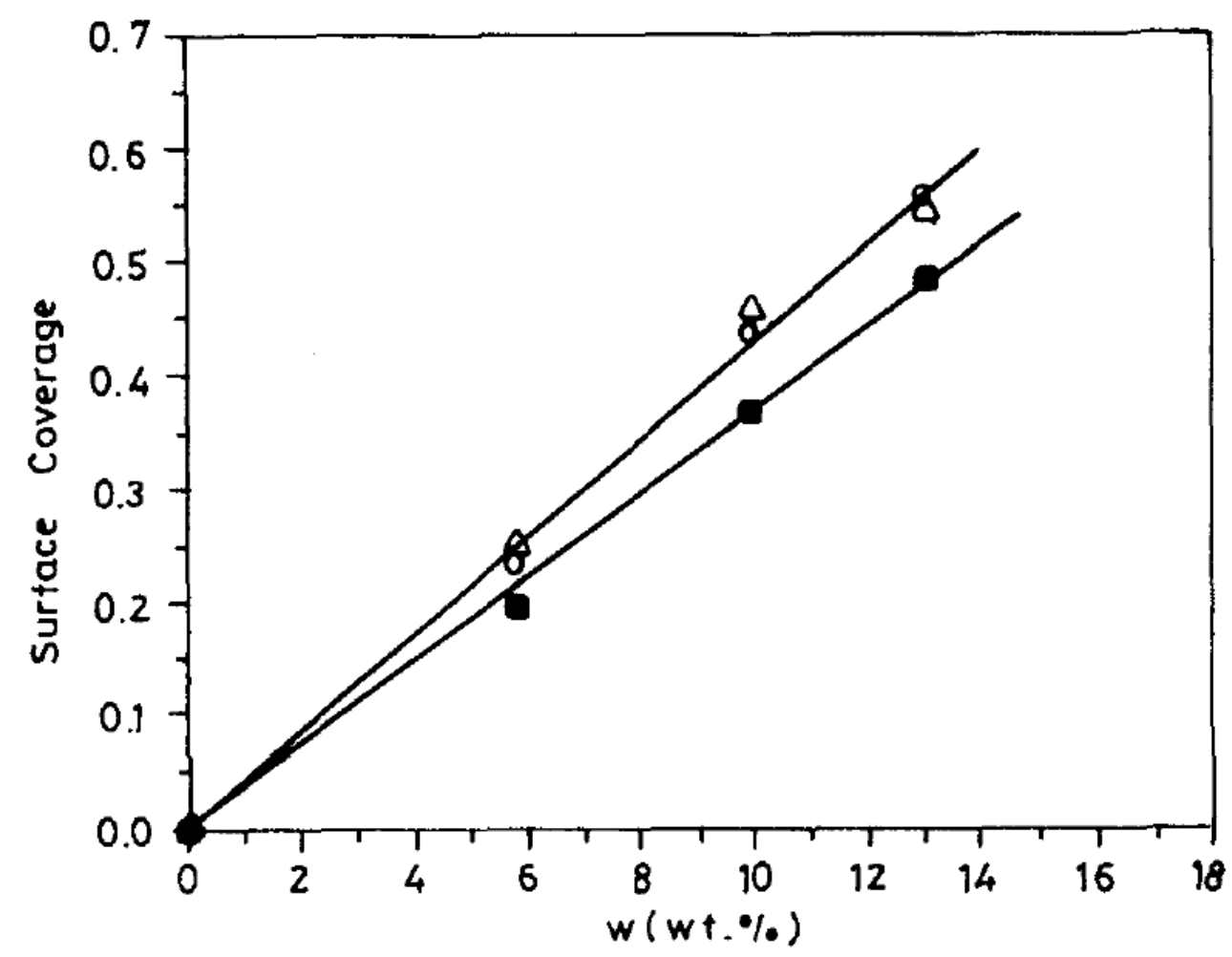

Figure 2.15: Surface coverage as a function of tungsten loading ( $\mathrm{O}=\mathrm{ISS} ; \quad \Delta=\mathrm{CO}$ adsorption; = electrophoretic measurements) (Llambias et al., 1998) 
For the purpose of this project, the specific loadings that were tested were 10,16 and $20 \mathrm{wt} \%$ $\mathrm{WO}_{3}$. Extrapolation of the graph above indicates that these specific loadings fall below the monolayer surface coverage.

\subsubsection{Surface structure of $\mathrm{WO}_{3} / \mathrm{Al}_{2} \mathrm{O}_{3}$}

Much research into the investigation of the surface structure of $\mathrm{WO}_{3} / \mathrm{Al}_{2} \mathrm{O}_{3}$ has been undertaken using various techniques including Laser Raman Spectroscopy (LRS), X-ray photoelectron spectroscopy (XPS), X-ray absorption near-edge spectroscopy (XANES), and temperature programmed reduction (TPR). Two structures that have been suggested for the tungsten oxide species on the alumina support are octahedral and tetrahedral surface complexes. Horsley et al. (1987) has made use of XANES and Laser Raman Spectroscopy to determine which of the two surface complexes are present as well as to determine how coordinated water affects the structure. XANES spectra for $\mathrm{WO}_{3}, \mathrm{Al}_{2}\left(\mathrm{WO}_{4}\right)_{3}$ and $\mathrm{WO}_{3} / \mathrm{Al}_{2} \mathrm{O}_{3}$ was compared. The authors prepared a 2 and $10 \mathrm{wt} \% \mathrm{WO}_{3} / \mathrm{Al}_{2} \mathrm{O}_{3}$ catalyst by the incipient wetness method and this was calcined at $500^{\circ} \mathrm{C}$. A second sample of 2 and $10 \mathrm{wt} \% \mathrm{WO}_{3} / \mathrm{Al}_{2} \mathrm{O}_{3}$ was prepared in the same way but was heated after calcining in $20 \%$ oxygen in helium, without air exposure, to remove any further water bonded to the catalyst. It is known that $\mathrm{Al}_{2}\left(\mathrm{WO}_{4}\right)_{3}$ has tetrahedral $\mathrm{WO}_{4}$ groups and this is indicated by a sharp, well-defined pre-edge feature on the XANES spectra. For less than a monolayer surface coverage, their results showed that the pre-edge feature in the XANES spectra for the $\mathrm{WO}_{3} / \mathrm{Al}_{2} \mathrm{O}_{3}$ catalyst with water removed was very similar to the spectra for $\mathrm{Al}_{2}\left(\mathrm{WO}_{4}\right)_{3}$, suggesting that the $\mathrm{WO}_{3} / \mathrm{Al}_{2} \mathrm{O}_{3}$ catalyst also has tetrahedral $\mathrm{WO}_{4}$ groups. Horsley et al. (1987) also found that the XANES spectra for the 2 and $10 \mathrm{wt} \% \mathrm{WO}_{3} / \mathrm{Al}_{2} \mathrm{O}_{3}$ catalyst was identical implying that loading did not affect the surface structure. The $\mathrm{WO}_{3} / \mathrm{Al}_{2} \mathrm{O}_{3}$ catalyst that underwent calcination only, was found to have a less intense pre-edge feature because some water molecules present bonded to the tetrahedral structure, resulting in some surface tungsten oxide octahedra. The Laser Raman Spectroscopy agreed with the results obtained from XANES and the Raman band gives evidence that $\mathrm{W}=\mathrm{O}$ and $\mathrm{W}-\mathrm{O}-\mathrm{W}$ bonds are present which indicate tetrahedral coordination of the tungsten oxide in the absence of water as shown in Figure 2.16.

The W-O-W bonds indicate the dimeric form of a fraction of the surface tungsten oxide species. Another important finding by Horsley et al. (1987) is that calcination of the catalyst at extremely high temperatures such as $950^{\circ} \mathrm{C}$ causes a decrease in the surface area of the alumina support. 

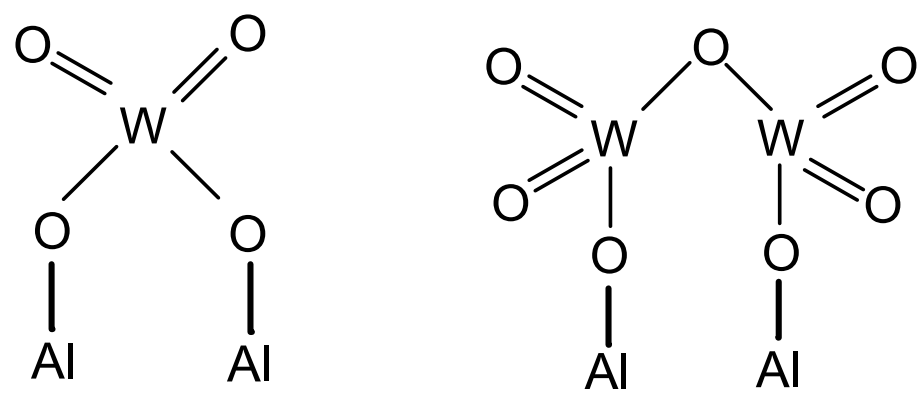

Figure 2.16: Tetrahedral coordination of the tungsten oxide (van der Vlies, 2002)

During the formation of $\mathrm{WO}_{3} / \mathrm{Al}_{2} \mathrm{O}_{3}$, the tungsten oxide $\left(\mathrm{WO}_{3}\right)$ bonds to either one or two $\mathrm{OH}$ groups on the surface of alumina. This results in the formation of either a Lewis or Brønsted acid site represented by Figure 2.17 (a) and (b) respectively (Logie et al., 1999).

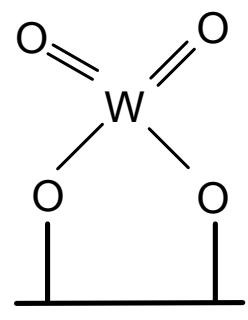

$\mathrm{Al}_{2} \mathrm{O}_{3}$

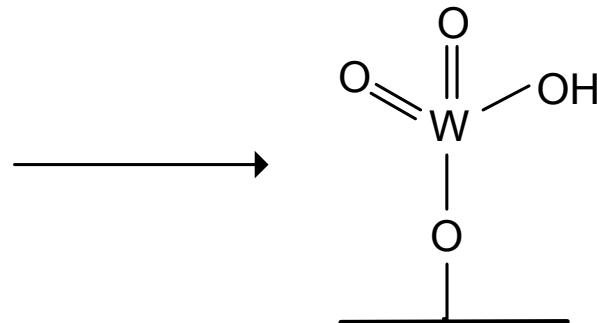

$\mathrm{Al}_{2} \mathrm{O}_{3}$

(a)

(b)

Figure 2.17: Formation of $\mathrm{WO}_{3} / \mathrm{Al}_{2} \mathrm{O}_{3}$ as a (a) Lewis acid site (b) Brønsted acid site (Logie et al., 1999)

It is known that Lewis acid sites play a key role in the performance of the catalyst since they are responsible for the adsorption of the reactant onto the surface i.e. initiation of the metathesis reaction as well as the catalyst stability (Logie et al., 1999). However, they are also responsible for its low tolerance to poisons and deactivation. It was found that Brønsted acid sites are mainly responsible for negative side reactions such as isomerization and play no part in initiating the reaction (van Roosmalen and Mol, 1982; Schekler-Nahama et al., 1997). It is important therefore to limit the number of Brønsted acid sites to a minimum, while still achieving an optimum acidity to achieve optimum metathesis activity (Spamer, 2003). 
Logie et al. (1999) suggested that the formation of the Brønsted acid site is dependent on the calcination temperature and tungsten loading and that an increase of either promotes the formation of Brønsted acid sites over Lewis acid sites. They postulated that a calcination temperature of $200^{\circ} \mathrm{C}$ led to the formation of mainly Lewis acid sites.

\subsection{The $\mathrm{WO}_{3} / \mathrm{SiO}_{2}$ catalyst}

\subsubsection{Tungsten trioxide loading on silica}

Research into the optimum loading of tungsten trioxide on a silica support was conducted by Spamer et al. (2003). Various specific loadings of tungsten trioxide in the range of $3-20 \mathrm{wt} \%$ $\mathrm{WO}_{3}$ were investigated for the metathesis of 1 -octene at $460^{\circ} \mathrm{C}, 5.6 \mathrm{LSHV}$ and atmospheric pressure. The catalysts were prepared in that study using the wet impregnation method.

The results from their study provided relationships between the conversion and the $\mathrm{WO}_{3}$ loadings as well as the selectivity to linear $\mathrm{C}_{14}$ products and the $\mathrm{WO}_{3}$ loadings. The relationship between the conversion of 1 -octene and the time online provided an indication of the catalyst deactivation for each loading. The plots of each of these relationships, as produced by Spamer et al. (2003), are given in Figure 2.18 and Figure 2.19.

According to Spamer et al. (2003), the selectivity as well as the conversion was found to stabilise from a loading of $8 \mathrm{wt} \% \mathrm{WO}_{3}$. At lower loadings, below $6 \mathrm{wt} \%$, the selectivity is higher and was found to be the highest at the lowest $\mathrm{WO}_{3}$ loading of $3 \mathrm{wt} \%$. The conversion however, was found to have the opposite trend, the highest conversion being at $8 \mathrm{wt} \%$ and above. Deactivation of the catalysts was found to occur faster in the catalysts with the lower loadings of $\mathrm{WO}_{3}$ whereas the conversion in catalysts with higher loadings of $\mathrm{WO}_{3}$ remained constant indicating no signs of catalyst deactivation for the time online. 


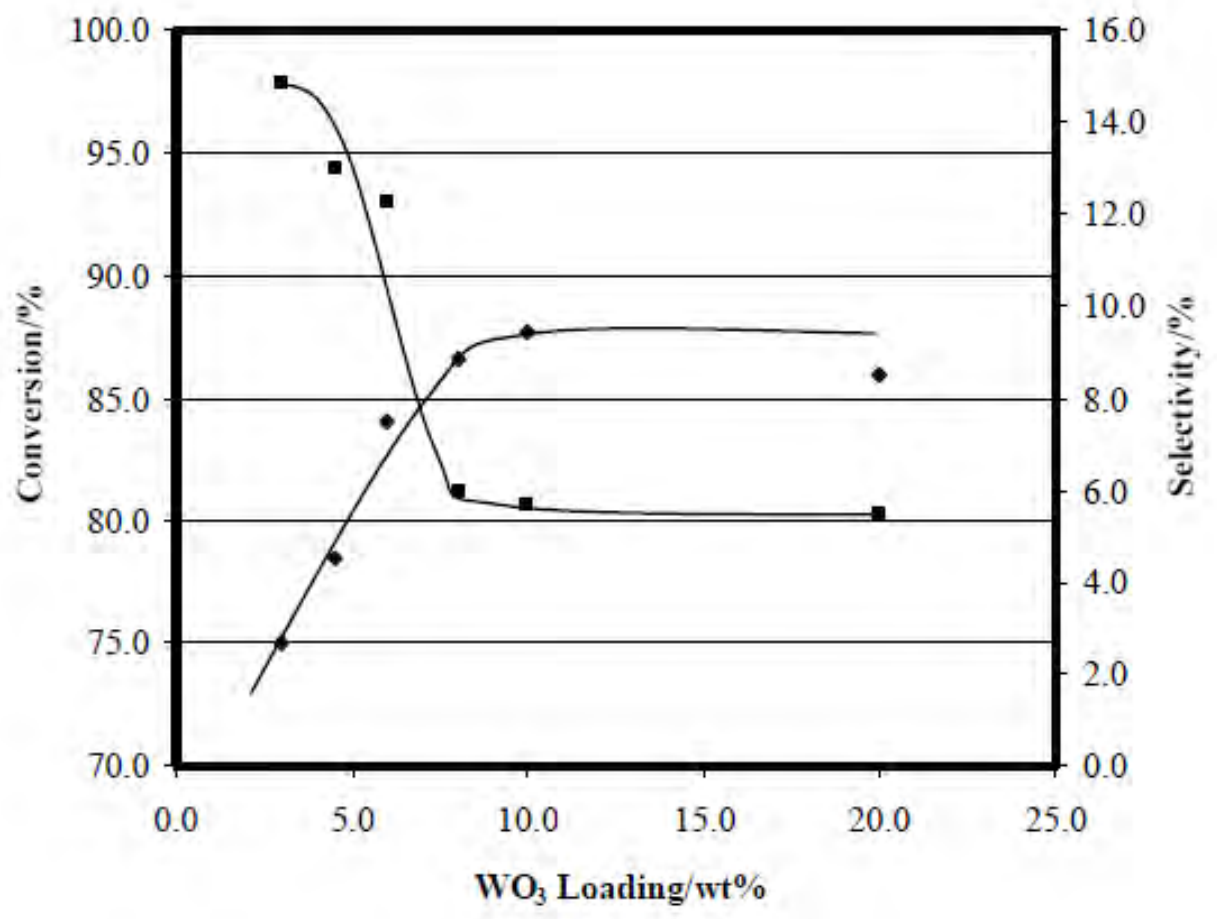

Figure 2.18: Conversion and selectivity to linear $\mathrm{C}_{14}$ products as a function of the $\mathrm{WO}_{3}$ loading ( = conversion and $\boldsymbol{E}$ = selectivity to linear $\mathrm{C}_{14}$ products) (Spamer et al., 2003)

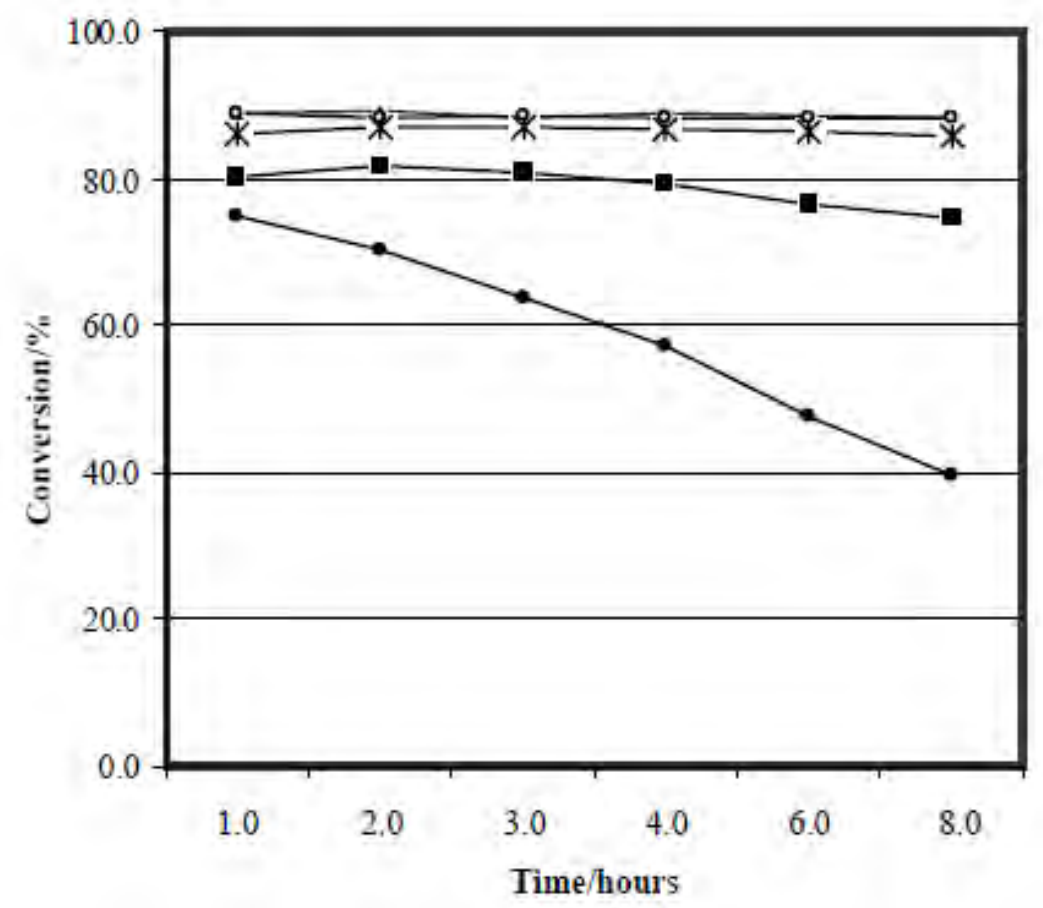

Figure 2.19 : Conversion as a function of time on-line for catalyst with varying $\mathrm{WO}_{3}$ loadings $\left(\boldsymbol{O}=3 \mathrm{wt} \% \mathrm{WO}_{3} / \mathrm{SiO}_{2} ; \quad \boldsymbol{\square}=4.5 \mathrm{wt} \% \mathrm{WO}_{3} / \mathrm{SiO}_{2} ; \boldsymbol{\Delta}=6 \mathrm{wt} \% \mathrm{WO}_{3} / \mathrm{SiO}_{2} ; \quad \boldsymbol{X}=8 \mathrm{wt} \%\right.$ $\mathrm{WO}_{3} / \mathrm{SiO}_{2}$ and $\mathrm{O}=20 \mathrm{wt} \% \mathrm{WO}_{3} / \mathrm{SiO}_{2}$ ) (Spamer et al., 2003) 


\subsubsection{Surface structure of $\mathrm{WO}_{3} / \mathrm{SiO}_{2}$}

The surface structure of the $\mathrm{WO}_{3} / \mathrm{SiO}_{2}$ catalyst is a combination of crystalline bulk oxide and surface compounds (Thomas and Moulijn, 1980). The crystalline bulk oxide increases with an increase in the loading of tungsten oxide. According to Thomas and Moulijn (1980), the Raman spectra show two types of tungsten compounds. The first is the crystalline trioxide and the second is the surface compound believed to be a distorted tungstate octahedra. They also found that the crystalline tungsten trioxide is inactive in the metathesis reactions. Copéret (2009) found that in the silica supported catalyst, the $\mathrm{Si}$ is tetracoordinated and is found in mainly the tetrahedral geometry.

\subsection{Isomerization reactions and the reduction of isomerization activity}

It is known that acid sites are responsible for catalysing isomerization reactions (Spamer et al., 2003). Therefore the number of acid sites on a catalyst and their strength is an important factor that determines the selectivity towards the desired range of products.

Apart from being used as a support for catalysts, as in this study, alumina itself catalyses many reactions. After high temperature treatment of the alumina catalyst, water is removed which results in the formation of cations, anions and hydroxyl groups on the surface of the catalyst which in turn form Lewis and Brønsted acid sites (Kriel, 2008). When dehydrated alumina was used to catalyse alpha-olefin reactions, a large amount of isomerization was found to occur (Kriel, 2008).

In metathesis reactions, the selectivity towards the primary metathesis products is an important factor, thus the highest selectivity achievable is aimed for. Improving the selectivity of a catalyst would require a reduction in the double bond isomerization reactions. This can be achieved by the addition of alkali, alkali-earth or thallium metal ions, which act as a poison to the acid sites responsible for these isomerization reactions (Spamer et al., 2003). Common alkali-earth metal ions used include sodium, potassium, rubidium and caesium.

Van Roosmalen and Mol (1982) found that Brønsted acid sites were responsible for the negative side reactions including isomerization. It was also discovered that poisoning of the Brønsted 
acid sites does not affect the catalytic activity, indicating that these acid sites do not play a role in the formation of the metal carbene initiator and thus the initiation of the metathesis reaction.

From previous literature studies, it is believed that the alkali-earth metal ions replace the hydrogen molecules of the support. Spamer (2003) conducted research into the reduction of isomerization on an $8 \mathrm{wt} \% \mathrm{WO}_{3} / \mathrm{SiO}_{2}$ catalyst for the metathesis of 1-octene by doping the catalyst with potassium. The results indicated success in the reduction of isomerization and an improvement in the selectivity and the yield of the desired metathesis products at low potassium loadings of 0.05 and $0.1 \mathrm{wt} \%$. However, at the highest loading investigated ( $0.5 \mathrm{wt} \%$ potassium), a large decrease in metathesis activity (to $12 \%$ ) was noted as well as a decline in the selectivity toward the desired metathesis products.

\subsection{Coke formation and catalyst deactivation}

Deactivation of the active sites and thus reduction in catalytic activity of the catalyst can occur due to sintering i.e. thermal deactivation, poisoning by impurities found in the feed or fouling due to carbonaceous deposition (coking) which blocks the pores of the catalyst. The process conditions employed and the reaction itself determines which type of deactivation will occur.

In the case of the metathesis reaction, fouling is mainly due to coking, as carbon is present in the organic feed and the product. Although the formation of coke does cause catalyst deactivation, the extent of catalyst deactivation cannot be determined by measuring the amount of coke formed (Harmse et al., 2010). This is due to the fact that the coke forms on both the active parts of the catalyst responsible for the metathesis reaction, as well as the support. In order to determine the amount of catalyst deactivation, only the coke formation on the active parts of the catalyst would be of interest.

There has been much debate over whether olefins or aromatics act as the precursor of coke formation. The majority consensus from previous studies is that the formation of coke is mainly attributed to aromatics acting as the coke precursor (Hughes, 1984). Eberly et al. (1966) used infrared spectroscopy to compare a fresh catalyst to one with coke deposits. The findings indicated that aromatics were present on the surface as well as a low hydrogen content. For the coke formation mechanism, it was therefore proposed that after hydrocarbons were absorbed onto the surface, reactions including condensation and elimination of hydrogen took place. Hydrogen elimination was believed to be via the formation of hydrogen gas or by hydrogen 
transfer (Eberly et al., 1966). Trimm et al. (1982) describes the formation of the aromatics in a similar manner with the condensation being a Diels-Alder type reaction. These reactions are given below with butadiene as an example in Figure 2.20.

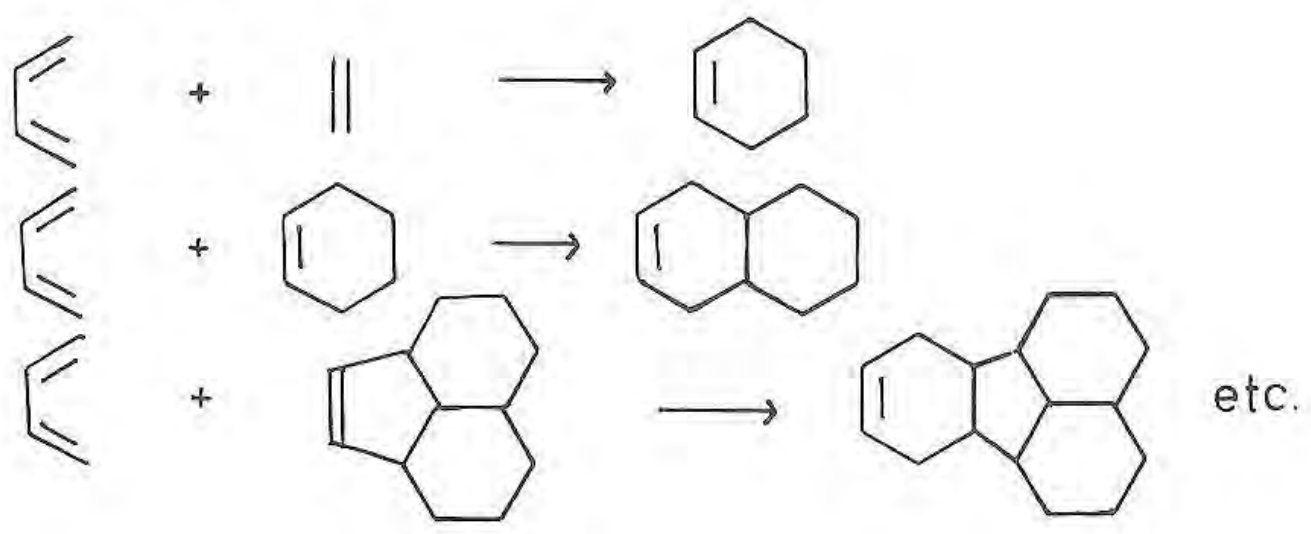

Figure 2.20: Diels-Alder type condensation reactions involving butadiene (Trimm et al., 1982)

The above reactions are not the only type of reactions involved in the formation of aromatics. Other, more complex reactions can also occur. The aromatics have high molecular masses and size. Due to their size, their vapour pressure is low and they may be present as liquid droplets. These droplets are then pyrolysed into coke on the surface of the catalyst.

One of the methods that can be employed to reduce the amount of coke deposits is to alter the catalyst to improve its selectivity. Improving the selectivity reduces cracking reactions and the formation of aromatic rings.

\subsection{Catalyst Characterisation}

\subsubsection{Surface Area Measurements - BET-method}

Catalyst characterisation includes measuring the surface area of the porous catalyst that is exposed. This is usually carried out by the physical adsorption of gases that are non-polar such as nitrogen (Anderson and Pratt, 1985). The BET method is commonly used for analysing the 
physical adsorption data obtained. Various gases that could be used for the adsorption have different adsorption temperatures and these are given in Table 2.2.

Table 2.2: Typical adsorption temperatures for gases used in surface area measurements (Adapted from Anderson and Pratt, 1985).

\begin{tabular}{|l|c|}
\hline Gas & Typical adsorption temperature (K) \\
\hline Nitrogen & 77 \\
\hline Argon & 77 \\
\hline Xenon & 90 \\
\hline Methane & 90 \\
\hline n-Butane & 273 \\
\hline Carbon dioxide & 195 \\
\hline
\end{tabular}

Degassing of the catalyst sample is required before the physical adsorption of the chosen gas. The temperature and time of degassing is specific to the catalyst sample and can be determined experimentally.

\subsubsection{Surface characterisation - Fourier transform infrared spectroscopy (FTIR)}

Fourier transform infrared spectroscopy falls under the category of vibrational spectroscopy where the objective is to characterise the catalyst surface by determining the bonding of the molecules present on the surface (Anderson and Pratt, 1985). Identification of the bonding is based on the fact that although all molecules vibrate at the same frequency in each mode, a particular group or bond dominates the movement (Anderson and Pratt, 1985). Known group frequencies from literature are used to identify particular groups or bonds, from the infrared spectra obtained.

It is known that the alumina support itself is acidic in nature. Previous studies of the support indicate 5 types of surface $\mathrm{OH}$ groups (Stiles, 1987). These include 2 types of basic groups, 2 types of acidic groups and 1 neutral group. According to Mol and Leeuwen (2008), the IR bands 
of the $\mathrm{OH}$ groups are between $3400-3800 \mathrm{~cm}^{-1}$, with the bands of the lowest frequency belonging to the acidic $\mathrm{OH}$ group.

\subsubsection{Acid site characterisation}

The activity and selectivity of the catalyst is dependent on the number and strength of acid sites present. Many techniques are available to characterise the surface acidity of the catalyst. These include characterisation by the use of indicators and titration, temperature programmed desorption of a base and adsorption of a base followed by infrared spectrophotometry.

\subsubsection{Hammett indicators}

Hammett indicators are neutral bases that are converted to conjugate acids by reaction with the acid surface (Matsuzaki, 1968). They are used to determine the acid strength of a catalyst by observing the colour change of the indicator.

The acid strength can be expressed by the $\mathrm{H}_{0}$ acidity function given below:

$$
H_{0}=p K_{a}+\log [B] /\left[B H^{+}\right]
$$

Where

$$
\begin{aligned}
& {[\mathrm{B}]=\text { concentration of the neutral base }} \\
& {[\mathrm{BH}]=\text { concentration of its conjugate acid }} \\
& \mathrm{pK}_{\mathrm{a}}=\mathrm{pK}_{\mathrm{BH}+}
\end{aligned}
$$

If a Hammett indicator is converted to its acid form and the corresponding colour change observed, the $\mathrm{H}_{0}$ value of the acid site is less than or equal to the $\mathrm{pK}_{\mathrm{a}}$ value of the conjugate acid 
(Yurdakoc et al., 1998). A list of Hammett indicators with $\mathrm{pK}_{\mathrm{a}}$ values and colour changes is given in Table 2.3.

Table 2.3: Hammett indicators used for acid strength determination (Yurdakoc et al., 1998)

\begin{tabular}{|l|c|c|c|c|}
\hline Indicator & $\begin{array}{c}\text { Colour } \\
\text { Base } \\
\text { Form }\end{array}$ & $\begin{array}{c}\text { Colour } \\
\text { Acid } \\
\text { Form }\end{array}$ & $\mathrm{pK}_{a}$ & $\begin{array}{c}{\left[\mathrm{H}_{2} \mathrm{SO}_{4}\right]} \\
\%\end{array}$ \\
\hline Neutral red & yellow & red & +6.8 & $8.10^{-8}$ \\
\hline Methyl red & yellow & red & +4.8 & - \\
\hline Phenylazonaphtylamine & yellow & red & +4.0 & $5.10^{-5}$ \\
\hline p- Dimethylaminoazobenzene & yellow & red & +3.3 & $3.10^{-4}$ \\
\hline 2-Amino-5-azotoluene & yellow & red & +2.0 & $5.10^{-3}$ \\
\hline Benzeneazodiphylamine & yellow & purple & +1.5 & $2.10^{-2}$ \\
\hline Crystal violet & blue & yellow & +0.8 & 0.1 \\
\hline p- Nitrobenzeneazo-(p'-nitro-dipehylamine) & orange & purple & +0.43 & - \\
\hline Dicinnamalacetone & yellow & red & -3.0 & 48 \\
\hline Benzalacetophenone & colourless & yellow & -5.6 & 71 \\
\hline Anthraquinone & colourless & yellow & -8.2 & 90 \\
\hline 2,4,6-Trinitroaniline & colourless & yellow & -10.10 & 98 \\
\hline p-Nitrotoluene & colourless & yellow & -11.35 & $*$ \\
\hline m-Nitrotoluene & colourless & yellow & -11.99 & $*$ \\
\hline p-Nitrofluorobenzene & colourless & yellow & -12.44 & $*$ \\
\hline p-Nitrochlorobenzene & colourless & yellow & -12.70 & $*$ \\
\hline m-Nitrochlorobenzene & colourless & yellow & -13.16 & $*$ \\
\hline 2,4-Dinitrotoluene & colourless & yellow & -13.75 & $*$ \\
\hline 2,4-Dinitrofluorobenzene & colourless & yellow & -14.52 & $*$ \\
\hline 1,3,5-Trinitrotoluene & colourless & yellow & -16.04 & $*$ \\
\hline & & & & \\
\hline
\end{tabular}

The amine titration method (n-butylamine titration) is used to determine the concentration of acid sites present. A sample of solid catalyst suspended in benzene together with approximately $3 \mathrm{ml}$ of indicator is titrated using n-butylamine until endpoint. This method allows for the determination of the sum of the amount of Lewis and Brønsted acid sites present. However, it is not possible to distinguish between the two by this method. 


\subsubsection{2. $\mathrm{NH}_{3}$-TPD}

Temperature programmed desorption (TPD) with ammonia is a catalyst characterisation method used to determine the number of acid sites present on a catalyst. This method was used by Harmse et al. (2010) to determine the number of acid sites on the support materials, silica and $\gamma$ alumina as well as on an $8 \mathrm{wt} \%$ loading of tungsten trioxide over silica and $\gamma$-alumina. The results obtained from the $\mathrm{NH}_{3}$-TPD profile indicated that the number of acid sites of the support alone is less than that found on the supported catalyst. The main conclusion of importance was that the acid sites found on the $\mathrm{WO}_{3} / \mathrm{SiO}_{2}$ catalyst was fewer in number and weaker in strength when compared to the acid sites found on the $\mathrm{WO}_{3} / \mathrm{Al}_{2} \mathrm{O}_{3}$ catalyst (Harmse et al., 2010).

\subsubsection{FTIR with pyridine adsorption}

Lewis acid sites and Brønsted acid sites are identifiable on a catalyst by performing infrared spectrophotometry after adsorption of a base such as pyridine. Each acid site adsorbs pyridine in a different form. It is expected that at the Brønsted acid sites, the adsorbed species would be in the form $\mathrm{C}_{5} \mathrm{H}_{5} \mathrm{NH}^{+}$and at the Lewis acid site, it would be in the form $\mathrm{C}_{5} \mathrm{H}_{5} \mathrm{~N}$ (Anderson and Pratt, 1985).

In a study on the metathesis of 1-butene, Harmse et al. (2010) investigated an $8 \mathrm{wt} \%$ loading of tungsten trioxide over silica, silica-alumina and $\gamma$-alumina as catalysts. The acidity of the samples was characterised by analysis of FTIR spectra after the adsorption of pyridine. From the FTIR results after pyridine adsorption for the silica support, no Lewis acid sites were found to be present. The FTIR spectra after pyridine adsorption for the $\mathrm{WO}_{3} / \mathrm{SiO}_{2}$ catalyst indicated an adsorption band representative of the Lewis acidity. Thus the Lewis acidity is attributed to the Lewis acidity of the tungsten on the silica support. For the $\mathrm{WO}_{3} / \mathrm{Al}_{2} \mathrm{O}_{3}$ catalyst, no peaks representing Brønsted acidity were found. Therefore, the percentage of Lewis acid sites according to Harmse et al. (2010) was 100 for the $\mathrm{WO}_{3} / \mathrm{Al}_{2} \mathrm{O}_{3}$ catalyst and $\mathrm{WO}_{3} / \mathrm{SiO}_{2}$ catalyst. 


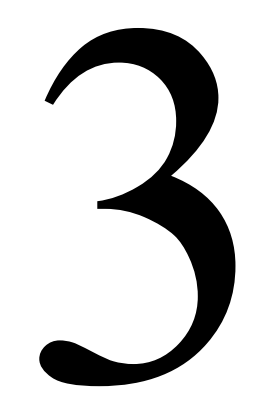

\section{CHAPTER THREE}

\section{EXPERIMENTAL PLAN}

\subsection{Experimental plan for the investigation of the $\mathrm{WO}_{3} / \mathrm{Al}_{2} \mathrm{O}_{3}$ catalyst}

The experimental plan was designed using a combination of the One-Variable-At-a-Time (OVAT) approach as well as the factorial design method. The OVAT method does not account for interaction between the various factors being tested since only one factor is varied at a time while all the other factors remain constant. Interaction between factors is evident when a factor affects the output differently at different levels of another factor (Montgomery, 1998). Therefore the optimum results obtained from the OVAT approach may not be the optimum results achievable overall unless the factors being tested are completely independent of each other (Leardi, 2009).

From a previous study by Lokhat (2008), it was found that there is only a weak interaction between space time $\left(\mathrm{W}_{\text {cat }} / \mathrm{F}_{\text {in }}\right)$ and reaction temperature and no interaction between feed composition of 1-hexene and space time. The definition of interaction is as mentioned previously in the first paragraph. Thus the OVAT approach was acceptable and was used with respect to the reaction temperature and feed composition of 1-hexene where the optimum loading of tungsten trioxide was determined for a constant value for the space time of 200g.min. $\mathrm{mol}^{-1}$.

In the case of the complete factorial design, all possible combinations of the factors and levels are accounted for. The factorial design method can be explained by using the simple $2^{k}$ factorial 
design. The number of experiments that would be required is equal to $2^{k}$ where ' $\mathrm{k}$ ' is the number of factors being tested and ' 2 ' is the number of levels for each factor (Leardi, 2009). A two level factorial design is the simplest possible design; however, the number of levels for each factor is not limited to two. It is also possible for each factor to have a different number of levels. In the case of using a two factor design with $A$ and $B$ being the factors and $a$ and $b$ being the levels, there will be $a$ levels of $A$ and $b$ levels of $B$ (Montgomery and Runger, 2007).

According to DeCoursey (2003), all experiments should not be laid out prior to the start of experimental work. Exploratory runs should first be conducted and analysed, to focus on an area for detailed analysis. This results in a 'sequential' or 'evolutionary' experimental design (DeCoursey, 2003).

For the purpose of determining the optimum loading of tungsten trioxide on the $\mathrm{WO}_{3} / \mathrm{Al}_{2} \mathrm{O}_{3}$ catalyst for this project, a 3 factor design was used with different levels for each factor. The three factors under investigation were the specific loading of tungsten trioxide, reaction temperature and feed composition of 1-hexene. The range of experimental conditions under investigation was $8-20 \%$ for the specific loading of tungsten trioxide, $420-500^{\circ} \mathrm{C}$ for reaction temperature and $30-80 \mathrm{~mol} \%$ for the feed composition of 1-hexene. Four levels were used for temperature implying four reaction temperatures, three for the specific loading of tungsten and two for the composition of 1-hexene in the feed. The values used for the experiments were within the ranges given above. A total of $\left(2^{1} \cdot 3^{1} \cdot 4^{1}\right)=24$ experiments were thus investigated. The three specific loadings chosen were 10, 16 and $20 \mathrm{wt} \%$; the four temperatures were 420,445 , 470 and $495^{\circ} \mathrm{C}$ and the two compositions were 0.5 and $0.8 \mathrm{~mol} \% 1$-hexene in the feed. Table 3.1 lists all the possible combinations of the various factors and levels which make up the 24 experiments conducted: 
Chapter 3 - Experimental Plan|39

Table 3.1: Table of experimental points to determine the optimum loading of tungsten trioxide on $\mathrm{WO}_{3} / \mathrm{Al}_{2} \mathrm{O}_{3}$ (for a fixed reactor space time)

\begin{tabular}{|c|c|c|c|}
\hline $\begin{array}{c}\text { Run } \\
\text { number }\end{array}$ & $\begin{array}{l}\% \mathrm{WO}_{3} \\
\text { loading }\end{array}$ & Temperature $\left({ }^{\circ} \mathrm{C}\right)$ & $\begin{array}{l}\text { Mol fraction 1-hexene } \\
\text { in feed }\end{array}$ \\
\hline 1 & 10 & 420 & 0.5 \\
\hline 2 & 10 & 445 & 0.5 \\
\hline 3 & 10 & 470 & 0.5 \\
\hline 4 & 10 & 495 & 0.5 \\
\hline 5 & 10 & 420 & 0.8 \\
\hline 6 & 10 & 445 & 0.8 \\
\hline 7 & 10 & 470 & 0.8 \\
\hline 8 & 10 & 495 & 0.8 \\
\hline 9 & 16 & 420 & 0.5 \\
\hline 10 & 16 & 445 & 0.5 \\
\hline 11 & 16 & 470 & 0.5 \\
\hline 12 & 16 & 495 & 0.5 \\
\hline 13 & 16 & 420 & 0.8 \\
\hline 14 & 16 & 445 & 0.8 \\
\hline 15 & 16 & 470 & 0.8 \\
\hline 16 & 16 & 495 & 0.8 \\
\hline 17 & 20 & 420 & 0.5 \\
\hline 18 & 20 & 445 & 0.5 \\
\hline 19 & 20 & 470 & 0.5 \\
\hline 20 & 20 & 495 & 0.5 \\
\hline 21 & 20 & 420 & 0.8 \\
\hline 22 & 20 & 445 & 0.8 \\
\hline 23 & 20 & 470 & 0.8 \\
\hline 24 & 20 & 495 & 0.8 \\
\hline
\end{tabular}




\subsection{Experimental plan for the investigation of the $\mathrm{WO}_{3} / \mathrm{SiO}_{2}$ catalyst and potassium doped $\mathrm{WO}_{3} / \mathrm{SiO}_{2}$ catalyst}

As discussed previously in Section 3.1, the OVAT approach does not account for any interaction that may occur between the factors and thus the factorial design provides a better approach to experimental design. A complete factorial design accounts for all possible combinations of factors and levels. In cases where exploratory work is required or the number of runs when using the factorial design is large and resources are limited, a complete factorial design may not be feasible. In these cases, an alternative design such as the fractional factorial design is considered. For the reasons stated above, fractional factorial designs were chosen for use in the investigation of the $\mathrm{WO}_{3} / \mathrm{SiO}_{2}$ catalyst and potassium doped $\mathrm{WO}_{3} / \mathrm{SiO}_{2}$ catalyst.

More specifically, half factorial designs with added centre points were used. Addition of a centre point to an experimental design allows for the determination of the presence of curvature, as well as providing an independent estimate of error (Montgomery and Runger, 2007) and allowing for the monitoring of process drift (NIST/SEMATECH, 2010).

The half factorial design can be explained by using the simple $2^{k}$ factorial design as an example once again. A half fraction of the $2^{k}$ factorial design consists of half the runs as compared to the full factorial design and is represented as a $2^{k-1}$ fractional factorial design. This also implies that $2^{k-1}$ experimental runs will be conducted. As with a 2-level 3-factor full factorial design, the 2level 3-factor half factorial design can be represented graphically by a cube as given below (Figure 3.1).

For the half factorial design, either the principal fraction (Figure 3.1- a) or the alternate fraction (Figure 3.1-b) can be chosen for use. For this particular factorial design, the defining relation is $\mathrm{I}=\mathrm{ABC}$ and $\mathrm{ABC}$ is the generator where $\mathrm{A}, \mathrm{B}$ and $\mathrm{C}$ are the factors and +1 and -1 are the high and low levels respectively (Montgomery and Runger, 2007). The only difference between the principal fraction and the alternate fraction is the sign in the defining relation i.e. for the principal fraction $\mathrm{I}=+\mathrm{ABC}$ and for the alternate fraction $\mathrm{I}=-\mathrm{ABC}$. The design tables for the principal and alternate fractions for a $2^{3-1}$ design are given in Table 3.2 and Table 3.3 below. 


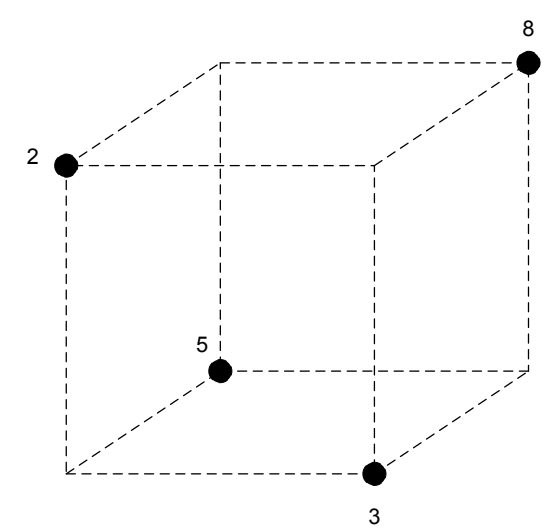

(a)

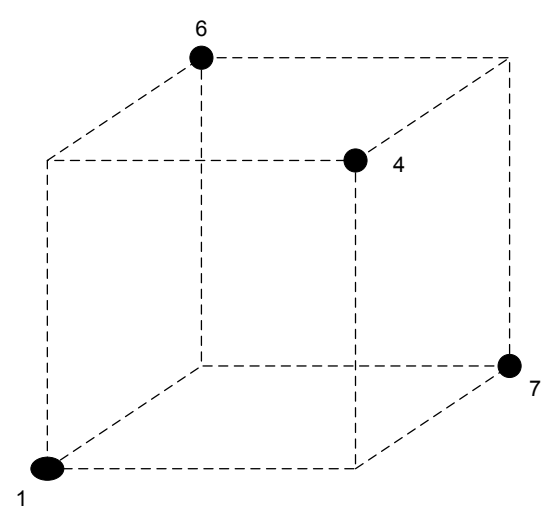

(b)

Figure 3.1: $\mathrm{A} 2^{3-1}$ fractional factorial design (a) the principal fraction $\mathrm{I}=+\mathrm{ABC}(\mathrm{b})$ the alternate fraction $\mathrm{I}=-\mathrm{ABC}$

Table 3.2: $\mathrm{A} 2^{3-1}$ design table representing the principal fraction

\begin{tabular}{|c|c|c|c|c|}
\hline \multicolumn{5}{|c|}{ Principal fraction I $=\mathbf{A B C}$} \\
\hline \multirow{2}{*}{ Point on cube } & \multicolumn{4}{|c|}{ Design factors } \\
\cline { 2 - 5 } & $\mathbf{A}$ & $\mathbf{B}$ & $\mathbf{C}=\mathbf{A}^{*} \mathbf{B}$ & Response \\
\hline $\mathbf{2}$ & -1 & -1 & +1 & $\mathrm{y}_{2}$ \\
\hline $\mathbf{3}$ & +1 & -1 & -1 & $\mathrm{y}_{3}$ \\
\hline $\mathbf{5}$ & -1 & +1 & -1 & $\mathrm{y}_{5}$ \\
\hline $\mathbf{8}$ & +1 & +1 & +1 & $\mathrm{y}_{8}$ \\
\hline
\end{tabular}

Table 3.3: A $2^{3-1}$ design table representing the alternate fraction

\begin{tabular}{|c|c|c|c|c|}
\hline \multicolumn{5}{|c|}{ Alternate fraction I = -ABC } \\
\hline \multirow{2}{*}{ Point on cube } & \multicolumn{4}{|c|}{ Design factors } \\
\cline { 2 - 5 } & $\mathbf{A}$ & $\mathbf{B}$ & $\mathbf{C}=\mathbf{A}^{* \mathbf{B}}$ & Response \\
\hline $\mathbf{1}$ & -1 & -1 & -1 & $\mathrm{y}_{1}$ \\
\hline $\mathbf{4}$ & +1 & -1 & +1 & $\mathrm{y}_{4}$ \\
\hline $\mathbf{6}$ & -1 & +1 & +1 & $\mathrm{y}_{6}$ \\
\hline $\mathbf{7}$ & +1 & +1 & -1 & $\mathrm{y}_{7}$ \\
\hline
\end{tabular}


The responses from the experimental runs are represented by $y_{\mathrm{i}}$. The concept of the main effect of a factor can be explained as the effect the factor has on the response when the level of that specific factor is changed. If the response to a change in levels of a factor is different at different levels of other factors, interaction between the factors is said to occur (Montgomery and Runger, 2007).

The estimates for the main effects are calculated for each factor $\mathrm{A}, \mathrm{B}$ and $\mathrm{C}$ as $l_{A}, l_{B}$ and $l_{C}$ as given below (NIST/SEMATECH, 2010) by using the sign corresponding to the response for each of the factors. The alternate fraction will be used to demonstrate the calculation.

$$
\begin{aligned}
& l_{A}=(1 / 2)\left(y_{4}+y_{7}\right)-(1 / 2)\left(y_{1}+y_{6}\right) \ldots . . \text { Effect due to factor } \mathrm{A} \\
& l_{B}=(1 / 2)\left(y_{6}+y_{7}\right)-(1 / 2)\left(y_{1}+y_{4}\right) \ldots . . \text { Effect due to factor B } \\
& l_{C}=(1 / 2)\left(y_{4}+y_{6}\right)-(1 / 2)\left(y_{1}+y_{7}\right) \ldots . . \text { Effect due to factor } \mathrm{C}
\end{aligned}
$$

In the case of a three factor half factorial design, the main effect and interaction are compounded. This means that $l_{A}$ is equal to the sum of the main effect, $\mathrm{A}$ and the effect due to interaction, $\mathrm{BC}$. Similarly, $l_{B}$ is equal to $\mathrm{B}+\mathrm{AC}$ and $l_{C}$ is equal to $\mathrm{C}+\mathrm{AB}$. The $2^{3-1}$ design is categorised as a resolution III design. In these designs, the main effects are not compounded with any other main effects but the main effects and two-factor interactions are compounded (Montgomery and Runger, 2007).

The $2^{3-1}$ fractional factorial design with an added centre point was used to determine the optimum operating conditions for the metathesis reaction when using the $8 \mathrm{wt} \% \mathrm{WO}_{3} / \mathrm{SiO}_{2}$ catalyst. The design can be represented as a cube (Figure 3.2) where the five round points represent the different limits of the three factors. The three factors that were varied were the reaction temperature, 1-hexene feed composition and the space time as represented by the $\mathrm{x}, \mathrm{y}$ and $\mathrm{z}$ axis respectively. Experiments were conducted in replicates of two at each of the five points.

The design was used to determine the optimum operating conditions for the $8 \mathrm{wt} \% \mathrm{WO}_{3} / \mathrm{SiO}_{2}$ catalyst in terms of the three factors. At this optimum point, experimental runs were conducted to investigate the effect of doping on the catalyst. The three specific loadings of potassium were $0.05,0.1$ and $0.5 \mathrm{wt} \%$ doped onto the $8 \mathrm{wt} \% \mathrm{WO}_{3} / \mathrm{SiO}_{2}$ catalyst. 


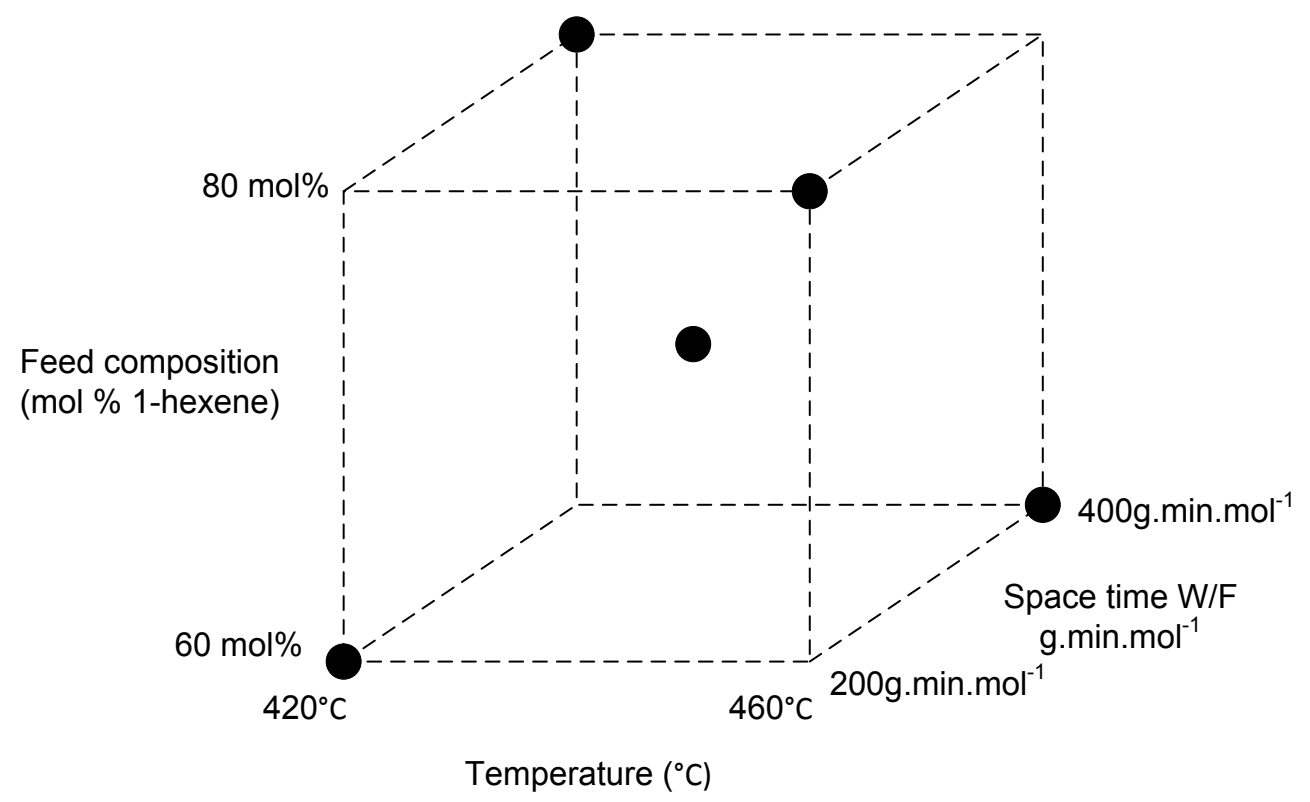

Figure 3.2: Depiction of the $2^{3-1}$ fractional factorial design represented by a cube

More information can be gained from a half factorial design with more than three factors. With four factors being varied, a $2^{4-1}$ fractional factorial design is used. This is referred to as a resolution IV design where the main effects are not compounded with any other main effects or two-factor interactions but the two-factor interactions are compounded with each other (Montgomery and Runger, 2007). For a $2^{4-1}$ factorial design, the defining relation is $I=A B C D$. For the purpose of representing this design graphically, two cubes are used to represent the four factors each at two levels.

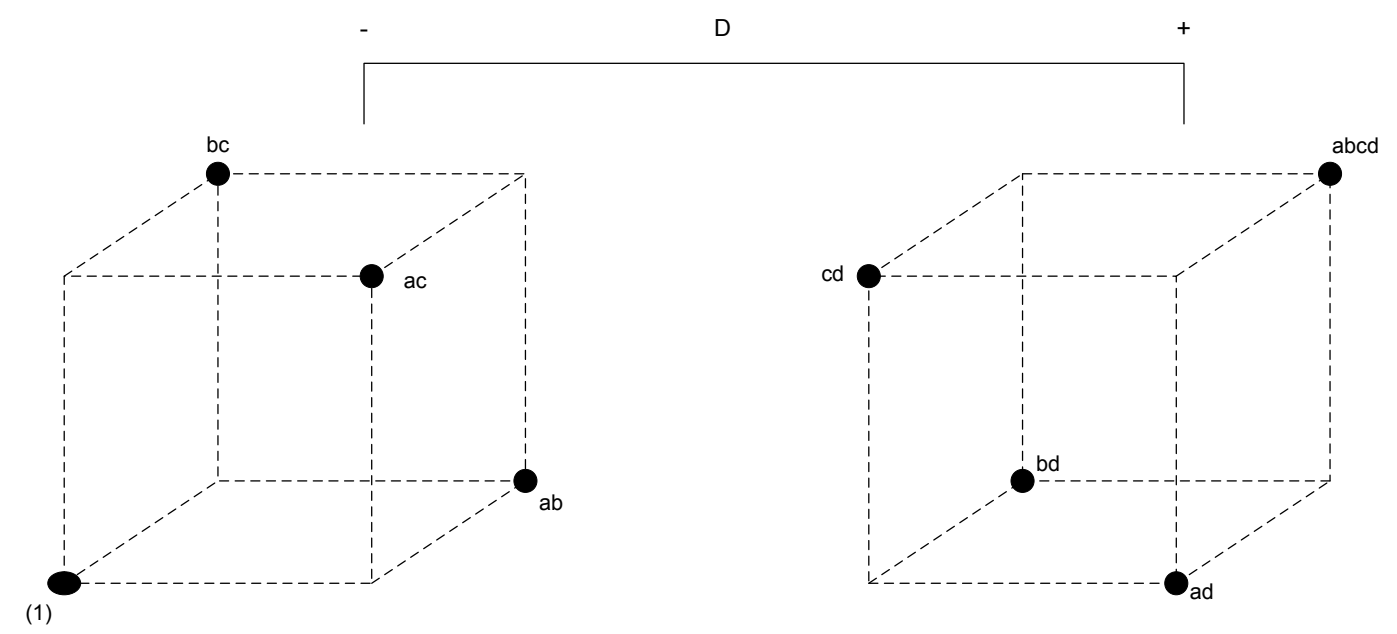

Figure 3.3: A $2^{4-1}$ fractional factorial design (Montgomery and Runger, 2007) 
Factors $\mathrm{A}, \mathrm{B}$ and $\mathrm{C}$ are represented by the $\mathrm{x}, \mathrm{y}$ and $\mathrm{z}$ axis on each cube and factor $\mathrm{D}$ is represented by the linking of the two cubes as a high and low level. This is shown in Figure 3.3 where the alternate and principal fractions are used to depict the design.

Table 3.4: $\mathrm{A} 2^{4-1}$ design table

\begin{tabular}{|c|c|c|c|c|c|}
\hline \multirow{2}{*}{$\begin{array}{c}\text { Treatment } \\
\text { Combination }\end{array}$} & $\mathbf{4}$ & $\mathbf{B}$ & $\mathbf{C}$ & $\mathbf{D}=\mathbf{A}^{*} \mathbf{B} * \mathbf{C}$ & $\mathbf{Y}$ \\
\cline { 2 - 6 } & $\mathbf{A})$ & -1 & -1 & -1 & $\mathrm{y}_{(1)}$ \\
\hline $\mathbf{a d}$ & +1 & -1 & -1 & +1 & $\mathrm{y}_{\mathrm{ad}}$ \\
\hline $\mathbf{b d}$ & -1 & +1 & -1 & +1 & $\mathrm{y}_{\mathrm{bd}}$ \\
\hline $\mathbf{a b}$ & +1 & +1 & -1 & -1 & $\mathrm{y}_{\mathrm{ab}}$ \\
\hline $\mathbf{c d}$ & -1 & -1 & +1 & +1 & $\mathrm{y}_{\mathrm{cd}}$ \\
\hline $\mathbf{a c}$ & +1 & -1 & +1 & -1 & $\mathrm{y}_{\mathrm{ac}}$ \\
\hline $\mathbf{b c}$ & -1 & +1 & +1 & -1 & $\mathrm{y}_{\mathrm{bc}}$ \\
\hline $\mathbf{a b c d}$ & +1 & +1 & +1 & +1 & $\mathrm{y}_{\mathrm{abcd}}$ \\
\hline
\end{tabular}

The design table for the $2^{4-1}$ fractional factorial design is given in Table 3.4. In the case of this design, $2^{4-1}=8$ runs will be required. Since the main effects and the two factor interactions are not compounded, the estimates for each can easily be calculated using the signs at each response for each factor as shown previously.

Main effect estimates:

$$
\begin{aligned}
& l_{A}=(1 / 4)\left(y_{a d}+y_{a b}+y_{a c}+y_{a b c d}\right)-(1 / 4)\left(y_{(1)}+y_{b d}+y_{c d}+y_{b c}\right) \\
& l_{B}=(1 / 4)\left(y_{b d}+y_{a b}+y_{b c}+y_{a b c d}\right)-(1 / 4)\left(y_{(1)}+y_{a d}+y_{c d}+y_{a c}\right) \\
& l_{C}=(1 / 4)\left(y_{c d}+y_{a c}+y_{b c}+y_{a b c d}\right)-(1 / 4)\left(y_{(1)}+y_{a d}+y_{b d}+y_{a b}\right) \\
& l_{D}=(1 / 4)\left(y_{a d}+y_{b d}+y_{c d}+y_{a b c d}\right)-(1 / 4)\left(y_{(1)}+y_{a b}+y_{a c}+y_{b c}\right)
\end{aligned}
$$


Two-factor interaction estimates:

$$
\begin{aligned}
& l_{A B}=(1 / 4)\left(y_{(1)}+y_{a b}+y_{c d}+y_{a b c d}\right)-(1 / 4)\left(y_{a d}+y_{b d}+y_{a c}+y_{b c}\right) \\
& l_{A C}=(1 / 4)\left(y_{(1)}+y_{b d}+y_{a c}+y_{a b c d}\right)-(1 / 4)\left(y_{a d}+y_{a b}+y_{c d}+y_{b c}\right) \\
& l_{B C}=(1 / 4)\left(y_{(1)}+y_{a d}+y_{b c}+y_{a b c d}\right)-(1 / 4)\left(y_{b d}+y_{a b}+y_{c d}+y_{a c}\right)
\end{aligned}
$$

The normal probability plot and analysis of variance (ANOVA) can be used to test the significance of the main effects and two factor interactions. The normal probability plot is a graphical method used to determine visually if the results obtained conform to a normal distribution and to determine which effects or interactions are significant (Montgomery and Runger, 2007). To construct the plot, the calculated effects are plotted against the standardised normal score, $z_{j}$. The standardised normal scores are obtained from the observed cumulative frequencies and the use of the cumulative standard normal distribution tables as given below:

$$
\frac{j-0.5}{n_{\text {observations }}}=P\left(Z \leq z_{j}\right)=\Phi\left(z_{j}\right)
$$

where $n_{\text {observations }}=$ total number of observations/points

$$
\begin{aligned}
& j=\text { the count } \\
& z_{j}=\text { the standardised normal scores }
\end{aligned}
$$

Any outliers in the normal probability plot are deemed to have a significant effect.

The $\mathrm{F}$ - ratios $\left(\mathrm{F}_{0}\right)$ calculated for each main effect and interaction in the analysis of variance (ANOVA) table (Table 3.5) is of importance when determining the significance of the effects. The F-ratios are compared to the critical F-values at the chosen level of significance, $\alpha$, revealing which effects and interactions are significant. 
Table 3.5: The analysis of variance (ANOVA) table

\begin{tabular}{|c|c|c|c|c|}
\hline $\begin{array}{c}\text { Source of } \\
\text { Variation }\end{array}$ & $\begin{array}{c}\text { Sum of } \\
\text { Squares }\end{array}$ & $\begin{array}{c}\text { Degrees of } \\
\text { freedom }\end{array}$ & Mean Square & $\mathbf{F}_{\mathbf{0}}$ \\
\hline$A$ & $S S_{A}$ & $a-1$ & $M S_{A}=\frac{S S_{A}}{a-1}$ & $\frac{M S_{A}}{M S_{E}}$ \\
\hline$B$ & $S S_{B}$ & $b-1$ & $M S_{B}=\frac{S S_{B}}{b-1}$ & $\frac{M S_{B}}{M S_{E}}$ \\
\hline$C$ & $S S_{C}$ & $c-1$ & $M S_{C}=\frac{S S_{C}}{c-1}$ & $\frac{M S_{C}}{M S_{E}}$ \\
\hline$D$ & $S S_{D}$ & $d-1$ & $M S_{D}=\frac{S S_{D}}{d-1}$ & $\frac{M S_{D}}{M S_{E}}$ \\
\hline$A B$ & $S S_{A B}$ & $(a-1)(b-1)$ & $M S_{A B}=\frac{S S_{A B}}{(a-1)(b-1)}$ & $\frac{M S_{A B}}{M S_{E}}$ \\
\hline$A C$ & $S S_{A C}$ & $(a-1)(c-1)$ & $M S_{A C}=\frac{S S_{A C}}{(a-1)(c-1)}$ & $\frac{M S_{A C}}{M S_{E}}$ \\
\hline$B C$ & $S S_{B C}$ & $(b-1)(c-1)$ & $M S_{B C}=\frac{S S_{A B}}{(b-1)(c-1)}$ & $\frac{M S_{B C}}{M S_{E}}$ \\
\hline Error & $S S_{E}$ & $a b c(n-1)$ & $M S_{E}=\frac{S S_{E}}{a b c(n-1)}$ & \\
\hline Total & $S S_{T}$ & $a b c n-1$ & & \\
\hline
\end{tabular}

The sum of squares for the main effect and interaction for a $2^{k}$ design with $n$ replicates is given by:

$$
S S=\frac{(\text { contrast })^{2}}{n 2^{k}}
$$

where

$$
\text { contrast }=\text { Effect } \times n 2^{k-1}
$$

Thus, for the $2^{k-1}$ design, the sum of squares was calculated as follows:

$$
S S=\frac{(\text { contrast })^{2}}{n 2^{(k-1)}}
$$

where

$$
\text { contrast }=\text { Effect } \times n 2^{(k-1)-1}
$$


A further investigation into the effects of potassium doping on the $8 \mathrm{wt} \% \mathrm{WO}_{3} / \mathrm{SiO}_{2}$ catalyst was undertaken using a four factor fractional factorial design. The four factors that were of interest for the investigation were the specific loading of potassium, the reaction temperature, the 1-hexene feed composition and the space time. The reaction temperature, the 1-hexene feed composition and the space time were varied at two levels, as before, while the specific loading of potassium was investigated at three levels $(0.05,0.1$ and $0.5 \mathrm{wt} \%)$. Thus a $2^{3-1} \cdot 3^{1}$ half factorial design with added centre points was used. This comprised of a total of $2^{3-1} \cdot 3^{1}=12$ experimental runs plus 3 added centre point experimental runs.

The design can be represented as three cubes (Figure 3.4) where the five round points in each cube represent the different limits of the three factors. The three factors were varied as before i.e. the reaction temperature, 1-hexene feed composition and the space time as represented by the $\mathrm{x}, \mathrm{y}$ and $\mathrm{z}$ axis respectively. Experiments were conducted in replicates of two at each of the five points. The statistical analysis, as given for the $2^{4-1}$ factorial design was used to identify the significant effects and interactions

\subsection{Centre point addition}

The $2^{k}$ factorial design system works on the assumption of linearity or approximate linearity with regard to the factor effects. As mentioned previously, the addition of a centre point to the factorial design allows for the determination of the presence of curvature as well as provides an independent estimate of error (Montgomery and Runger, 2007). The curvature sum of squares is given by

$$
S S_{\text {curvature }}=\left(\frac{\bar{y}_{F}-\bar{y}_{C}}{\sqrt{\frac{1}{n_{F}}+\frac{1}{n_{C}}}}\right)^{2}
$$

where $\bar{y}_{F}=$ average of the responses

$\bar{y}_{C}=$ average of the $n_{c}$ runs at the centre points

$n_{F}=$ number of factorial design points

$n_{C}=$ number of observations at the centre points 


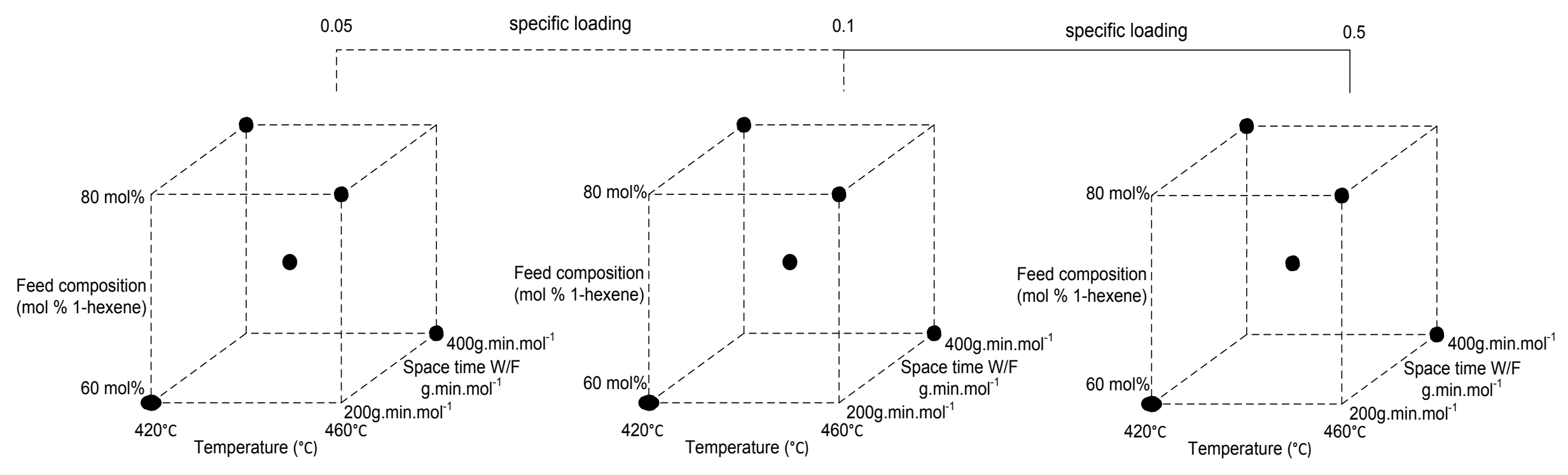

Figure 3.4: Depiction of experimental design for potassium doping investigation 
The independent estimate of error is given by

$$
M S_{E}=\frac{\sum_{\text {centre points }}\left(y_{i}-\bar{y}_{C}\right)^{2}}{n_{c}-1}
$$

The presence of curvature can be determined by either finding the difference $\bar{y}_{F}-\bar{y}_{C}$ or by calculating the curvature sum of squares and comparing it to the mean squares error calculated from the centre points, as given above. If the difference $\bar{y}_{F}-\bar{y}_{C}$ obtained is small then the assumption of linearity is valid. If the curvature sum of squares and the mean squares error method is used, the sum of squares of curvature should be smaller than the mean squares error for the assumption of linearity to hold.

\subsection{Randomisation and replication}

It is important to minimize the error due to interfering factors when conducting experimental runs. Two strategies can be employed to achieve this, randomisation and replication.

Randomisation of the order in which the experimental runs are conducted, is important in order to reduce the systematic error in measurements (DeCoursey, 2003). Systematic error arises from interfering factors such as machine wear, air temperature etc. Thus by randomisation of the experiments, the interfering factors are 'averaged out' and the bias is minimized (DeCoursey, 2003).

A replicate is a repeat of a run at the exact conditions of the first run. In order for measurements to be uniform, at least two replicates (experimental runs) must be conducted (NIST/ SEMATECH, 2010). When many factors are under investigation and many experimental runs are required to be conducted, an experiment is performed just twice to allow results to be obtained quickly and economically (DeCoursey, 2003). 


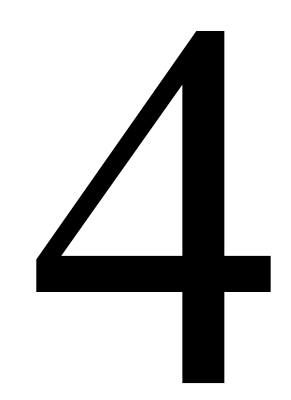

\section{CHAPTER FOUR}

\section{EXPERIMENTAL EQUIPMENT}

An existing lab-scale gas-phase fixed bed metathesis reactor system (Figure 4.2) designed and commissioned by Lokhat (2008) and a Shimadzu GC 2014 gas chromatograph (Figure 4.10) at the School of Chemical Engineering of the University of KwaZulu-Natal were used to conduct the required experimental work and product analysis. The metathesis system has been successfully used by Lokhat (2008) to investigate the metathesis of 1-hexene over a $\mathrm{WO}_{3} / \mathrm{SiO}_{2}$ catalyst. An overview of the experimental equipment and specifications is given in this chapter and a more detailed explanation on its setup can be found in Lokhat (2008). The process instrumentation diagram for the system is given in Figure 4.1. 
Chapter 4 - Experimental Equipment $\mathbf{5}$

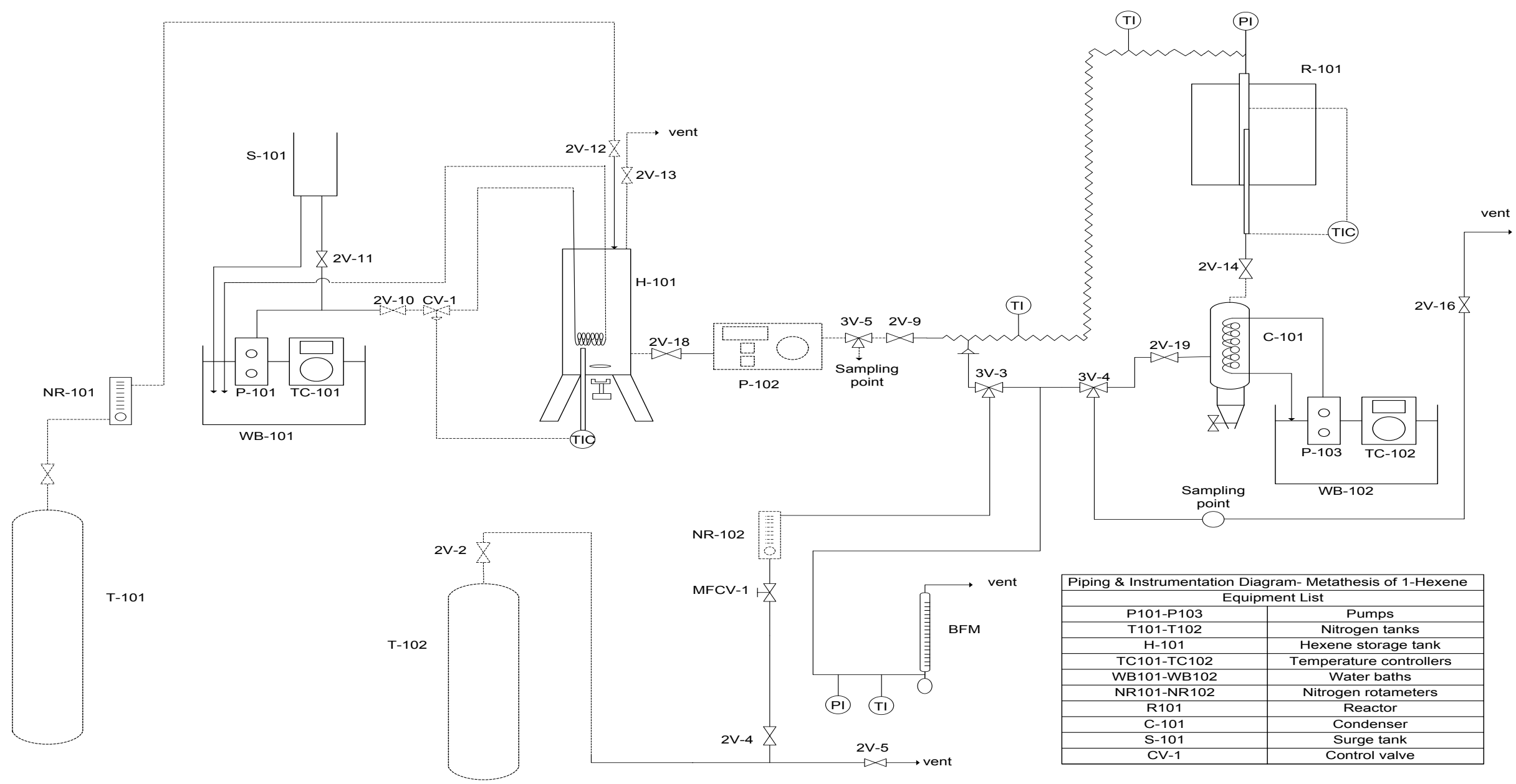

Figure 4.1: Piping and instrumentation diagram for metathesis of 1-hexene 


\subsection{The lab-scale metathesis system apparatus}

The lab-scale gas-phase fixed bed metathesis reactor system used in this project consisted of the apparatus listed below. A description of each section of the reactor system is also provided.

\subsubsection{1-Hexene storage and heating apparatus}

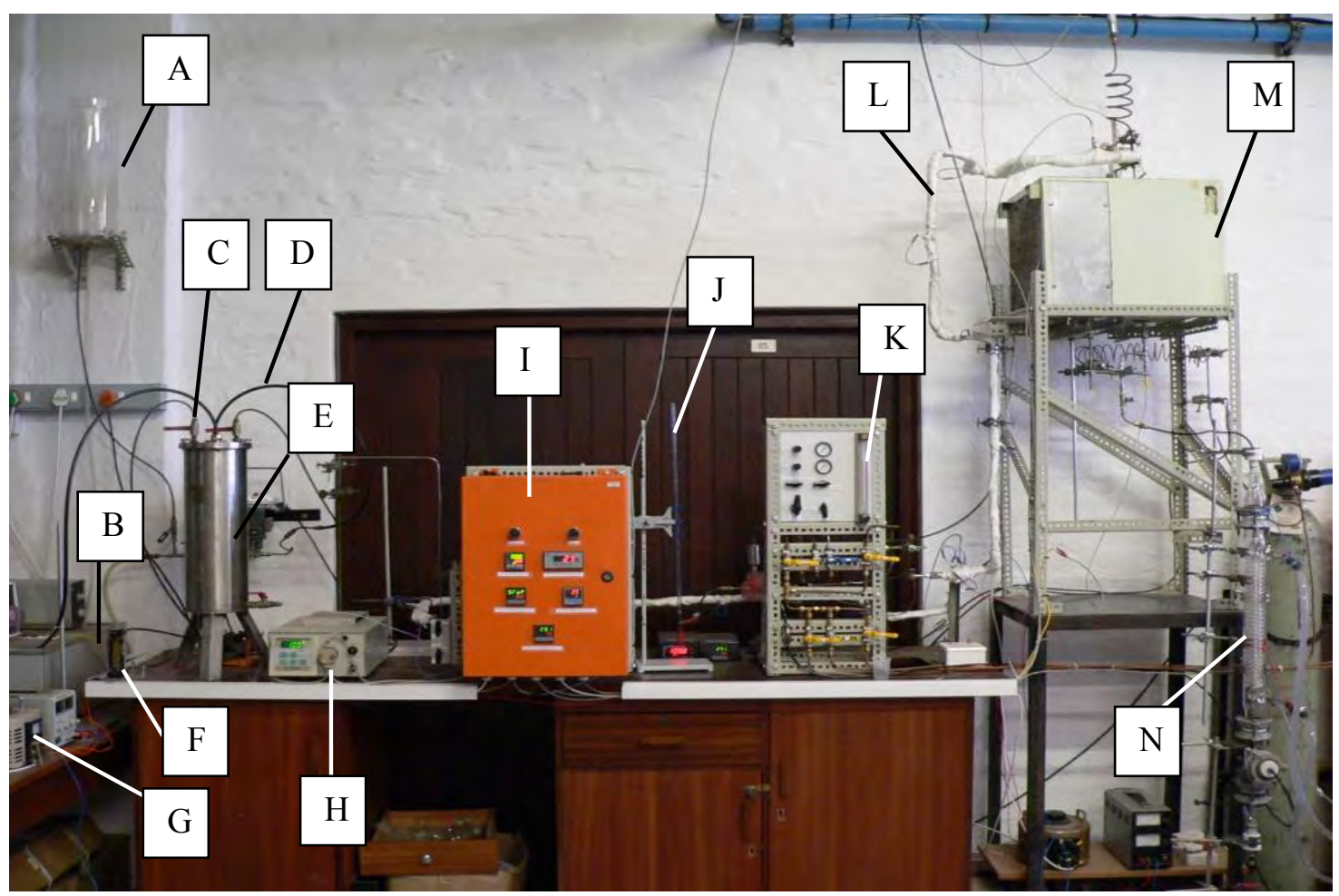

Figure 4.2: Lab-scale gas-phase fixed bed metathesis reactor system

A - Surge tank; B - Grant water bath with temperature controller and pump; C - Nitrogen inlet/outlet to 1-hexene tank (valves 2V-12 and 2V-13); D - Water inlet/outlet; E - 1-hexene tank; F - A Krohne Gepruft rotameter; G - Variac; H - Spectrochrom isocratic pump; I Control box; $\mathbf{J}$ - bubble flow meter; $\mathbf{K}$ - nitrogen rotameter; $\mathbf{L}$ - stainless steel piping with wound nichrome resistance wire; $\mathbf{M}$ - furnace containing reactor tube; $\mathbf{N}$ - condenser

- 1-hexene 316 stainless steel feed storage tank ( 40l) with a $3 / 8$ inch OD copper coil

- A Krohne Gepruft rotameter to control the flow of $\mathrm{N}_{2}$ into the 1-hexene tank

- A Grant water bath with a Labcon pump and Polyscience temperature controller

- A Pt-100 temperature sensor 
- A RKC CB-100 digital temperature controller

- A $1 / 4$ inch Bauman series 51000 control valve, with a Fischer Type-3661 electropneumatic positioner and a $67 \mathrm{CFR}$ regulator

- Magnetic stirrer

- A surge tank

The 1-hexene feed was stored under nitrogen in the temperature controlled storage tank with continuous stirring (Figure 4.3).

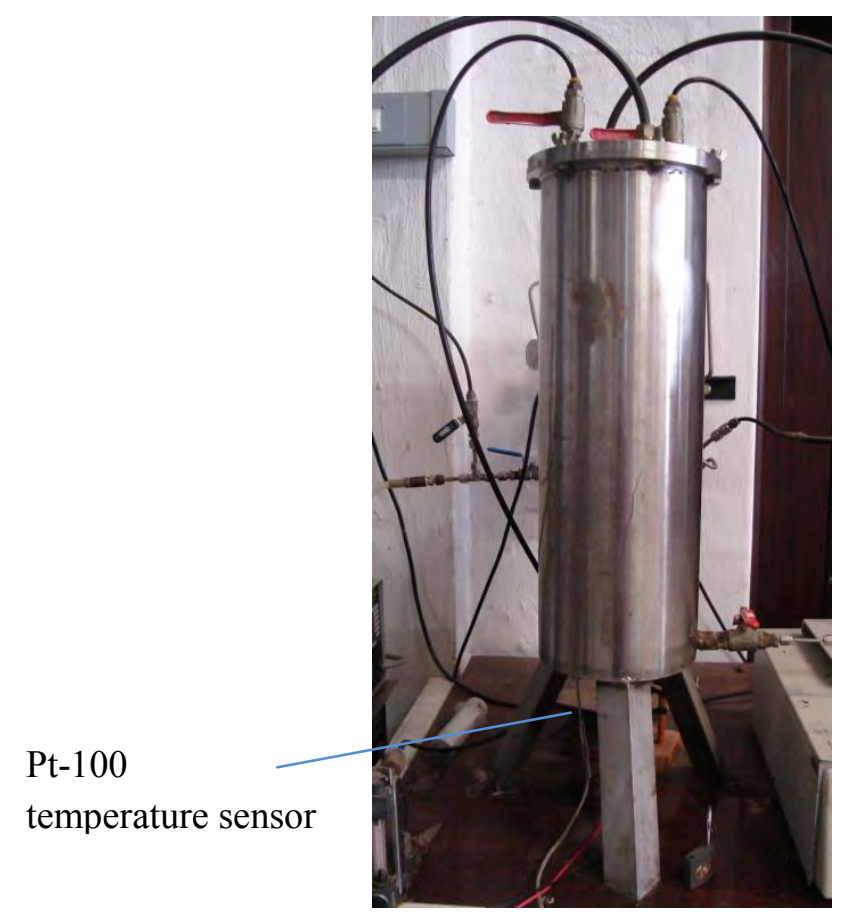

Figure 4.3: 1-Hexene feed storage tank

The purpose of the nitrogen gas was twofold. The first was to prevent poisoning of the catalyst downstream by oxygenates. Oxygenates are formed when 1-hexene comes into contact with air. Thus nitrogen was used to purge the tank of air and form a vapour blanket above the reactant feed. The second purpose of the nitrogen was to provide a positive pressure on the pump suction side (Lokhat, 2008). Temperature control of the feed tank was accomplished by pumping heated water obtained from the temperature controlled water bath (Figure 4.5) through coils within the tank. 


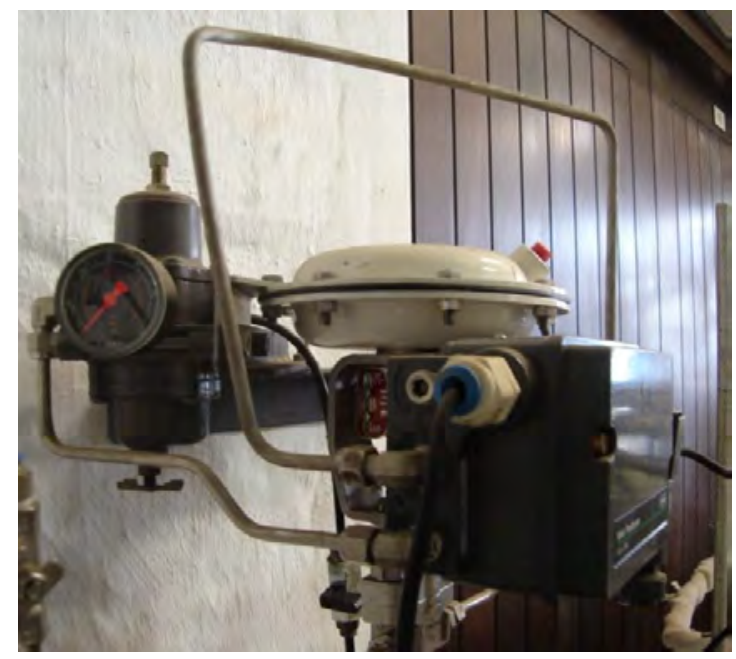

Figure 4.4: Control valve

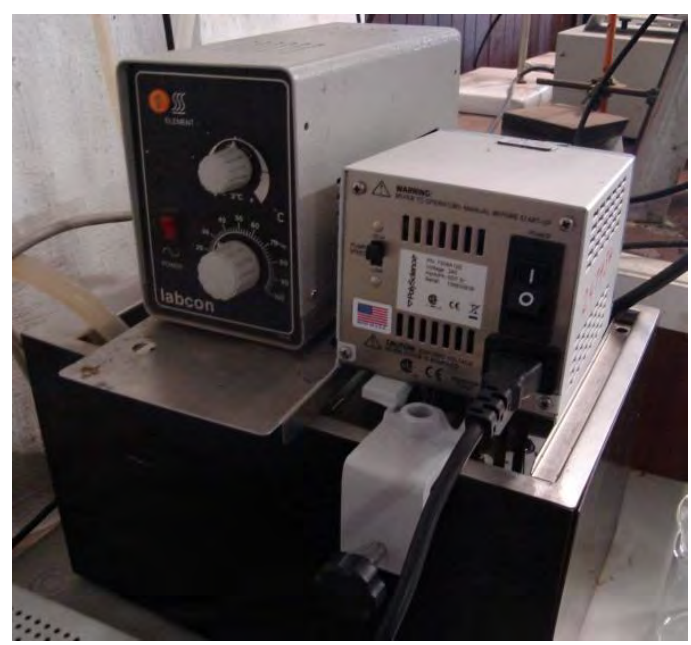

Figure 4.5: Temperature controlled water bath

The Pt-100 temperature sensor was fixed into the tank and was used to monitor the temperature of the feed in the tank. The digital temperature controller and control valve were used to regulate the flow into the tank relative to a set point of $30^{\circ} \mathrm{C}$. A surge tank was present for the event of the control valve failing close, as this would allow the water to be diverted back into the water bath.

\subsubsection{Feed delivery system apparatus}

- A Spectrochrom P100 isocratic pump

- $1 / 8$ inch stainless steel piping with wound nichrome resistance wire connected to two $250 \mathrm{~V}$ variable voltage transformers from Yokoyama Electric Works (AC/DC dynamics) 
- Two Pt-100 temperature sensors/thermometers

- I-on electro-m® temperature display

- CB-100 temperature display

- Bailey Porter Fischer 10A6132NB1C precision bore flowrator tube (rotameter) for $\mathrm{N}_{2}$

- Bubble flow meter

- Pt-100 temperature probe for bubble flow meter temperature measurement

- Honeywell Sensotec TJE absolute pressure transducer (0-6 bar) for bubble flow meter pressure measurement

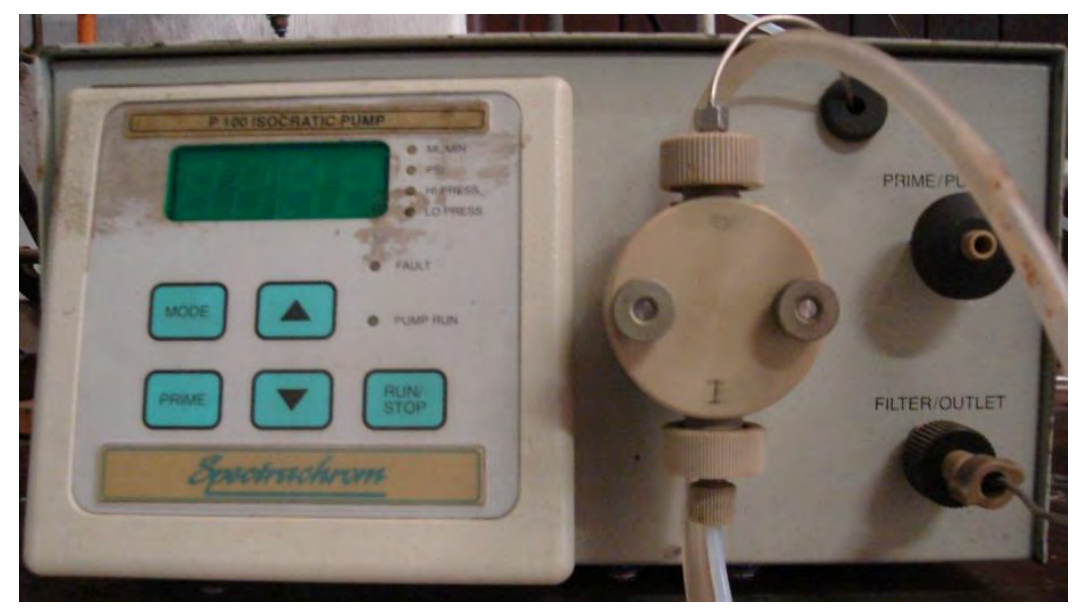

Figure 4.6: Spectrochrom P100 isocratic pump

The heated feed from the storage tank was pumped by the Spectrochrom isocratic pump (Figure 4.6) through the electrically heated piping. A 3-way ball valve was positioned after the pump to allow for the collection of feed samples as and when required for calibration or GC analysis. Calibration of the pump for a wide range of flows was undertaken by measuring the time it takes to collect a certain mass of sample (refer to Appendix A).The electrically heated piping was lagged using glass fibre sheath and an outer layer of glass cloth. It was maintained at a temperature above the boiling point of hexene. The vapourized hexene was then mixed with nitrogen in the desired ratio. Two temperature probes were positioned on the heated line to monitor the temperature. The first was the mixing point temperature indicator located after the nitrogen/hexene mixing point and the second was the reactor inlet temperature indicator. The nitrogen was metered using flow control valves and a gas rotameter. Calibration of the gas rotameter was undertaken by diverting the 3 way ball valve positioned after the rotameter towards the bubble flow meter. The calibration chart for the rotameter can be found in Appendix A. The bubble flow meter was also used to check the flow rate of nitrogen before the start of an 
experimental run. The Honeywell Sensotec TJE pressure transducer and a Pt-100 temperature probe were used for bubble flow meter temperature and pressure measurements.

\subsubsection{Reactor module}

- A 316 stainless steel tube (length $=437 \mathrm{~mm}, \mathrm{OD}=1 / 2 \mathrm{inch}, \mathrm{ID}=9.2 \mathrm{~mm}$ ) as the reactor

- Two Swagelok tube reducing unions

- A Wika model S-10 pressure transmitter

- TOHO TTM-004 digital controller for pressure display

- Sheathed Type-K thermocouple ( $1 / 16$ inch)

- Carbolite MTF single zone electric furnace

- Shinko JCS digital PID controller

The mixture of 1-hexene feed and nitrogen entered the reactor. The reactor was a stainless steel tube placed vertically in the electric furnace. The vertical arrangement allows for the downflow of gas which maintains the catalyst packing. The reactor module was positioned higher up above the condenser to allow for the heavy reaction products to fall by gravity (Lokhat, 2008). A pressure transmitter was fixed to the reactor head. The reactor tube can be seen in Figure 4.7.

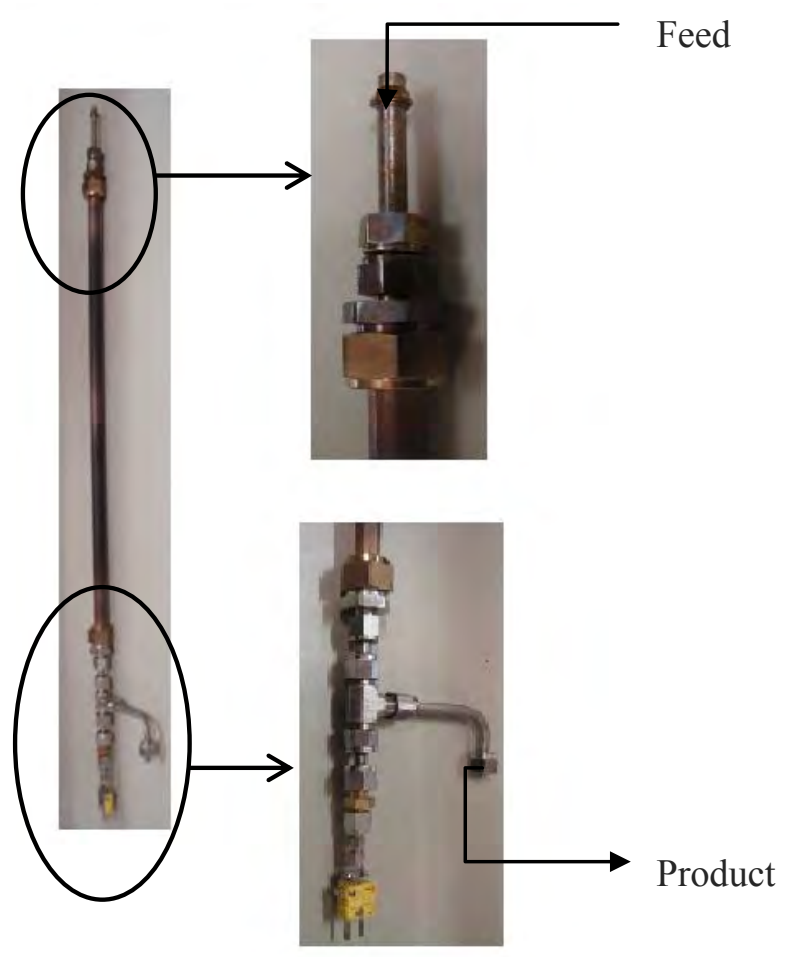

Figure 4.7: Stainless steel reactor tube with fittings 
The catalyst was packed into the reactor tube between glass wool. This is illustrated in Figure 4.8. The type-K thermocouple was positioned within the reactor to monitor the temperature. The Shinko JCS digital PID controller was used to control the furnace temperature. This was linked to a computer via the Shinko JC-300 (DCL-300) Monitoring Software which provides a chart display of the reactor temperature versus time. This enables the user to establish how good the temperature control is and to change the PID settings using online trial and error tuning if necessary. Good temperature control was essential since the reaction temperature was one of the factors that were being tested and deviations from the set point will cause erroneous results.
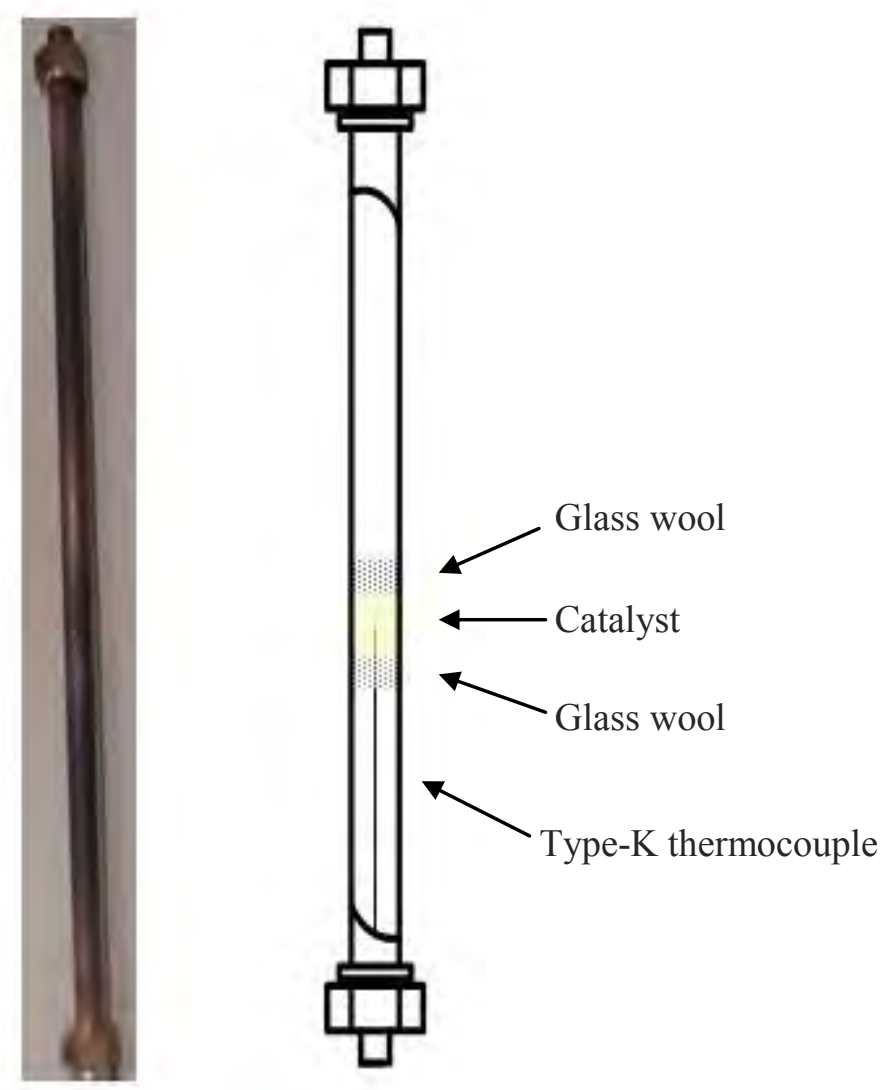

Figure 4.8: Reactor tube (outer and cross sectional view)

\subsubsection{Product collection apparatus}

- A water bath with a Labcon TBR-100 refrigerated cooling water circulator and Grant temperature controller

- A Corning QVF $-\mathrm{HE} 1 \frac{1}{2}$ glass condenser (length $\left.=550 \mathrm{~mm}, \mathrm{OD}=60 \mathrm{~mm}\right)$ 
Reaction product flow was determined using the bubble flow meter apparatus mentioned above for nitrogen flow measurements. The reaction products leaving the reactor were in the gas phase and thus the heavy reaction products $\left(\mathrm{C}_{5}-\mathrm{C}_{16}\right)$ were condensed in the Corning QVF - HE 11/2 glass condenser (

Figure 4.9) and collected for later gas chromatography analysis. The lighter products $\left(\mathrm{C}_{2}-\mathrm{C}_{8}\right)$ were sampled directly at the septum sampling point using a gas tight syringe and analysed immediately. The use of this syringe ensured that there is no loss of gas sample to the atmosphere. The lighter products were bubbled through a tank with water and thereafter vented.

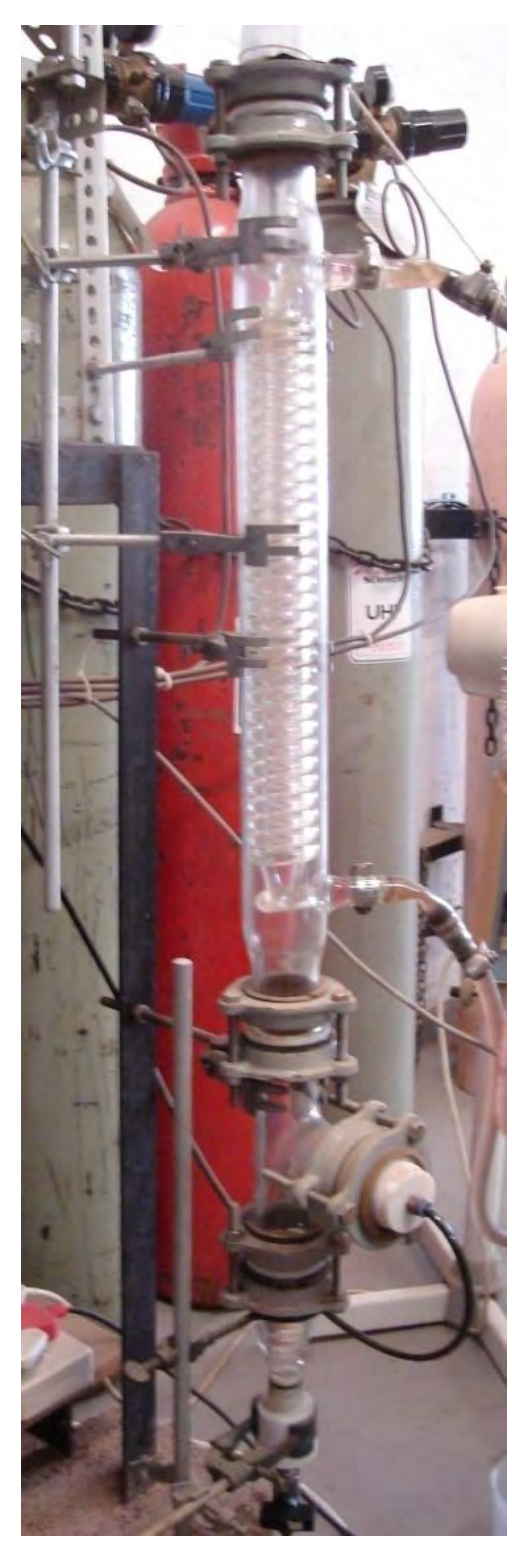

Figure 4.9 : Corning QVF -HE 11/2 glass condenser 


\subsection{The gas chromatograph}

Analysis of the reaction products was performed using a Shimadzu GC 2014 gas chromatograph (Figure 4.10) with a 10\% Silicone Chromosorb WHP SE-30 packed GC column (length $=3 \mathrm{~m}$ and internal diameter $=2 \mathrm{~mm}$ ) and a flame ionization detector. The carrier gas used was nitrogen. The method of analysis of the reaction products by the GC is discussed in Chapter 5 .

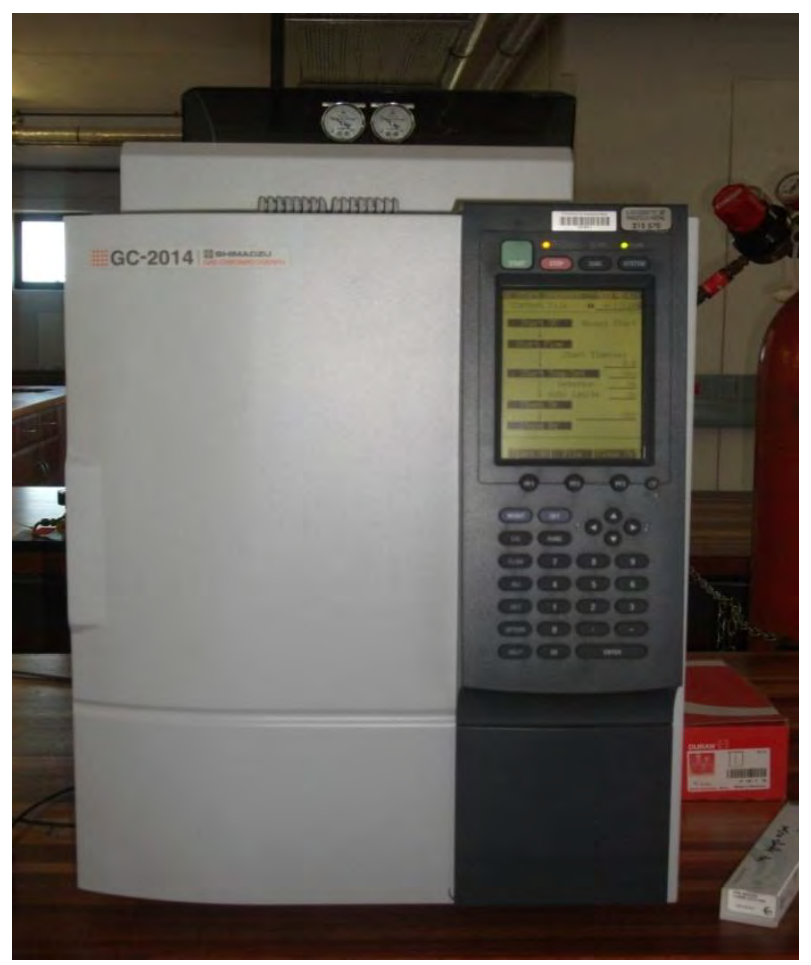

Figure 4.10: Shimadzu GC 2014 gas chromatograph 


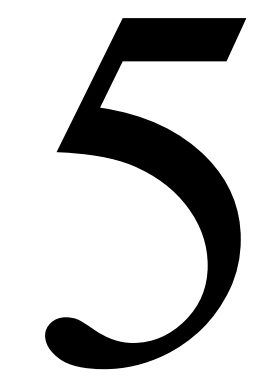

\section{CHAPTER FIVE}

\section{EXPERIMENTAL METHODS}

\subsection{Catalyst Preparation}

The steps involved in the preparation of the catalyst were key to producing a catalyst of high activity and good selectivity. The two main stages in the preparation of the catalyst were the dispersion of the tungsten metal salt on to the alumina support and thereafter the conversion of the tungsten metal salt to the oxide state by calcination. The chosen technique for the first stage was the impregnation method since only a small quantity of tungsten metal salt would be needed to be spread through the support. The support allows the catalyst to achieve a high surface area. The integrity of the support must be ensured when considering supported catalysts in the gas environment. Degradation of both the alumina and silica supports is avoided by carrying out the reaction anhydrously. The integrity of the catalyst itself was ensured by storing the 1-hexene under nitrogen. This was to prevent the poisoning of the catalyst downstream by oxygenates which are formed when 1-hexene comes into contact with air. The technical details of the catalyst preparation steps and conditions are discussed further.

\subsubsection{0 and $16 \mathrm{wt} \% \mathrm{WO}_{3} / \mathrm{Al}_{2} \mathrm{O}_{3}$ catalyst preparation}

The catalyst was prepared by using the wet impregnation method as discussed in Section 2.6. A calculated amount of the precursor salt i.e. ammonium metatungstate hydrate (Sigma Aldrich, 
99.9\% purity), according to the desired specific loading, was dissolved in distilled water to form an aqueous solution. For the $10 \mathrm{wt} \%$ loading, $1.181 \mathrm{~g}$ salt was required and $2.025 \mathrm{~g}$ was required for the $16 \mathrm{wt} \%$ catalyst. 10 grams of crushed $\left(\mathrm{d}_{\text {particle }}=300-700 \mu \mathrm{m}\right)$ support material, alumina (aluminium oxide, gamma-phase, catalyst support, high surface area) was wet with distilled water for each loading. The wetted alumina was acidified by the dropwise addition of nitric acid $\left(55 \% \mathrm{HNO}_{3}\right)$. Three drops of acid were added for the $10 \mathrm{wt} \%$ catalyst and 21 drops were added for the $16 \mathrm{wt} \%$ catalyst. The aqueous solution of ammonium metatungstate hydrate was then added to the alumina. This slurry like mixture was stirred at ambient temperature on a rotary evaporator for approximately 20 hours. The catalyst was then dried under vacuum at $80^{\circ} \mathrm{C}$ for 1.5 hours using a rotovap. This was followed by the removal of the catalyst from the rotovap into a calcination tube which was placed in a furnace. The temperature was then ramped at $1^{\circ} \mathrm{C} / \mathrm{min}$ to $200^{\circ} \mathrm{C}$ and the catalyst was finally calcined at $200^{\circ} \mathrm{C}$ under air overnight.

\subsection{2. $20 \mathrm{wt} \% \mathrm{WO}_{3} / \mathrm{Al}_{2} \mathrm{O}_{3}$ catalyst preparation}

The catalyst preparation method discussed above (Section 5.1.1) was also used to prepare the $20 \mathrm{wt} \%$ catalyst. Approximately 4 drops of $\mathrm{HNO}_{3}$ was used per $7 \mathrm{ml}$ of total water used to dissolve the ammonium metatungstate hydrate, wet the alumina and form a slurry-like mixture. The stirring and drying conditions were the same, however, the calcination temperature was increased to $500^{\circ} \mathrm{C}$ and the total calcination time was 18 hours.

\subsubsection{Potassium doped $\mathrm{WO}_{3} / \mathrm{SiO}_{2}$ catalyst preparation}

The $8 \mathrm{wt} \% \mathrm{WO}_{3} / \mathrm{SiO}_{2}$ catalyst was prepared at Sasol for use in a previous research study at the School of Chemical Engineering. This was also used as the standard in the preparation of the potassium doped $\mathrm{WO}_{3} / \mathrm{SiO}_{2}$ catalyst at loadings of $0.05,0.1$ and $0.5 \mathrm{wt} \%$ potassium. Calculated amounts of potassium nitrate $\left(\mathrm{KNO}_{3}\right.$, Merck Chemicals, assay min. 99.0\%) were dissolved in distilled water to form an aqueous solution. The $8 \mathrm{wt} \% \mathrm{WO}_{3} / \mathrm{SiO}_{2}$ catalyst $\left(\mathrm{d}_{\text {particle }}=300-700 \mu \mathrm{m}\right)$ was wet with distilled water. The dissolved salt solution was added to the wet $8 \mathrm{wt} \% \mathrm{WO}_{3} / \mathrm{SiO}_{2}$ catalyst. The mixture was then stirred on a rotary evaporator for approximately 20 hours followed by drying under vacuum at $80^{\circ} \mathrm{C}$ for 2 hours using a rotovap. The final stage was calcination of the catalyst by raising the temperature at $1{ }^{\circ} \mathrm{C} / \mathrm{min}$ to $550^{\circ} \mathrm{C}$ and thereafter calcining at $550^{\circ} \mathrm{C}$ overnight. 


\subsection{Materials and operating procedure}

The feed material, 1-hexene, used for all experimental runs was obtained from Sigma-Aldrich with a purity $\geq 96.0 \%$. High purity nitrogen $(99.99 \%)$ from Afrox was used for both the purging of the feed tank and to obtain the desired feed gas composition of 1-hexene.

The Labcon TBR-100 refrigerated cooling water circulator and Grant temperature controller were switched on first to allow the temperature of the circulating water to reach the set point of $2^{\circ} \mathrm{C}$. The control box main plug switch was then turned on, followed by the instrument switch on the control box. The variacs were turned on and the temperature of the electrically heated line was monitored on the 'mixing point temperature indicator' and 'the reactor inlet temperature indicator' found on the control box. These ensured that the temperature in the heated line was higher than the boiling point of hexene. The Polyscience temperature controller, for heating the water to be used in the hexene tank, was turned on. The set point for the controller was $55^{\circ} \mathrm{C}$, which ensured that there was enough water in the water bath.

Once all the temperatures had reached their set points, the magnetic stirrer below the 1-hexene tank was switched on. The instrument air supply valve for the control valve regulator was opened and the Labcon pump was turned on. The feed tank temperature controller found on the control box was then turned on by pressing and holding the R/S button until the 'STOP' value was replaced by the process temperature. The set point on this controller was $30^{\circ} \mathrm{C}$. The $\mathrm{N}_{2}$ feed tank primer cylinder was opened and the Krohne Gepruft rotameter, to control the flow of $\mathrm{N}_{2}$ into the 1-hexene tank, was opened to a low setting. The inlet and outlet $\mathrm{N}_{2}$ valves $(2 \mathrm{~V}-12$ and $2 \mathrm{~V}-13$ ) found above the hexene tank were opened as well as valve $2 \mathrm{~V}-18$. The Spectrochrom P100 isocratic pump for delivery of 1-hexene was switched on and the desired pump setting for the particular run was set. Valve 2V-9 was opened and RUN/START button was pressed on the pump. The furnace switch was turned on, on the control box and the set point value was adjusted to the desired temperature for the particular run. The PID settings were entered by pressing the up and round arrow buttons simultaneously. The PID settings used were $\mathrm{P}=25$, $\mathrm{I}=585$ and $\mathrm{D}=60$. The computer was switched on and the logging software was initialised. The furnace main plug switch was turned on. The nitrogen cylinder valve was opened. Valves $2 \mathrm{~V}-2$ and $2 \mathrm{~V}-4$ were then opened and the rotameter was set using MFCV-1 (anticlockwise). This ensured that valve $2 \mathrm{~V}-19$ was always open to allow the gas to be vented. The bubble flow meter was used to test the flow rate of the feed gas by directing valve $3 \mathrm{~V}-3$ to 'feed gas to bubble flow meter'. The temperature, pressure, volume and time were recorded. Valve 3V-3 was thereafter returned to its original position directing the feed gas to the reactor. 
Once the reactor temperature had reached its set point and stabilized, the liquid which had collected in the condenser, was drained using the drain valve. The timer was then started for the reaction period. The duration of the reaction period was dependent on the flow rate of 1-hexene and the time it took to collect a substantial amount of condensed product. The GC was turned on. A beaker was weighed and its mass noted. It was placed below the drain valve for the collection of condensed product.

After the prescribed time, the flow rate of the product gas was tested by directing valve $3 \mathrm{~V}-4$ to 'product gas to bubble flow meter'. The temperature, pressure, volume and time were recorded. Valve $3 \mathrm{~V}-4$ was thereafter returned to its original position directing the product gas to the vent. The product gas was sampled directly from the sampling point using a gas tight syringe and was injected into the GC for analysis. The use of this syringe ensured that there was no loss of gas sample to the atmosphere. The condenser drain valve was opened and the timer stopped to mark the end of the reaction period. The drain valve was closed and the mass of the beaker with the condensed product was noted. A small amount of the product liquid was transferred into a sample bottle for later analysis. The sample bottle was refrigerated immediately. The integrity of the sample bottle was previously tested for evaporation losses. The sample was kept for a maximum of 12 to 18 hours before the analysis was undertaken.

\subsection{GC Analysis}

Analysis of samples of the reaction products was done using gas-liquid chromatography. The gas chromatograph (GC) machine that was used was the Shimadzu GC 2014 gas chromatograph with a $10 \%$ Silicone SE-30 packed GC column and flame ionization detector using nitrogen as the carrier gas. The operating conditions and the metathesis gas and liquid analysis temperature programs are provided in Table 5.1 and 5.2, respectively. 
Chapter 5 - Experimental Methods $\mid 64$

Table 5.1: GC operating conditions and temperature program used for analysis of gas phase metathesis products

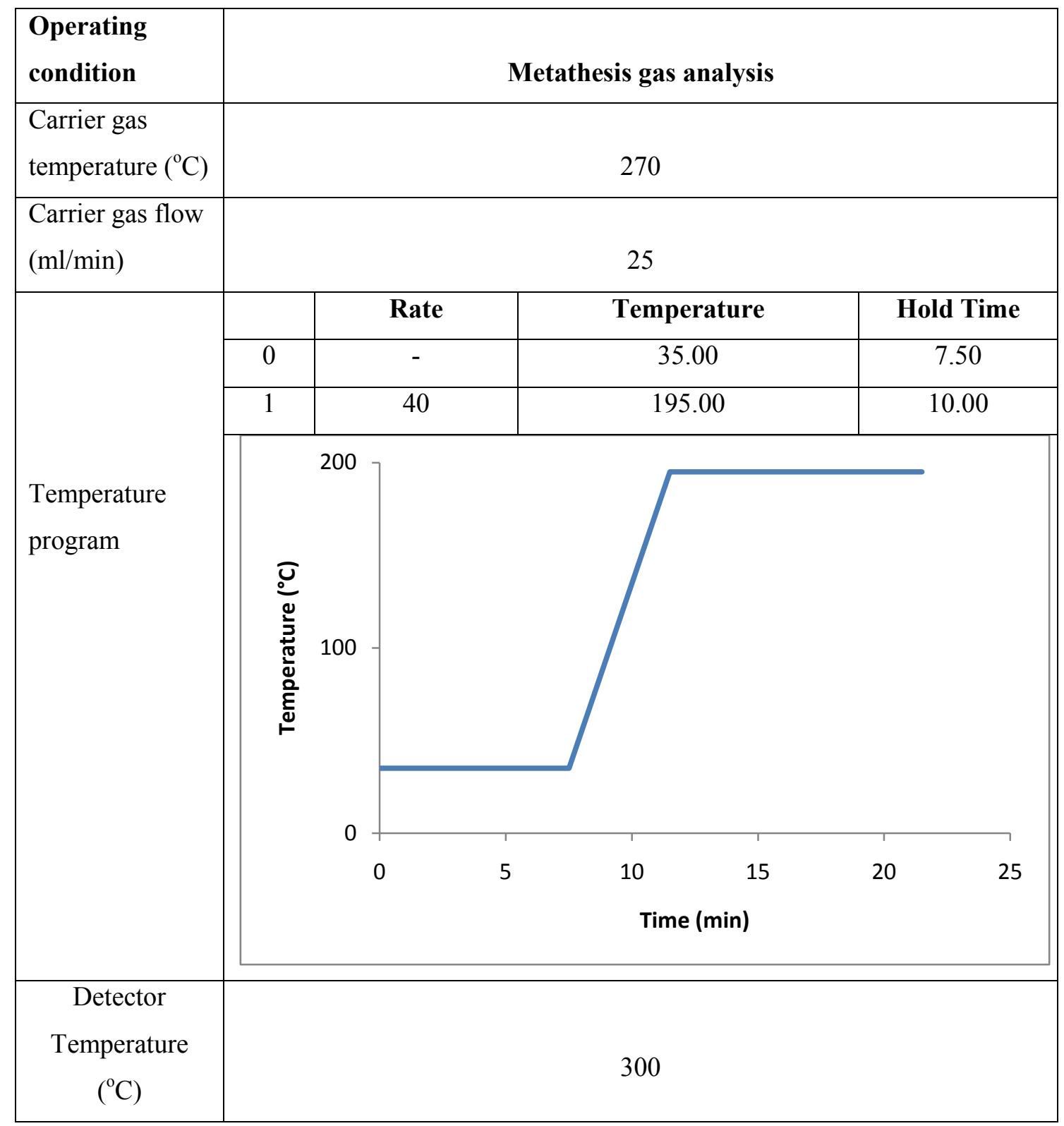


Table 5.2: GC operating conditions and temperature program for analysis of liquid phase metathesis products

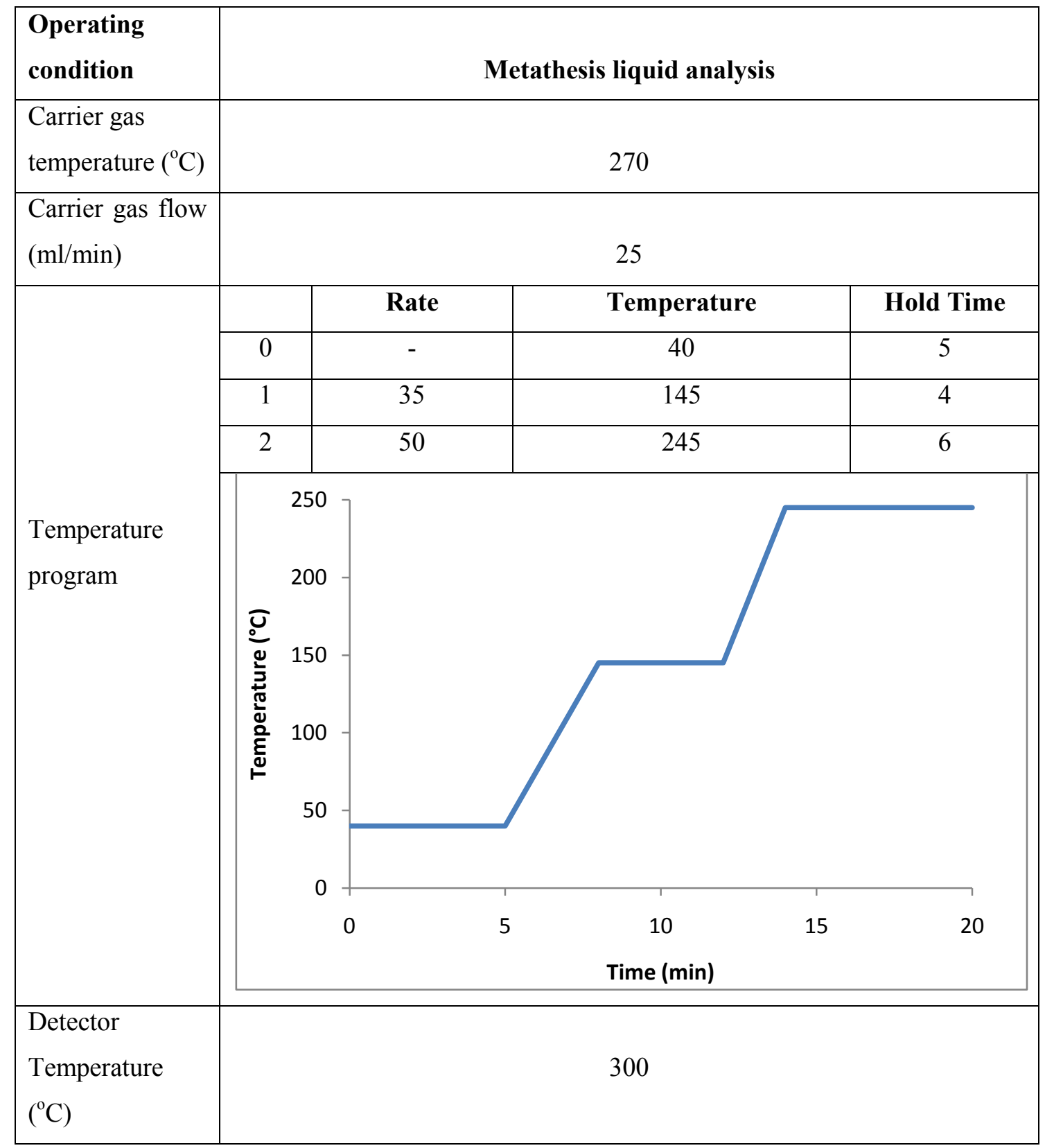

The internal normalisation method was used for calibrating the G.C to obtain the relative response factors. These relative response factors were used in the analysis of the product sample and determination of the mass concentrations of the components in the sample. Thus the relative response factor $f_{i, k}$, was determined for each of the components as listed in Table 5.3. The response factor is given by Equation 5.1. 


$$
m_{i}=f_{i} \times A_{i}
$$

where $m_{i}=$ mass of component $i$

$$
\begin{aligned}
& f_{i}=\text { response factor of component } i \\
& A_{i}=\text { area peak of component } i
\end{aligned}
$$

For the calibration of the GC, 1-hexene was chosen as the reference component or the substance for internal normalisation and was used in the calculation of the relative response factors (Rouessac, 2007). A ratio with respect to the reference component $k$ (1-hexene) was used to make the standard solutions. The relative response factor was obtained using the mass, $m$ and area peaks, $A$ (obtained from the GC chromatograms) of the component and reference component, $i$ and $k$ respectively, as follows:

$$
\begin{gathered}
\frac{m_{i}}{m_{k}}=\frac{f_{i} \times A_{i}}{f_{k} \times A_{k}} \\
\frac{A_{k}}{A_{i}}=f_{i, k} \times \frac{m_{k}}{m_{i}}
\end{gathered}
$$

Where the relative response factor $f_{i, k}$ is:

$$
f_{i, k}=\frac{f_{i}}{f_{k}}
$$

A plot of $\frac{A_{k}}{A_{i}}$ vs. $\frac{m_{k}}{m_{i}}$ gives a straight line with a slope $=f_{i, k}$. The mass fraction of each component in the reaction product can be obtained from the following equation by using the relative response factors and peak areas obtained from the GC.

$$
w_{i}=\frac{f_{i, k} A_{i}}{\sum f_{j, k} A_{j}}
$$

For the liquid calibrations for the GC, the method of finding the relative response factors for each component was performed as discussed above, where known masses of each component were mixed and injected into the GC to produce elution peaks of different areas. Samples of volume $0.5 \mu \mathrm{l}$ were injected into the GC to prevent detector overloading. Calibrations for 
pentene, heptene, octene, nonene and decene were undertaken. Alkane solutions of tetradecane and pentadecane were available for use and were also calibrated to provide an idea of the retention time of $\mathrm{C}_{14}$ and $\mathrm{C}_{15}$ alkenes. Various ratios of the reference component i.e. 1-hexene to the other components were used. The calibration plots (Appendix B) were obtained for the liquid components, the slope of each giving the relative response factor for the specific component with reference to 1-hexene (

Table 5.3). Solutions of $\mathrm{C}_{11}-\mathrm{C}_{16}$ alkenes were unavailable and the relative response factors for these components were assumed to be 1 as the relative response factors for components $\mathrm{C}_{5}-\mathrm{C}_{10}$ remained constant at approximately one.

Table 5.3: List of relative response factor $\left(f_{i, k}\right)$ values for each component (reference component :1-hexene)

\begin{tabular}{|c|c|c|}
\hline \multicolumn{2}{|c|}{ Component } & $f_{i, k}$ \\
\hline ethylene & $\mathrm{C}_{2}$ & 0.767 \\
\hline propylene & $\mathrm{C}_{3}$ & 0.822 \\
\hline butene & $\mathrm{C}_{4}$ & 0.835 \\
\hline pentene & $\mathrm{C}_{5}$ & 1.0021 \\
\hline hexene & $\mathrm{C}_{6}$ & 1 \\
\hline heptene & $\mathrm{C}_{7}$ & 1.01 \\
\hline octene & $\mathrm{C}_{8}$ & 1.0162 \\
\hline nonene & $\mathrm{C}_{9}$ & 1.044 \\
\hline decene & $\mathrm{C}_{10}$ & 1.004 \\
\hline undecene & $\mathrm{C}_{11}$ & 1 \\
\hline dodecene & $\mathrm{C}_{12}$ & 1 \\
\hline tridecene & $\mathrm{C}_{13}$ & 1 \\
\hline tetradecene & $\mathrm{C}_{14}$ & 1 \\
\hline pentadecene & $\mathrm{C}_{15}$ & $\mathrm{C}_{16}$ \\
\hline hexadecene & & 1 \\
\hline
\end{tabular}

The $f_{i, k}$, values for the components found only in the gas phase were an updated set from Lokhat (2008) and can be found in

Table 5.3. These included the lighter olefins such as ethylene, propylene and butene. A calibration cell was constructed to allow for a mixture of gas and a vapourised liquid of known composition to be analysed. A $60 \mathrm{ml}$ sample with $1 / 3$ of each gas component, i.e. ethylene, 
propylene and butene, was injected into the calibration cell. The ideal gas equation was used for converting the volume of gas into a molar quantity. A liquid sample of the reference component (1-hexene) ranging between $1 \mu 1-10 \mu 1$ was injected and once vapourised, a sample of the mixture was obtained for injection into the GC for calibration.

\subsection{Gas- chromatography- mass- spectrometry (GCMS)}

The GCMS used for analysis of the liquid product sample was the Shimadzu GCMS QP2010 with a Restek Rtx-200ms capillary column and operating in SCAN mode (30 - $500 \mathrm{~m} / \mathrm{z}$ ). The temperature program for the oven was 40 to $240^{\circ} \mathrm{C}$ at a rate of $2^{\circ} \mathrm{C} / \mathrm{min}$. The injector, interface and ion source temperatures were $250^{\circ} \mathrm{C}, 200^{\circ} \mathrm{C}$ and $250^{\circ} \mathrm{C}$ respectively. The split ratio was $1: 200$.

\subsection{Catalyst characterisation}

\subsubsection{FTIR Analysis}

The FTIR analysis was conducted using a Perkin Elmer Spectrum 100 FT-IR spectrometer. Each catalyst sample of 10,16 and $20 \mathrm{wt} \% \mathrm{WO}_{3} / \mathrm{Al}_{2} \mathrm{O}_{3}$ was crushed to a fine powder and placed onto analysis plates. The entire wavelength range was transmitted to obtain the absorbance spectra for analysis.

\subsubsection{BET surface area measurements}

The BET surface area analysis was done on a Micromeritics ASAP 2020 Analyzer. The samples were degassed prior to analysis to remove any surface impurities. Degassing was undertaken overnight at a temperature of $200^{\circ} \mathrm{C}$ under nitrogen. 


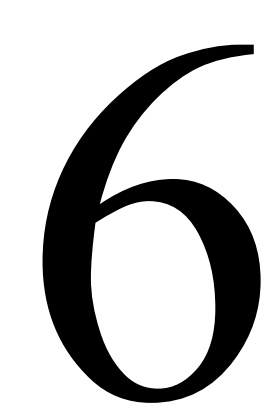

\section{CHAPTER SIX}

\section{RESULTS AND DISCUSSION}

\subsection{The $\mathrm{WO}_{3} / \mathrm{Al}_{2} \mathrm{O}_{3}$ catalyst: experimental results and discussion}

The choice of investigating alumina as a catalyst support stemmed from the use of alumina as a support in other metathesis reactions, using other metal oxides such as molybdenum and rhenium. The chemical properties and structure of molybdenum and tungsten are very similar as evidenced by their placement on the periodic table.

It was initially believed that the alumina support is less acidic than the silica support since dehydration increases with the movement from alumina to silica as can be seen in Figure 6.1 (Tanabe, 1989). As the acidity of the catalyst is a key factor in the amount of isomerization that occurs, a less acidic catalyst is more desirable in order to reduce the negative effect of isomerization.

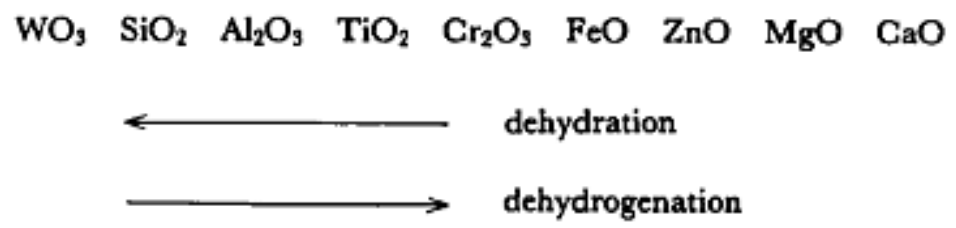

Figure 6.1 : Selectivity sequence towards dehydration and dehydrogenation (Tanabe, 1989) 
However, the acidity of the catalyst supports, as determined through chemical characterisation testing, indicate that the strength and number of acid sites on the $\mathrm{WO}_{3} / \mathrm{Al}_{2} \mathrm{O}_{3}$ catalyst is greater than for the $\mathrm{WO}_{3} / \mathrm{SiO}_{2}$ catalyst (Harmse et al., 2010). Tungsten oxide itself is also known to have an acidic nature.

Initially, a $4^{3}$ full factorial design was to be used to determine the optimum operating conditions when using the $\mathrm{WO}_{3} / \mathrm{Al}_{2} \mathrm{O}_{3}$ catalyst. This design was chosen since it incorporates all possible combinations of factors and levels and would thus give a good indication of the optimum specific loading and operating conditions. These were determined by the analysis of the catalyst performance. The catalyst performance was assessed in terms of 1-hexene conversion, selectivity and yield of the primary metathesis product 5-decene, selectivity and yield of the detergent range olefins $\left(\mathrm{C}_{10}-\mathrm{C}_{16}\right)$ as well as amount of isomerization. Each of these assessment criteria can be defined by the equations that govern them as given below.

The conversion, $\mathrm{X}$, gives an indication of the amount of reactant 1-hexene that has been converted. It is defined as the molar flow rate of 1-hexene that has reacted divided by the inlet molar flow rate of the reactant, 1-hexene. The total molar flowrate of 1-hexene out $\left(F_{(1-\text { hexene,total })}^{\text {out }}\right)$ is obtained by the addition of the molar flowrate of 1-hexene leaving as gas and liquid.

$$
X_{(1-\text { hexene })}=\frac{F_{(1-\text { hexene })}^{\text {in }}-F_{(1-\text { hexene, } \text { total })}^{\text {out }}}{F_{(1-\text { hexene })}^{\text {in }}} \times 100
$$

The selectivity of $\mathrm{C}_{10}-\mathrm{C}_{16}$ olefins gives an indication of how selective the reactions were in producing the desired range of olefins. It is defined as the sum of the molar flow rates of the $\mathrm{C}_{10}-\mathrm{C}_{16}$ range of olefins divided by the molar flow rate of 1-hexene that has reacted.

$$
\text { Selectivity }_{\left(C_{10}-C_{16}\right)}=\frac{\sum F_{\left(C_{10}-C_{16}\right)}}{F_{(1-\text { hexene })}^{\text {in }}-F_{(1-\text { hexene,total })}^{\text {out }}} \times 100
$$




$$
\text { Selectivity }_{\left(C_{10}\right)}=\frac{F_{\left(C_{10}\right)}}{F_{(1-\text { hexene })}^{\text {in }}-F_{(1-\text { hexene,total })}^{\text {out }}} \times 100
$$

The yield of product indicates the amount of desired product i.e. detergent range olefins produced in the reaction. It is defined as the sum of the molar flow rates of the $\mathrm{C}_{10}-\mathrm{C}_{16}$ range of olefins divided by the molar flow rate of 1-hexene in.

$$
\operatorname{Yield}_{\left(C_{10}-C_{16}\right)}=\frac{\sum F_{\left(C_{10}-C_{16}\right)}}{F_{(1-\text { hexene })}^{\text {in }}} \times 100
$$

Similarly, the yield for decene is given as

$$
\operatorname{Yield}_{\left(C_{10}\right)}=\frac{F_{\left(C_{10}\right)}}{F_{(1-\text { hexene })}^{\text {in }}} \times 100
$$

The yield of the isomerized hexenes was calculated using Equation 6.6 to give an indication of the isomerization activity. It is defined as the sum of the molar flow rates of the isomerized hexenes divided by the molar flow rate of 1-hexene in.

$$
\text { Yield of isomerised hexenes }=\frac{F_{(\text {isomerised hexenes })}}{F_{(1-\text { hexene })}^{\text {in }}} \times 100
$$

where

$$
F_{(\text {isomerised hexenes })}=F_{(\text {linear isomers })}+F_{(\text {branched isomers })}
$$


The $10 \mathrm{wt} \% \mathrm{WO}_{3} / \mathrm{Al}_{2} \mathrm{O}_{3}$ catalyst was prepared first using the wet impregnation method as described in Section 5.1.1. The purpose of the addition of $\mathrm{HNO}_{3}$ was to reduce the equilibrium $\mathrm{pH}$ to below the iso-electric point (IEP). For alumina, this is between a $\mathrm{pH}$ of 8.5 and 9. An acidic medium is produced when doing so, where the hydroxyl groups in alumina would become polarized positively allowing for the adsorption of the tungsten anions as discussed in Section 2.7.1.1. The actual $\mathrm{pH}$ of the solution after the addition of the 3 drops of 55\% nitric acid $\left(\mathrm{HNO}_{3}\right)$ was not measured as this was expected to be far below the iso-electric point. After a few randomized experimental runs using the $10 \mathrm{wt} \% \mathrm{WO}_{3} / \mathrm{Al}_{2} \mathrm{O}_{3}$ catalyst, it was noted that the yields obtained (Figure 6.2 and Figure 6.3) were far below those available in literature either using other metathesis catalysts for the metathesis of 1-hexene or using a $\mathrm{WO}_{3} / \mathrm{Al}_{2} \mathrm{O}_{3}$ catalyst for the metathesis of other alkenes. No literature was available to compare the results directly in terms of using the $\mathrm{WO}_{3} / \mathrm{Al}_{2} \mathrm{O}_{3}$ catalyst for the metathesis of 1-hexene. However, it was suspected that the preparation procedure used had resulted in the production of sites on the catalyst that were not active for metathesis. This led to low observed yields of the higher olefins.

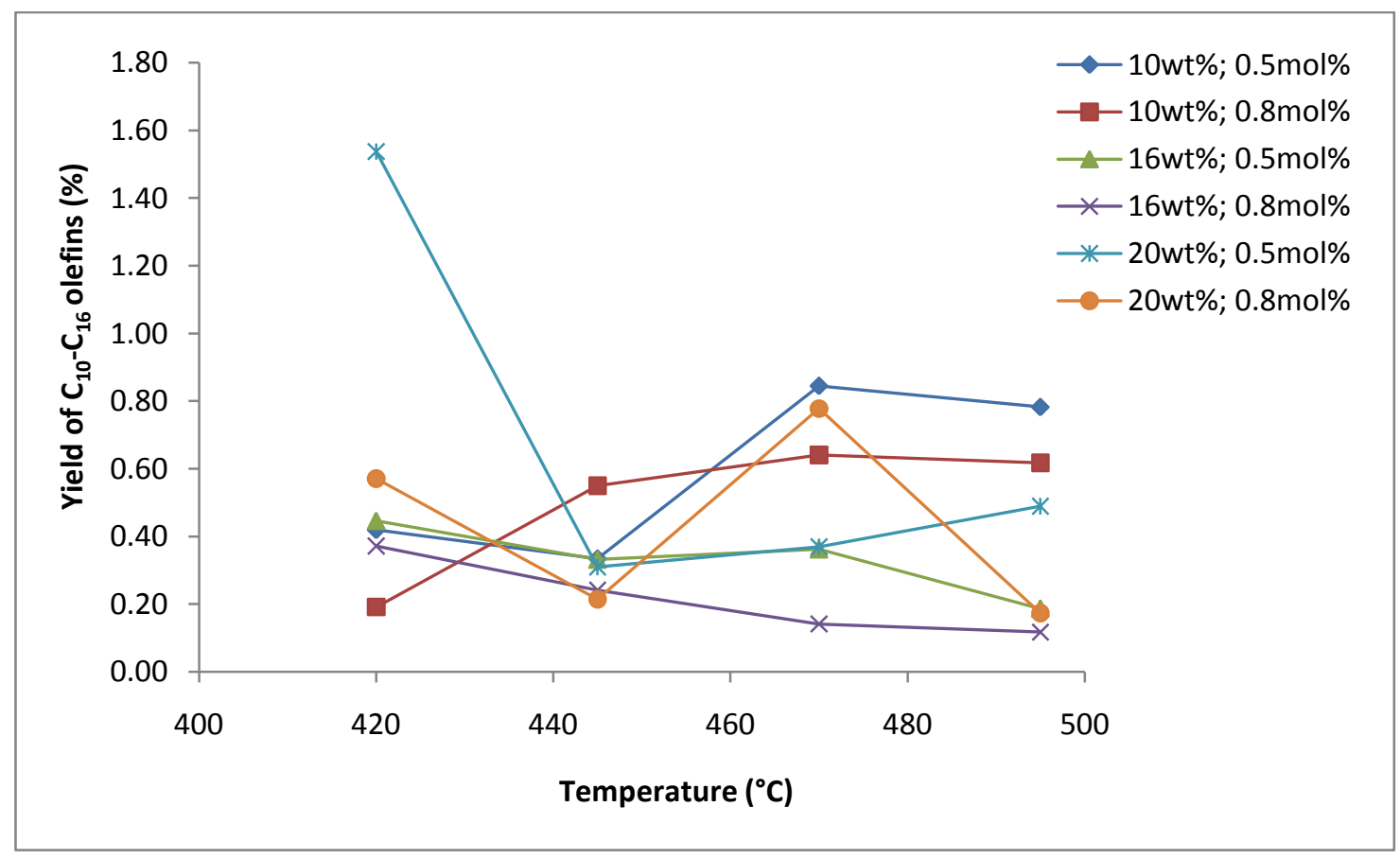

Figure 6.2: Yield of detergent range olefins vs. reaction temperature at different specific loadings of $\mathrm{WO}_{3}$ and 1-hexene feed compositions $\left(\mathrm{WO}_{3} / \mathrm{Al}_{2} \mathrm{O}_{3}\right.$ catalyst)

Due to the poor results observed in the preliminary experimental runs, it was decided that exploratory runs with the same three factors but fewer levels for each factor was a better option 
in determining whether the alumina supported tungsten trioxide was suitable for the metathesis of 1-hexene. This would require fewer resources and would enable conclusions to be drawn faster.

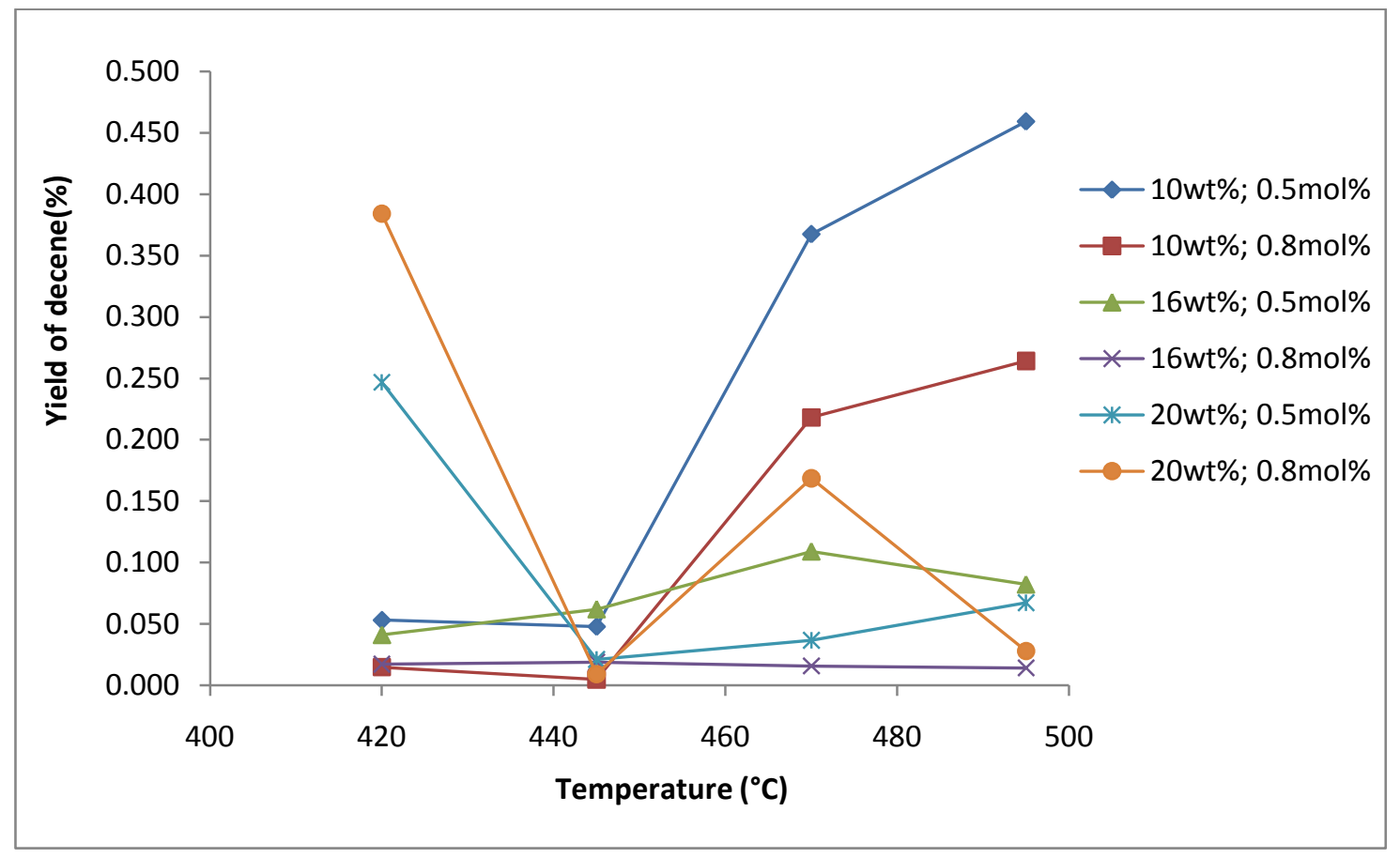

Figure 6.3: Yield of decene vs. reaction temperature at different specific loadings of $\mathrm{WO}_{3}$ and 1hexene feed compositions $\left(\mathrm{WO}_{3} / \mathrm{Al}_{2} \mathrm{O}_{3}\right.$ catalyst $)$

This would also result in an 'evolutionary' or 'sequential' design (DeCoursey, 2003) where it would be possible to decide whether to continue the investigation of the $\mathrm{WO}_{3} / \mathrm{Al}_{2} \mathrm{O}_{3}$ catalyst by completing the $4^{3}$ full factorial design experimental runs or whether to investigate other possible catalyst supports.

The levels for the reaction temperature remained at four, however the levels for the specific loading of tungsten trioxide and feed composition of 1-hexene were reduced to three and two respectively. This resulted in a $2^{1} \cdot 3^{1} \cdot 4^{1}$ full factorial design with 24 experimental runs instead of the 64 experimental runs previously required when undertaking the $4^{3}$ full factorial design. The chosen levels of specific loading of tungsten trioxide and feed composition of 1-hexene were still within the desired range to be investigated and were chosen to be towards the upper and lower limits of the ranges. The three levels of specific loadings were 10, 16 and $20 \mathrm{wt} \% \mathrm{WO}_{3}$ over alumina and the two levels of 1 -hexene feed composition were 0.5 and $0.8 \mathrm{~mol} \%$. 
Possible causes for the poor results as well as methods to improve it were considered. The method of preparation of the catalyst is an important factor that determines the structure of the catalyst. The structure of the catalyst has to be correct in order to obtain a high activity and good selectivity. The wet impregnation method was chosen as the method for preparation of the supported tungsten catalysts since only a small amount of the expensive metal is required. However, there are many steps comprising the wet impregnation method, where the conditions at which the step was carried out may not have been the optimum. The steps investigated were the addition of acid and the calcination time and temperature. For the preparation of the $16 \mathrm{wt} \%$ $\mathrm{WO}_{3} / \mathrm{Al}_{2} \mathrm{O}_{3}$ catalyst, more than 3 drops of nitric acid were added whilst keeping all other preparation conditions the same (refer to Section 5.1.1). This was done since the lower the $\mathrm{pH}$ of the medium, the higher is the adsorption of the tungstate anions. A better performing catalyst was expected, but the results revealed that it performed comparatively worse than the $10 \mathrm{wt} \%$ catalyst (Figure 6.2 and Figure 6.3). At the lower reaction temperature $\left(420^{\circ} \mathrm{C}\right)$, the yield of decene as well as the yield of $\mathrm{C}_{10}-\mathrm{C}_{16}$ olefins were found to be very close for both the specific loadings used, however at the higher temperatures, the $10 \mathrm{wt} \%$ catalyst produced higher yields of both decene and the $\mathrm{C}_{10}-\mathrm{C}_{16}$ range olefins. This could possibly be due to the fact that too much acid had been added in the preparation stage. When acid is added, it allows for better dispersion of the metal but it also causes the metal to penetrate into the alumina support. Acres et al. (1981) found that when no acid was added, the metal was not well dispersed and was found on the surface on the support. Therefore, it is possible that the addition of too much of nitric acid may have caused the metal to penetrate more deeply into the support. Even though it would have then a better dispersion, the active sites would be inaccessible for the metathesis reaction.

In order to determine the amount of acid that would bring the impregnation solution up to the correct $\mathrm{pH}$ of 2-3, tests were conducted on several acidified solutions. These solutions were made up by adding varying drops of nitric acid to $7 \mathrm{ml}$ of distilled water. The $7 \mathrm{ml}$ of distilled water was approximated as the amount that would be required to dissolve the ammonium metatungstate hydrate, wet the alumina and form a slurry like mixture. Three, six and nine drops of nitric acid were added to each vial containing $7 \mathrm{ml}$ of distilled water and universal indicator paper was used to get an indication of the colour change (Figure 6.4). The colour change of the universal indicator paper to orange-red for the 3 drop solution and a darker red for the other two solutions indicated that a $\mathrm{pH}$ of 2-3 would be achieved by adding approximately 3-4 drops nitric acid per $7 \mathrm{ml}$ distilled water. 


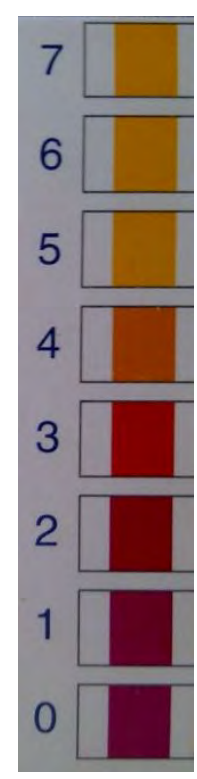

Figure 6.4: Universal indicator paper colour change according to $\mathrm{pH}$

As mentioned before, the calcination step was also considered as a possible cause for the poor catalyst performance. The two variables in the calcination stage were the calcination temperature and time. A temperature of $200^{\circ} \mathrm{C}$ was used to calcine both the $10 \mathrm{wt} \%$ and $16 \mathrm{wt}$ $\% \mathrm{WO}_{3} / \mathrm{Al}_{2} \mathrm{O}_{3}$ catalysts. This was the temperature of choice for the calcination stage since it was demonstrated by Logie et al. (1999) that calcining at a temperature of $200^{\circ} \mathrm{C}$ leads to the formation of mainly Lewis acid sites. The Lewis acid sites are desired over the formation of Brønsted acid sites as they play a role in the initiation of the metathesis reaction whereas the Brønsted acid sites are only responsible for catalysing isomerization reactions. However, research by Perego et al. (1997) and Satterfield (1991), into the form of alumina for use as a catalyst support, revealed that $\gamma$-alumina is the desired form of alumina due to its high surface area and it is formed when calcination occurs above $450^{\circ} \mathrm{C}$. The effect of the calcination time on the metathesis activity was studied by Huang et al. (2007) for a similar metathesis system (refer to Section 2.6.2). They found the optimum calcination time to be 18 hours, beyond which the number of tetrahedral surface tungsten oxide species and thus the metathesis activity decreased. Thus, the $20 \mathrm{wt} \% \mathrm{WO}_{3} / \mathrm{Al}_{2} \mathrm{O}_{3}$ catalyst was prepared by incorporating the changes to the amount of acid added, the calcination temperature and the calcination time. The amount of acid added was 4 drops per $7 \mathrm{ml}$ of distilled water, the calcination temperature was increased to $500^{\circ} \mathrm{C}$ and the catalyst was calcined for 18 hours. The results obtained for the 10,16 and $20 \mathrm{wt} \%$ catalysts at all combinations of factors and levels for the $2^{1} \cdot 3^{1} \cdot 4^{1}$ full factorial design is given in Table 6.1 and is presented graphically in Figure 6.2 to Figure 6.6. These include plots of the conversion of 
1-hexene, the yield of the detergent range olefins, the yield of decene as well as the isomerization activity. The relative response factors for the isomerized hexene were assumed to be the same as that found for 1-hexene as given in

Table 5.3.

Table 6.1: Table of experimental runs conducted and results for $\mathrm{WO}_{3} / \mathrm{Al}_{2} \mathrm{O}_{3}$ catalyst

\begin{tabular}{|c|c|c|c|c|c|c|c|c|c|}
\hline Run & $\begin{array}{c}\text { Specific } \\
\text { loading } \\
(w t \% \\
\left.W_{3}\right)\end{array}$ & $\begin{array}{r}\text { Temp } \\
\left({ }^{\circ} \mathrm{C}\right)\end{array}$ & $\begin{array}{c}\text { Mol \% } \\
\text { 1-hexene } \\
\text { in feed }\end{array}$ & $\begin{array}{c}\text { Conversion } \\
\text { of 1-hexene } \\
(\%)\end{array}$ & $\begin{array}{c}\text { Selectivity } \\
\mathrm{C}_{10}-\mathrm{C}_{16} \\
\text { (\%) }\end{array}$ & $\begin{array}{c}\text { Yield } \\
\mathrm{C}_{10}-\mathrm{C}_{16} \\
(\%)\end{array}$ & $\begin{array}{l}\text { Selectivity } \\
\qquad \begin{array}{c}\mathrm{C}_{10} \\
(\%)\end{array}\end{array}$ & $\begin{array}{c}\text { Yield } C_{10} \\
(\%)\end{array}$ & $\begin{array}{c}\text { Yield of } \\
\text { isomerized } \\
\text { hexenes (\%) }\end{array}$ \\
\hline 1 & 10 & 420 & 0.5 & 88.91 & 0.47 & 0.42 & 0.060 & 0.053 & 85.73 \\
\hline 2 & 10 & 445 & 0.5 & 89.38 & 0.37 & 0.33 & 0.054 & 0.048 & 64.42 \\
\hline 3 & 10 & 470 & 0.5 & 88.41 & 0.96 & 0.84 & 0.416 & 0.367 & 71.89 \\
\hline 4 & 10 & 495 & 0.5 & 91.35 & 0.86 & 0.78 & 0.503 & 0.459 & 66.33 \\
\hline 5 & 10 & 420 & 0.8 & 89.14 & 0.21 & 0.19 & 0.017 & 0.015 & 88.92 \\
\hline 6 & 10 & 445 & 0.8 & 90.03 & 0.61 & 0.55 & 0.006 & 0.005 & 86.08 \\
\hline 7 & 10 & 470 & 0.8 & 89.75 & 0.71 & 0.64 & 0.243 & 0.218 & 76.16 \\
\hline 8 & 10 & 495 & 0.8 & 90.88 & 0.68 & 0.62 & 0.291 & 0.264 & 72.32 \\
\hline 9 & 16 & 420 & 0.5 & 88.07 & 0.51 & 0.45 & 0.047 & 0.041 & 83.01 \\
\hline 10 & 16 & 445 & 0.5 & 91.13 & 0.36 & 0.33 & 0.068 & 0.062 & 79.66 \\
\hline 11 & 16 & 470 & 0.5 & 87.29 & 0.42 & 0.36 & 0.125 & 0.109 & 85.50 \\
\hline 12 & 16 & 495 & 0.5 & 91.28 & 0.20 & 0.19 & 0.09 & 0.082 & 69.18 \\
\hline 13 & 16 & 420 & 0.8 & 89.44 & 0.42 & 0.37 & 0.019 & 0.017 & 85.75 \\
\hline 14 & 16 & 445 & 0.8 & 90.59 & 0.27 & 0.24 & 0.021 & 0.019 & 84.55 \\
\hline 15 & 16 & 470 & 0.8 & 90.53 & 0.16 & 0.14 & 0.017 & 0.016 & 87.35 \\
\hline 16 & 16 & 495 & 0.8 & 88.44 & 0.13 & 0.12 & 0.016 & 0.014 & 84.82 \\
\hline 17 & 20 & 420 & 0.5 & 89.22 & 1.72 & 1.54 & 0.28 & 0.247 & 83.45 \\
\hline 18 & 20 & 445 & 0.5 & 89.98 & 0.34 & 0.31 & 0.023 & 0.021 & 77.57 \\
\hline 19 & 20 & 470 & 0.5 & 90.14 & 0.41 & 0.37 & 0.041 & 0.037 & 79.49 \\
\hline 20 & 20 & 495 & 0.5 & 90.85 & 0.54 & 0.49 & 0.074 & 0.067 & 76.40 \\
\hline 21 & 20 & 420 & 0.8 & 88.80 & 0.64 & 0.57 & 0.433 & 0.384 & 82.09 \\
\hline 22 & 20 & 445 & 0.8 & 91.02 & 0.24 & 0.21 & 0.01 & 0.009 & 87.59 \\
\hline 23 & 20 & 470 & 0.8 & 89.11 & 0.88 & 0.78 & 0.189 & 0.169 & 76.44 \\
\hline 24 & 20 & 495 & 0.8 & 88.55 & 0.20 & 0.17 & 0.032 & 0.028 & 85.52 \\
\hline
\end{tabular}




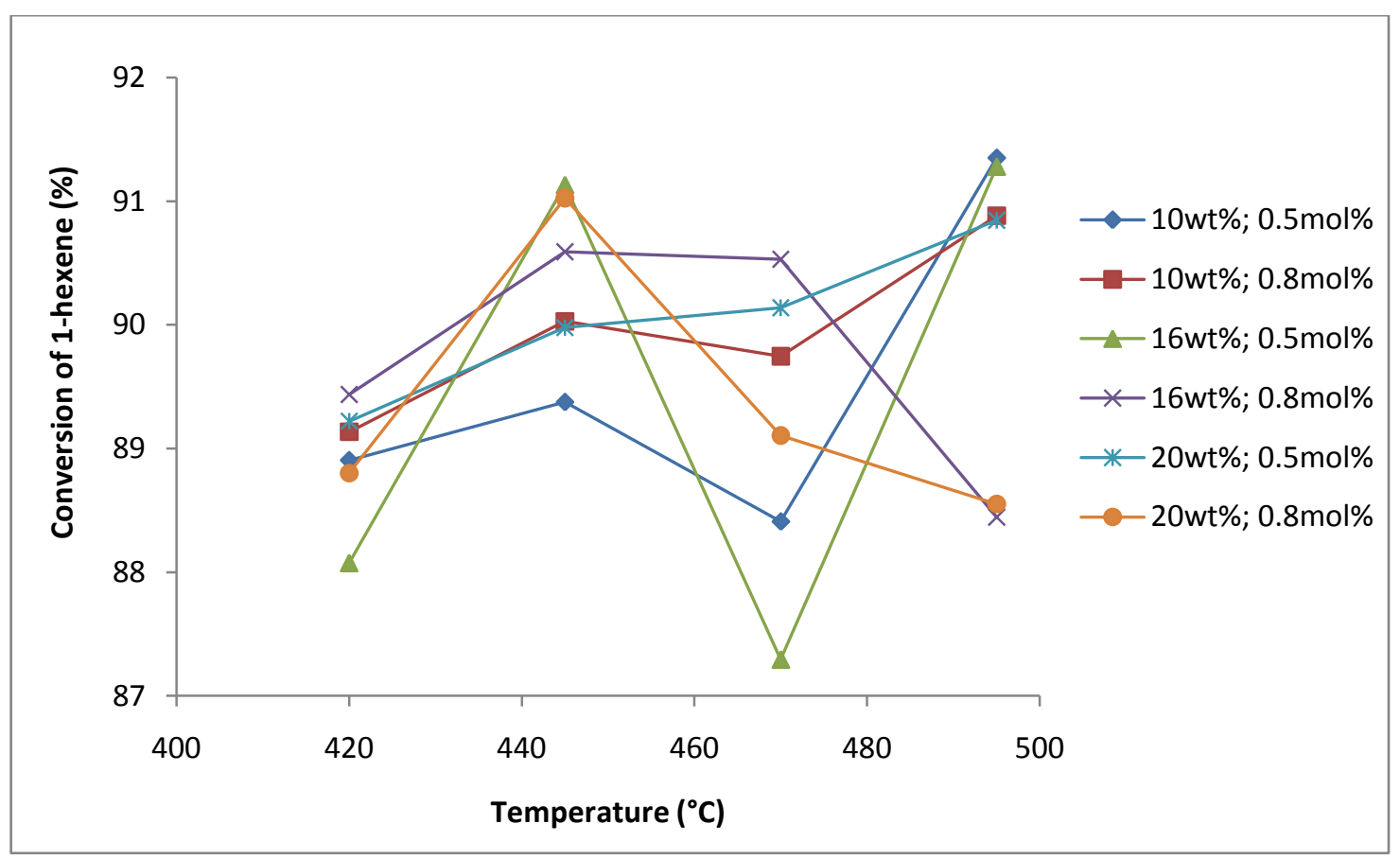

Figure 6.5: Conversion of 1-hexene vs. reaction temperature at different specific loadings of $\mathrm{WO}_{3}$ and 1-hexene feed compositions $\left(\mathrm{WO}_{3} / \mathrm{Al}_{2} \mathrm{O}_{3}\right.$ catalyst)

The conversion of 1-hexene (Figure 6.5) was found to be high for all experimental runs with the range being between $87-91 \%$. This indicates high activity of the catalyst, however analysis of the selectivity of the catalyst towards the primary metathesis product and the detergent range olefins is low (Table 6.1). This is due to the alumina support behaving more as an isomerization catalyst than as a support in the metathesis reaction. Thus the high conversion is due to the activity of the catalyst towards the isomerization reactions and not the desired metathesis reaction.

The main aim was to optimize the yields of the primary metathesis product, decene as well as the detergent range products $\left(\mathrm{C}_{10}-\mathrm{C}_{16}\right)$. All results produced indicated low yields of both the detergent range olefins as well as the yield of decene (Figure 6.2 and Figure 6.3). The yields obtained for decene were far below $1 \%$ and the highest yield of the detergent range olefins was $1.54 \%$ using a $20 \mathrm{wt} \%$ catalyst with $50 \mathrm{~mol} \% 1$-hexene in the feed at the reaction temperatures of $420^{\circ} \mathrm{C}$. The highest yield for decene was obtained using the $10 \mathrm{wt} \%$ catalyst with $50 \mathrm{~mol} \% 1$ hexene in the feed at the higher reaction temperature $495^{\circ} \mathrm{C}$. 
A sample of the liquid product from an experimental run using the $\mathrm{WO}_{3} / \mathrm{Al}_{2} \mathrm{O}_{3}$ catalyst was injected into the GCMS for analysis. It can be noted from the GCMS results (Table 6.2) that many isomers of 1-hexene are present in the liquid product sample indicating many undesired isomerization reactions taking place. The components from Table 6.2 considered to be isomerized hexenes include all the components with six carbon numbers. Although the hexadienes are included, they are present in very small quantities according to the GCMS trace.

Table 6.2: List of components present in the liquid product identified by the GCMS ( $\mathrm{WO}_{3} / \mathrm{Al}_{2} \mathrm{O}_{3}$ catalyst)

\begin{tabular}{|c|c|}
\hline Component & Carbon number \\
\hline 2-methyl-1-propene & 4 \\
\hline 2-methyl-2-butene & 5 \\
\hline 2-methy-1-butene & 5 \\
\hline 3-methyl-1-pentene & 6 \\
\hline 3-methyl-2-pentene & 6 \\
\hline 3-hexene & 6 \\
\hline 2-hexene & 6 \\
\hline 1-hexene & 6 \\
\hline 2,3 dimethyl butene & 6 \\
\hline 3-methyl 1,3 pentadiene & 6 \\
\hline 1,4 hexadiene & 6 \\
\hline 2,4 hexadiene & 6 \\
\hline 4-methyl 2- hexene & 7 \\
\hline 3,4 dimethyl 2-pentene & 7 \\
\hline 3- ethyl 2-pentene & 7 \\
\hline 2-heptene & 7 \\
\hline 2-methyl 2,4 hexadiene & 7 \\
\hline 3-methyl 2-hexene & 7 \\
\hline 2-octene & 8 \\
\hline 4-octene & 8 \\
\hline 2,3 dimethyl 3-hexene & 8 \\
\hline 4-nonene & 9 \\
\hline 2-nonene & 9 \\
\hline 5-decene & 10 \\
\hline 4-decene (cis) & 10 \\
\hline 2-decene & 10 \\
\hline trans-3-decene & 10 \\
\hline 3-undecene & 11 \\
\hline
\end{tabular}


Figure 6.6 gives a measure of the isomerization of 1-hexene. It can be seen that the amount of isomerization is extremely high for all runs using the $\mathrm{WO}_{3} / \mathrm{Al}_{2} \mathrm{O}_{3}$ catalyst. Thus the isomerization of 1-hexene is believed to account for the high conversion of the 1-hexene observed in Figure 6.5.

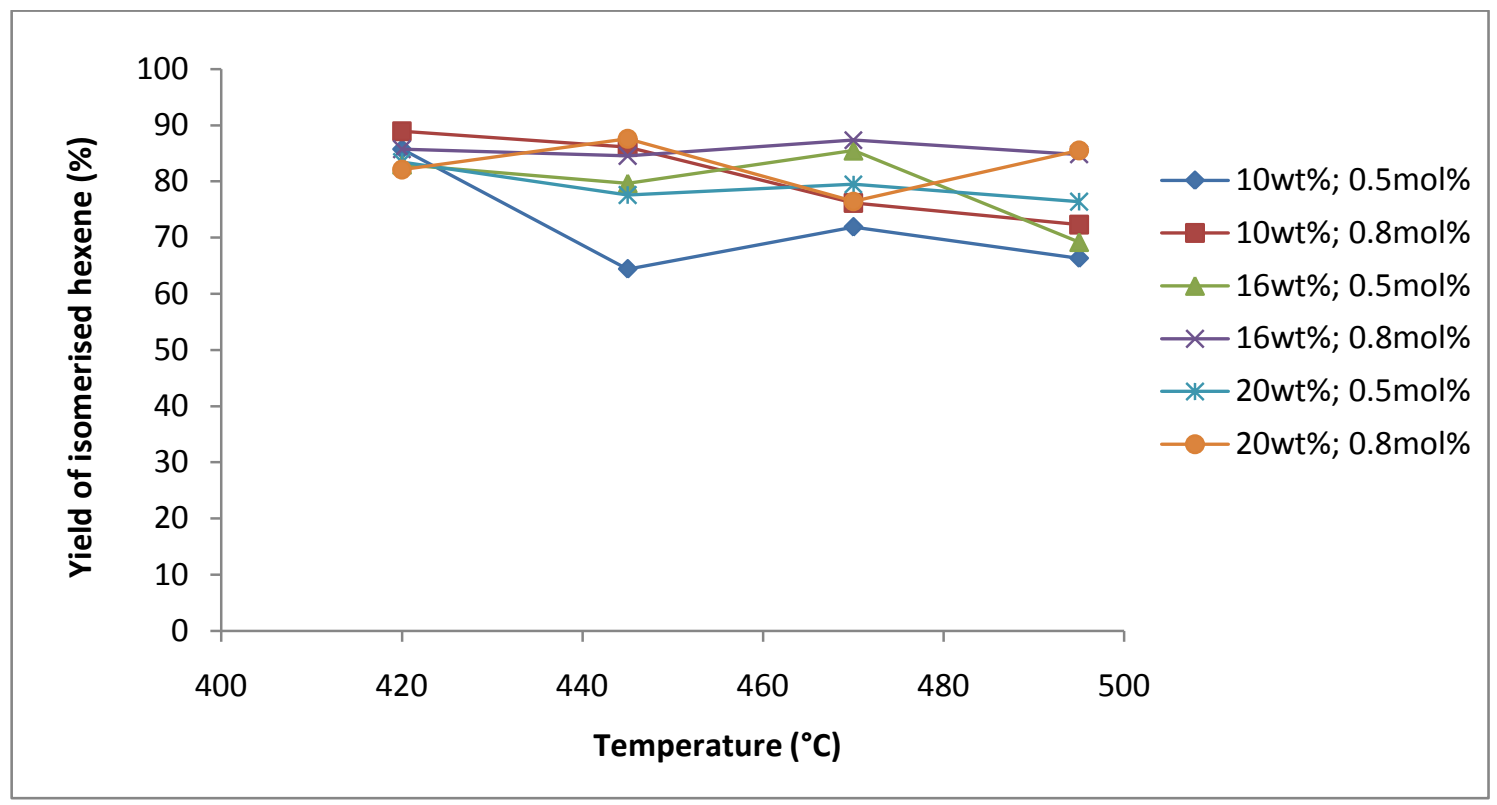

Figure 6.6: Yield of isomerized hexene vs. reaction temperature at different loadings and hexene compositions $\left(\mathrm{WO}_{3} / \mathrm{Al}_{2} \mathrm{O}_{3}\right.$ catalyst $)$

The yields of decene and the detergent range discussed is the portion of the metathesis product distribution that was of interest to the study. Cracking of the 1-hexene into lighter olefins also occurred as evidenced by the presence of these lighter olefins in the gas chromatograms (Appendix E). The yields of the $\mathrm{C}_{2}$ to $\mathrm{C}_{9}$ olefins are given in Table 6.3.

The BET surface area for each specific loading of tungsten trioxide is given in Table 6.4. The results given are the averages of 11 BET surface area analysis tests conducted for each loading of tungsten trioxide at the School of Pure and Applied Chemistry. A decrease in surface area is observed with an increase in specific loading as expected. The surface area for the $16 \mathrm{wt} \%$ loading, however, was found to be lower than that for the $20 \mathrm{wt} \%$ loading. This could possibly be due to the addition of too much acid to the $16 \mathrm{wt} \% \mathrm{WO}_{3} / \mathrm{Al}_{2} \mathrm{O}_{3}$ catalyst resulting in a further reduction of the surface area. 
Table 6.3: Yield of $\mathrm{C}_{2}$ to $\mathrm{C}_{9}$ olefins $\left(\mathrm{WO}_{3} / \mathrm{Al}_{2} \mathrm{O}_{3}\right.$ catalyst)

\begin{tabular}{|c|c|c|c|c|c|c|c|}
\hline \multicolumn{7}{|c|}{ Yield } \\
\hline & C2 & C3 & C4 & C5 & C7 & C8 & C9 \\
\hline Run 1 & 0.59 & 1.64 & 2.68 & 2.30 & 0.96 & 0.28 & 0.17 \\
\hline Run 2 & 1.24 & 1.70 & 2.38 & 1.81 & 0.73 & 0.10 & 0.08 \\
\hline Run 3 & 4.69 & 5.73 & 8.56 & 4.17 & 1.40 & 0.29 & 0.61 \\
\hline Run 4 & 8.30 & 7.39 & 8.61 & 4.24 & 1.41 & 0.15 & 0.71 \\
\hline Run 5 & 0.30 & 0.31 & 0.50 & 0.72 & 0.51 & 0.23 & 0.11 \\
\hline Run 6 & 0.47 & 0.70 & 0.95 & 1.12 & 0.85 & 0.33 & 0.09 \\
\hline Run 7 & 3.29 & 3.01 & 3.92 & 3.23 & 1.55 & 0.84 & 0.41 \\
\hline Run 8 & 9.00 & 6.64 & 6.52 & 3.63 & 1.59 & 0.78 & 0.46 \\
\hline Run 9 & 0.32 & 1.04 & 0.89 & 1.13 & 0.86 & 0.46 & 0.14 \\
\hline Run 10 & 0.57 & 0.96 & 0.94 & 1.14 & 1.02 & 0.48 & 0.19 \\
\hline Run 11 & 2.96 & 5.66 & 4.29 & 2.72 & 1.36 & 0.29 & 0.25 \\
\hline Run 12 & 2.53 & 2.53 & 2.53 & 2.01 & 1.72 & 0.42 & 0.18 \\
\hline Run 13 & 0.12 & 0.24 & 0.25 & 0.50 & 0.57 & 0.27 & 0.10 \\
\hline Run 14 & 0.35 & 0.65 & 0.48 & 0.77 & 0.69 & 0.26 & 0.15 \\
\hline Run 15 & 0.84 & 0.71 & 0.53 & 0.58 & 0.96 & 0.05 & 0.03 \\
\hline Run 16 & 2.77 & 2.52 & 1.76 & 0.99 & 1.59 & 0.16 & 0.07 \\
\hline Run 17 & 0.17 & 0.68 & 0.61 & 0.91 & 0.66 & 0.28 & 0.02 \\
\hline Run 18 & 0.33 & 0.78 & 0.80 & 1.14 & 1.20 & 0.55 & 0.21 \\
\hline Run 19 & 1.36 & 2.24 & 1.91 & 1.64 & 1.08 & 0.25 & 0.12 \\
\hline Run 20 & 3.99 & 4.30 & 3.21 & 1.99 & 1.60 & 0.43 & 0.20 \\
\hline Run 21 & 0.27 & 1.59 & 1.85 & 2.53 & 1.64 & 0.28 & 0.63 \\
\hline Run 22 & 0.17 & 0.12 & 0.10 & 0.10 & 0.39 & 0.04 & 0.02 \\
\hline Run 23 & 1.16 & 3.64 & 2.75 & 3.21 & 1.99 & 0.94 & 0.39 \\
\hline Run 24 & 1.35 & 1.41 & 1.07 & 0.73 & 1.15 & 0.14 & 0.03 \\
\hline
\end{tabular}

From analysis of the results obtained, it is clear that every possible change made to the catalyst preparation method was unsuccessful in producing a high performance metathesis catalyst. The $\mathrm{WO}_{3} / \mathrm{Al}_{2} \mathrm{O}_{3}$ catalyst behaved as an isomerization catalyst rather than a catalyst for the metathesis reaction. It is believed that the inferior performance of the $\mathrm{WO}_{3} / \mathrm{Al}_{2} \mathrm{O}_{3}$ catalyst can be explained by the findings of Rodríguez-Ramos et al. (1995). They studied the metathesis of propene over alumina supported tungsten and molybdenum oxide catalysts. They found that 
there is a high degree of interaction between the $\mathrm{WO}_{3}$ and alumina which results in catalytic active sites being produced that are specific for isomerisation and cracking reactions and not for metathesis. The number of catalytic active sites for the metathesis reaction itself is low and is found on the surface of the catalyst. The metathesis activity has a direct impact on the yield of higher olefins. It was also found that at higher loadings of $\mathrm{WO}_{3}(15 \mathrm{wt} \%)$ on alumina, the formation of octahedral polymeric tungstate structures occur. These structures trap $\mathrm{H}_{2} \mathrm{O}$ and form stable hydroxyl groups which block the active sites for the metathesis reactions. The hydroxyl groups promote the polymerization, isomerisation and cracking reactions which are typically catalysed by acid sites. As part of this study, the OH groups on the 10, 16 and $20 \mathrm{wt} \%$ $\mathrm{WO}_{3} / \mathrm{Al}_{2} \mathrm{O}_{3}$ catalysts were examined using FTIR spectroscopy. The resultant spectra (Appendix C, Figures C.1 to C.3) indicate strong bands present between 3400 and $3500 \mathrm{~cm}^{-1}$ for all three loadings. As discussed in Section 2.12.2, the $3400-3800 \mathrm{~cm}^{-1}$ IR bands represent the OH groups of alumina, with the bands of the lowest frequency belonging to the acidic group. Thus, the bands found on the $\mathrm{WO}_{3} / \mathrm{Al}_{2} \mathrm{O}_{3}$ catalysts are believed to be due to the presence of the strong acidic $\mathrm{OH}$ groups on the surface on the catalyst. It is known that alumina is used as a catalyst in isomerization reactions due to its acidic nature. The presence of the strong acidic $\mathrm{OH}$ groups on the $\mathrm{WO}_{3} / \mathrm{Al}_{2} \mathrm{O}_{3}$ catalyst surface is possibly the reason why the catalyst is still performing as an isomerization catalyst rather than one for the metathesis reaction.

Another theory to the inferior performance of the $\mathrm{WO}_{3} / \mathrm{Al}_{2} \mathrm{O}_{3}$ catalyst is that the metathesis sites are selectively deactivated by coke deposition, but sites for parallel reactions such as cracking and isomerisation remain unchanged (Rodríguez-Ramos et al, 1995 and Schalkwyk et al, 2003). However, there is very little support for this theory. Due to the inferior catalyst performance the investigation of other possible, better performing metathesis catalysts was pursued.

Table 6.4: BET surface area for $\mathrm{WO}_{3} / \mathrm{Al}_{2} \mathrm{O}_{3}$ at varying specific loadings of $\mathrm{WO}_{3}$

\begin{tabular}{|c|c|}
\hline Sample & BET surface area $\left(\mathbf{m}^{2} / \mathbf{g}\right)$ \\
\hline $10 \mathrm{wt} \% \mathrm{WO}_{3} / \mathrm{Al}_{2} \mathrm{O}_{3}$ & 230 \\
\hline $16 \mathrm{wt} \% \mathrm{WO}_{3} / \mathrm{Al}_{2} \mathrm{O}_{3}$ & 208 \\
\hline $20 \mathrm{wt} \% \mathrm{WO}_{3} / \mathrm{Al}_{2} \mathrm{O}_{3}$ & 215 \\
\hline
\end{tabular}

\subsection{The $\mathrm{WO}_{3} / \mathrm{SiO}_{2}$ catalyst and $\mathrm{K}$ doped $\mathrm{WO}_{3} / \mathrm{SiO}_{2}$ catalyst : experimental results and discussion}


The choice of silica as the support for investigation was based on its less acidic nature and the investigation of the doping of the catalyst was based on its ability to reduce the number of acid sites even further. The $2^{3-1}$ half factorial design as discussed in Section 3.2 was used to determine the optimum operating conditions for the $\mathrm{WO}_{3} / \mathrm{SiO}_{2}$ catalyst, in terms of the reaction temperature, feed composition of 1-hexene as well as the reactor space time, after which the area in which to focus for the investigation of the potassium doped $\mathrm{WO}_{3} / \mathrm{SiO}_{2}$ catalyst would be found. Randomised experimental runs in replicates of two were conducted and included the centre point as illustrated in the design cube (Figure 3.2).

A specific loading of $8 \mathrm{wt} \% \mathrm{WO}_{3}$ over silica was chosen for the study. The justification for this choice was based on a previous study by Spamer et al. (2003) as reviewed in Section 2.9.1. According to the research, at lower loadings, below $6 \mathrm{wt} \% \mathrm{WO}_{3}$, the selectivity to linear metathesis products was much higher (up to $8 \%$ higher) than for higher loadings. However, the catalyst deactivated much faster with time and the conversion was lower than for the higher loadings (Spamer, 2003). Thus, there is a trade off between the selectivity of the metathesis products achievable and the time taken until deactivation begins. Spamer's data showed no signs of catalyst deactivation at the $8 \mathrm{wt} \%$ loading as the conversion remained constant throughout. The maximum conversion achievable was also reached at the $8 \mathrm{wt} \%$ loading. Since the deactivation of the catalyst is an important factor to consider over and above the maximum selectivity achievable, the loading of $8 \mathrm{wt} \% \mathrm{WO}_{3}$ was used.

The results obtained for the $8 \mathrm{wt} \% \mathrm{WO}_{3} / \mathrm{SiO}_{2}$ catalyst are given in Table 6.5 and Figure 6.7 to Figure 6.10. These are based on the assessment criteria as discussed previously in Section 6.1. The yields of decene and the detergent range discussed is the portion of the metathesis product distribution that was of interest to the study. As with the $\mathrm{WO}_{3} / \mathrm{Al}_{2} \mathrm{O}_{3}$ catalyst, cracking of the 1hexene into lighter olefins also occurred. The yields of the $\mathrm{C}_{2}$ to $\mathrm{C}_{9}$ olefins are given in Table 6.6 .

Table 6.5 provides the average values of the results of the experimental runs conducted while the figures show the results from the two replicates conducted at each set of conditions. A visual comparison of the replicates at each set of conditions for the yield of the detergent range olefins and the yield of decene show little variability between the two replicates. The calculated variance between the two replicates for each experimental run confirms the little variability (Table 6.5). 
Table 6.5 : Experimental runs and results for the $\mathrm{WO}_{3} / \mathrm{SiO}_{2}$ catalyst

\begin{tabular}{|c|c|c|c|c|c|}
\hline & \multicolumn{5}{|c|}{ Run } \\
\hline & 1 & 2 & 3 & 4 & 5 \\
\hline Temperature $\left({ }^{\circ} \mathrm{C}\right)$ & 420 & 460 & 420 & 460 & 440 \\
\hline $\begin{array}{l}\text { Feed gas composition } \\
\text { (mol \% 1-hexene) }\end{array}$ & 60 & 80 & 80 & 60 & 70 \\
\hline $\begin{array}{l}\text { Reactor space time } \\
\left(\text { g.min.mol }{ }^{-1}\right)\end{array}$ & 200 & 200 & 400 & 400 & 300 \\
\hline $\begin{array}{l}\text { Conversion of 1-hexene } \\
\text { (average \%) }\end{array}$ & 64.02 & 88.59 & 74.38 & 82.73 & 79.65 \\
\hline $\begin{array}{l}\text { Yield } \mathrm{C}_{10}-\mathrm{C}_{16} \text { olefins } \\
\text { (average \%) }\end{array}$ & 0.85 & 6.42 & 3.51 & 8.30 & 5.09 \\
\hline $\begin{array}{l}\text { Variance for yield } \mathrm{C}_{10}-\mathrm{C}_{16} \\
\text { olefins }\end{array}$ & 0.0017 & 0.4778 & 0.4719 & 0.0595 & 0.0098 \\
\hline $\begin{array}{l}\text { Selectivity of } \mathrm{C}_{10}-\mathrm{C}_{16} \text { olefins } \\
\text { (average \%) }\end{array}$ & 1.33 & 7.24 & 4.70 & 10.04 & 6.40 \\
\hline $\begin{array}{l}\text { Yield of decene (average } \\
\% \text { ) }\end{array}$ & 0.76 & 4.32 & 2.67 & 5.92 & 4.00 \\
\hline $\begin{array}{l}\text { Variance for yield of } \\
\text { decene }\end{array}$ & 0.0007 & 0.0973 & 0.2446 & 0.4431 & 0.0051 \\
\hline $\begin{array}{l}\text { Selectivity of decene } \\
\text { (average \%) }\end{array}$ & 1.19 & 4.89 & 3.57 & 7.18 & 5.02 \\
\hline $\begin{array}{l}\text { Yield of isomerized hexenes } \\
(\%)\end{array}$ & 54.03 & 25.95 & 37.27 & 13.61 & 34.38 \\
\hline
\end{tabular}

Analysis of the results obtained indicates high conversions of 1-hexene for all runs of between 64 and $88 \%$ (Figure 6.7). It is evident from the results of conversion and yields of decene and the detergent range, that the reaction temperature is an important factor. The higher reaction temperature of $460^{\circ} \mathrm{C}$ provided improved results for both yields. This finding is in line with that of Mol and Leeuwen (2008) who also found the optimum reaction temperature to be $460^{\circ} \mathrm{C}$ when using an $8 \mathrm{wt} \% \mathrm{WO}_{3} / \mathrm{SiO}_{2}$ catalyst. The highest yields and selectivities of the detergent range olefins as well as decene were obtained at the reaction conditions of $460^{\circ} \mathrm{C}, 60 \mathrm{~mol} \% 1$ hexene in the feed and 400 g.min.mol ${ }^{-1}$. This was a conversion of $82 \%$ of 1 -hexene, a yield of detergent range olefins at $8.3 \%$ and a yield of decene at $5.92 \%$. 
Table 6.6: Yield of $\mathrm{C}_{2}$ to $\mathrm{C}_{9}$ olefins $\left(\mathrm{WO}_{3} / \mathrm{SiO}_{2}\right.$ catalyst)

\begin{tabular}{|l|c|c|c|c|c|c|c|}
\hline & C2 & C3 & C4 & C5 & C7 & C8 & C9 \\
\hline Run 1 & 0.44 & 0.49 & 0.51 & 1.22 & 1.30 & 0.64 & 0.68 \\
\hline Run 1-repeat & 0.24 & 0.28 & 0.34 & 1.05 & 1.11 & 0.61 & 0.66 \\
\hline Run 2 & 3.71 & 7.62 & 7.24 & 11.96 & 9.92 & 6.25 & 5.46 \\
\hline Run 2-repeat & 3.00 & 8.84 & 9.50 & 13.27 & 12.35 & 8.21 & 6.51 \\
\hline Run 3 & 1.93 & 4.48 & 4.89 & 7.20 & 6.20 & 3.74 & 2.99 \\
\hline Run 3-repeat & 0.00 & 0.01 & 3.22 & 7.80 & 8.10 & 4.89 & 4.16 \\
\hline Run 4 & 3.49 & 5.31 & 6.23 & 9.06 & 7.90 & 4.98 & 4.48 \\
\hline Run 4-repeat & 2.38 & 7.22 & 9.72 & 12.49 & 11.14 & 7.66 & 5.66 \\
\hline Run 5 & 2.01 & 3.03 & 3.57 & 7.28 & 7.42 & 4.37 & 4.09 \\
\hline Run 5-repeat & 7.57 & 11.40 & 8.01 & 9.96 & 7.71 & 4.50 & 4.20 \\
\hline
\end{tabular}

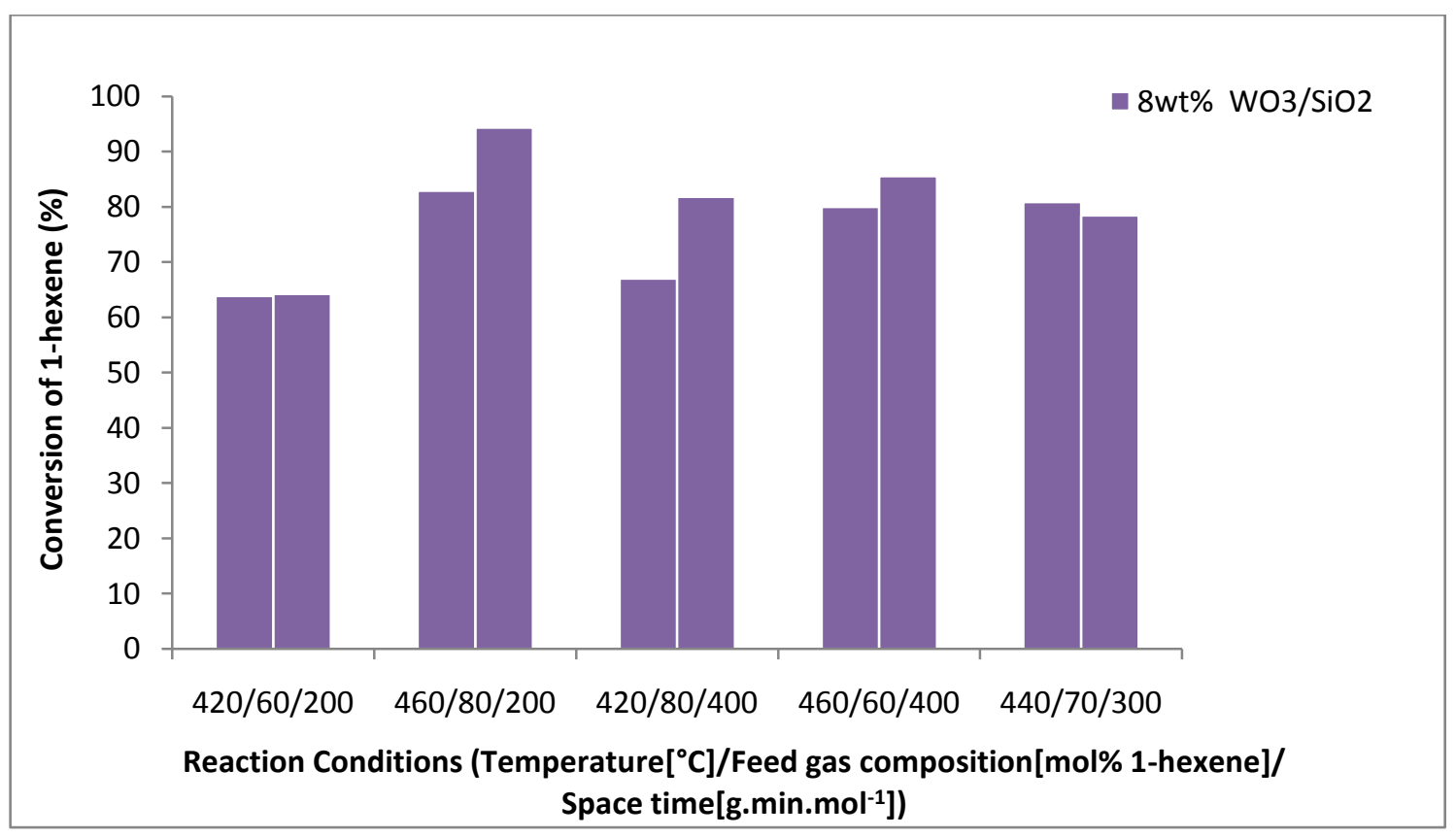


Figure 6.7: Conversion of 1-hexene vs. reaction conditions $\left(\mathrm{WO}_{3} / \mathrm{SiO}_{2}\right.$ catalyst, replicates shown for each reaction condition)

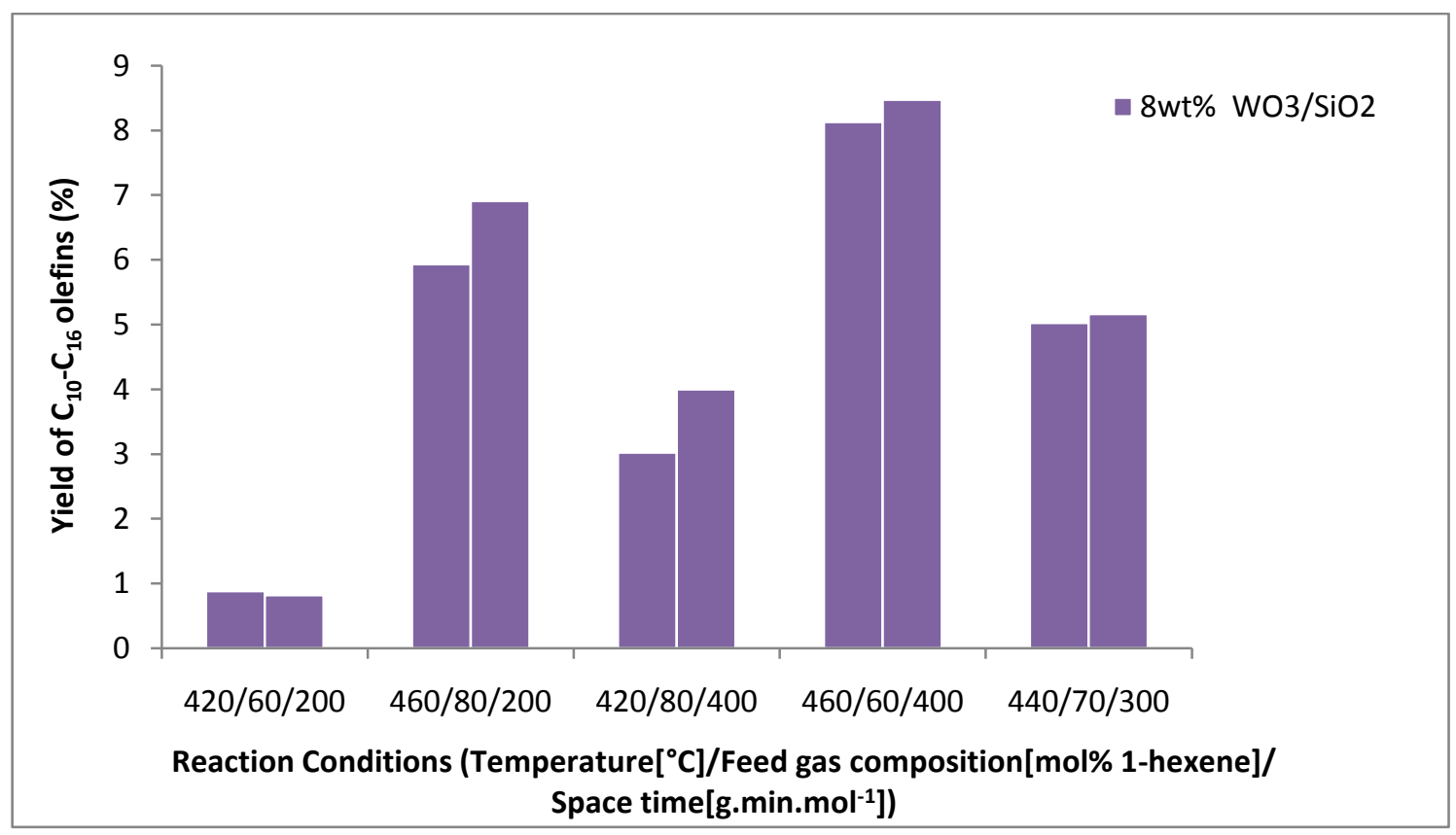

Figure 6.8: Yield of detergent range olefins vs. reaction conditions $\left(\mathrm{WO}_{3} / \mathrm{SiO}_{2}\right.$ catalyst, replicates shown for each reaction condition)

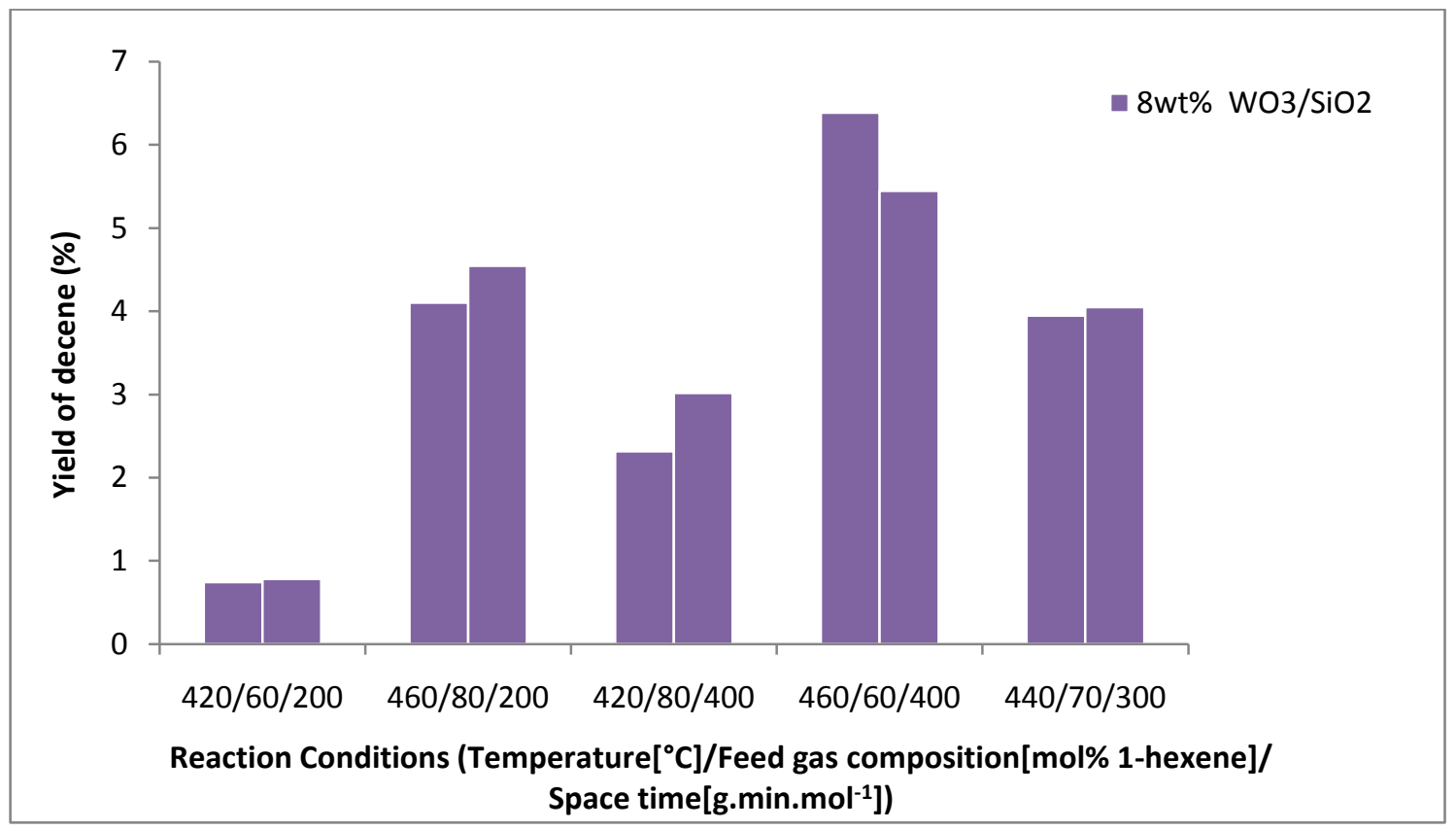

Figure 6.9 : Yield of decene vs. reaction conditions $\left(\mathrm{WO}_{3} / \mathrm{SiO}_{2}\right.$ catalyst, replicates shown for each reaction condition) 


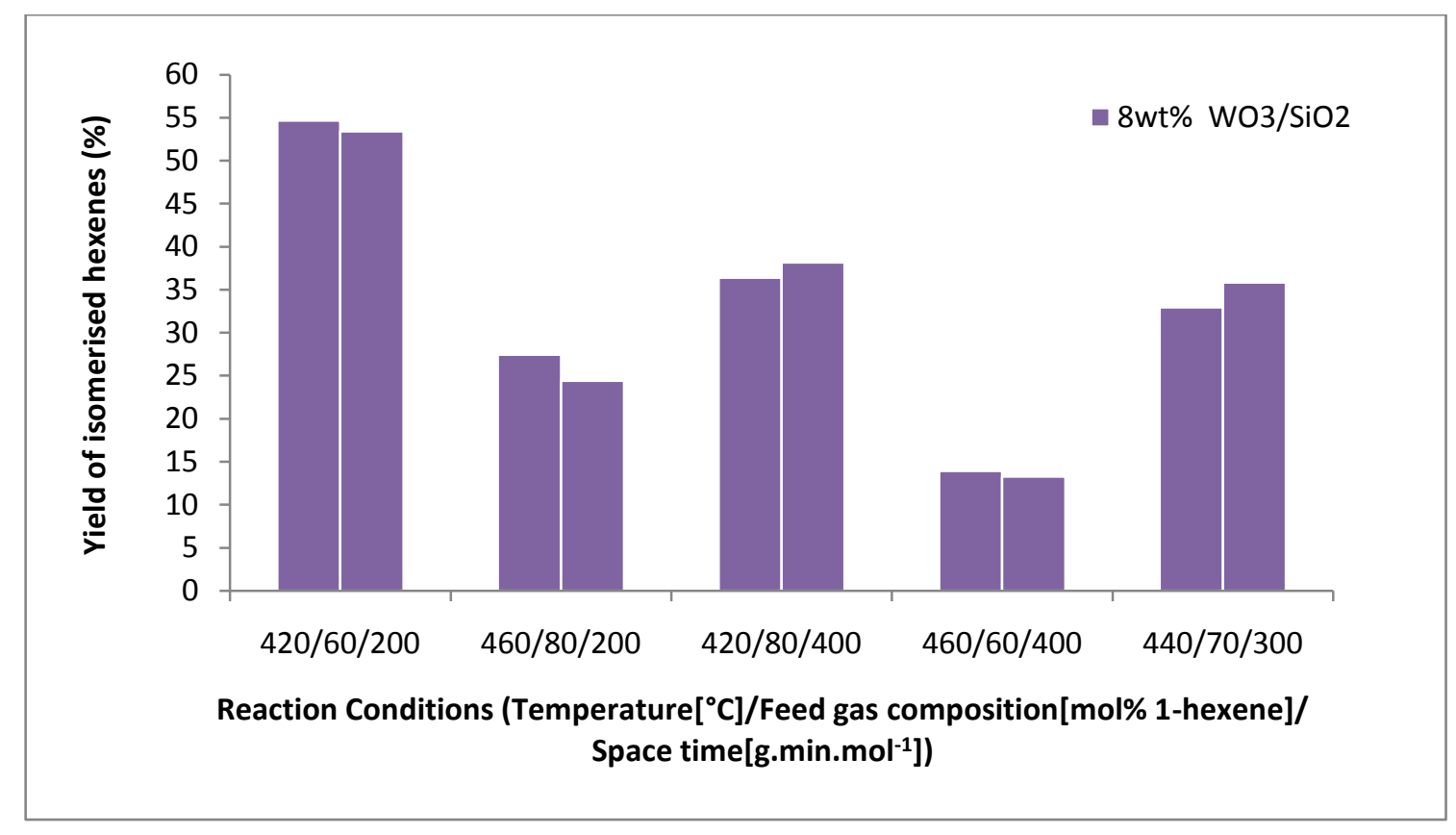

Figure 6.10: Yield of isomerized hexene vs. reaction conditions $\left(\mathrm{WO}_{3} / \mathrm{SiO}_{2}\right.$ catalyst, replicates shown for each reaction condition)

Figure 6.10 gives a measure of the isomerization of 1-hexene into isomers of hexene (e.g. 2hexene and 3-hexene). A higher yield value indicates more isomerization and cracking. At the reaction conditions of $460^{\circ} \mathrm{C}, 60 \mathrm{~mol} \%$ 1-hexene in the feed and $400 \mathrm{~g} \cdot \mathrm{min} \cdot \mathrm{mol}^{-1}$ mentioned above, the least amount of isomerization and cracking occurs indicating that it is necessary to reduce the amount of isomerization and cracking occurring in order to increase the yields and selectivity. This is achieved by doping the $8 \mathrm{wt} \% \mathrm{WO}_{3} / \mathrm{SiO}_{2}$ catalyst with alkali earth metal ions which in the case of this study was potassium. It is believed that the alkali-earth metal ions replace the hydrogen molecules of the silica support (Spamer, 2003) thereby reducing the isomerization activity.

Experimental runs for the investigation of doping were first conducted in the optimised region found when using the $8 \mathrm{wt} \% \mathrm{WO}_{3} / \mathrm{SiO}_{2}$ catalyst i.e. reaction conditions of $460^{\circ} \mathrm{C}, 60 \mathrm{~mol} \% 1$ hexene in the feed and a space time of 400 g.min.mol ${ }^{-1}$. The results are given in Figure 6.11 to Figure 6.14 where the replicates for each experimental run are shown. The yields of the $\mathrm{C}_{2}$ to $\mathrm{C}_{9}$ olefins are given in Table 6.8. 
Table 6.7: Experimental runs and results for the $\mathrm{K}$ doped $\mathrm{WO}_{3} / \mathrm{SiO}_{2}$ catalyst in the optimised $\mathrm{WO}_{3} / \mathrm{SiO}_{2}$ region

\begin{tabular}{|c|c|c|c|}
\hline & \multicolumn{3}{|c|}{ Run } \\
\hline & $\begin{array}{c}1 \\
(0.05 w t \% ~ K) \\
\end{array}$ & $\begin{array}{c}2 \\
(0.1 w t \% ~ K) \\
\end{array}$ & $\begin{array}{c}3 \\
(0.5 w t \% \mathrm{~K}) \\
\end{array}$ \\
\hline Temperature $\left({ }^{\circ} \mathrm{C}\right)$ & 460 & 460 & 460 \\
\hline $\begin{array}{l}\text { Feed gas composition } \\
\text { (mol \% 1-hexene) }\end{array}$ & 60 & 60 & 60 \\
\hline $\begin{array}{l}\text { Reactor space time } \\
\left(\text { g.min.mol }{ }^{-1}\right)\end{array}$ & 400 & 400 & 400 \\
\hline $\begin{array}{l}\text { Conversion of 1-hexene } \\
\text { (average \%) }\end{array}$ & 90.68 & 72.80 & 36.79 \\
\hline $\begin{array}{l}\text { Yield } \mathrm{C}_{10}-\mathrm{C}_{16} \text { olefins } \\
\text { (average } \% \text { ) }\end{array}$ & 6.17 & 9.88 & 9.10 \\
\hline $\begin{array}{l}\text { Variance for yield } \mathrm{C}_{10}-\mathrm{C}_{16} \\
\text { olefins }\end{array}$ & 2.077 & 1.532 & 2.358 \\
\hline $\begin{array}{l}\text { Selectivity of } \mathrm{C}_{10}-\mathrm{C}_{16} \text { olefins } \\
\text { (average \%) }\end{array}$ & 6.80 & 13.58 & 24.64 \\
\hline Yield of decene (average \%) & 4.41 & 7.90 & 8.72 \\
\hline Variance for yield of decene & 0.361 & 1.398 & 1.852 \\
\hline $\begin{array}{l}\text { Selectivity of decene } \\
\text { (average \%) }\end{array}$ & 4.87 & 10.87 & 23.62 \\
\hline $\begin{array}{l}\text { Yield of isomerized hexenes } \\
(\%)\end{array}$ & 26.89 & 11.62 & 9.97 \\
\hline
\end{tabular}

Table 6.8: Yield of $\mathrm{C}_{2}$ to $\mathrm{C}_{9}$ olefins in the optimised $\mathrm{WO}_{3} / \mathrm{SiO}_{2}$ region

\begin{tabular}{|c|c|c|c|c|c|c|c|}
\hline \multicolumn{8}{|c|}{ Yield } \\
\hline & $\mathrm{C} 2$ & $\mathrm{C} 3$ & $\mathrm{C} 4$ & C5 & C7 & C8 & C9 \\
\hline $8 \mathrm{wt} \% \mathrm{WO}_{3} / \mathrm{SiO}_{2}$ & 2.93 & 6.27 & 7.98 & 10.78 & 9.52 & 6.32 & 5.07 \\
\hline $0.05 \mathrm{wt} \% \mathrm{~K}$ doped $\mathrm{WO}_{3} / \mathrm{SiO}_{2}$ & 4.88 & 11.89 & 10.00 & 12.53 & 10.65 & 6.71 & 5.93 \\
\hline $\begin{array}{l}\mathrm{O.05wt}_{\text {(repeat) }} \mathrm{K} \mathrm{doped} \mathrm{WO}_{3} / \mathrm{SiO}_{2} \\
\text { (reat }\end{array}$ & 8.37 & 15.46 & 12.51 & 12.99 & 10.33 & 6.19 & 5.24 \\
\hline $0.1 \mathrm{wt} \% \mathrm{~K}$ doped $\mathrm{WO}_{3} / \mathrm{SiO}_{2}$ & 2.31 & 2.31 & 3.02 & 7.36 & 7.29 & 4.39 & 4.71 \\
\hline $\begin{array}{l}\text { 0.1wt\% K doped } \mathrm{WO}_{3} / \mathrm{SiO}_{2} \\
\text { (repeat) }\end{array}$ & 3.82 & 3.87 & 4.50 & 7.81 & 7.65 & 4.76 & 4.77 \\
\hline $0.5 \mathrm{wt} \% \mathrm{~K}$ doped $\mathrm{WO}_{3} / \mathrm{SiO}_{2}$ & 10.07 & 2.12 & 1.64 & 2.05 & 2.13 & 0.79 & 1.17 \\
\hline $\begin{array}{l}0.5 w t \% ~ \\
\text { (repeat) }\end{array}$ & 12.64 & 2.51 & 1.60 & 2.33 & 2.63 & 0.85 & 1.69 \\
\hline
\end{tabular}


Three loadings of potassium $(0.05,0.1$ and $0.5 \mathrm{wt} \% \mathrm{~K})$ were investigated by impregnation of the $8 \mathrm{wt} \% \mathrm{WO}_{3} / \mathrm{SiO}_{2}$ catalyst with a solution of potassium nitrate $\left(\mathrm{KNO}_{3}\right)$. Decomposition of the potassium nitrate during the calcination stage is believed to occur at approximately $400^{\circ} \mathrm{C}$ (Perrichon et al., 1988) resulting in the formation of $\mathrm{K}_{2} \mathrm{O}, \mathrm{NO}_{2}, \mathrm{NO}$ and $\mathrm{O}_{2}$ as proposed by Hüttinger and Minges (1986). The equation for the decomposition reaction is given as follows:

$$
2 \mathrm{KNO}_{3} \rightarrow \mathrm{K}_{2} \mathrm{O}+\mathrm{O}_{2}+\mathrm{NO}+\mathrm{NO}_{2}
$$

The $\mathrm{K}_{2} \mathrm{O}$ structure was one of the two structures identified by Millar et al. (1996) from the infrared spectra of the potassium doped silica catalyst. The other was $\mathrm{SiO}-\mathrm{K}^{+}$groups resulting from the replacement of the hydroxyl groups on silica with the potassium ions.

The conversion for the $0.5 \mathrm{wt} \%$ loading dropped the most to approximately $40 \%$ as compared to $83 \%$ for the $8 \mathrm{wt} \%$ catalyst with no doping. This seems to indicate the possibility that the Brønsted acid sites responsible for the isomerization reactions are poisoned first by the potassium and only as the loading of potassium increases does the Lewis acid sites become targeted. Thus, at higher loadings of potassium, the conversion drops significantly due to the poisoning of the Lewis acid sites, which are responsible for the initiation of the metathesis reaction.

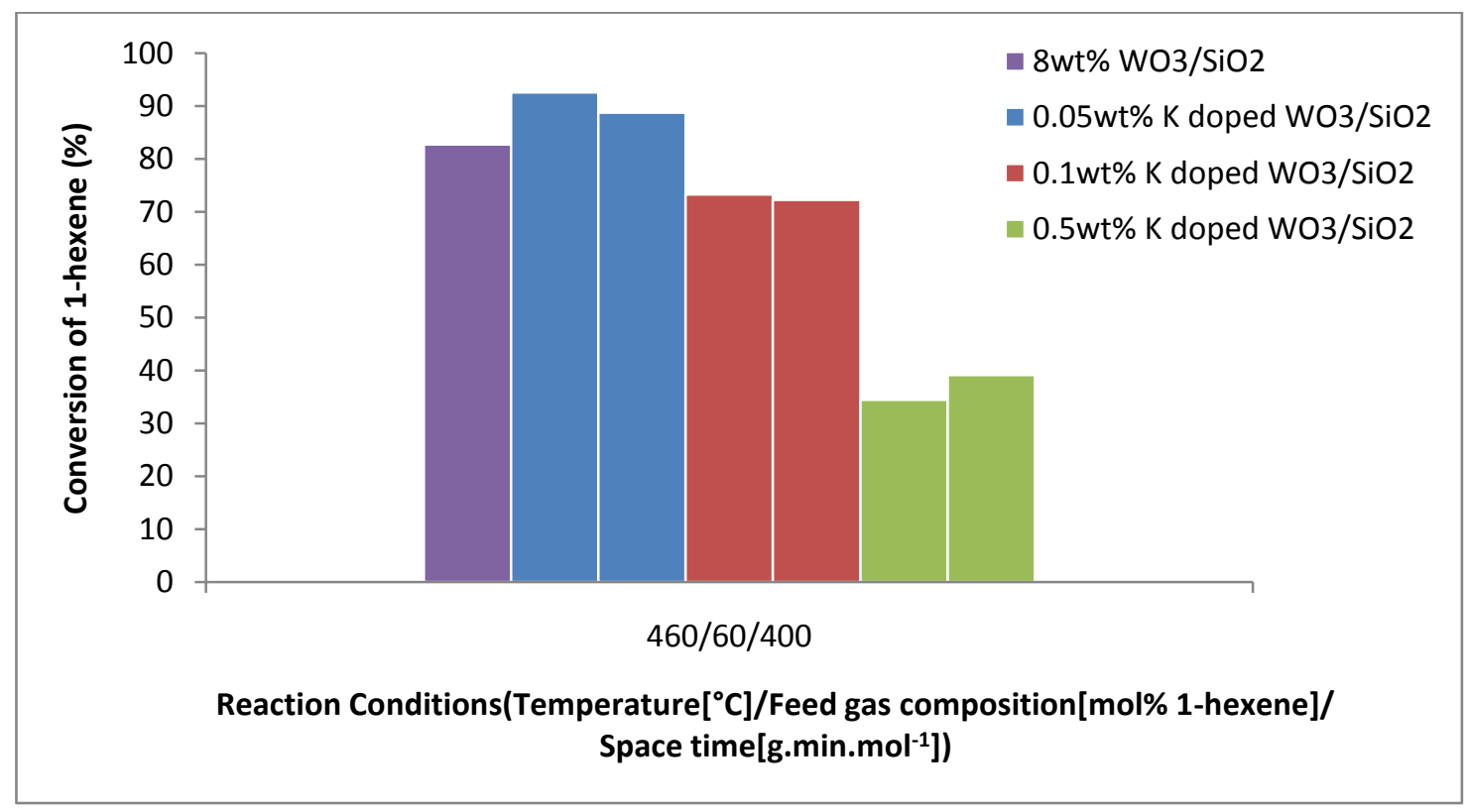

Figure 6.11: Conversion of 1-hexene vs. reaction conditions of $\mathrm{K}$ doped $\mathrm{WO}_{3} / \mathrm{SiO}_{2}$ in the optimised $\mathrm{WO}_{3} / \mathrm{SiO}_{2}$ region 
The yield of the detergent range olefins as well as the yield of the primary metathesis product, decene, showed an improvement for the 0.1 and $0.5 \mathrm{wt} \%$ loading of potassium, when compared to the catalyst with no doping, as expected (Figure 6.12 and Figure 6.13). An increase by approximately $2 \%$ for the yield of decene and $1.5 \%$ for the detergent range olefins was achieved.

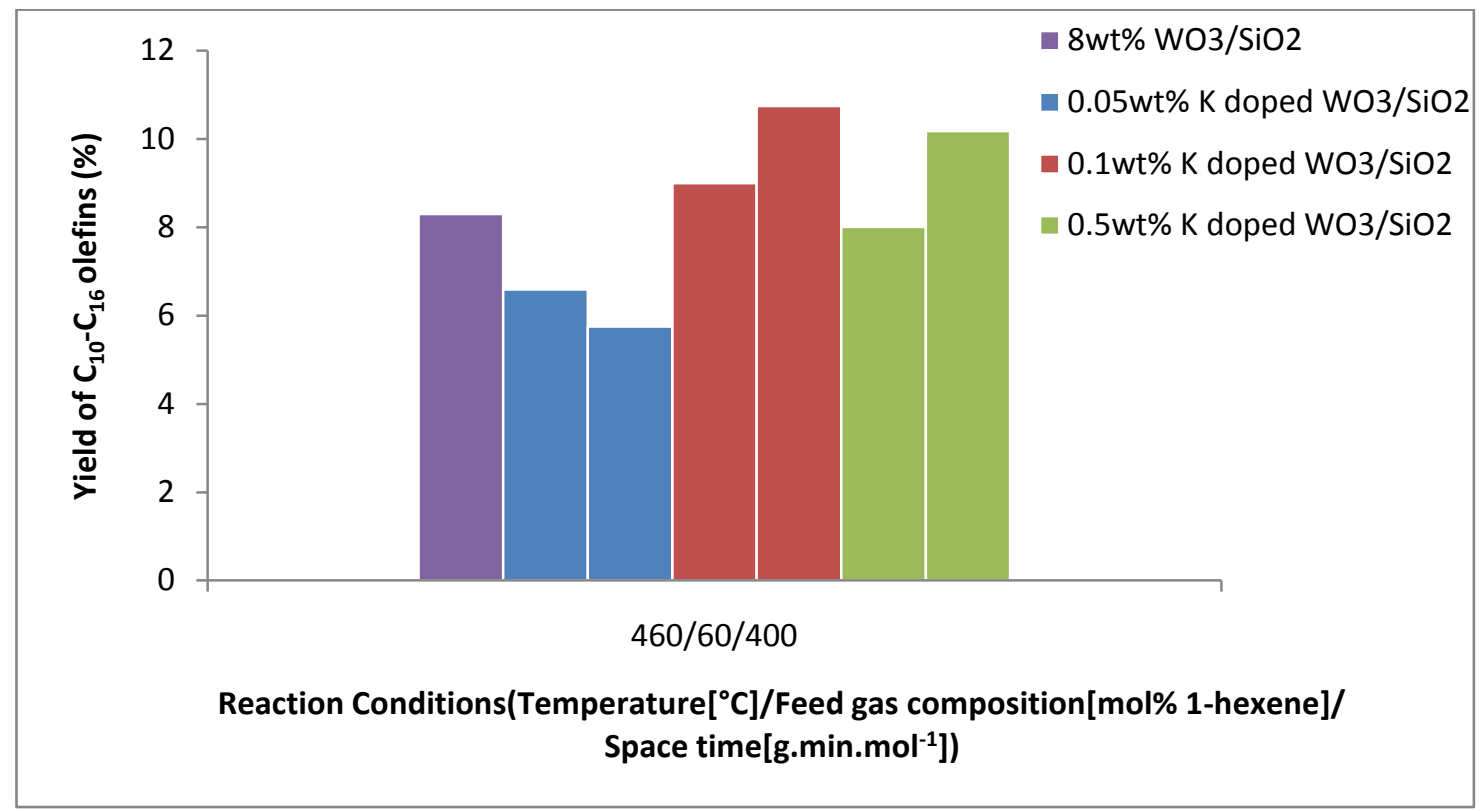

Figure 6.12 : Yield of detergent range olefins vs. reaction conditions of $\mathrm{K}$ doped $\mathrm{WO}_{3} / \mathrm{SiO}_{2}$ in the optimised $\mathrm{WO}_{3} / \mathrm{SiO}_{2}$ region

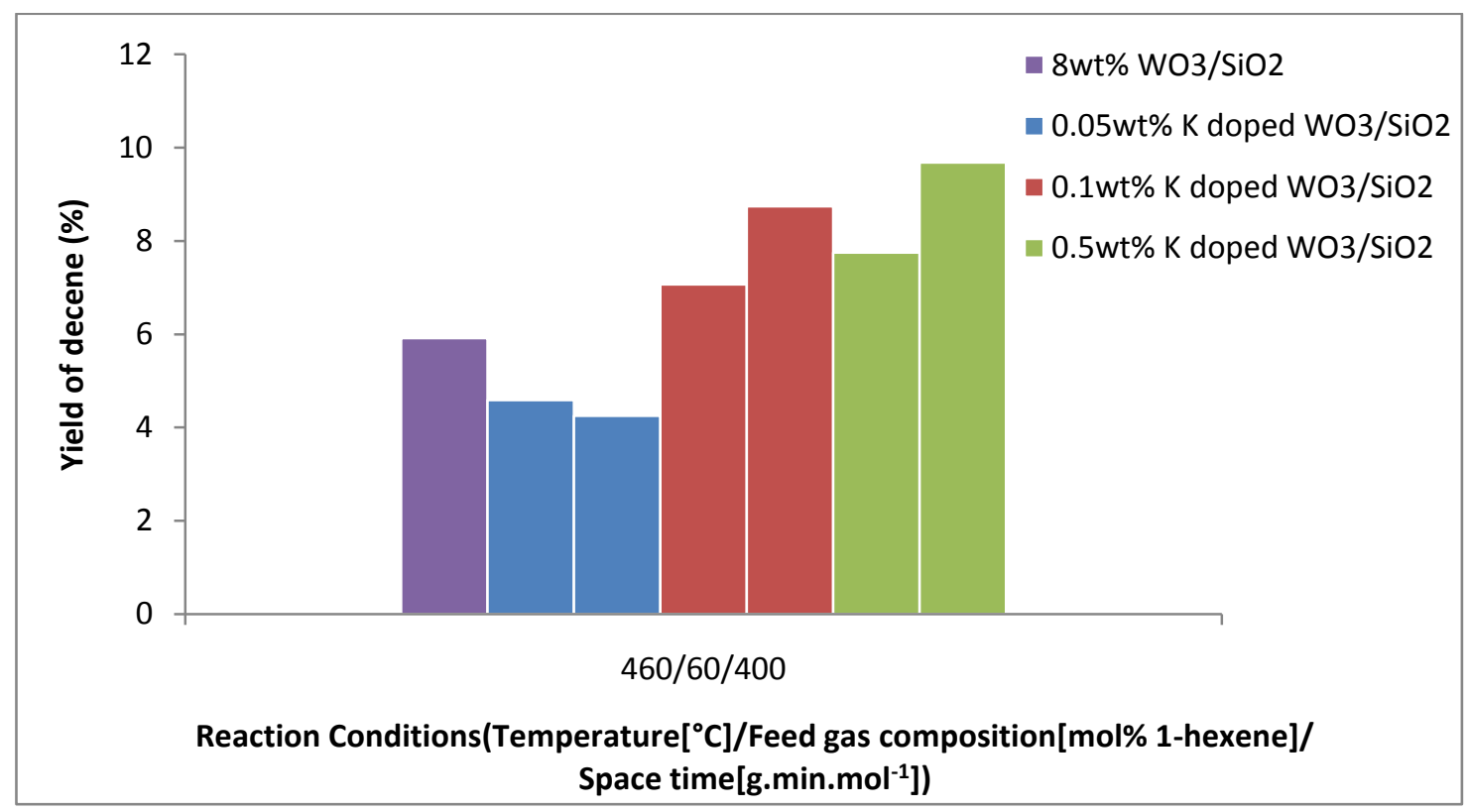

Figure 6.13: Yield of decene vs. reaction conditions of $\mathrm{K}$ doped $\mathrm{WO}_{3} / \mathrm{SiO}_{2}$ in the optimised $\mathrm{WO}_{3} / \mathrm{SiO}_{2}$ region 
It is evident from the 0.1 and $0.5 \mathrm{wt} \%$ loadings of potassium in Figure 6.14 that the isomerization decreases with an increase in the potassium loading. From Table 6.7 it is noted that the $0.5 \mathrm{wt} \%$ catalyst stands out with the highest selectivity of $24.64 \%$ towards the detergent range olefins and $23.62 \%$ towards decene. This is as a result of the decrease in the isomerization and in the $\mathrm{C}_{2}$ to $\mathrm{C}_{9}$ olefins produced (Table 6.8). The high selectivity indicates that the addition of potassium at a loading of $0.5 \mathrm{wt} \%$ produces a catalyst that is highly selective toward the metathesis products. Although the selectivity improved significantly, the yields of the detergent range olefins and decene increased by a small percentage only (Figure 6.12 and Figure 6.13). The increase for the detergent range olefins was by $0.79 \%$ and $2.8 \%$ for decene as compared to the catalyst with no doping. It is possible that the reason for the small increase is the decreased activity of the catalyst as indicated by the low conversions. Thus, although a highly selective catalyst was produced, it was at the loss of catalytic activity.

The results concerning the $0.05 \mathrm{wt} \%$ potassium loading were the complete opposite of what was expected. All literature indicates that the addition of an alkali earth metal will poison the acid sites of the catalyst, thereby reducing isomerization. However, from Figure 6.14, a large increase in the amount of isomerization is noted, even more than for the catalyst with no doping. This increase in isomerization is believed to have reduced the yield of both decene and the detergent range olefins to below the yields obtained for the catalyst with no doping (Figure 6.12 and Figure 6.13).

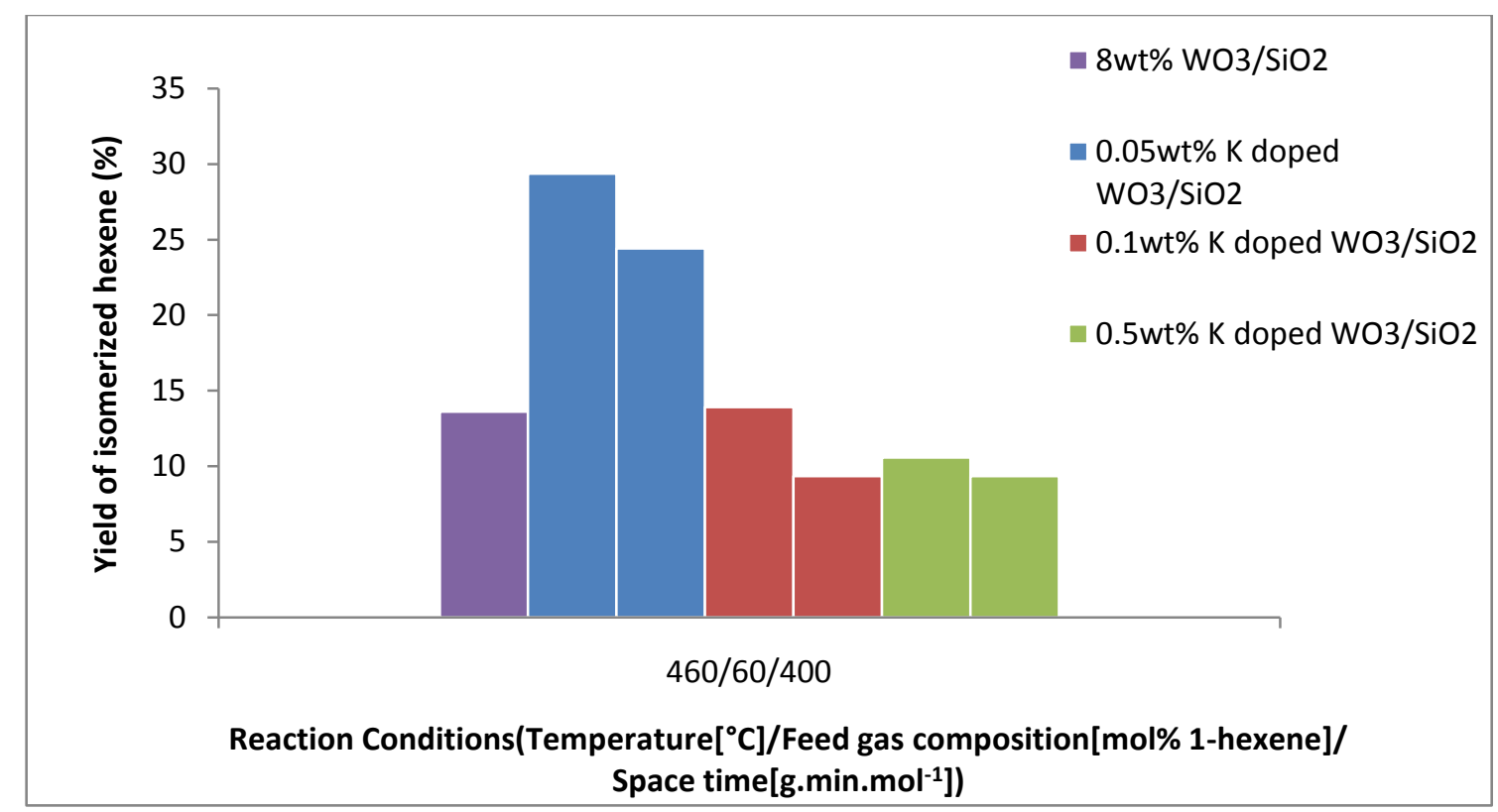

Figure 6.14: Yield of isomerized hexene vs. reaction conditions of $\mathrm{K}$ doped $\mathrm{WO}_{3} / \mathrm{SiO}_{2}$ in the optimised $\mathrm{WO}_{3} / \mathrm{SiO}_{2}$ region 
The analysis of the results above confirmed the expected increase in selectivity and yield and the reduction of isomerization for the 0.1 and $0.5 \mathrm{wt} \%$ loading of potassium. The percentage increase, however, was relatively small. Also, the lower yields for the $0.05 \mathrm{wt} \%$ loading of potassium were not expected. Thus, further investigation into the potassium doped catalyst was undertaken by exploring the entire range of reaction conditions used for the investigation of the $8 \mathrm{wt} \% \mathrm{WO}_{3} / \mathrm{SiO}_{2}$ catalyst with no doping. This resulted in a $2^{3-1} \cdot 3^{1}$ half factorial design with two replicates of each experimental run. The results obtained are given in Figure 6.15 to Figure 6.18.

Analysis of the $0.5 \mathrm{wt} \%$ loading at the other reaction conditions reveal that the improved performance of the catalyst in terms of the higher yields achieved was only for the reaction conditions of $460^{\circ} \mathrm{C}, 60 \mathrm{~mol} \%$ 1-hexene and 400 g.min. $\mathrm{mol}^{-1}$. Extremely low yields of both the detergent range and decene, much lower than those of the catalyst with no doping were produced at the other reaction conditions investigated (Figure 6.16 and Figure 6.17). The conversion was also found to be even lower, dropping to approximately $10 \%$ and this was possibly the reason for the low yields (Figure 6.15). The purpose of doping with potassium, however, was achieved since it can be seen from Figure 6.18 that the amount of isomerization is very low.

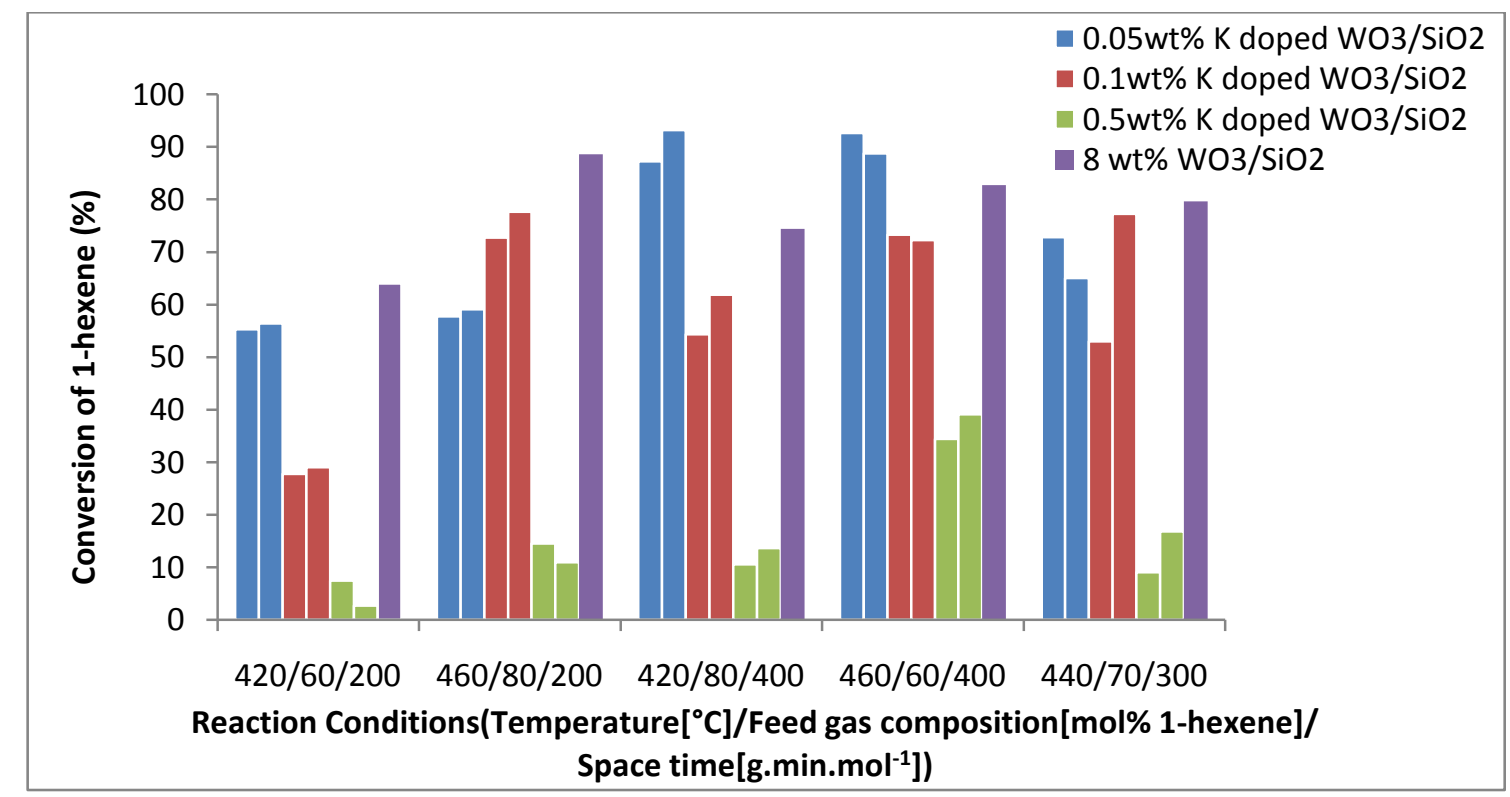

Figure 6.15: Conversion of 1-hexene vs. reaction conditions of $\mathrm{K}$ doped $\mathrm{WO}_{3} / \mathrm{SiO}_{2}$ for all reaction conditions

The $0.1 \mathrm{wt} \%$ loading of potassium was the only loading where the yields of decene and the detergent range were higher than that of the catalyst with no doping for all reaction conditions 
(Figure 6.16 and Figure 6.17). The yield of the detergent range olefins and the yield of decene were found to be higher with the higher reaction temperature of 440 and $460^{\circ} \mathrm{C}$. The feed gas composition and space time did not appear to have any significant affect on the yield production at these higher temperatures.

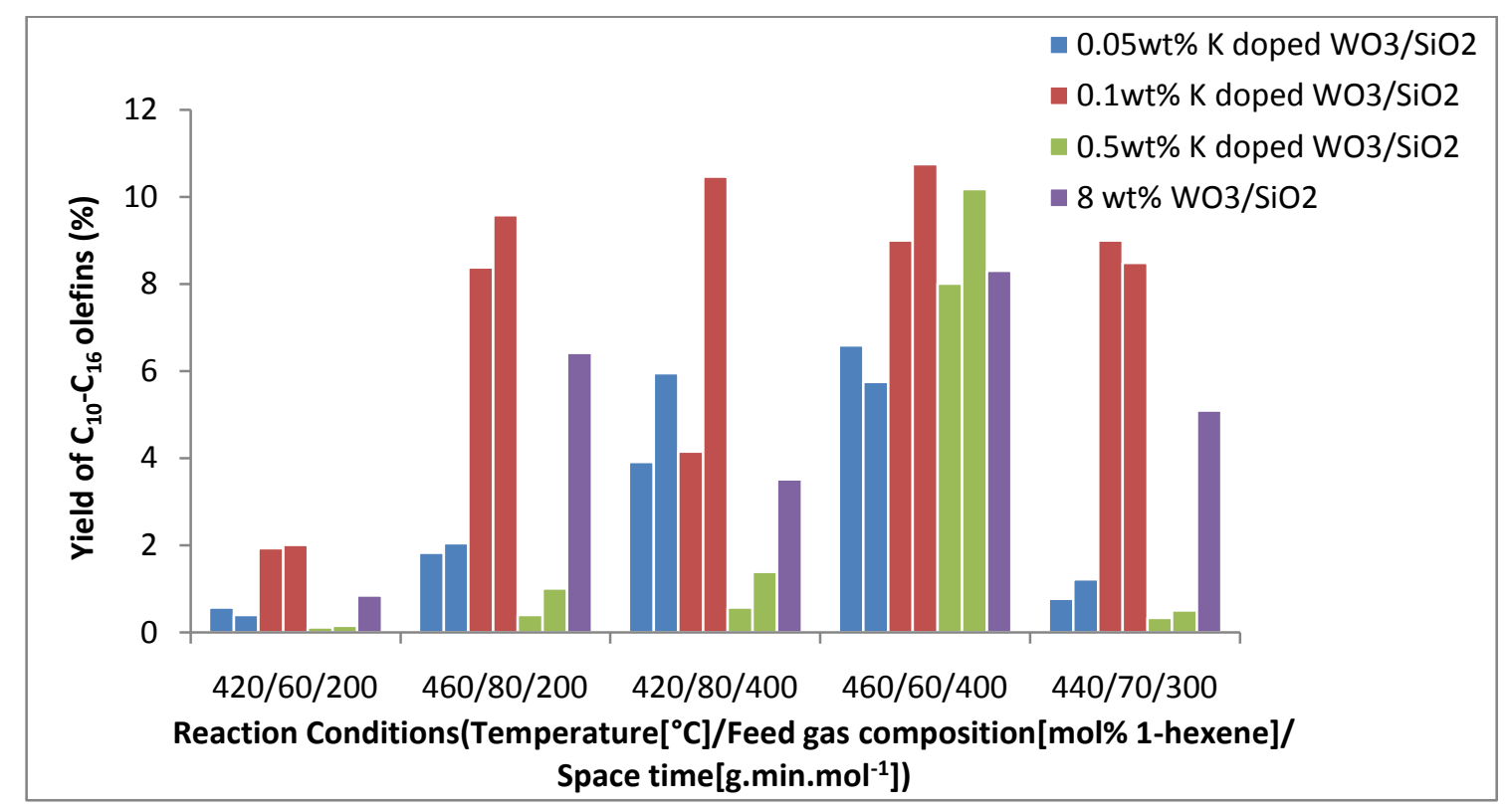

Figure 6.16: Yield of detergent range olefins vs. reaction conditions of $\mathrm{K}$ doped $\mathrm{WO}_{3} / \mathrm{SiO}_{2}$ for all reaction conditions

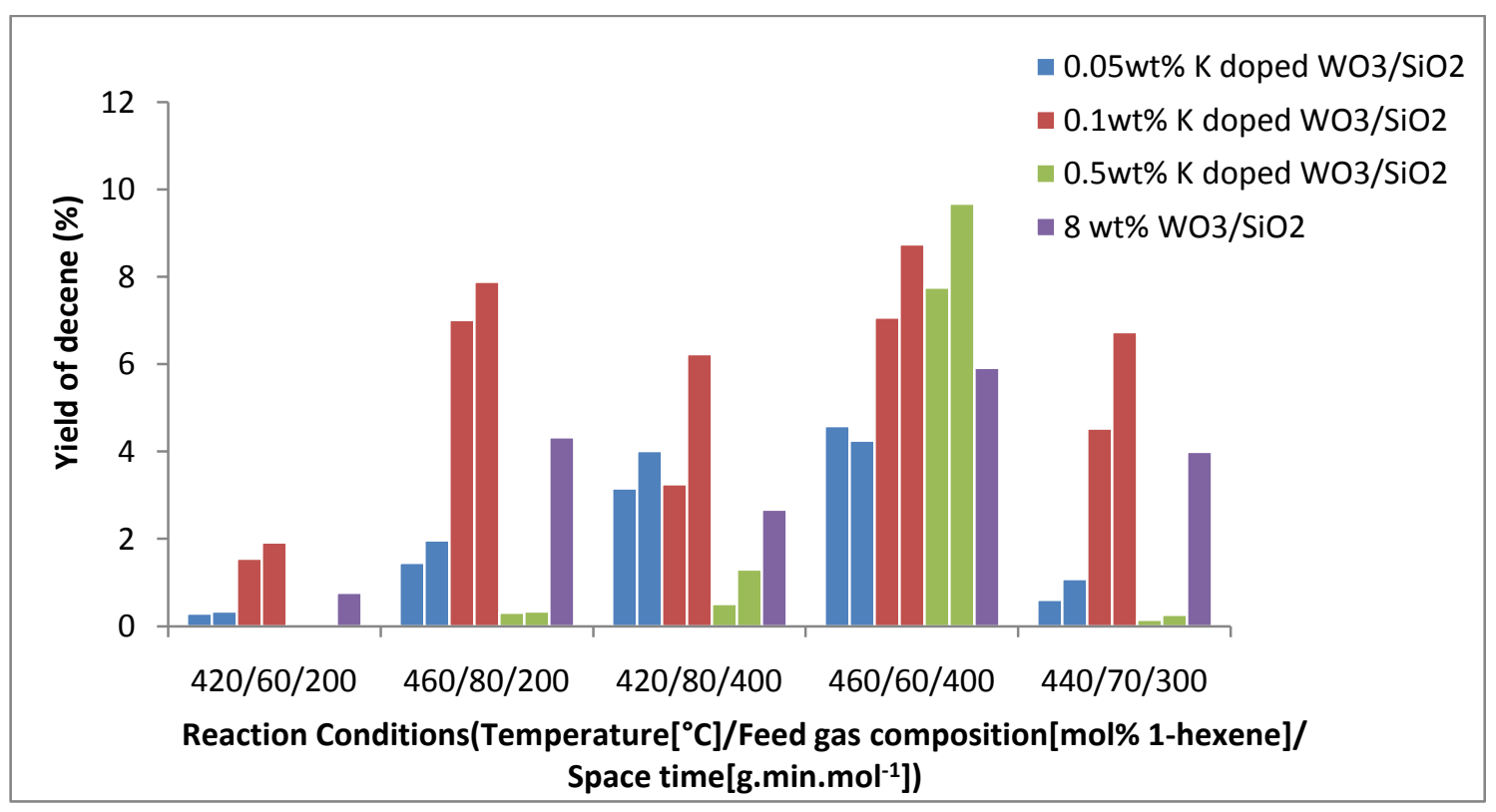

Figure 6.17: Yield of decene vs. reaction conditions of $\mathrm{K}$ doped $\mathrm{WO}_{3} / \mathrm{SiO}_{2}$ for all reaction conditions 
The $0.05 \mathrm{wt} \%$ loading was found to have the same effect on the catalyst as was observed for the optimised region. An increased amount of isomerization of 1-hexene was found to occur as before (Figure 6.18). The yields of both the detergent range olefins and decene were found to be lower than that of the $8 \mathrm{wt} \% \mathrm{WO}_{3} / \mathrm{SiO}_{2}$ with no doping except for the experimental run conducted at $420^{\circ} \mathrm{C}, 80 \mathrm{~mol} \%$ 1-hexene and 400 g.min.mol ${ }^{-1}$ (Figure 6.16 and Figure 6.17).

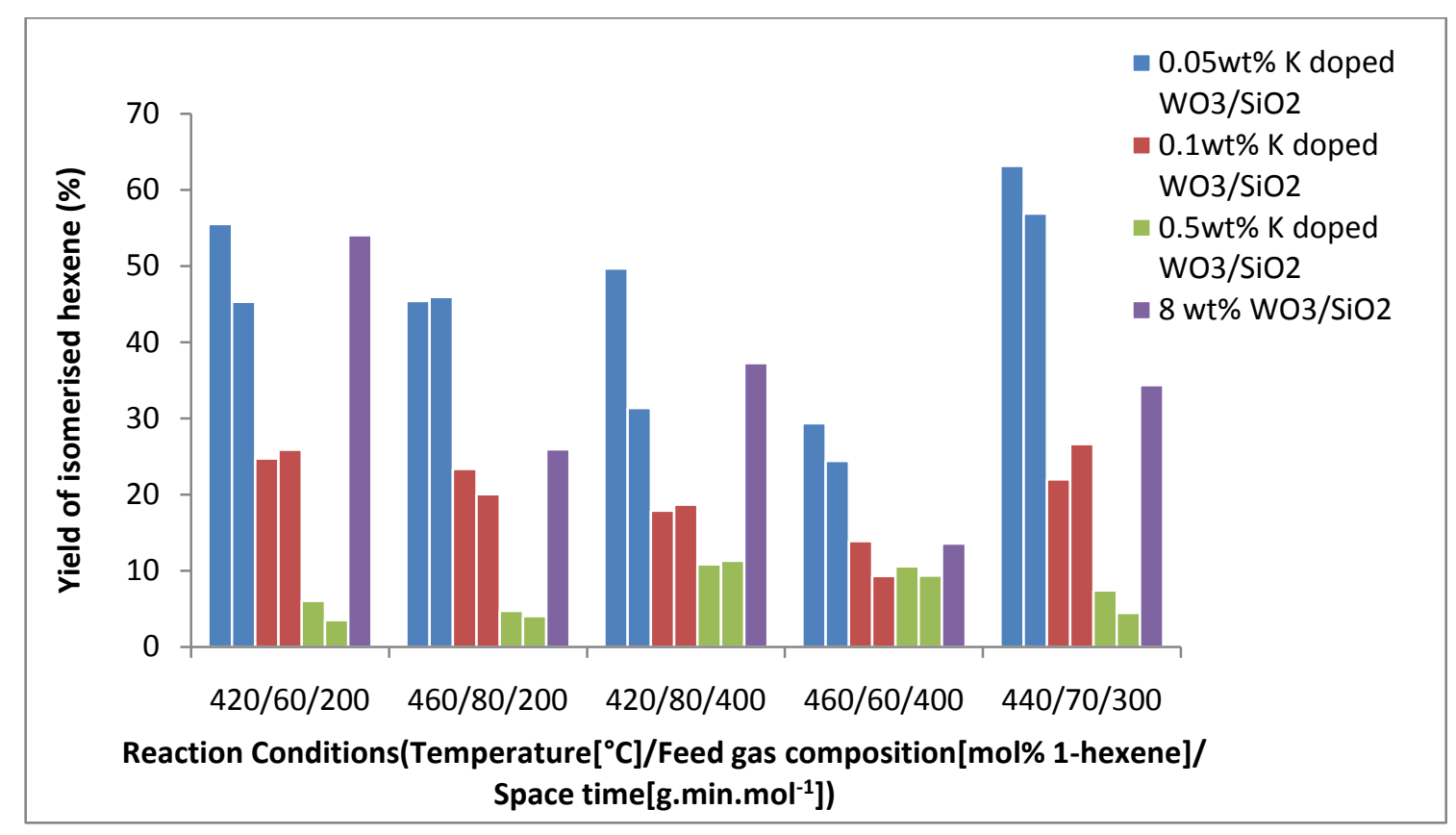

Figure 6.18: Yield of isomerized hexene vs. reaction conditions of $\mathrm{K}$ doped $\mathrm{WO}_{3} / \mathrm{SiO}_{2}$ for all reaction conditions

Table 6.9: BET surface area for $\mathrm{WO}_{3} / \mathrm{SiO}_{2}$ and $\mathrm{K}$ doped $\mathrm{WO}_{3} / \mathrm{SiO}_{2}$

\begin{tabular}{|c|c|}
\hline Sample & BET surface area $\left(\mathbf{m}^{2} / \mathbf{g}\right)$ \\
\hline $8 \mathrm{wt} \% \mathrm{WO}_{3} / \mathrm{SiO}_{2}$ & 175 \\
\hline $0.05 \mathrm{wt} \% \mathrm{~K}$ doped $8 \mathrm{wt} \% \mathrm{WO}_{3} / \mathrm{SiO}_{2}$ & 173 \\
\hline $0.1 \mathrm{wt} \% \mathrm{~K}$ doped $8 \mathrm{wt} \% \mathrm{WO}_{3} / \mathrm{SiO}_{2}$ & 159 \\
\hline $0.5 \mathrm{wt} \% \mathrm{~K}$ doped $8 \mathrm{wt} \% \mathrm{WO}_{3} / \mathrm{SiO}_{2}$ & 154 \\
\hline
\end{tabular}

It was found from the BET surface area analysis (Table 6.9) that the addition of potassium decreased the specific surface area of the catalyst as compared to the catalyst with no doping and that the higher the percentage loading, the more the surface area decreased. The observed 
loss of surface area can be explained by the conglomeration of the intergranular porosity of the support with the alkali metal (Perrichon et al., 1988).

\subsection{Mechanism for the metathesis of 1 -hexene}

The model proposed by Van Roosmalen and Mol (1982) to describe the formation of the active centres and thus the mechanism for the metathesis reaction can be used to explain the metathesis of 1-hexene over silica and alumina.

As reviewed earlier in Section 2.4., Van Roosmalen and Mol (1982) described the structure for the dehydrated $\mathrm{WO}_{3} / \mathrm{SiO}_{2}$ catalyst prepared by the wet impregnation method as:

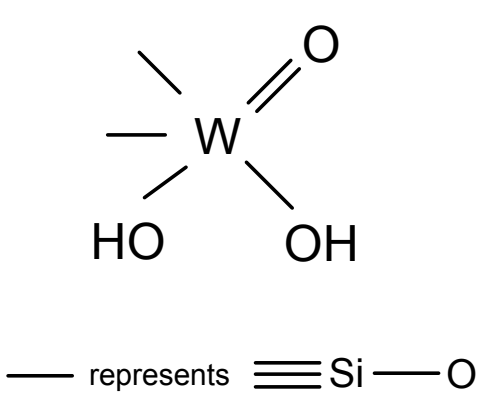

Figure 6.19: Structure of the dehydrated $\mathrm{WO}_{3} / \mathrm{SiO}_{2}$ catalyst (Van Roosmalen and Mol, 1982)

The structure of the dehydrated $\mathrm{WO}_{3} / \mathrm{Al}_{2} \mathrm{O}_{3}$ catalyst was given by Logie et al. (1999) as follows (Figure 6.20):

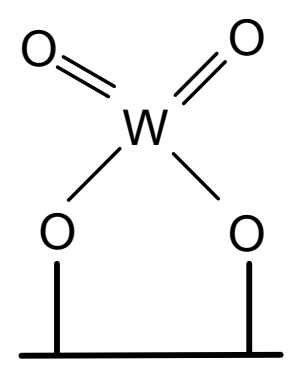

$\mathrm{Al}_{2} \mathrm{O}_{3}$

Figure 6.20: Structure of the dehydrated $\mathrm{WO}_{3} / \mathrm{Al}_{2} \mathrm{O}_{3}$ catalyst (Logie et al., 1999) 
The structure of the tungsten trioxide supported on silica and alumina is similar and thus the mechanism reactions henceforth will be described only for the metathesis of 1-hexene using silica as the support. The proposed formation of the Lewis acid/alkene complex for the metathesis of 1-hexene specifically is illustrated in the following reaction (Figure 6.21).

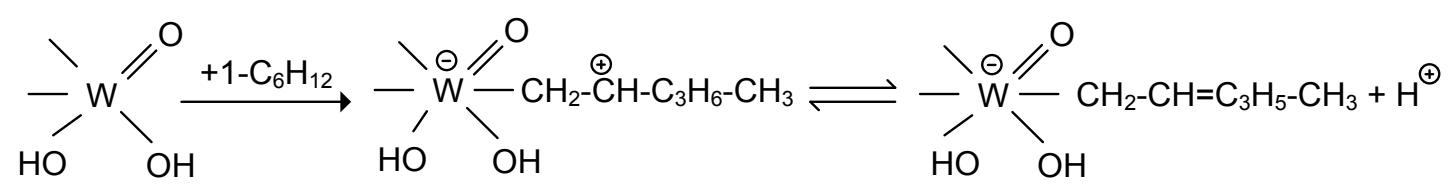

Figure 6.21: Formation of the Lewis acid/alkene complex for the metathesis of 1-hexene

This chemisorption of the 1-hexene olefin results in the donation of a proton. According to Van Roosmalen and Mol (1982), the stronger the Lewis acid, the greater will the tendency be to donate a proton. In the reaction, the tungsten/support complex behaves as the Lewis acid. Comparison of the tungsten/silica and tungsten/alumina catalyst in terms of Lewis acidity strength indicated that the $\mathrm{WO}_{3} / \mathrm{Al}_{2} \mathrm{O}_{3}$ catalyst contains stronger Lewis acid sites (Harmse et al., 2010). Thus there would be a greater tendency for the $\mathrm{WO}_{3} / \mathrm{Al}_{2} \mathrm{O}_{3}$ catalyst to donate a proton. This in turn could imply that the $\mathrm{WO}_{3} / \mathrm{Al}_{2} \mathrm{O}_{3}$ catalyst would have a higher activity when compared to the $\mathrm{WO}_{3} / \mathrm{SiO}_{2}$ catalyst since more carbene initiators would eventually be formed.

Reduction of the catalysts were undertaken by prolonged contact with the reactant alkene i.e. 1hexene. Oxidative pre-treatment and hydrogen pre-treatment of the catalysts were not undertaken since previous studies by Lokhat (2008) indicated that the conversion of 1-hexene as well as the $\mathrm{C}_{7}-\mathrm{C}_{16}$ yield and selectivity were reduced by these pre-treatments.

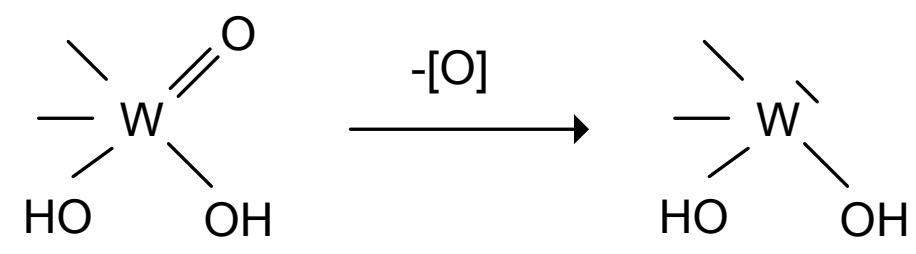

Figure 6.22: Reduction of the $\mathrm{WO}_{3} / \mathrm{SiO}_{2}$ catalyst 
Reduction of the $\mathrm{WO}_{3} / \mathrm{SiO}_{2}$ catalyst is accompanied by a colour change of the catalyst from yellow to blue, due to the $\mathrm{WO}_{3}$ being reduced to $\mathrm{WO}_{2.9}$. This colour changed was noted indicating that the surface had been reduced by the 1-hexene (Figure 6.23).

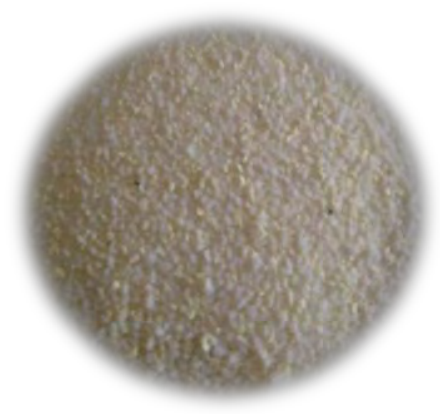

(a)

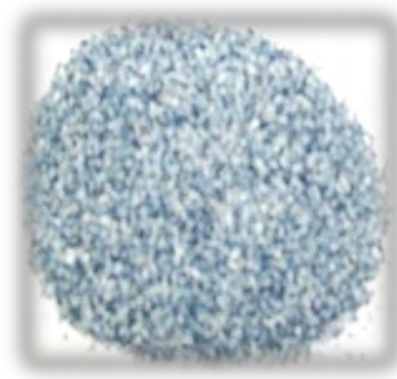

(b)

Figure 6.23 : Colour change of the $\mathrm{WO}_{3} / \mathrm{SiO}_{2}$ catalyst as a result of reduction (a) before reduction (b) after reduction

It is expected from the greater tendency for the $\mathrm{WO}_{3} / \mathrm{Al}_{2} \mathrm{O}_{3}$ catalyst to donate a proton, that it would have a higher activity and thus greater conversion. However, from the results in Figure 6.5 and Figure 6.7, it can be seen that the conversion of 1-hexene when using either the $\mathrm{WO}_{3} / \mathrm{Al}_{2} \mathrm{O}_{3}$ catalyst or the $\mathrm{WO}_{3} / \mathrm{SiO}_{2}$ catalyst is similar. This can be explained by the fact that it is more difficult to reduce the $\mathrm{WO}_{3} / \mathrm{Al}_{2} \mathrm{O}_{3}$ catalyst since there is a stronger interaction between the metal oxide and the support. This implies that there would be fewer reduced sites and even with more protons donated, the activity would be similar to the activity of the $\mathrm{WO}_{3} / \mathrm{SiO}_{2}$ catalyst.

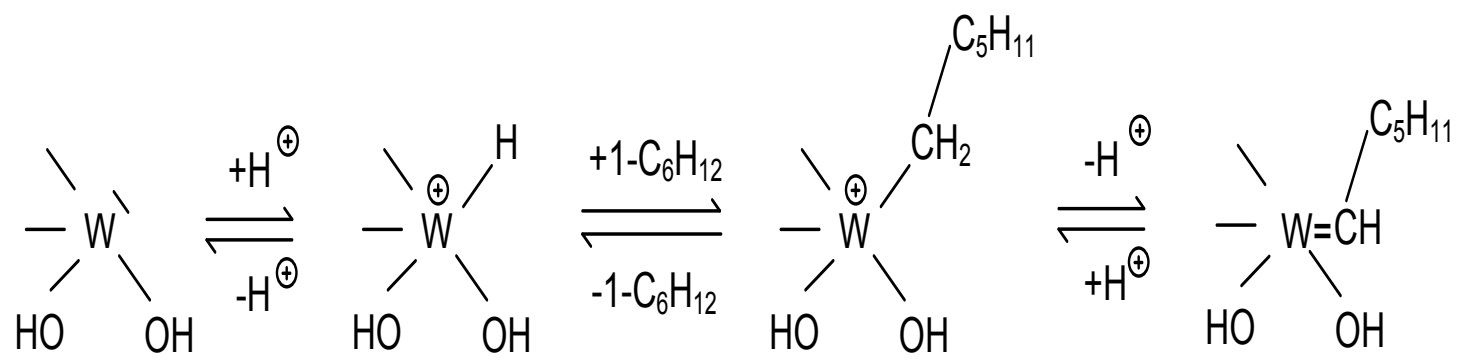

Figure 6.24: Formation of the metal carbene initiator 
The formation of the metal carbene initiator occurs as the final step in the mechanism cycle and is depicted as the reaction represented in Figure 6.24.

\subsection{Coke Formation}

The formation of coke on the spent catalysts was evident visually by the change in colour of the catalyst. The $\mathrm{WO}_{3} / \mathrm{Al}_{2} \mathrm{O}_{3}$ catalyst changed from white to blackish granules after an average exposure time of 45 minutes. The colour change for the $\mathrm{WO}_{3} / \mathrm{SiO}_{2}$ catalyst was from yellowish white to a blue/black mixture of granules. These can be seen in Figure 6.25 where pictures of the original and spent catalyst are given.
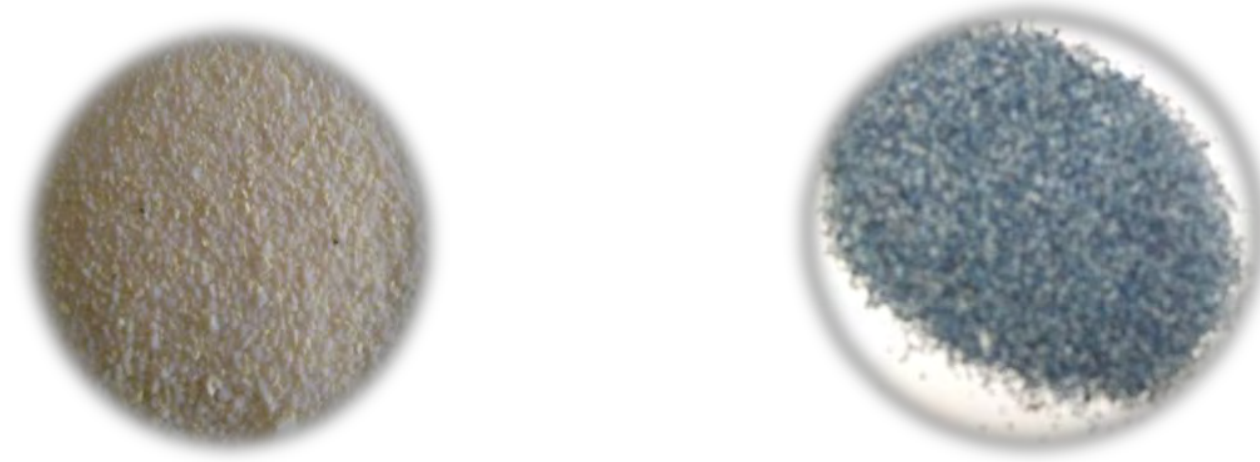

(a)
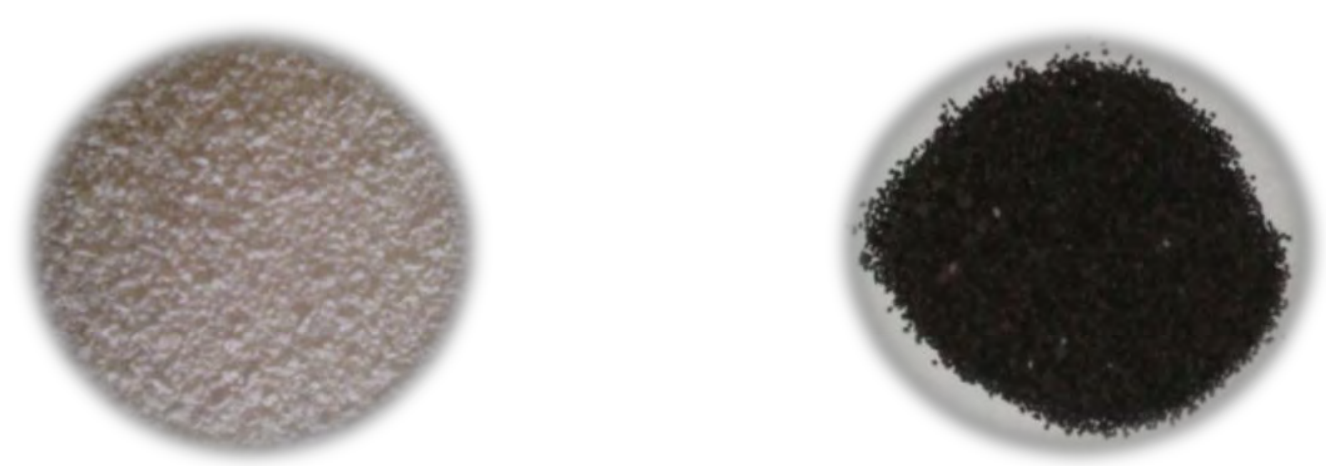

(b)

Figure 6.25: Original and spent catalysts (a) $\mathrm{WO}_{3} / \mathrm{SiO}_{2}$ catalyst (b) $\mathrm{WO}_{3} / \mathrm{Al}_{2} \mathrm{O}_{3}$ catalyst 
Previous authors discovered that the Diels-Alder type reaction is responsible for the formation of coke (refer to Section 2.11). This type of reaction is known to be catalysed by Lewis acids, although Langner and Meyer (1980) found that Bronsted acid sites were also involved in the formation of coke.

It is evident from the visual analysis of the spent catalyst samples that the $\mathrm{WO}_{3} / \mathrm{Al}_{2} \mathrm{O}_{3}$ catalyst has more coke formation compared to the $\mathrm{WO}_{3} / \mathrm{SiO}_{2}$ catalyst and the potassium doped $\mathrm{WO}_{3} / \mathrm{SiO}_{2}$ catalyst. This is attributed to the fact that the $\mathrm{WO}_{3} / \mathrm{Al}_{2} \mathrm{O}_{3}$ catalyst is more acidic in terms of acid strength as well as number of acid sites (Harmse et al., 2010) and the Diels-Alder type reaction is catalysed by acid sites. Since the $\mathrm{WO}_{3} / \mathrm{Al}_{2} \mathrm{O}_{3}$ catalyst was found to have more coke formation, the GCMS analysis of a sample of the liquid product shown in Table 6.2 was examined in more detail. This was done in order to determine the various components present in the product and to look for the presence of possible dienes that react to form aromatics which act as the precursor to the formation of coke. It can be seen that hexadiene is present as a component in the liquid product sample analysed. In the case of the metathesis reaction involving 1-hexene, some of the aromatics formed would be as a result of the Diels-Alder type reaction involving hexadiene.

\subsection{Carbon balance inconsistency}

A carbon balance was conducted for each experimental run undertaken using the three catalysts i.e. the $\mathrm{WO}_{3} / \mathrm{Al}_{2} \mathrm{O}_{3}$ catalysts as well as the $\mathrm{WO}_{3} / \mathrm{SiO}_{2}$ catalyst and $\mathrm{K}$ doped $\mathrm{WO}_{3} / \mathrm{SiO}_{2}$ catalysts. The purpose of a carbon balance is to provide information about the consistency of the data and the accuracy of measurements (Schell et al., 2003). The carbon balance inconsistency is given by Equation 6.7.

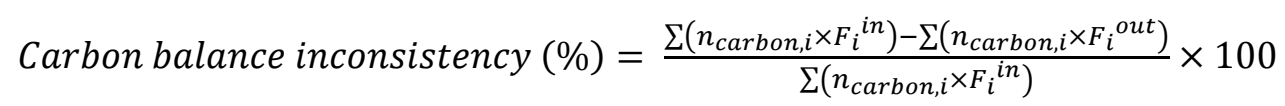

where $\quad n_{\text {carbon }, i}=$ number of carbon atoms in component $i$

$F_{i}=$ molar flow rate of component $i$ 
The carbon balance inconsistency was calculated for each experimental run using the 10, 16 and $20 \mathrm{wt} \% \mathrm{WO}_{3} / \mathrm{Al}_{2} \mathrm{O}_{3}$ catalysts (Figure 6.26). A fairly random scatter of carbon imbalance was noted indicating consistency in the experimental data.

The carbon balance consistency for the experimental runs using the $8 \mathrm{wt} \% \mathrm{WO}_{3} / \mathrm{SiO}_{2}$ catalyst and the $0.05,0.1$ and $0.5 \mathrm{wt} \% \mathrm{~K}$ doped $\mathrm{WO}_{3} / \mathrm{SiO}_{2}$ catalysts is given in Figure 6.27, for each of the five sets of reaction conditions. The random scatter of carbon imbalance is also present indicating consistency in the data and that the measurements of the streams containing the carbon species were accurate to within an approximate error of $10-15 \%$ (absolute). A mass balance conducted in a previous patent publication by Sasol Technology (Pty) Limited (2004) for the metathesis of 1-heptene and 1-octene also indicated a mass balance error of approximately $10 \%$.

The effect that the carbon balance inconsistency has on the selectivity, yield and conversion will not be high since the carbon balance inconsistency of $10-15 \%$ accounts for all carbons from the component $\mathrm{C}_{2}$ to $\mathrm{C}_{16}$. Therefore, the inconsistency of the carbons only related to the selectivity, yield or conversion will be a lower percentage error value.

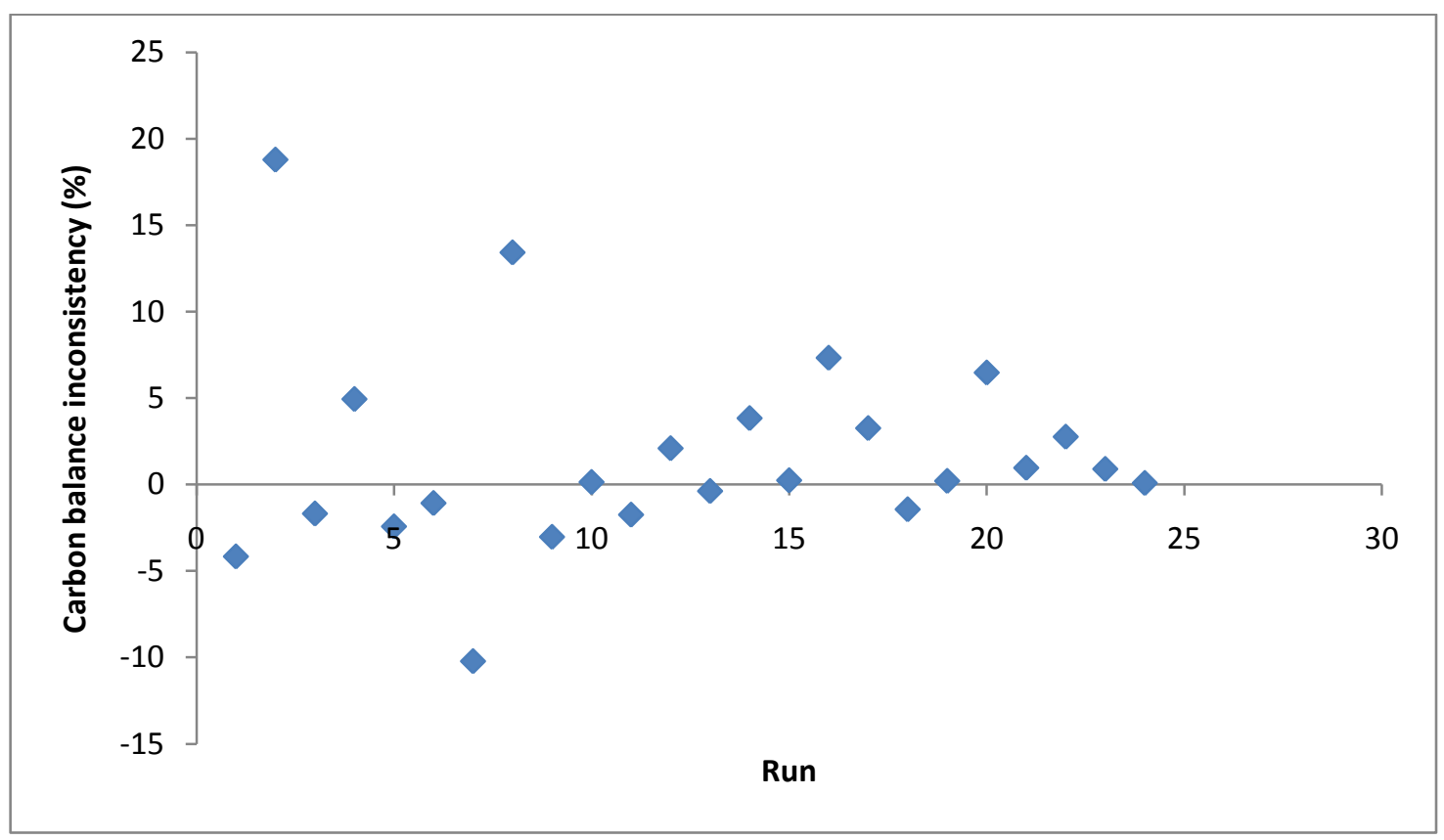

Figure 6.26: Carbon balance inconsistency for the 10,16 and $20 \mathrm{wt} \% \mathrm{WO}_{3} / \mathrm{Al}_{2} \mathrm{O}_{3}$ catalysts 


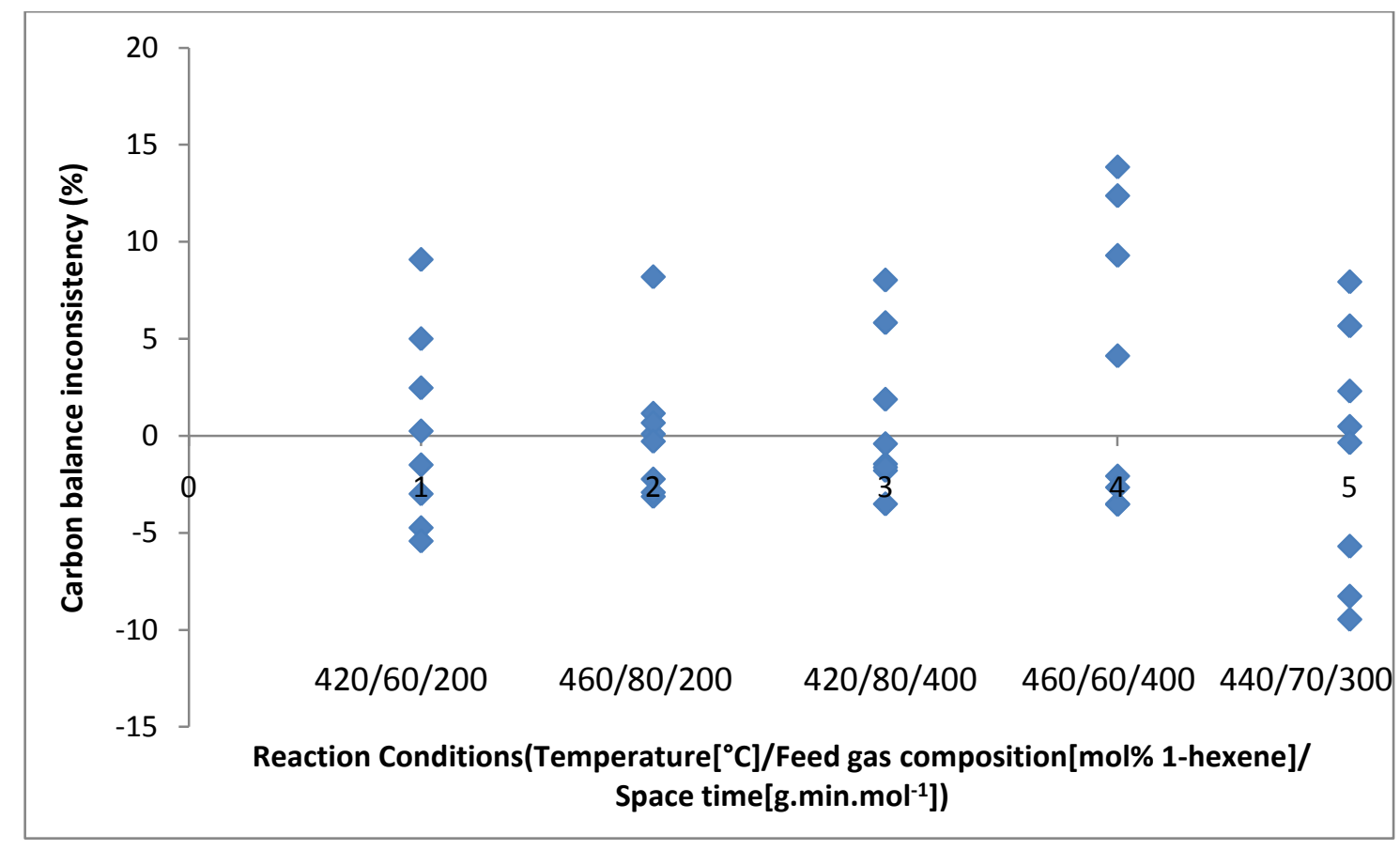

Figure 6.27: Carbon balance inconsistency for the $\mathrm{WO}_{3} / \mathrm{SiO}_{2}$ and $\mathrm{K}$ doped $\mathrm{WO}_{3} / \mathrm{SiO}_{2}$ catalysts

\subsection{Statistical analysis of the potassium doped $8 \mathrm{wt} \% \mathrm{WO}_{3} / \mathrm{SiO}_{2}$ catalyst}

A statistical analysis of the results using the $\mathrm{WO}_{3} / \mathrm{Al}_{2} \mathrm{O}_{3}$ catalyst was not undertaken due to the poor results obtained and the decision to not consider it as a viable option for the metathesis of 1-hexene. A statistical analysis was conducted for the experimental runs using the potassium doped $8 \mathrm{wt} \% \mathrm{WO}_{3} / \mathrm{SiO}_{2}$ catalyst.

For the purpose of statistical analysis of the experimental runs using the potassium doped $8 \mathrm{wt} \%$ $\mathrm{WO}_{3} / \mathrm{SiO}_{2}$ catalyst, the significance of the main effects and interactions were determined and the assumption of linearity was verified. The four factor design for the experimental runs consisted of the three operating conditions being varied at a high and a low level while the fourth factor, the specific loading was varied at three levels. Although three levels of specific loading were investigated, the determination of the significance of the main effects and interaction was undertaken with all factors at two levels. This was done since an indication of a high and low level for each factor was required, as discussed for the $2^{4-1}$ fractional factorial design in Section 3.2. The specific loading of 0.05 and $0.1 \mathrm{wt} \%$ potassium was chosen for the statistical analysis, however a combination of either with the $0.5 \mathrm{wt} \%$ loading could also be used. 
The statistical analysis for a $2^{4-1}$ fractional factorial design (Section 3.2) was described graphically using two cubes with the alternate and principal fractions used for each cube as an example. For the design used for this study, the alternate fraction was chosen for both cubes to allow the results to be compared at the same reaction conditions for each specific loading. This particular design is depicted in Figure 6.29 where the 5 points on each cube is at the same set of reaction conditions.

The design table for this particular design (Table 6.10) is a modified version of the design table, Table 3.4. The signage in the design table for the first cube remains the same, as the alternate fraction was also used for the first cube in Section 3.2. However, since the alternate fraction instead of the principal fraction is used for the second cube, the signage for the points on that cube would be obtained from $\mathrm{D}=-\mathrm{A} \times \mathrm{B} \times \mathrm{C}$ instead, as indicated in italics in Table 6.10.

Table 6.10: Design table for the potassium doped $\mathrm{WO}_{3} / \mathrm{SiO}_{2}$ catalyst $\left(2^{4-1}\right.$ fractional factorial design)

\begin{tabular}{|c|c|c|c|c|c|}
\hline \multirow[b]{2}{*}{$\begin{array}{c}\text { Treatment } \\
\text { Combination }\end{array}$} & \multicolumn{4}{|c|}{ Design factors } & \multirow[b]{2}{*}{$\begin{array}{c}\text { Response } \\
\text { Y } \\
\text { (Yield of } \\
\text { decene) }\end{array}$} \\
\hline & $\begin{array}{c}\text { A } \\
\text { (Temperature) }\end{array}$ & $\begin{array}{c}\text { B } \\
\text { (Feed gas } \\
\text { composition) }\end{array}$ & $\begin{array}{c}\mathrm{C} \\
\text { (Space } \\
\text { Time) }\end{array}$ & $\begin{array}{c}D=A \times B \times C \\
\text { or } \\
D=-A \times B \times C \\
\text { (Specific } \\
\text { Loading) }\end{array}$ & \\
\hline (1) & -1 & -1 & -1 & -1 & 0.32 \\
\hline ad & -1 & -1 & -1 & +1 & 1.73 \\
\hline cd & +1 & +1 & -1 & +1 & 7.44 \\
\hline ac & +1 & +1 & -1 & -1 & 1.71 \\
\hline abcd & -1 & +1 & +1 & +1 & 4.74 \\
\hline $\mathbf{a b}$ & +1 & -1 & +1 & -1 & 4.42 \\
\hline bc & -1 & +1 & +1 & -1 & 3.59 \\
\hline bd & +1 & -1 & +1 & +1 & 7.90 \\
\hline
\end{tabular}

The main effects and interactions were estimated using the signs of each column as discussed in Section 3.2 and are given in Table 6.11. 
Table 6.11: Calculated values of the effects and sum of squares of the factors and their combinations [A (temperature), B (feed gas composition) and C (space time)]

\begin{tabular}{|c|c|c|c|}
\hline & $\boldsymbol{l}_{\mathbf{i}}$ & Contrast & $\mathbf{S S}_{\mathbf{i}}$ \\
\hline $\mathbf{A}$ & $l_{\mathrm{A}}=2.7725$ & 22.18 & $\mathrm{SS}_{\mathrm{A}}=30.75$ \\
\hline $\mathbf{B}$ & $l_{\mathrm{B}}=0.7775$ & 6.22 & $\mathrm{SS}_{\mathrm{B}}=2.42$ \\
\hline $\mathbf{C}$ & $l_{\mathrm{C}}=2.3625$ & 18.90 & $\mathrm{SS}_{\mathrm{C}}=22.33$ \\
\hline $\mathbf{D}$ & $l_{\mathrm{D}}=2.9425$ & 23.54 & $\mathrm{SS}_{\mathrm{D}}=34.63$ \\
\hline $\mathbf{A B}$ & $l_{\mathrm{AB}}=-2.3625$ & -18.90 & $\mathrm{SS}_{\mathrm{AB}}=22.33$ \\
\hline $\mathbf{A C}$ & $l_{\mathrm{AC}}=-0.7775$ & -6.22 & $\mathrm{SS}_{\mathrm{AC}}=2.42$ \\
\hline $\mathbf{B C}$ & $l_{\mathrm{BC}}=-2.7725$ & -22.18 & $\mathrm{SS}_{\mathrm{BC}}=30.75$ \\
\hline
\end{tabular}

It is known from literature that the interactions $\mathrm{AB}, \mathrm{AC}$ and $\mathrm{BC}$ are compounded with interactions $\mathrm{CD}, \mathrm{BD}$ and $\mathrm{AD}$ respectively. The normal probability plot was used to determine the significance of the effects and interactions (Figure 6.28).

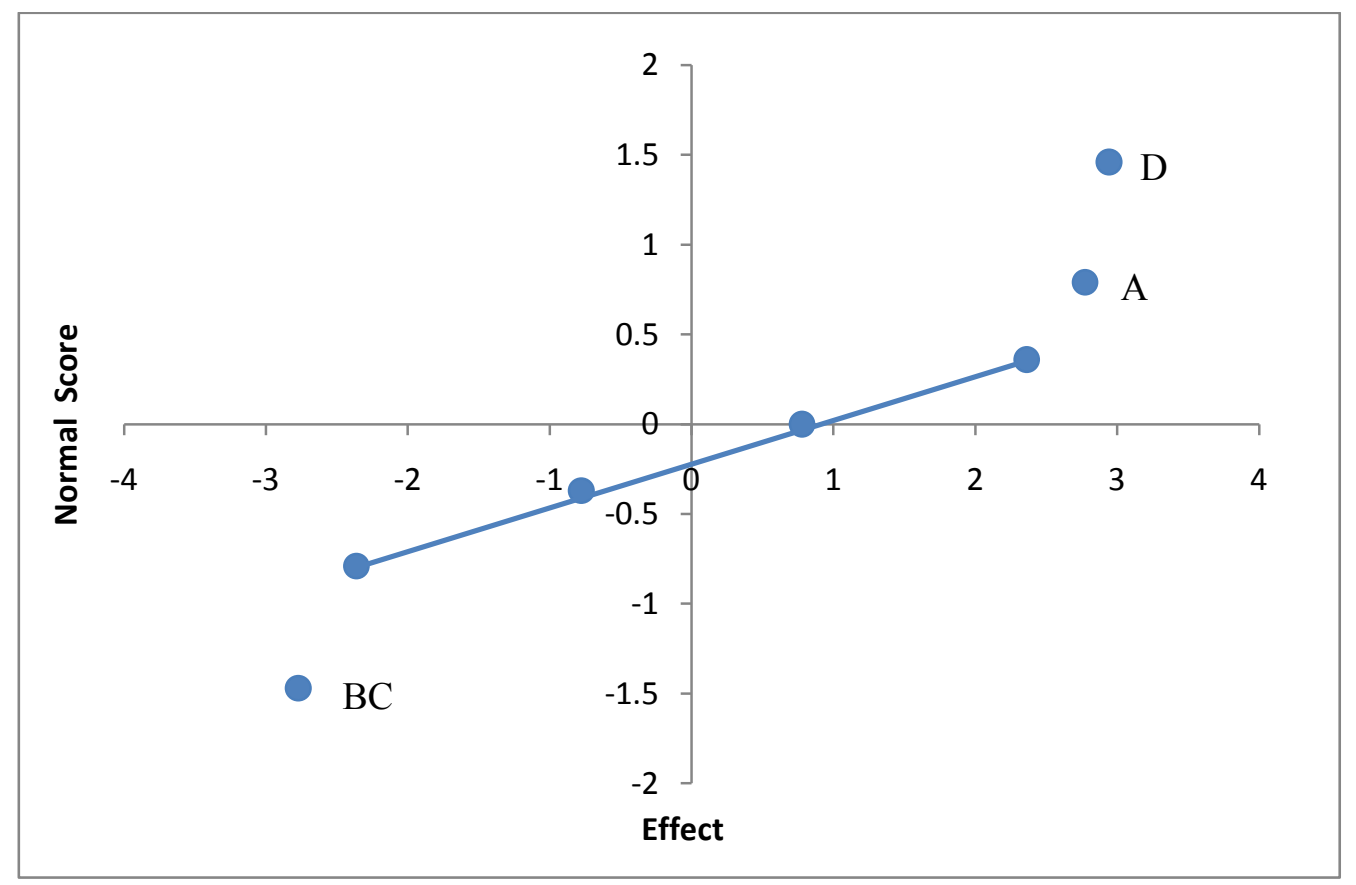

Figure 6.28: Normal probability plot 


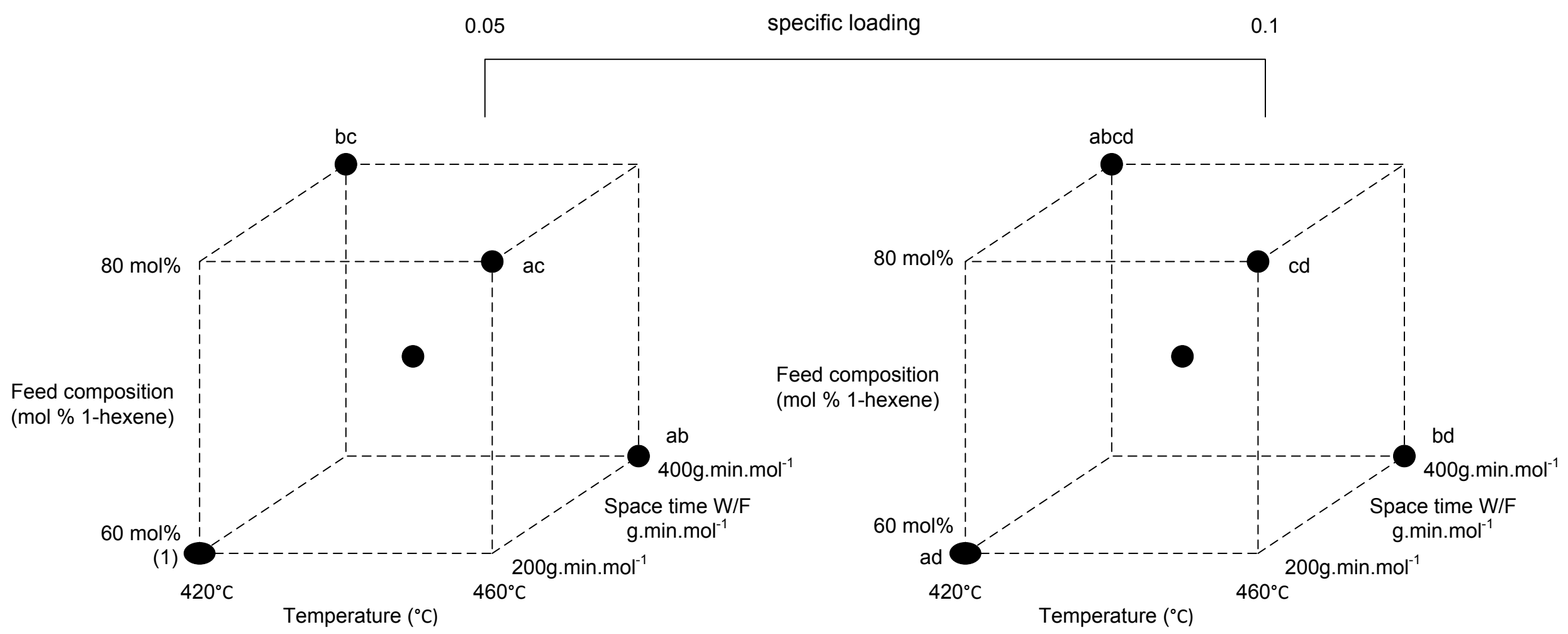

Figure 6.29: Depiction of the $2^{4-1}$ fractional factorial design represented by two cubes 
Examination of this plot reveals the main effect $\mathrm{A}$ and $\mathrm{D}$ as well as the interaction $\mathrm{BC}$ as the outliers. Since the BC interaction is compounded with the AD interaction, the result can be interpreted as the $\mathrm{AD}$ interaction being of significance since the main effects $\mathrm{A}$ and $\mathrm{D}$ individually are significant. The statistical analysis confirms the visual analysis that the temperature and specific loading individually have a strong effect on the results and it also indicates that the interaction of reaction temperature and the specific loading of potassium have a significant effect on the results.

The analysis of variance (ANOVA) table (Table 6.12) was used as an alternate method to determine the significance of the effects and interactions. The addition of centre points to the design resulted in the inclusion of curvature as a source of variance in the table. The mean square error in the ANOVA table was calculated from the centre points. Comparison of the curvature sum of squares to the mean square error indicates a much smaller curvature sum of squares value, thus the assumption of linearity holds. The difference $\bar{y}_{F}-\bar{y}_{C}=0.75$, being small, confirms this.

Table 6.12: ANOVA table for the potassium doped $\mathrm{WO}_{3} / \mathrm{SiO}_{2}$ catalyst

\begin{tabular}{|c|c|c|c|c|}
\hline $\begin{array}{c}\text { Source of } \\
\text { Variation }\end{array}$ & $\begin{array}{c}\text { Sum of } \\
\text { Squares }\end{array}$ & $\begin{array}{c}\text { Degrees of } \\
\text { freedom }\end{array}$ & Mean Square & $\mathbf{F}_{\mathbf{0}}$ \\
\hline $\mathrm{A}$ & 30.75 & 1 & 30.75 & $\mathbf{3 . 6 2}$ \\
\hline $\mathrm{B}$ & 2.42 & 1 & 2.42 & 0.28 \\
\hline $\mathrm{C}$ & 22.33 & 1 & 22.33 & 2.63 \\
\hline $\mathrm{D}$ & 34.63 & 1 & 34.63 & $\mathbf{4 . 0 8}$ \\
\hline $\mathrm{AB}$ & 22.33 & 1 & 22.33 & 2.63 \\
\hline $\mathrm{AC}$ & 2.42 & 1 & 2.42 & 0.28 \\
\hline BC & 30.75 & 1 & 30.75 & $\mathbf{3 . 6 2}$ \\
\hline Curvature & 1.48 & 1 & 1.48 & 0.17 \\
\hline Error & 67.94 & 8 & 8.493 & \\
\hline Total & 215.04 & 16 & & \\
\hline
\end{tabular}


The level of significance chosen was $\alpha=0.1$. The critical F-value at this level of significance was $f_{0.1,1,8}=3.46$. Comparisons of the F-ratios $\left(\mathrm{F}_{0}\right)$ to the critical F-value indicate that the main effects $\mathrm{A}$ and $\mathrm{D}$ as well as the interaction $\mathrm{BC}$ affect the yield of decene since $\mathrm{F}_{0}>$ critical $\mathrm{F}$ value. This means that the temperature and the specific loading of potassium as well as the interaction of both are significant while the other factors and interactions have a less significant effect on the yield. The interaction effect implies that the optimum temperature may only be the optimum at a particular specific loading. Practically, running at the optimum temperature and specific loading determined is important to obtain the highest yields whereas running over a wide range of feed compositions (60-80 mol\% 1-hexene) or space time (200-400 g.min.mol $\left.{ }^{-1}\right)$ do not affect the yield significantly. This result verifies the statistical results obtained by use of the normal probability plot above (Figure 6.28). 


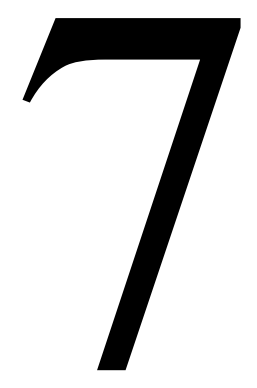

\section{CHAPTER SEVEN}

\section{CONCLUSION AND RECOMMENDATIONS}

Tungsten trioxide supported on alumina $\left(\mathrm{WO}_{3} / \mathrm{Al}_{2} \mathrm{O}_{3}\right)$ was found to be an inferior catalyst for the metathesis of 1-hexene at all combinations of specific loadings $\left(10,16\right.$ and $20 \mathrm{wt} \% \mathrm{WO}_{3}$ on alumina) and operating conditions tested (reaction temperatures of $420,445,470,495^{\circ} \mathrm{C}$ and 1 hexene feed composition of 0.5 and $0.8 \mathrm{~mol} \%$ ). Extremely low yields of the detergent range olefins and the primary metathesis product, decene, were obtained, all being below $1.5 \%$. Changes in the $\mathrm{pH}$ of the impregnation solution, the calcination time and the calcination temperature were found to have no effect on the yields of both the detergent range olefins $\left(\mathrm{C}_{10^{-}}\right.$ $\left.\mathrm{C}_{16}\right)$ and decene $\left(\mathrm{C}_{10}\right)$. Poor selectivity to these desired products was due to the large number of isomerization reactions taking place. The GCMS results showed the presence of nine isomers of hexene in the sample liquid product tested. FTIR spectra of the $\mathrm{WO}_{3} / \mathrm{Al}_{2} \mathrm{O}_{3}$ catalyst indicated the presence of acidic $\mathrm{OH}$ groups in the 3400 to $3500 \mathrm{~cm}^{-1}$ band region usually found on the alumina surface itself. The acidity of the $\mathrm{OH}$ groups is a desired characteristic when using alumina as an isomerization catalyst, since acid sites catalyse isomerization reactions. It was therefore concluded that the presence of these acidic hydroxyl groups on the $\mathrm{WO}_{3} / \mathrm{Al}_{2} \mathrm{O}_{3}$ catalyst was responsible for its poor performance as a metathesis catalyst and the high proportion of isomerization that occurred.

The optimum operating conditions for the $8 \mathrm{wt} \% \mathrm{WO}_{3} / \mathrm{SiO}_{2}$ catalyst was found to be a reaction temperature of $460^{\circ} \mathrm{C}$, a feed gas composition of $60 \mathrm{~mol} \%$ 1-hexene and a space time of $400 \mathrm{~g}$.min.mol ${ }^{-1}$. The conversion of 1 -hexene, the yield of the detergent range olefins $\left(\mathrm{C}_{10}-\mathrm{C}_{16}\right)$ 
and the yield of the primary metathesis product, decene $\left(\mathrm{C}_{10}\right)$ at the above mentioned reaction conditions were $82 \%, 8.30 \%$ and $5.92 \%$ respectively.

A large decrease in conversion (40\%) was observed when using the $0.5 \mathrm{wt} \%$ potassium doped $\mathrm{WO}_{3} / \mathrm{SiO}_{2}$ catalyst, as compared to the $0.1 \mathrm{wt} \%$ potassium doped $\mathrm{WO}_{3} / \mathrm{SiO}_{2}$ catalyst $(73 \%$ conversion) and the $8 \mathrm{wt} \% \mathrm{WO}_{3} / \mathrm{SiO}_{2}$ catalyst with no doping ( $83 \%$ conversion). This was attributed to the poisoning of the Brønsted acid sites first by the potassium, and as the loading of potassium increased, the Lewis acid sites responsible for the initiation of the metathesis reaction were targeted, resulting in the large drop in conversion.

Experimental runs conducted with potassium doping at 0.1 and $0.5 \mathrm{wt} \%$ on $\mathrm{WO}_{3} / \mathrm{SiO}_{2}$ catalyst, at the optimum conditions determined above, were found to be successful in reducing the isomerization and increasing the selectivity and yield of the detergent range olefins and decene. An increase of approximately $2 \%$ for the yield of decene and $1.5 \%$ for the detergent range olefins was achieved. The $0.5 \mathrm{wt} \%$ doping level achieved the highest selectivity of $24.64 \%$ towards the detergent range olefins and $23.62 \%$ towards decene. Although a high selectivity was achieved, the small increase in yields was due to the low conversion of 1 -hexene $(36.79 \%)$. The doping level of $0.05 \mathrm{wt} \%$ potassium on $\mathrm{WO}_{3} / \mathrm{SiO}_{2}$ catalyst displayed the opposite behavior than expected theoretically and further studies are recommended.

The surface area of the potassium doped catalysts was found to decrease with an increase in the loading of potassium due to the accumulation of the alkali metal in the pores of the support. The carbon balance conducted for all experimental runs using the $8 \mathrm{wt} \% \mathrm{WO}_{3} / \mathrm{SiO}_{2}$ catalyst and the potassium doped $\mathrm{WO}_{3} / \mathrm{SiO}_{2}$ catalysts indicated consistency in the data to within an approximate error of $10-15 \%$ (absolute).

Statistical analyses conducted on the potassium doped $\mathrm{WO}_{3} / \mathrm{SiO}_{2}$ catalyst by both the normal probability plot and the analysis of variance (ANOVA) table revealed that the effects of reaction temperature and specific loading of potassium were significant as well as the interaction between the two. The interaction effect implies that the optimum temperature may only be the optimum at a particular specific loading. In practice, this implies that running at the optimum temperature and specific loading determined is important to obtain the highest yields, whereas running over a wide range of feed compositions (60-80 mol\% 1-hexene) or space time (200-400 g.min.mol ${ }^{-1}$ ) does not significantly affect the yield produced. The assumption of linearity was also tested and found to hold true. 


\section{REFERENCES}

1. ACRES, G.J.K., BIRD, A.J., JENKINS, J.W. \& KING, F., 1981. The design and preparation of supported catalysts. In: C. KEMBALL, D.A. DOWDEN, Catalysis. RSC Publishing, 4, $1-30$

2. ANDERSON, J. R. \& PRATT, K. C., 1985., Introduction to Characterisation and Testing of Catalysts. Australia: Academic Press

3. COPÉRET, C., 2009. Stabilising reactive intermediates through site isolation. Pure Applied Chemistry, 81, 585-596

4. DECOURSEY. W.J., 2003. Statistics and Probability for Engineering Applicatiions with Microsoft Excel. USA: Elsevier Science.

5. DELAUDE, L. \& NOELS, A.F., 2001. Metathesis. Kirk-Othmer Encyclopedia of Chemical Technology, Vol. 26, pp. 920-958

6. LANGNER, B.E. \& MEYER, S., 1980. The Mechanism of Coke Formation in the Reaction of Butadiene on Calcined $\mathrm{NaNH}_{4}$-Y. In : B. DELMON \& G.F. FROMENT, Catalyst Deactivation. Amsterdam: Elsevier Scientific Publishing Company, pp. 91 102

7. DWYER, C.L., 2006. Metathesis of Olefins. In : G.P. CHIUSOLI \& P.M. MAITLIS, Metal Catalysis in Industrial Organic Processes. Cambridge, UK: RSC Publishing, pp. $201-216$

8. EBERLY, P.E., KIMBERLIN, C.N., MILLER, W.H. \& DRUSHEL, H.V., 1966. Coke Formation on Silica-Alumina Cracking Catalysts. Industrial \& Engineering Chemistry (Process Design \& Development) 5, 193

9. FIERRO, J.L.G. \& MOL, J.C., 2006. Metathesis of olefins on metal oxides. In: J.L.G. FIERRO, Metal Oxides, Chemistry and Applications. CRC Press, pp. 517 - 543

10. GRUBBS, R. H. 2004. Olefin metathesis. Tetrahedron, 60, 7117-7140.

11. HARMSE, L., VAN SCHALKWYK, C. \& VAN STEEN, E. 2010. On the product formation in 1-butene metathesis over supported tungsten catalysts. Catalysis Letters, 137, 123-131.

12. HORSLEY, J.A., WACHS, I.E., BROWN, J.M., VIA, G.H. \& HARDCASTLE, F.D. 1987. Structure of Surface Tungsten Oxide Species in the $\mathrm{WO}_{3} / \mathrm{Al}_{2} \mathrm{O}_{3}$ Supported Oxide System from X-Ray Absorption Near-Edge Spectroscopy and Raman Spectroscopy. Journal of Physical Chemistry, 91, 4014-4020

13. HUANG, S., CHEN, F., LIU, S., ZHU, Q., ZHU, X., XIN, W., FENG, Z., LI, C., WANG, Q. \& XU, L. 2007a. The influence of preparation procedures and tungsten 
loading on the metathesis activity of ethene and 2-butene over supported $\mathrm{WO}_{3}$ catalysts. Journal of Molecular Catalysis A: Chemical, 267, 224-233.

14. HUANG, S., LIU, S., ZHU, Q., ZHU, X., XIN, W., LIU, H., FENG, Z., LI, C., XIE, S., WANG, Q. \& XU, L. 2007b. The effect of calcination time on the activity of $\mathrm{WO} 3 / \mathrm{Al} 2 \mathrm{O} 3 / \mathrm{HY}$ catalysts for the metathesis reaction between ethene and 2-butene. Applied Catalysis A: General, 323, 94-103.

15. HUGHES, R, 1984. Deactivation of Catalysts, London: Academic Press Inc.

16. HÜTTINGER, K. J. \& MINGES, R., 1986. Influence of the catalyst precursor anion in catalysis of water vapour gasification of carbon by potassium: 1 . Activation of the catalyst precursors. Fuel, 65, 1112-1121

17. KRIEL, F.H., 2008. Catalytic Isomerization of internal and terminal alkenes. Thesis $(\mathrm{PhD})$, Department of Chemistry, University of Johannesburg

18. LEARDI, R., 2009. Experimental Design in Chemistry: A tutorial. Analytica Chimica Acta, 652, 161-172

19. LLAMBIAS, F.J.G., ESCALONA, N., PFAFF, C., SCOTT, C. \& GOLDWASSER, J., 1999. Comparison of Surface Coverage Values of Tungsten-Alumina Catalysts Determined by Different Methods. Reaction Kinetics Catalysis Letters, 66, 225-229

20. LOGIE, V., MAIRE, G., MICHEL, D. \& VIGNES, J.L., 1999. Skeletal Isomerization of Hexenes on Tungsten Oxide Supported on Porous $\alpha$-Alumina. Journal of Catalysis, 188, $90-101$

21. LOKHAT, D., 2008. Metathesis of 1-Hexene over a $\mathrm{WO}_{3} / \mathrm{SiO}_{2}$ Catalyst in a Gas Phase Fixed Bed Reactor. Thesis (MSc), University of KwaZulu- Natal

22. MATAR, S. \& HATCH, L.F., 2001. Chemistry of petrochemical processes. $2^{\text {nd }}$ ed. USA: Butterworth- Heinemann

23. MATSUZAKI, I., NITTA, M \& TANABE, K., 1968. Application of Hammett Indicators to Estimating Coverages of Acid Sites of Silica-Alumina by Nitrogen, Ethylene, Water, Ethyl Alcohol, Pyridine and N-Butylamine. Journal of the Research Institute for Catalysis, 17, 46-53

24. MILLAR, G. J. \& ROCHESTER, C.H., 1996. A Fourier-transform infrared study of $\mathrm{CO}_{2}$ and $\mathrm{CO}_{2} / \mathrm{H}_{2}$ interactions with caesium-doped copper catalysts. Topics in Catalysis $3,103-114$

25. MOL, J. C. \& LEEUWEN, P.W.N.M. 2008. Metathesis of Alkenes. Handbook of Heterogeneous Catalysis, pp. 3240-3256

26. MOL, J. C. 2004. Industrial applications of olefin metathesis. Journal of Molecular Catalysis A: Chemical, 213, 39-45. 
27. MONTGOMERY, D.C., 1998., Engineering Statistics. USA: John Wiley and Sons

28. MONTGOMERY, D.C. \& RUNGER, G.C., 2007. Applied Statistics and Probability for Engineers. USA: John Wiley \& Sons.

29. NIST/SEMATECH. (2010). e-Handbook of Statistical Methods [online]. US, NIST. Available from: http://itl.nist.gov/div898/handbook/index.htm [Accessed MarchNovember 2011]

30. PEREGO, C. \& VILlA, P. 1997. Catalyst Preparation Methods. Catalysis Today, 34, 281-305

31. PERRICHON, V. \& DURUPTY, M.C., 1988. Thermal Stability of Alkali Metals Deposited on Oxide Supports and their Influence on the Surface Area of the Support. Applied Catalysis, 42, 217-227

32. PINNA, F. 1998. Supported Metal Catalyst Preparation. Catalysis Today, 41, 129-137

33. RODRIGUEZ-RAMOS, I., GUERRERO-RUIZ, A., HOMS, N., RAMIREZ DE LA PISCINA, P., FIERRO, J.L.G. 1994. Reactions of propene on supported molybdenum and tungsten oxides. Journal of Molecular Catalysis A: General, 95, 147-154.

34. ROUESSAC, F. \& ROUESSAC, A., 2007. Chemical Analysis: Modern Instrumentation Methods and Techniques. $2^{\text {nd }}$ Ed. England: John Wiley and Sons Ltd

35. ROUHI, A.M., 2002. Olefin Metathesis: Big Deal Reaction. Chemical \& Engineering News. 23 December. pp. 29-33

36. SASOL TECHNOLOGY (PTY) LIMITED. 2004. Metathesis catalyst and process. South African patent application WO 2004/016351 A1. 2004-02-26.

37. SATTERFIELD, C.N., 1991. Heterogeneous Catalysis in Industrial Practice, $2^{\text {nd }}$ edition. United States: McGraw- Hill, Inc

38. SCHALKWYK, C. V., SPAMER, A., MOODLEY, D. J., DUBE, T., REYNHARDT, J. \& BOTHA, J. M. 2003. Application of a $\mathrm{WO}_{3} / \mathrm{SiO}_{2}$ catalyst in an industrial environment: part I. Applied Catalysis A: General, 255, 121-131.

39. SCHALKWYK, C., SPAMER, A., MOODLEY, D. J., DUBE, T., REYNHARDT, J., BOTHA, J. M. \& VOSLOO, H. C. M. 2003. Factors that could influence the activity of a WO3/SiO2 catalyst: Part III. Applied Catalysis A: General, 255, 143-152.

40. SCHEKLER-NAHAMA, F., CLAUSE, O., COMMEREUC, D. \& SAUSSEY, J. 1997. Influence of Lewis acidity of rhenium heptoxide supported on alumina catalyst on the catalytic performances in olefin metathesis. Applied Catalysis A: General,167, 237-245

41. SCHELL, D.J., FARMER, J., NEWMAN, M. \& McMILLAN, J.D., 2003. DiluteSulphuric Acid Pretreatment of Corn Stover in Pilot-Scale Reactor. Humana Press Inc., 03, 105-108 
42. SPAMER, A., DUBE, T. I., MOODLEY, D. J., VAN SCHALKWYK, C. \& BOTHA, J. M. 2003. Application of a $\mathrm{WO}_{3} / \mathrm{SiO}_{2}$ catalyst in an industrial environment: part II. Applied Catalysis A: General, 255, 133-142

43. SPAMER, A., DUBE, T. I., MOODLEY, D. J., VAN SCHALKWYK, C. \& BOTHA, J. M. 2003. The reduction of isomerization activity on a $\mathrm{WO}_{3} / \mathrm{SiO}_{2}$ metathesis catalyst. Applied Catalysis A: General, 255, 153-167

44. STILES, A.B., 1987. Catalyst Supports and Supported Catalysts: Theoretical and Applied Concepts, United States: Butterworth Publishers

45. TANABE, K., MISONO, M., ONO, Y. \& HATTORI, H., 1989. New solid acids and bases: their catalytic properties, Amsterdam: Elsevier Science Publishers B.V.

46. THOMAS, R. \& MOULIJN, J. A. 1980. Structure/metathesis activity relations of silica supported molyndenum and tungsten oxide. Journal of Molecular Catalysis, 8, 161-174

47. TRIMM, D.L., 1982. Introduction to Catalyst Deactivation. In : FIGUEIREDO, J.L., Progress in Catalyst Deactivation. The Netherlands: Martinus Nijhoff Publishers. 3- 22

48. TRIMM, D.L., 1982. Coke Formation in the Gas Phase and on Surfaces. In : FIGUEIREDO, J.L., Progress in Catalyst Deactivation. The Netherlands: Martinus Nijhoff Publishers. 31- 43

49. VAN DER VLIES, A.J., 2002. Chemical Principles of the Sulfidation Reaction of Tungsten Oxides. Thesis (PhD), Swiss Federal Institute of Technology Zurich.

50. VAN ROOSMALEN, A.J. \& MOL, J.C., 1982. Active Centers for the Metathesis and Isomerization of Alkenes on Tungsten Oxide/Silica Catalysts. Journal of Catalysis. 78,17-23

51. WAGNER, P.H., 1992. Olefin Metathesis- Applications for the nineties. Chemistry and Industry, 4 May, pp. 330-333

52. YURDAKOÇ, M., AKÇAY, M., TONBUL, Y. \& YURDAKOÇ, K. 1999. Acidity of Silica-Alumina Catalysts by Amine Titration Using Hammett Indicators and FT-IR Study of Pyridine Adsorption. Turkish Journal of Chemistry, 23, 319-327 


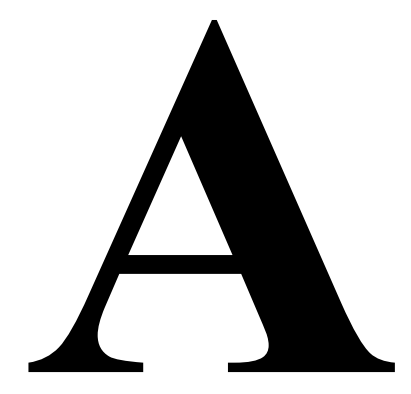

\section{APPENDIX A}

\section{EQUIPMENT CALIBRATION PLOTS}

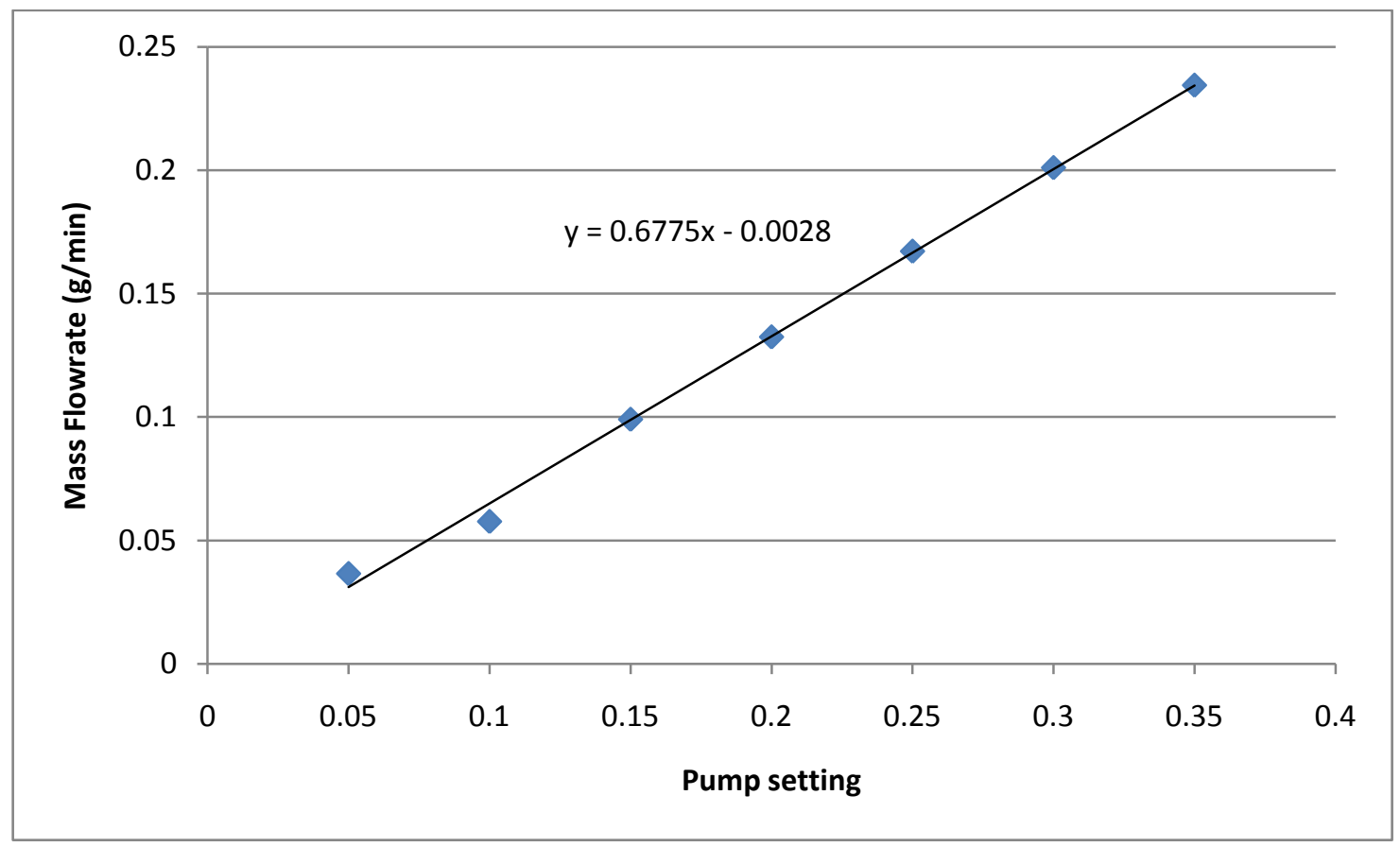

Figure A.1: Spectrochrom P100 isocratic pump calibration for 1-hexene 


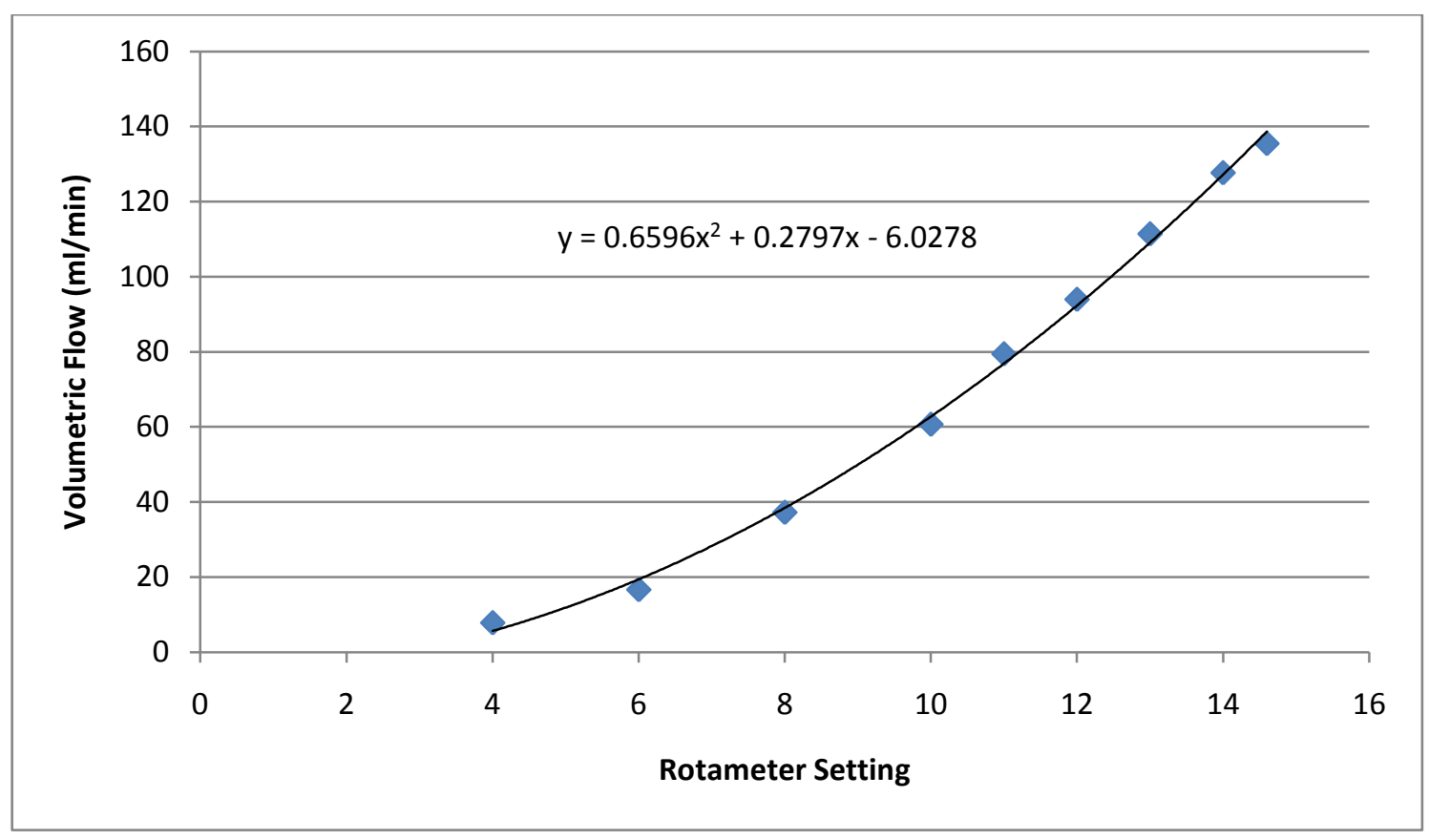

Figure A.2: Rotameter calibration for the Bailey Porter Fischer 10A6132NB1C precision bore flowrator tube using nitrogen gas 


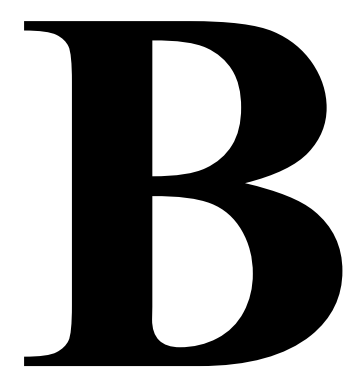

APPENDIX B

\section{GC CALIBRATION PLOTS}

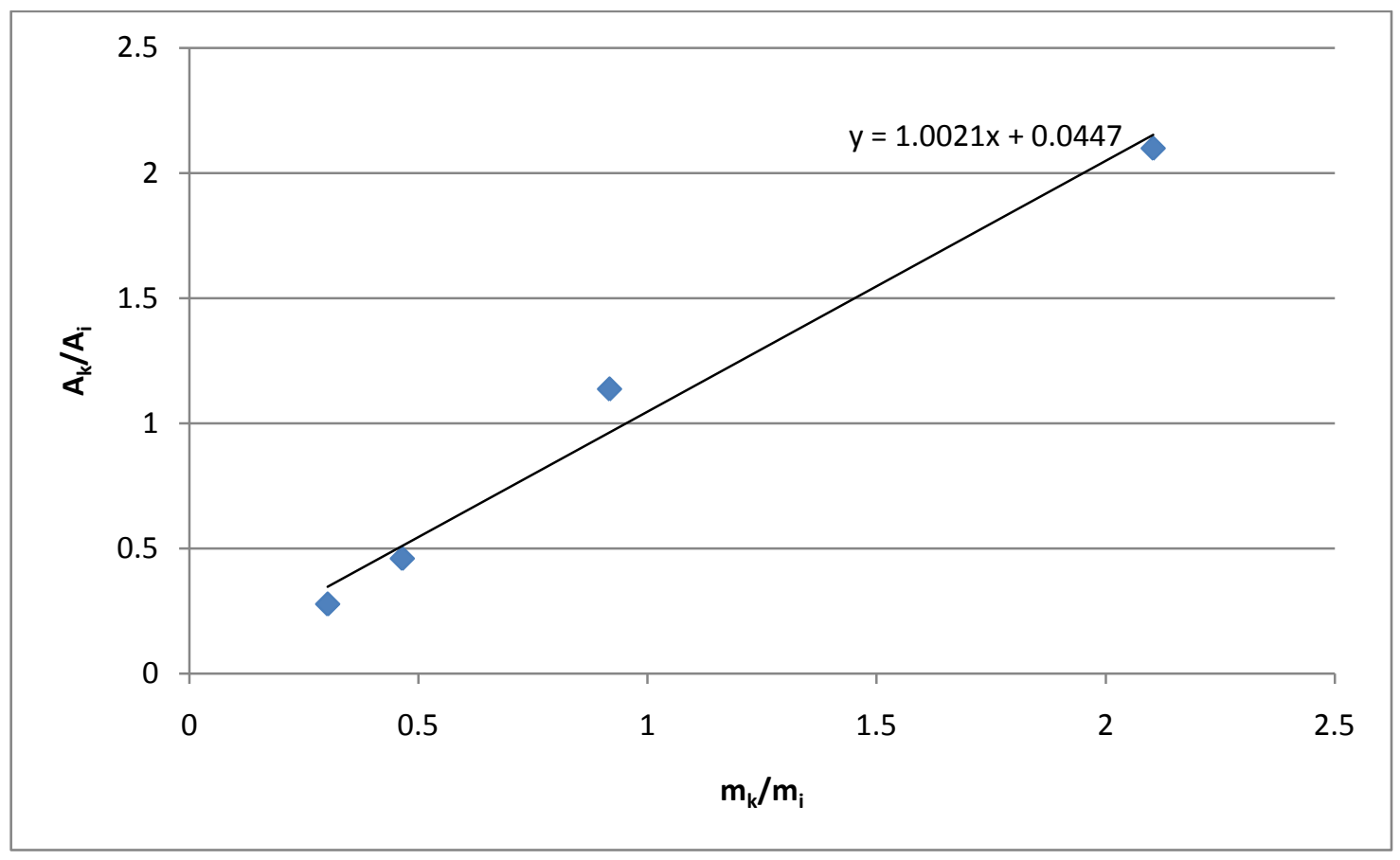

Figure B.1: GC calibration plot for pentene 


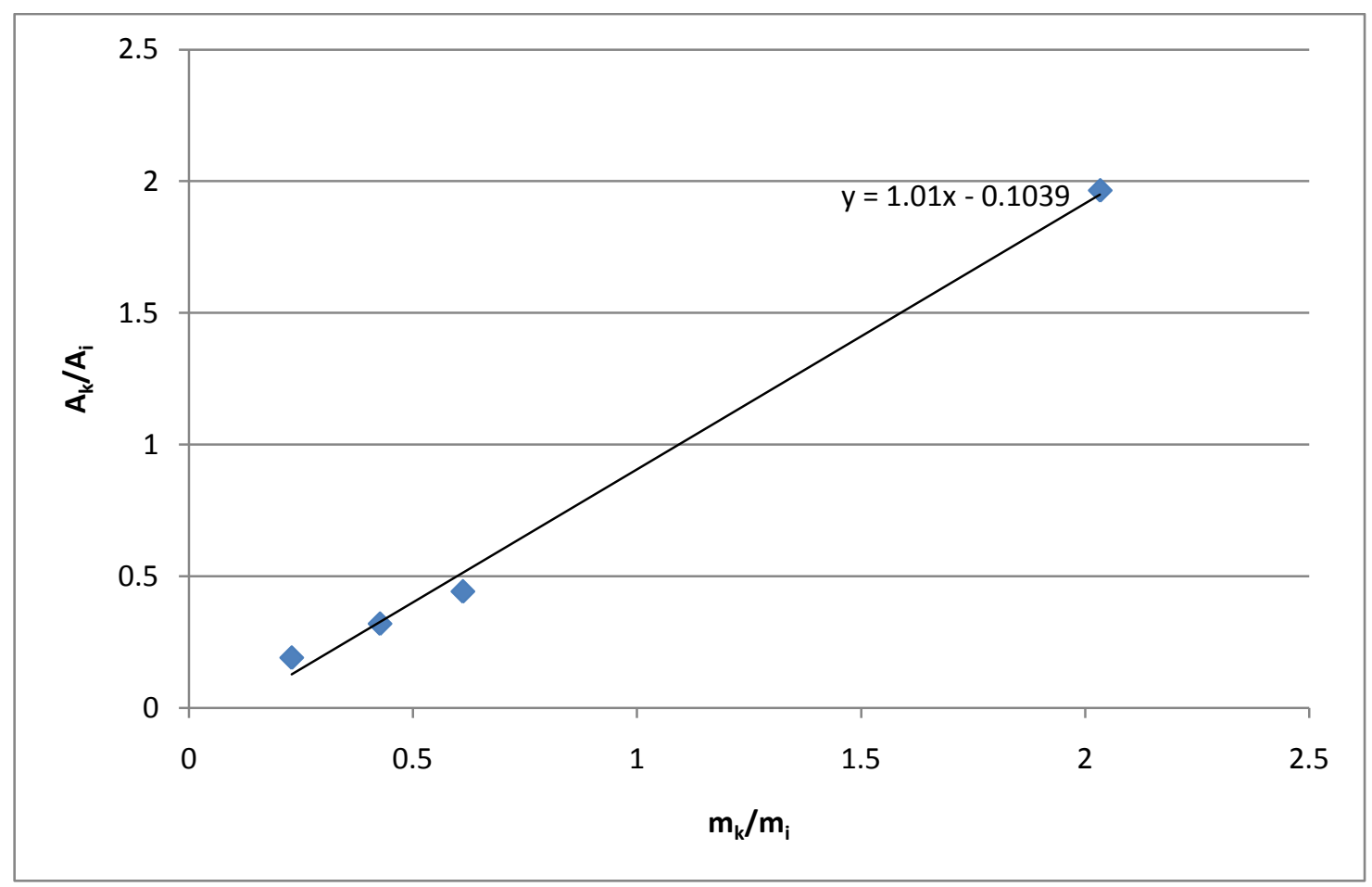

Figure B.2: GC calibration plot for heptene

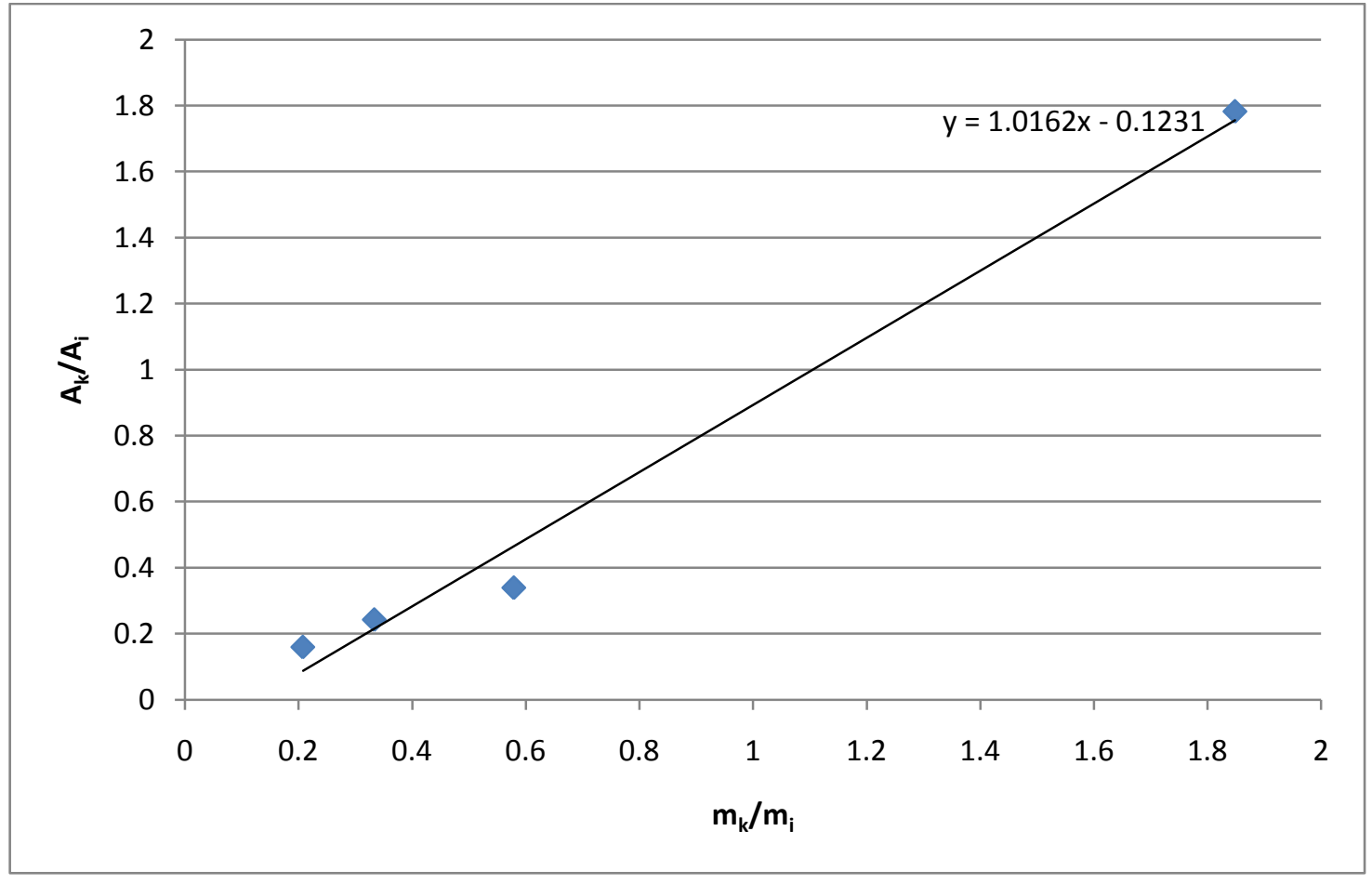

Figure B.3: GC calibration plot for octene 


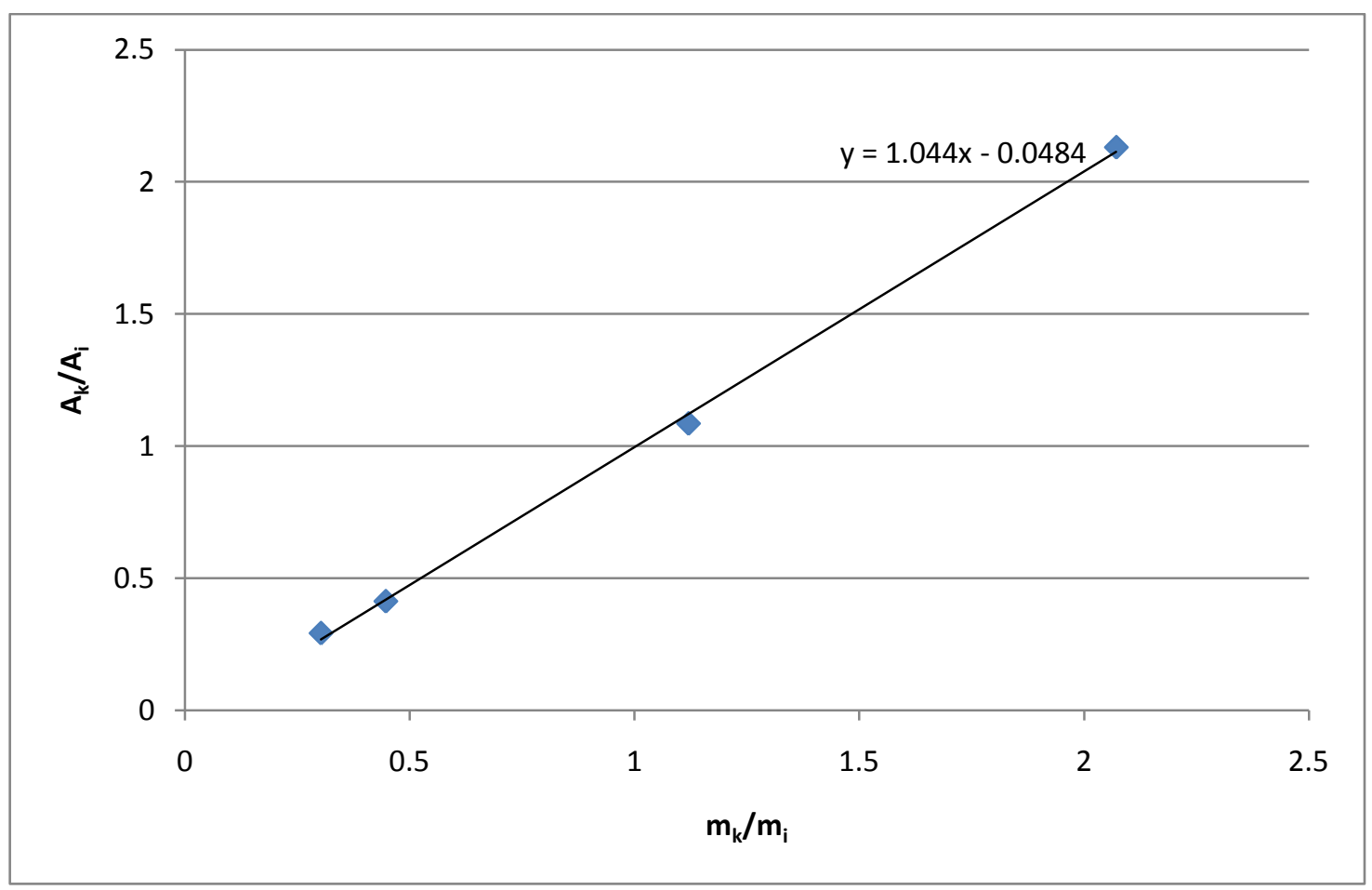

Figure B.4: GC calibration plot for nonene

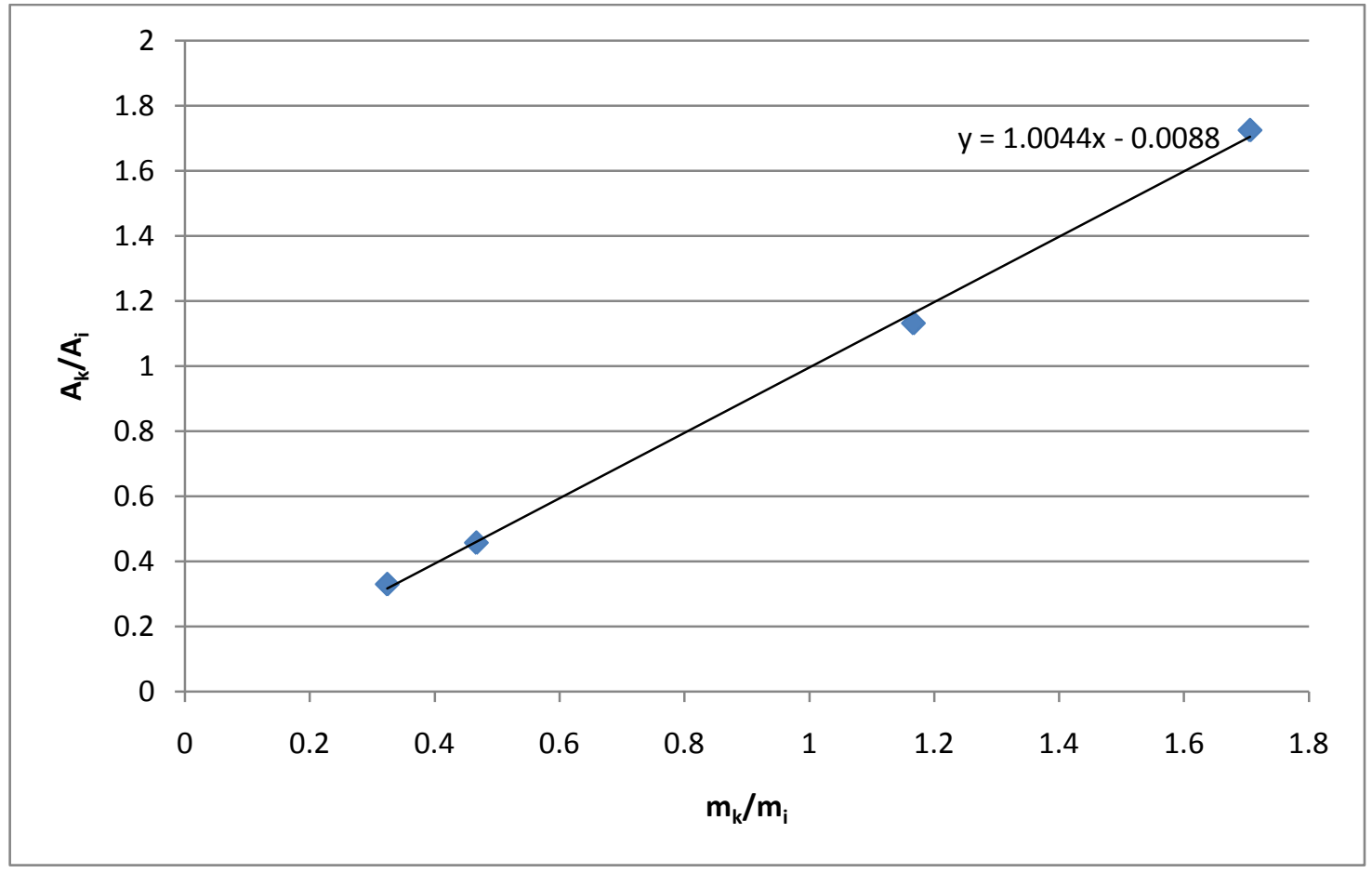

Figure B.5: GC calibration plot for decene 


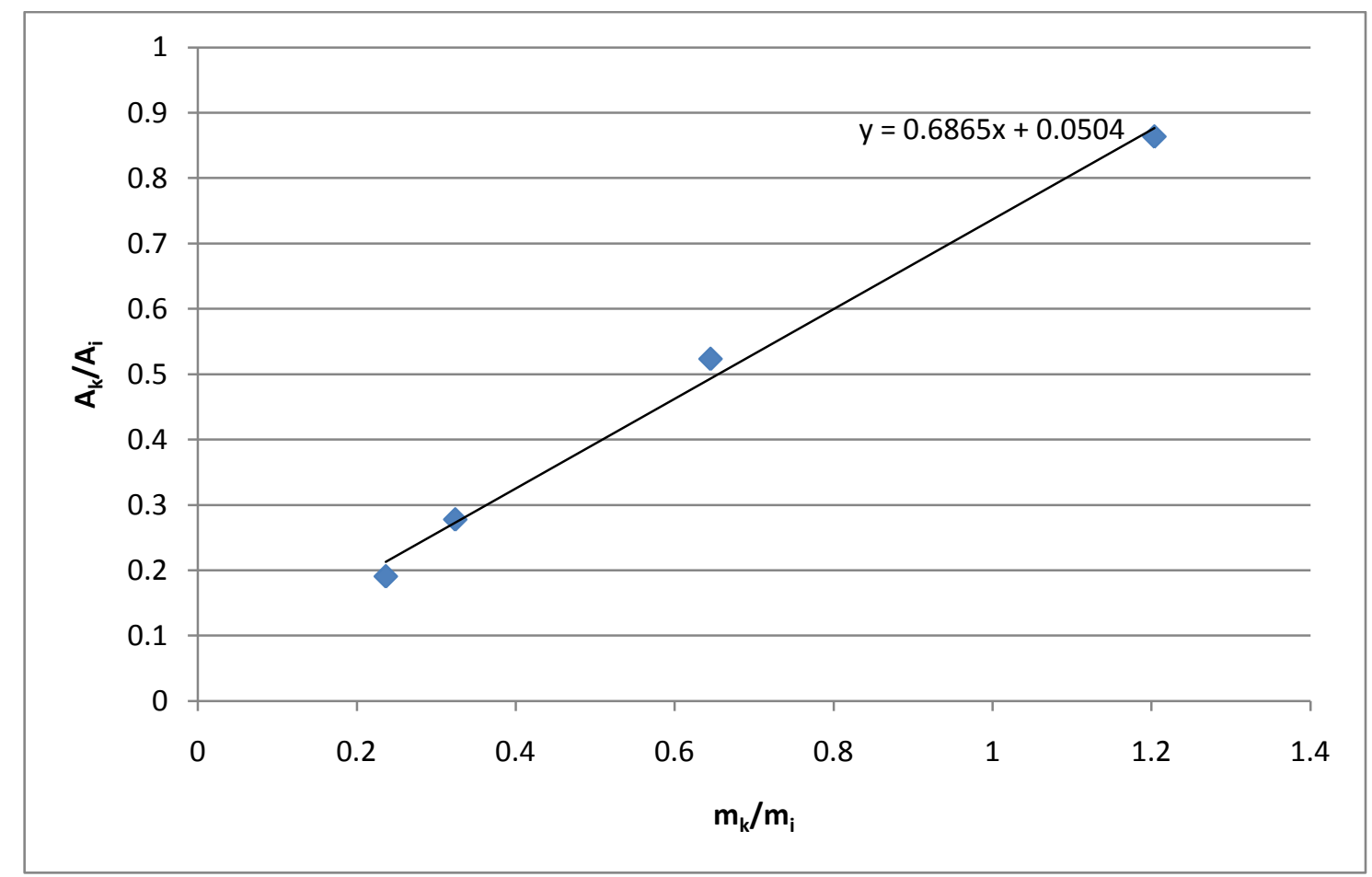

Figure B.6: GC calibration plot for tetradecane

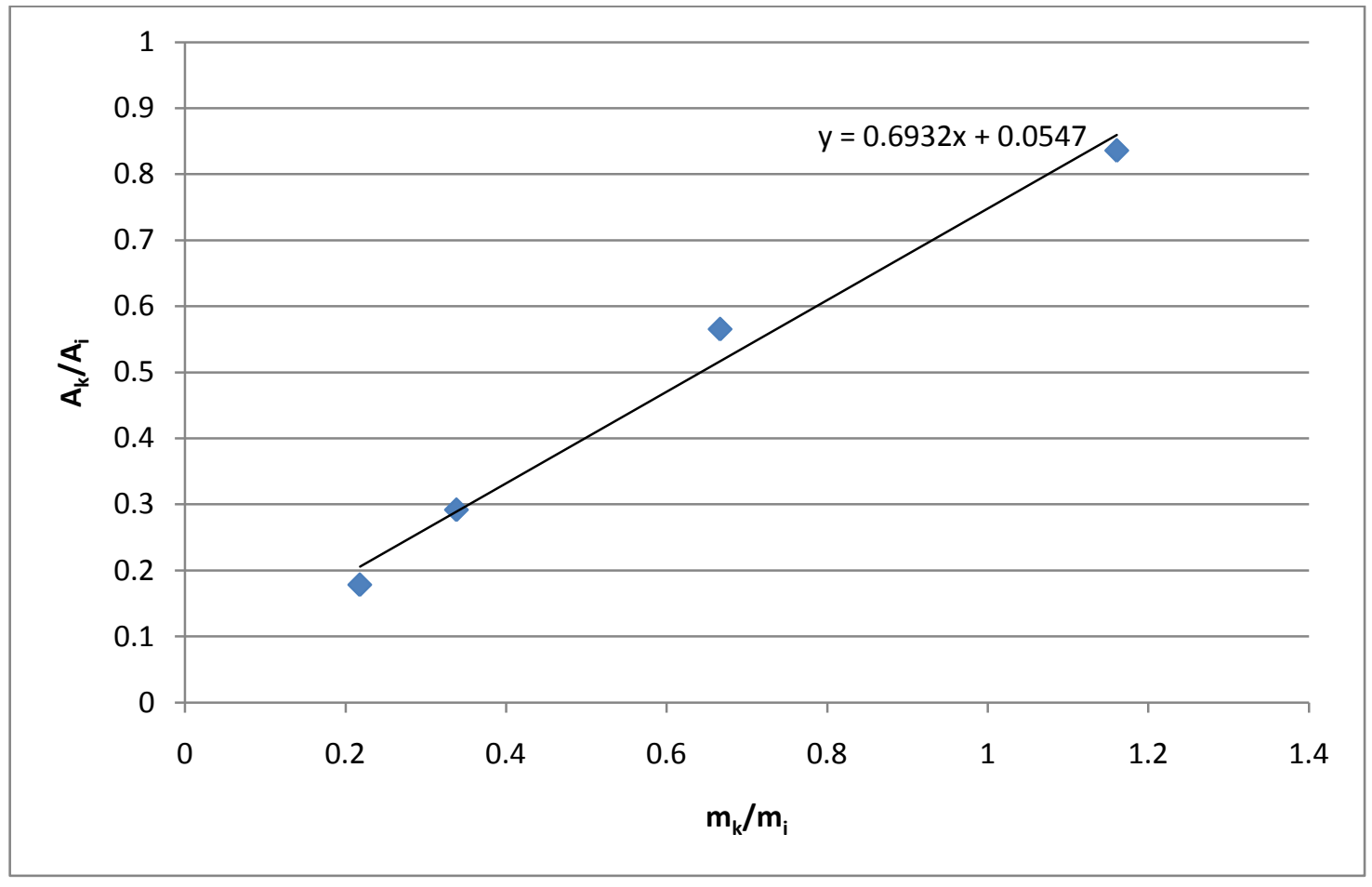

Figure B.7: GC calibration plot for pentadecane 


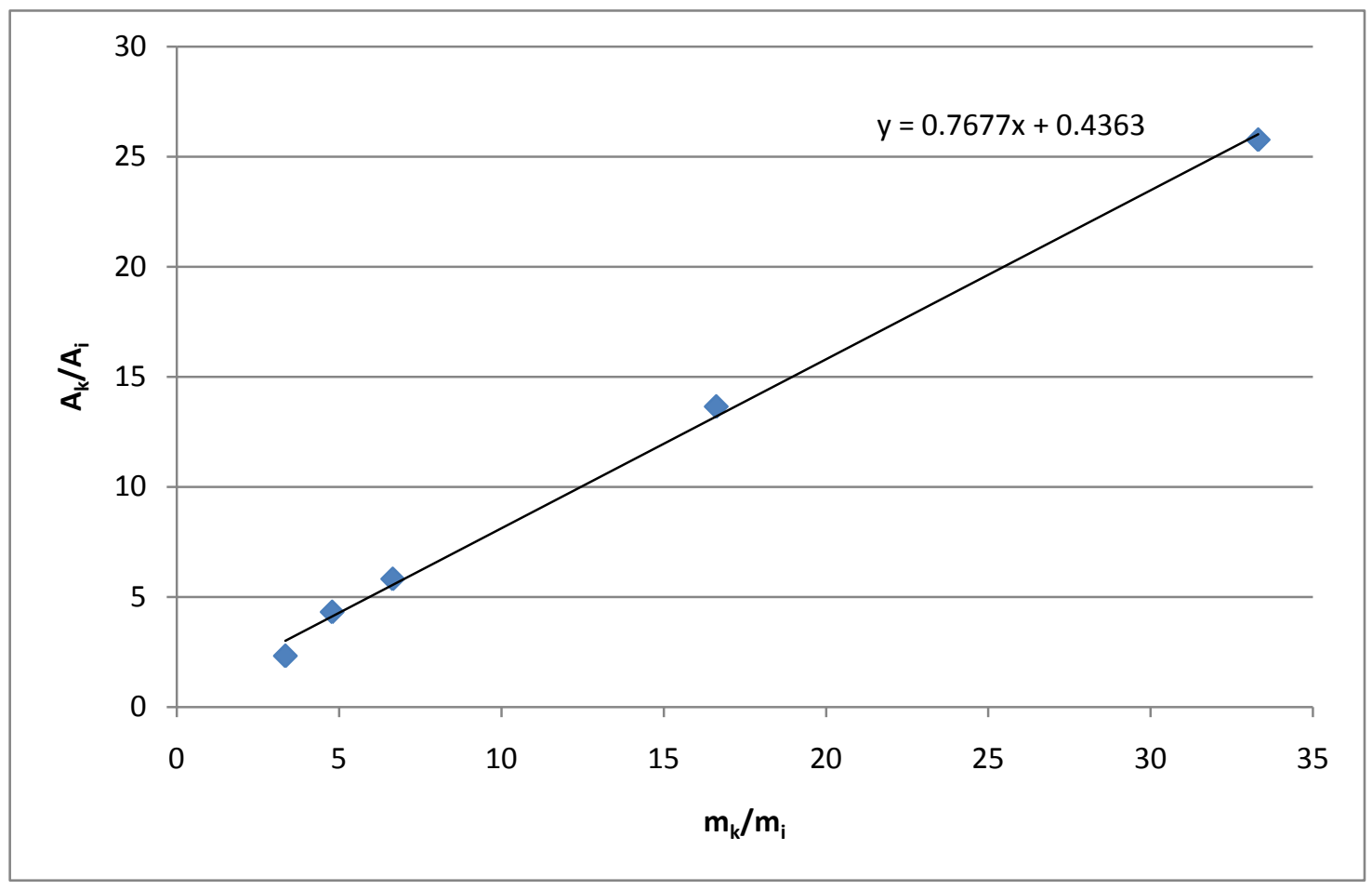

Figure B.8: GC calibration plot for ethylene (updated from Lokhat, 2008)

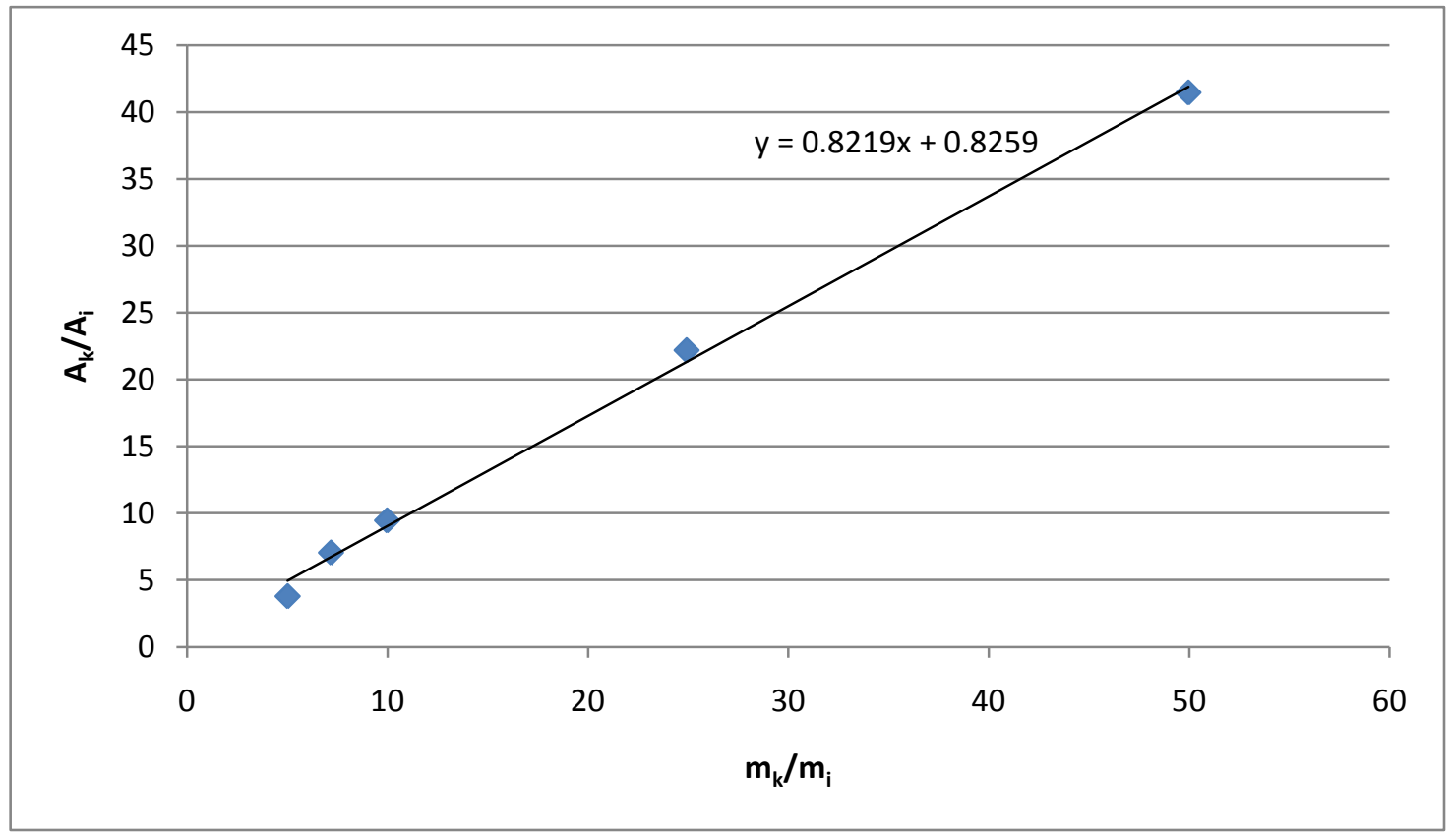

Figure B.9: GC calibration plot for propylene (updated from Lokhat, 2008) 


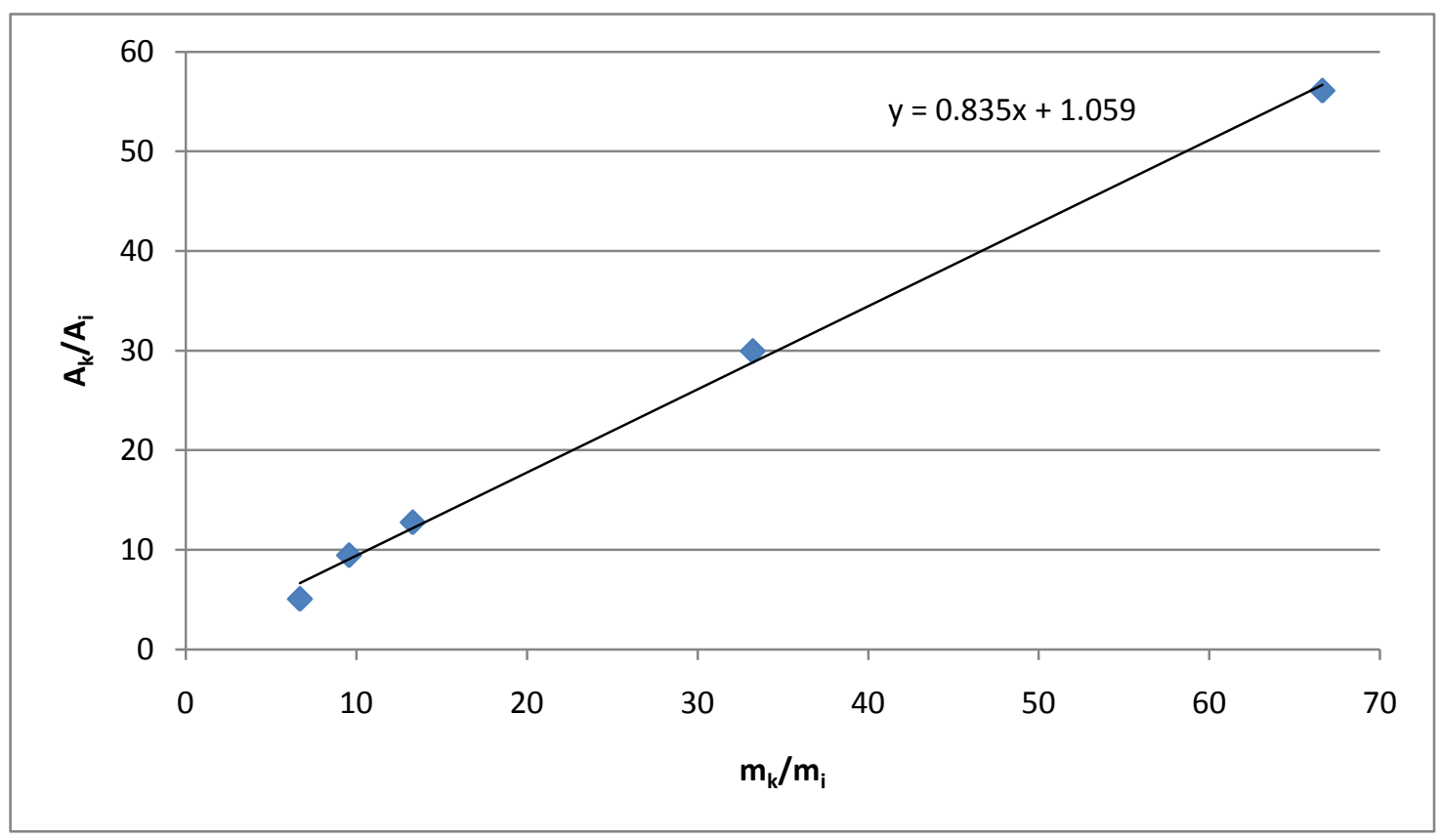

Figure B.10: GC calibration plot for butene (updated from Lokhat, 2008) 


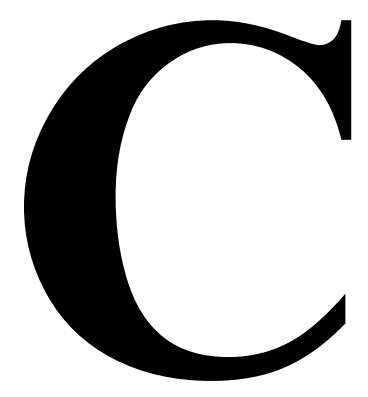

\section{APPENDIX C}

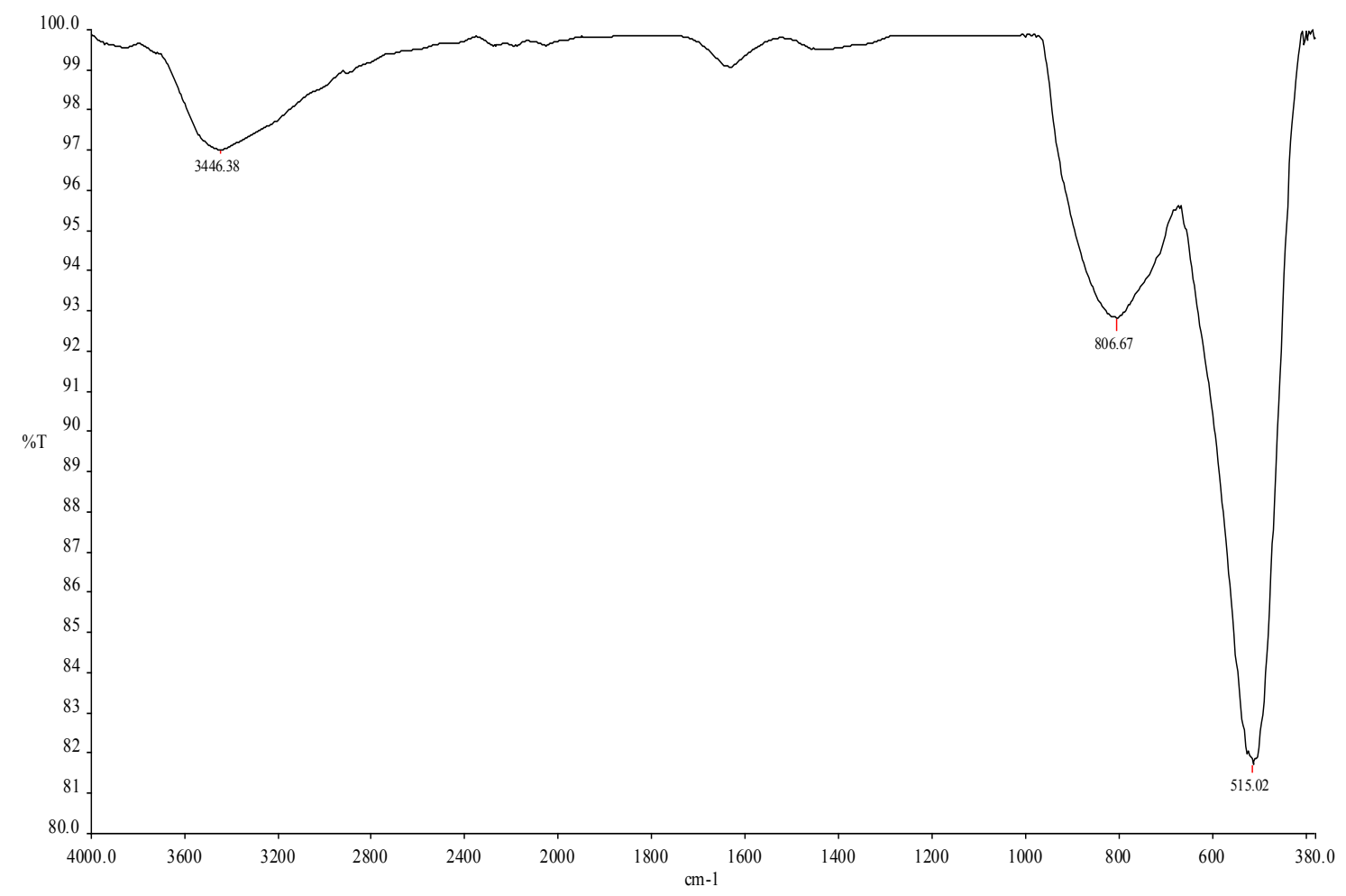

Figure C.1: FTIR spectra for $10 \mathrm{wt} \% \mathrm{WO}_{3} / \mathrm{Al}_{2} \mathrm{O}_{3}$ 


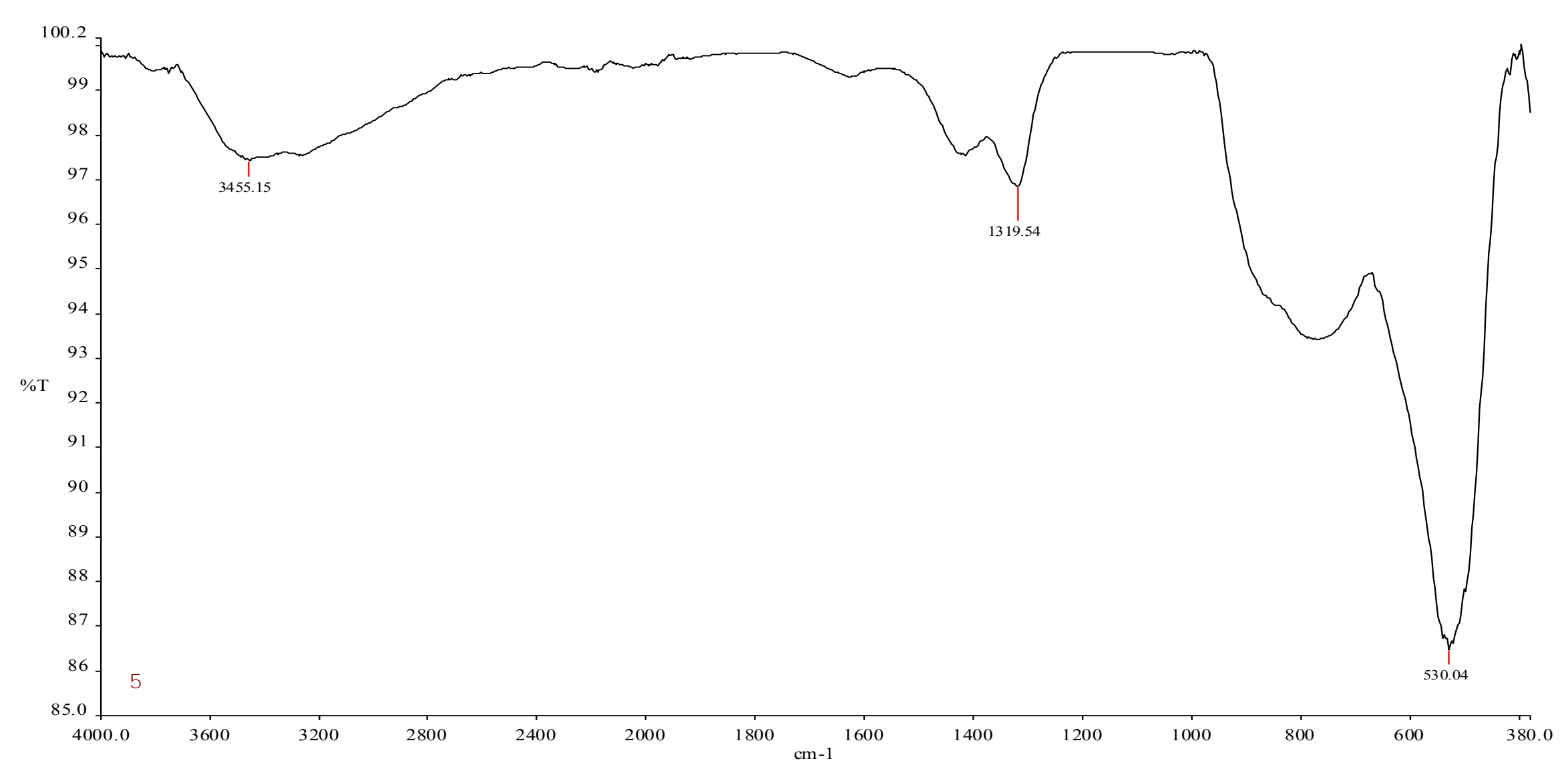

Figure C.2: FTIR spectra for $16 \mathrm{wt} \% \mathrm{WO}_{3} / \mathrm{Al}_{2} \mathrm{O}_{3}$ 


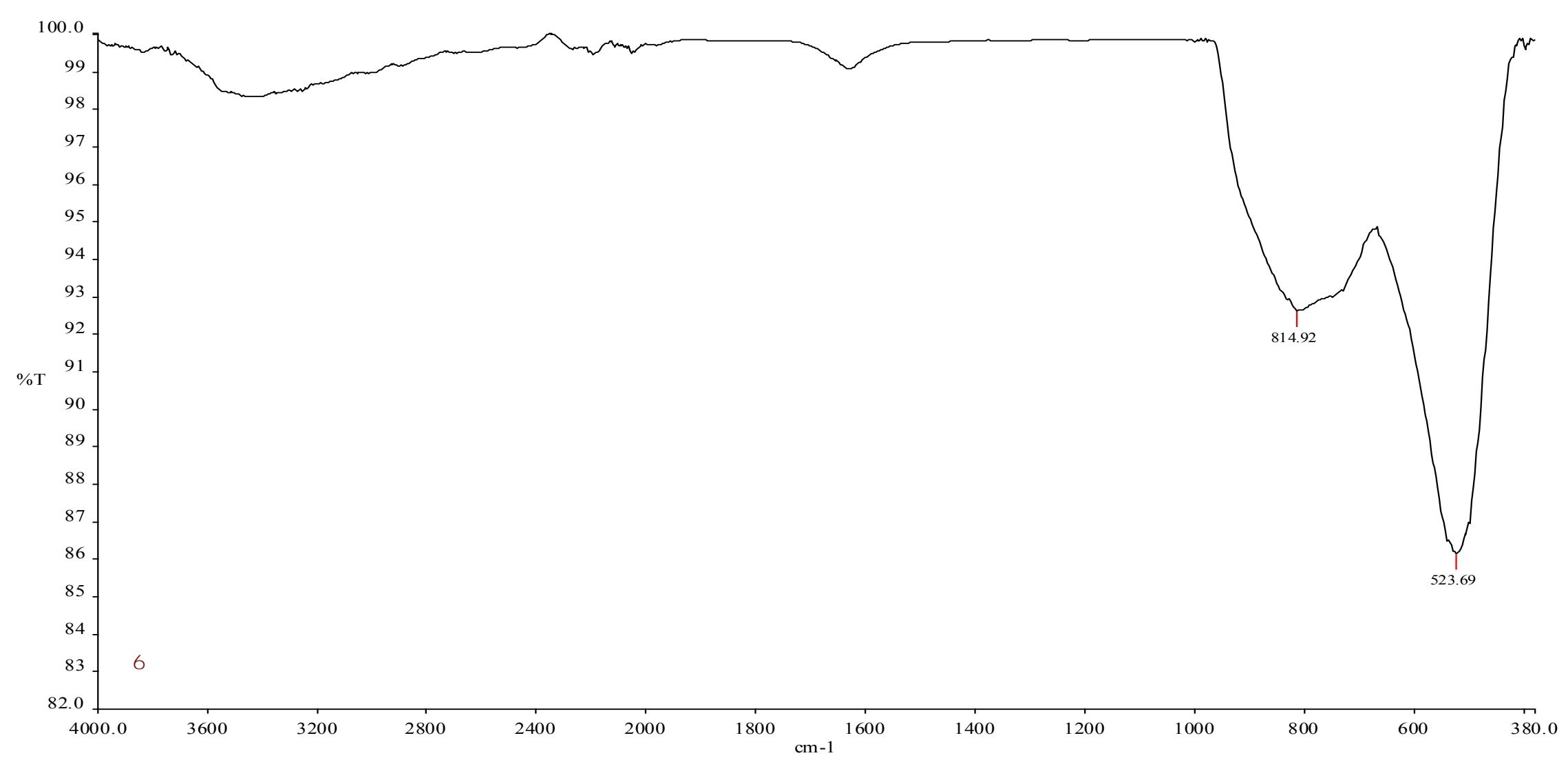

Figure C.3: FTIR spectra for $20 \mathrm{wt} \% \mathrm{WO}_{3} / \mathrm{Al}_{2} \mathrm{O}_{3}$ 


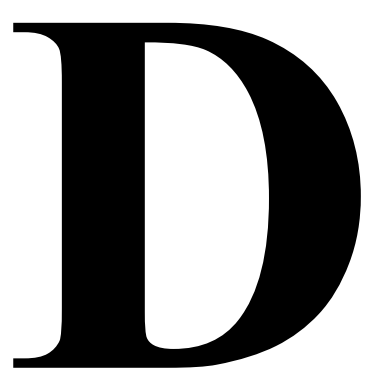

APPENDIX D

\section{SAMPLE CALCULATIONS}

\section{- Catalyst preparation sample calculation}

The following sample calculation was performed for the preparation of the $10 \mathrm{wt} \% \mathrm{WO}_{3} / \mathrm{Al}_{2} \mathrm{O}_{3}$ catalyst.

Mass $\mathrm{Al}_{2} \mathrm{O}_{3}=10.006 \mathrm{~g}$

Mass of catalyst desired $=$ Mass $\mathrm{Al}_{2} \mathrm{O}_{3}+$ Mass $\mathrm{WO}_{3}$ required

$$
\begin{aligned}
& =\text { Mass } \mathrm{Al}_{2} \mathrm{O}_{3}+\left(\text { Mass catalyst desired } \times \frac{\text { specific loading }}{100}\right) \\
& =10.006+\text { Mass catalyst desired } \times \frac{10}{100}
\end{aligned}
$$

Dividing through by the mass of catalyst desired gives:

$1=\frac{10.006}{\text { Mass of catalyst desired }}+\frac{10}{100}$

$1-\frac{10}{100}=\frac{10.006}{\text { Mass of catalyst desired }}$

$0.9=\frac{10.006}{\text { Mass of catalyst desired }}$ 
$\therefore$ Mass of catalyst desired $=\frac{10.006}{0.9}$

$$
=11.118 \mathrm{~g}
$$

Mass $\mathrm{WO}_{3}$ required $=$ Mass catalyst desired $\times \frac{\text { specific loading }}{100}$

$$
\begin{aligned}
& =11.118 \times \frac{10}{100} \\
& =\mathbf{1 . 1 1 2} \mathbf{g}
\end{aligned}
$$

Molar mass of $W_{3}=\mathbf{2 3 1 . 8 3 7 ~} \mathrm{g} / \mathbf{m o l}$

Moles of $\mathrm{WO}_{3}$ required $=\frac{\text { Mass } \mathrm{WO}_{3} \text { required }}{\text { Molar mass of } \mathrm{WO}_{3}}$

$$
\begin{aligned}
& =\frac{1.112}{231.837} \\
& =0.0048 \text { moles }
\end{aligned}
$$

Moles of $W$ metal $=\mathbf{0 . 0 0 4 8}$ moles

Molar mass of AMT (ammonium metatungstatehydrate) $=2956.3 \mathrm{~g} / \mathbf{m o l}$

AMT formula $=\left(6\left(\mathrm{NH}_{4}\right)\left[\mathrm{H}_{2} \mathrm{~W}_{12} \mathrm{O}_{40}\right] \cdot \mathrm{xH}_{2} \mathrm{O}\right)$

12 moles $W$ in 1 mole $A M T$

$$
\begin{aligned}
\text { Moles AMT } & =\frac{\text { Moles of } W \text { metal }}{12} \\
& =\frac{0.004795515}{12} \\
& =\mathbf{0 . 0 0 0 4} \text { moles }
\end{aligned}
$$

Mass AMT $=$ Moles AMT $\times$ Molar mass of $A M T$

$$
=0.0004 \times 2956.3
$$

$=1.181 \mathrm{~g}$ 


\section{- Experimental analysis sample calculation}

The following sample calculation was performed for run 1 using the $10 \mathrm{wt} \% \mathrm{WO}_{3} / \mathrm{Al}_{2} \mathrm{O}_{3}$ catalyst.

$$
\begin{aligned}
& \text { Mass flow of liquid product }\left(\frac{g}{\mathrm{~min}}\right)=\frac{\text { mass of product collected }(\mathrm{g})}{\text { collection time }(\mathrm{min})} \\
& \qquad=\frac{15.59}{86.43}=\mathbf{0 . 1 8 \mathrm { g } / \mathbf { m i n }} \\
& \begin{aligned}
F_{N 2}^{\text {in }} & =\frac{P \dot{V}}{R T} \\
& =\frac{B F M \text { feed } \text { pressure } \times B F M \text { feed volumetric flow }}{R \times B F M \text { feed temperature }} \\
& =\frac{(99.1 \times 1000) \times\left(\frac{5}{4.88}\right) \times 10^{-6}}{8.314 \times(23.1+273.15)} \\
& =\mathbf{4 . 1 1} \times \mathbf{1 0}^{-5} \mathbf{m o l} / \mathbf{s}
\end{aligned}
\end{aligned}
$$

$$
\begin{aligned}
F_{(1-\text { hexene })} & \text { in } \\
= & \frac{\text { mass flow hexene in }\left(\frac{g}{\mathrm{~min}}\right)}{60 \times M M_{\text {hexene }}} \\
= & \frac{0.2104}{60 \times 84.161} \\
= & 4.17 \times \mathbf{1 0}^{-5} \mathrm{~mol} / \mathrm{s}
\end{aligned}
$$

$$
\begin{aligned}
F_{\text {total }}^{\text {in }} & =F_{(1-\text { hexene })}{ }^{\text {in }}+F_{N 2}{ }^{\text {in }} \\
& =4.17 \times 10^{-5}+4.11 \times 10^{-5} \\
& =\mathbf{8 . 2 8} \times \mathbf{1 0}^{-5} \mathbf{m o l} / \mathrm{s}
\end{aligned}
$$

mol frac hexene feed $=\frac{F_{\left(1-\text { hexene }^{\text {in }}\right.}}{F_{\text {total }}{ }^{\text {in }}}$

$$
=\frac{4.17 \times 10^{-5}}{8.28 \times 10^{-5}}=\mathbf{0 . 5}
$$

$F_{\text {gas product }}^{\text {out }}($ with nitrogen $)=\frac{P \dot{V}}{R T}$ 


$$
\begin{aligned}
& \text { A p pendix D }-\mathrm{Sample} \mathrm{Calculations} \\
& =\frac{\text { BFMproduct pressure } \times B F M \text { product volumetric flow }}{R \times B F M \text { product temperature }} \\
& =\frac{(98.8 \times 1000) \times\left(\frac{5}{4.12}\right) \times 10^{-6}}{8.314 \times(23.5+273.15)} \\
& =\mathbf{4 . 8 6} \times \mathbf{1 0}^{-5} \mathbf{m o l} / \mathrm{s}
\end{aligned}
$$

$$
\begin{aligned}
F_{\text {organic gas product }}^{\text {out }} & =F_{\text {gas product }}{ }^{\text {out }}-F_{N 2}^{\text {in }} \\
& =4.86 \times 10^{-5}-4.11 \times 10^{-5} \\
& =\mathbf{7 . 4} \times \mathbf{1 0}^{-6} \mathbf{m o l} / \mathrm{s}
\end{aligned}
$$

The sample calculation for the determination of the mol fraction of each component in the gas sample using the GC peak areas is given for $\mathrm{C}_{5}$.

$$
\begin{aligned}
& A_{C 5}=193896947.4 \\
& F_{C 5, C 6} \times A_{C 5}=1.0021 \times 193896947.4 \\
& =194304131 \\
& w_{C 5}=\frac{F_{C 5, C 6} \times A_{C 5}}{\sum\left(F_{i, k} \times A_{i}\right)}=\frac{194304131}{4604232349}=\mathbf{0 . 0 4 2 2} \\
& n_{C 5}=\frac{w_{C 5}}{M M_{C 5}}=\frac{0.0422}{70.134}=\mathbf{0 . 0 0 0 6 0 1} \\
& y_{C 5}=\frac{n_{C 5}}{\sum n_{i}}=\frac{0.000601}{0.0132}=\mathbf{0 . 0 4 6} \\
& F_{C 5, \text { organic gas product }}^{\text {out }}=y_{C 5} \times F_{\text {organic gas product }}^{\text {out }} \\
& =0.046 \times 7.4 \times 10^{-6} \\
& =3.38 \times 10^{-7} \mathrm{~mol} / \mathrm{s}
\end{aligned}
$$

The same calculation is used to determine the mol fraction of each component in the liquid sample. An average liquid product molar mass is calculated using the mol fraction of each component.

$$
\begin{aligned}
& M M_{\text {avg liquid product }}=\sum x_{i} M M_{i}=\mathbf{8 4 . 5} \frac{\boldsymbol{g}}{\mathbf{m o l}} \\
& F_{\text {organic liquid product }} \text { out }=\frac{\text { Mass flow of liquid product }\left(\frac{g}{\mathrm{~min}}\right)}{M M_{\text {avg liquid product }}\left(\frac{\mathrm{g}}{\mathrm{mol}}\right) \times 60}=\frac{0.18}{84.5 \times 60}=\mathbf{3 . 5 6} \times \mathbf{1 0}^{-\mathbf{5}} \mathbf{m o l} / \mathbf{s}
\end{aligned}
$$




$$
\begin{aligned}
F_{C 5, \text { organic liquidproduct }}{ }^{\text {out }}=x_{C 5} \times F_{\text {organic liquid product }}^{\text {out }} \\
=0.016 \times 3.56 \times 10^{-5}=\mathbf{5 . 6 8} \times \mathbf{1 0}^{-7} \mathbf{m o l} / \mathbf{s}
\end{aligned}
$$

Similar calculations were undertaken for the other components present in the liquid and gas samples. The total outlet flow rate is the calculated.

$$
\begin{aligned}
F_{C 5, \text { total }}^{\text {out }} & =F_{C 5, \text { organic gas product }}{ }^{\text {out }}+F_{C 5, \text { organic liquidproduct }}{ }^{\text {out }} \\
& =3.38 \times 10^{-7}+5.68 \times 10^{-7}=\mathbf{9 . 0 5} \times \mathbf{1 0}^{-\mathbf{7}} \\
X_{(1-\text { hexene })} & =\frac{F_{(1-\text { hexene })^{\text {in }}-F_{(1-\text { hexene,total })}}^{\text {out }}}{F_{(1-\text { hexene })}^{\text {in }}} \times 100
\end{aligned}
$$$$
\text { Selectivity }_{\left(C_{10}-C_{16}\right)}=\frac{\sum F_{\left(C_{10}-C_{16}\right)}}{F_{(1-\text { hexene })^{\text {in }}-F_{(1-\text { hexene,total })}^{\text {out }}}} \times 100
$$$$
\operatorname{Yield}_{\left(C_{10}-C_{16}\right)}=\frac{\sum F_{\left(C_{10}-C_{16}\right)}}{F_{(1-\text { hexene })}} \times 100
$$

Selectivity $_{\left(C_{10}\right)}=\frac{F_{\left(C_{10}\right)}}{F_{(1-\text { hexene })}{ }^{\text {in }}-F_{(1-\text { hexene,total })}^{\text {out }}} \times 100$

$$
\text { Yield }_{\left(C_{10}\right)}=\frac{F_{\left(C_{10}\right)}}{F_{(1-\text { hexene })}^{\text {in }}} \times 100
$$

Similar calculations were performed for all other experimental runs conducted. 


$$
\begin{aligned}
l_{A} & =(1 / 4)\left(-y_{(1)}-y_{a d}+y_{c d}+y_{a c}-y_{a b c d}+y_{a b}-y_{b c}+y_{b d}\right) \\
& =(1 / 4)(-0.32-1.73+7.44+1.71-4.74+4.42-3.59+7.9) \\
& =2.77
\end{aligned}
$$

$$
\begin{aligned}
l_{B} & =(1 / 4)\left(-y_{(1)}-y_{a d}+y_{c d}+y_{a c}+y_{a b c d}-y_{a b}+y_{b c}-y_{b d}\right) \\
& =(1 / 4)(-0.32-1.73+7.44+1.71+4.74-4.42+3.59-7.9) \\
& =0.78
\end{aligned}
$$

$$
\begin{aligned}
l_{C} & =(1 / 4)\left(-y_{(1)}-y_{a d}-y_{c d}-y_{a c}+y_{a b c d}+y_{a b}+y_{b c}+y_{b d}\right) \\
& =(1 / 4)(-0.32-1.73-7.44-1.71+4.74+4.42+3.59+7.9) \\
& =2.36
\end{aligned}
$$

$$
\begin{aligned}
l_{D} & =(1 / 4)\left(-y_{(1)}+y_{a d}+y_{c d}-y_{a c}+y_{a b c d}-y_{a b}-y_{b c}+y_{b d}\right) \\
& =(1 / 4)(-0.32+1.73+7.44-1.71+4.74-4.42-3.59+7.9) \\
& =2.94
\end{aligned}
$$

$$
\begin{aligned}
l_{A B}=l_{C D} & =(1 / 4)\left(+y_{(1)}+y_{a d}+y_{c d}+y_{a c}-y_{a b c d}-y_{a b}-y_{b c}-y_{b d}\right) \\
& =(1 / 4)(+0.32+1.73+7.44+1.71-4.74-4.42-3.59-7.9) \\
& =-2.36
\end{aligned}
$$

$$
\begin{aligned}
l_{A C}=l_{B D} & =(1 / 4)\left(+y_{(1)}+y_{a d}-y_{c d}-y_{a c}-y_{a b c d}+y_{a b}-y_{b c}+y_{b d}\right) \\
& =(1 / 4)(+0.32+1.73-7.44-1.71-4.74+4.42-3.59+7.9)
\end{aligned}
$$




$$
\begin{aligned}
l_{B C}=l_{A D} & =(1 / 4)\left(+y_{(1)}+y_{a d}-y_{c d}-y_{a c}+y_{a b c d}-y_{a b}+y_{b c}-y_{b d}\right) \\
& =(1 / 4)(+0.32+1.73-7.44-1.71+4.74-4.42+3.59-7.9) \\
& =-2.78
\end{aligned}
$$

Normal probability plot calculation:

\begin{tabular}{|c|c|c|c|c|c|}
\hline $\mathbf{j}$ & $\mathbf{( j - 0 . 5 ) / \mathbf { n }}$ & $\mathbf{1 0 0 *}(\mathbf{j}-\mathbf{0 . 5}) / \mathbf{n}$ & $\mathbf{z j}$ & Effects in ascending order & \\
\hline $\mathbf{1}$ & 0.071 & 7.14 & -1.47 & -2.78 & $\mathrm{BC}$ \\
\hline $\mathbf{2}$ & 0.214 & 21.43 & -0.79 & -2.36 & $\mathrm{AB}$ \\
\hline $\mathbf{3}$ & 0.357 & 35.71 & -0.37 & -0.78 & $\mathrm{AC}$ \\
\hline $\mathbf{4}$ & 0.500 & 50.00 & 0 & 0.78 & $\mathrm{~B}$ \\
\hline $\mathbf{5}$ & 0.643 & 64.29 & 0.36 & 2.36 & $\mathrm{C}$ \\
\hline $\mathbf{6}$ & 0.786 & 78.57 & 0.79 & 2.78 & $\mathrm{~A}$ \\
\hline $\mathbf{7}$ & 0.929 & 92.86 & 1.46 & 2.94 & $\mathrm{D}$ \\
\hline
\end{tabular}

The standardised normal score $\left(\mathrm{z}_{\mathrm{j}}\right)$ was obtained from the observed cumulative frequency and the use of the cumulative standard normal distribution tables.

$$
\begin{aligned}
\text { contrast }_{A} & =\text { Effect }_{A} \times n 2^{(k-1)-1} \\
& =l_{A} \times\left(2 \times 2^{(4-1)-1}\right) \\
& =2.77 \times(2 \times 4) \\
& =22.18
\end{aligned}
$$

Similarly,

contrast $_{B}=6.22$

contrast $_{C}=18.90$ 


$$
\begin{aligned}
& \text { contrast }_{D}=23.54 \\
& \begin{array}{ll}
S S_{B}=2.42 & \text { contrast }_{A B=C D}=-18.9 \\
S S_{C}=22.33 & \text { contrast }_{A C=B D}=-6.22 \\
S S_{D}=34.63 & \text { contrast }_{B C=A D}=-22.18
\end{array} \\
& S S_{A B}=22.33 \\
& S S_{A C}=2.42 \\
& S S_{B C}=30.75 \\
& S S_{A}=\frac{\left(\text { contrast }_{A}\right)^{2}}{n 2^{(k-1)}} \\
& =\frac{(22.18)^{2}}{2 \times 2^{(4-1)}} \\
& =30.75
\end{aligned}
$$

Similarly,

$$
\begin{aligned}
S S_{\text {curvature }}= & \left(\frac{\bar{y}_{F}-\bar{y}_{C}}{\sqrt{\frac{1}{n_{F}}+\frac{1}{n_{C}}}}\right)^{2} \\
& =\left(\frac{3.98-3.24}{\sqrt{\frac{1}{8}+\frac{1}{4}}}\right)^{2} \\
& =1.48 \\
\bar{y}_{F}-\bar{y}_{C}=3.98-3.24 & \\
= & 0.75 \\
M S_{E}= & \frac{\sum_{\text {centre points }}\left(y_{i}-\bar{y}_{C}\right)^{2}}{n_{c}-1} \\
= & \frac{(0.6-3.23)^{2}+(1.08-3.23)^{2}+(4.53-3.23)^{2}+(6.73-3.23)^{2}}{4-1}
\end{aligned}
$$




$$
=8.493
$$

$$
\begin{aligned}
M S_{A} & =\frac{S S_{A}}{a-1} \\
& =\frac{30.75}{2-1} \\
& =30.75
\end{aligned}
$$

Similarly,

$$
\begin{aligned}
& M S_{B}=2.42 \\
& M S_{C}=22.33 \\
& M S_{D}=34.63 \\
& M S_{A B=C D}=22.33 \\
& M S_{A C=B D}=2.42 \\
& M S_{B C=A D}=30.75 \\
& F_{0}=\frac{M S_{A}}{M S_{E}} \\
& =\frac{30.75}{8.493} \\
& =3.62
\end{aligned}
$$

The F-ratios for factors and interactions $\mathrm{B}, \mathrm{C}, \mathrm{D}, \mathrm{AB}, \mathrm{AC}$ and $\mathrm{BC}$ were calculated similarly. 